UNIVERSIDAD POLITÉCNICA DE VALENCIA

DEPARTAMENTO DE INGENIERÍA QUÍMICA Y NUCLEAR
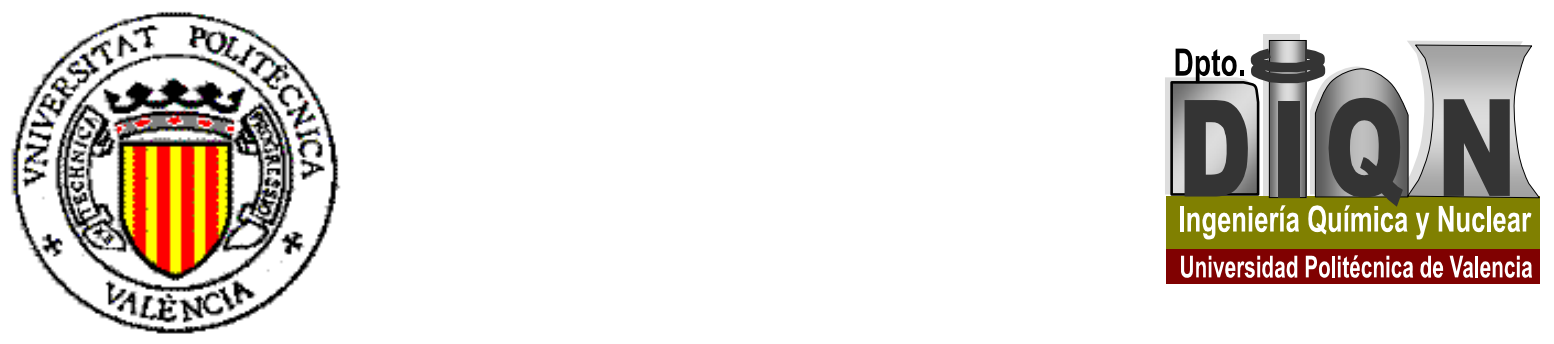

\title{
ESTUDIO DEL PROCESO DE NANOFILTRACIÓN PARA LA DESMINERALIZACIÓN DE LACTOSUERO DULCE
}

TESIS DOCTORAL

Presentada por:

Beatriz E. Cuartas Uribe

Dirigida por:

Dra. $\mathrm{M}^{\mathrm{a}}$. Isabel Alcaina Miranda

Dr. Enrique Soriano Costa

Valencia, 2005 



\section{AGRADECIMIENTOS}

Quiero expresar mi más sincero agradecimiento a todos los que me han ayudado y apoyado durante la realización de esta tesis doctoral:

A mis directores de tesis, María Isabel Alcaina Miranda y Enrique Soriano Costa, por dirigirme en el transcurso de este trabajo, por sus enseñanzas, consejos y la oportunidad de estar hoy expresándoles mi gratitud.

A mi familia y amigos por su cariño y aliento constante durante estos años de trabajo.

A Mariano y su familia, por ser también la mía, gracias por todo su apoyo y cariño.

A Mariano Ferris del Instituto de Hidrología y Medio Ambiente, así como a $M^{a}$ Carmen Beltrán de Ciencia Animal por toda su ayuda en la parte analítica.

A mis compañeros de trabajo por su apoyo en cada momento que lo precise. Por darme la oportunidad de ser uno de vosotros y que los momentos de mayor tensión no fueran nada comparados con los buenos momentos vividos. 

ÍNDICE DE TABLAS III

ÍNDICE DE FIGURAS IV

\section{ÍNDICE GENERAL}

1. INTRODUCCIÓN ..................................................................... 1

2. ANTECEDENTES ....................................................................... 7

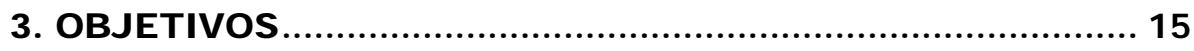

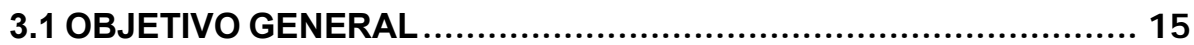
3.2 OBJETIVOS ESPECÍ́FICOS ....................................................... 15

4. MARCO TEÓRICO ................................................................. 19

4.1 ELABORACIÓN DEL QUESO ................................................... 19

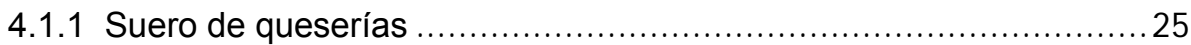

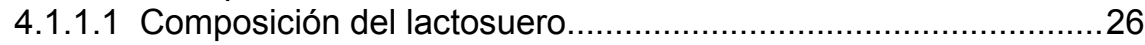

4.1.1.2 Productos derivados del suero ..............................................2

4.2 TECNOLOGÍAS DE MEMBRANA .............................................. 30

4.2.1 Introducción a las operaciones de membrana ............................. 30

4.2.2 Clasificación general de las operaciones de membrana .................. 32

4.2.2.1. Tipos de operación cuando la fuerza impulsora es la presión ...32

4.2.2.2. Tipos de operación según el mecanismo de separación de la

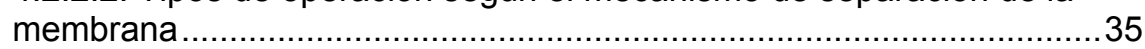

4.2.3 Estructura, configuración y materiales de membranas. ................... 35

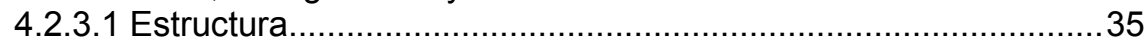

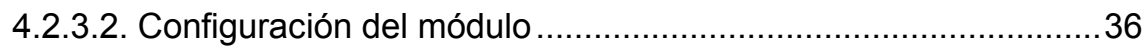

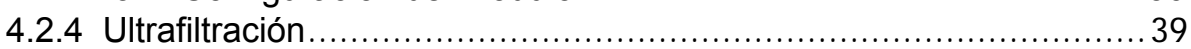

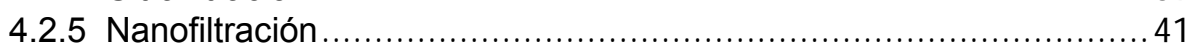

4.2.5.1 Influencia de la Presión osmótica ..............................................4 44

4.2.5.2 Polarización por concentración ...............................................45

4.2.5.3 Mecanismo de exclusión de Donnan.........................................47 
4.2.5.4 Mecanismo de exclusión dieléctrica ..............................................48

4.2.6 Ensuciamiento de las membranas en la industria láctea.................550

4.2.7 Limpieza de las membranas ................................................ 53

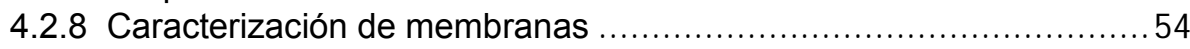

4.2.9 Perspectivas de las membranas en el sector lácteo......................59

4.3 MODELO MATEMÁTICO PARA MEMBRANAS DE NF ....................64

4.3.1 Índice del rechazo real para la lactosa.......................................6 64

4.3.2 Modelo DSPM (Donnan Steric Partioning Pore model).................... 66

5. METODOLOGÍA .......................................................................... 73

5.1 REVISIÓN BIBLIOGRÁFICA ........................................................ 73

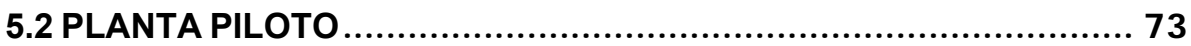

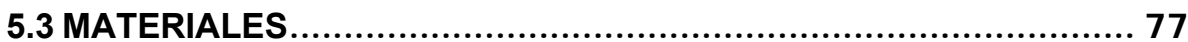

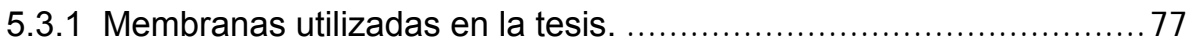

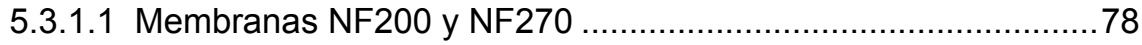

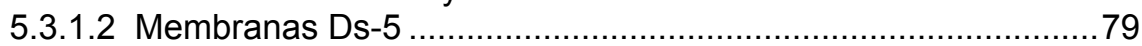

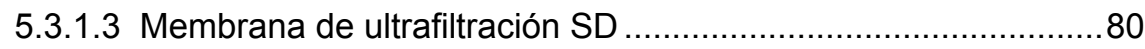

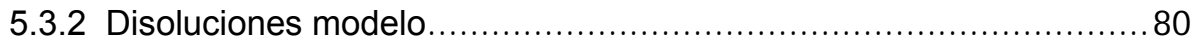

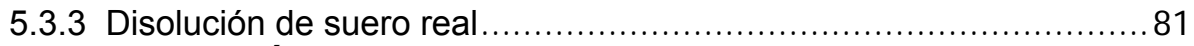

5.4 DESCRIPCIÓN DE LAS EXPERIENCIAS..................................... 81

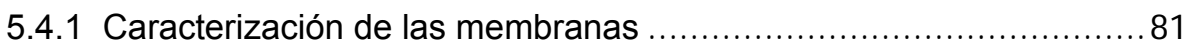

5.4 .2 Fase inicial .................................................................. 82

5.4.2.1. Disolución modelo de sales individuales ................................ 82

5.4.2.2. Disolución modelo de la mezcla de sales minerales...................83

5.4 .3 Fase intermedia ............................................................. 84

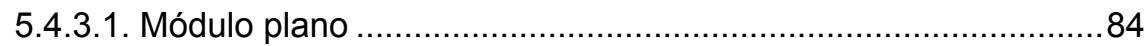

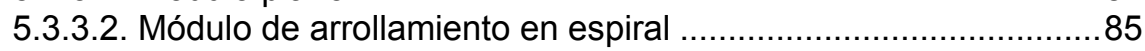

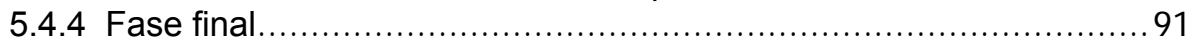

5.4.5 Modelización matemática..................................................... 93

5.4.6 Análisis económico........................................................... 93

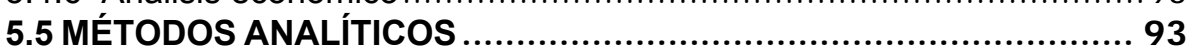

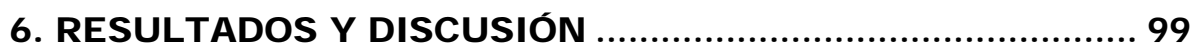

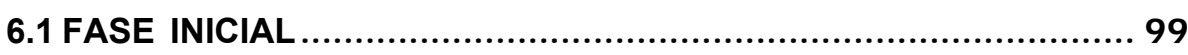

6.1.1 Estado estacionario de la disolución modelo de sales individuales....99

6.1.1.1 Disolución de cloruro de sodio ............................................100

6.1.1.2 Disolución de cloruro de potasio ...............................................104

6.1.1.3 Disolución de sulfato de magnesio .......................................... 108

6.1.1.4 Disolución de lactosa..............................................................111

6.1.2 Estado estacionario de la disolución modelo de mezcla de sales

minerales.......................................................................... 115

6.1.3 Influencia de la presión sobre la densidad de flujo de permeado y el

índice de rechazo ........................................................................ 124

6.1.3.1 Disolución modelo de sales individuales ..............................124 
6.1.3.2 Disolución modelo de la mezcla de sales minerales ................133

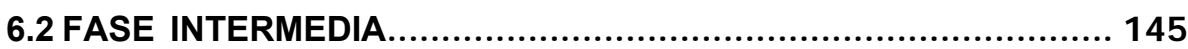

6.2.1 Módulo plano ............................................................ 145

6.2.2 Módulo de arrollamiento en espiral ................................... 151

6.2.2.1 Ensayo de la permeabilidad al agua ....................................151

6.2.2.2 Etapa a concentración constante. ........................................154

6.2.2.3 Etapa de concentración - diafiltración. ...................................162

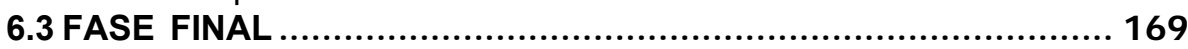

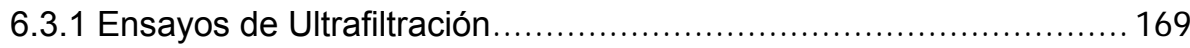

6.3.1.1 Ensayo de la permeabilidad al agua de la membrana de UF ..171

6.3.1.2 Caracterización de la membrana de UF con el suero real .......172

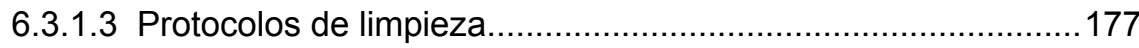

6.3.2 Ensayos de nanofiltración ................................................ 190

6.3.2.1. Comparación de las membranas NF200 y Ds-5 DL con el suero

real ultrafiltrado .............................................................................. 192

6.3.2.2. Caracterización de la membrana Ds-5 DL con el suero

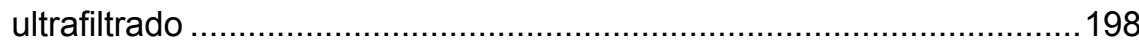

6.3.2.3. Desmineralización del permeado del suero UF con la membrana

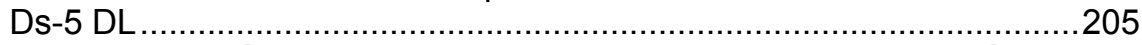

6.4 MODELIZACIÓN DE LAS MEMBRANAS DE NANOFILTRACIÓN ... 218

6.4.1 Obtención del índice de rechazo real de lactosa.......................... 218

6.4.2 Modelización por DSPM............................................... 220

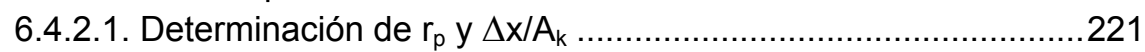

6.4.2.2. Determinación del índice de rechazo propuesto por el modelo222

6.5 ANÁLISIS ECONÓMICO DEL PROCESO POR MEMBRANAS ....... 224

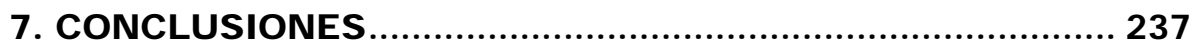

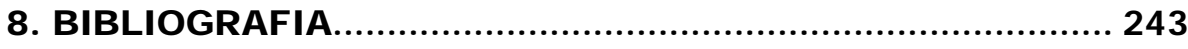

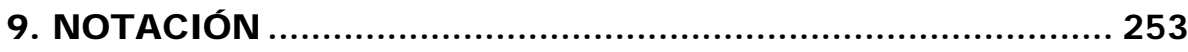

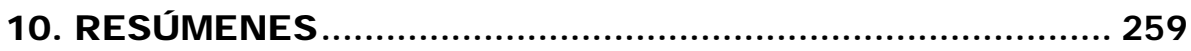

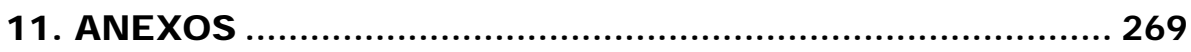

11.1 FICHAS TÉCNICAS DE LAS MEMBRANAS EMPLEADAS............ 269

11.1.1 Membrana NF 200.................................................. 270

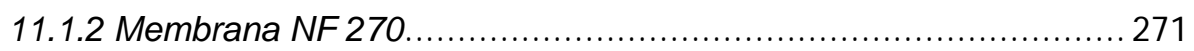

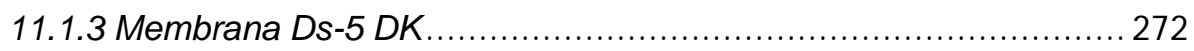

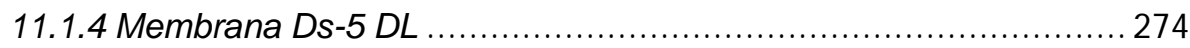

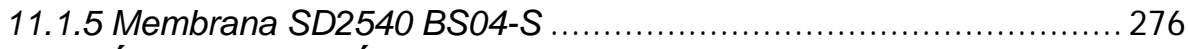

11.2 MÉTODOS ANALÍTICOS ........................................................... 278 
11.2.1 Procedimientos para la toma y conservación de muestras de

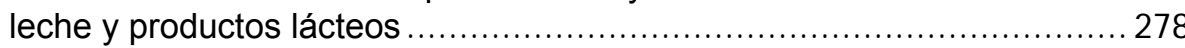

11.2.2 Técnicas analíticas empleadas ........................................... 279

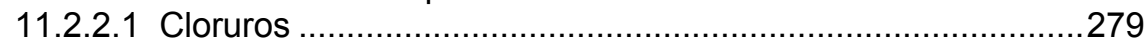

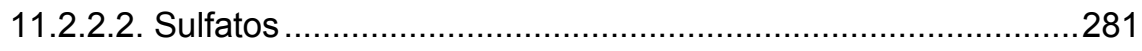

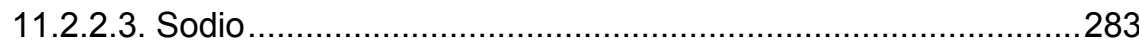

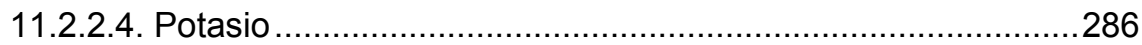

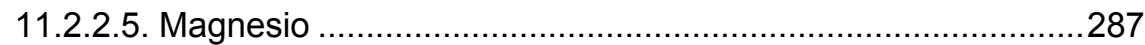

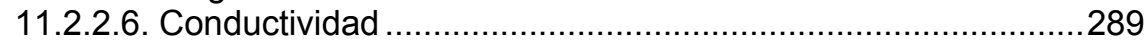

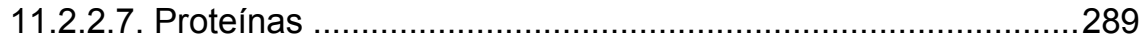

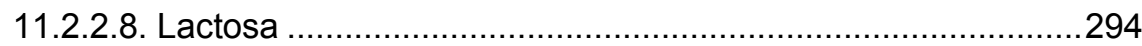

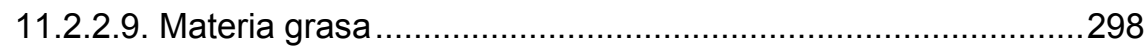

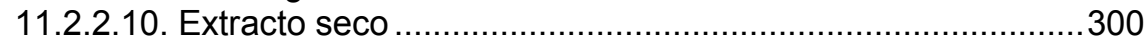

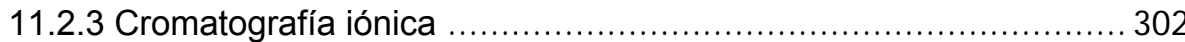

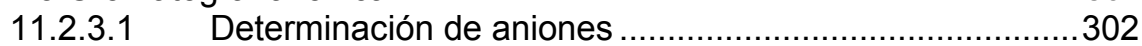

11.2.3.2 Determinación de cationes ...............................................306

\section{ÍNDICE DE TABLAS}

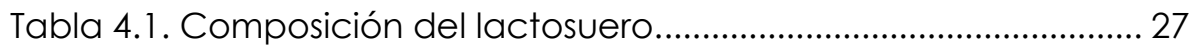

Tabla 4.2. Tipo de operación de membranas a presión........................ 33

Tabla 4.3. Aplicaciones industriales de las membranas de NF ............ 42

Tabla 4.4. Crecimiento del uso de membranas (en millones de dolares)

Tabla 4.5. Utilización de las membranas según el proceso industrial. 63

Tabla 5.1. Características de las membranas utilizadas. ...................... 77

Tabla 5.2. Caracterización de las membranas estudiadas .................. 79

Tabla 5.3. Productos químicos utilizados ................................................... 81

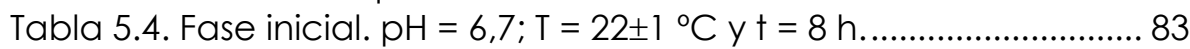

Tabla 5.5. Fase intermedia. $\Delta \mathrm{P}=0,95 \mathrm{MPa} ; \mathrm{pH}=6,5 ; \mathrm{T}=22 \pm 1^{\circ} \mathrm{C}$ y $t=8 \mathrm{~h}$

Tabla 5.6. Composición y pH de la disolución alimento, $\mathrm{pH}=6,50$ y

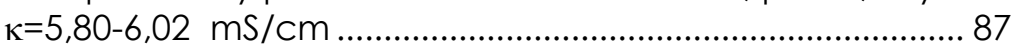

Tabla 5.7. Características de los iones de la disolución alimento.......87 87

Tabla 5.8. Fase Final. Ensayo de ultrafiltración. Membrana SD_10 kDa Suero real. $\mathrm{pH}=6,10 ; \kappa=6,30 \mathrm{mS} / \mathrm{cm} ; \mathrm{T}=16 \pm 1^{\circ} \mathrm{C} ; \Delta \mathrm{P}=0,3$ a $0,6 \mathrm{MPa}$ y $Q_{R}=600 \mathrm{~L} / \mathrm{h}$

Tabla 5.9. Fase final. Membranas NF200 y Ds-5 DL. Suero real. $\mathrm{pH}=$ $6,10-6,50 ; \kappa=5,88-, 4,30 \mathrm{mS} / \mathrm{cm} ; \mathrm{T}=16 \pm 2^{\circ} \mathrm{C} . \Delta \mathrm{P}=0,5$ a 2,5 MPa y

Tabla 5.10. Resumen de los métodos analíticos empleados 
Tabla 6.1. Resumen de $J_{p}$ y $\Delta \pi$ de las sales individuales.

Tabla 6.2 . Composición de la disolución alimento, $\mathrm{pH}=6,51 ; \kappa=5,98$ $\mathrm{mS} / \mathrm{cm}$

Tabla 6.3. Densidades de flujo de la mezcla de sales minerales....... 136

Tabla 6.4. Pesos atómicos, radios iónicos y entalpías de hidratación de cationes.

Tabla 6.5. Pesos atómicos, radios iónicos y entalpías de hidratación de aniones.

Tabla 6.6. Composición de la disolución alimento para cada experiencia. $\mathrm{pH}=6,5$.

Tabla 6.7. Composición del suero modelo.

Tabla 6.8. Relación entre la densidad de flujo de permeado y el incremento de presión osmótica a concentración constante.

Tabla 6.9. Densidad de flujo de soluto. Serie 1....

Tabla 6.10. Densidad de flujo de soluto. Serie 2.

Tabla 6.11. Densidad de flujo de soluto. Serie 3.

Tabla 6.12. Balance de cargas en la corriente de permeado........... 161

Tabla 6.13. Fuerza iónica (I) del permeado.

Tabla 6.14. Índice de rechazo para FRV $=2$

Tabla 6.15. Composición de la disolución alimento antes y después de diafiltrar

Tabla 6.16. Características de las proteínas típicas del suero lácteo

Tabla 6.17. Composición del lactosuero dulce. $\mathrm{pH}=6,10$ у $\kappa=6,30$ $\mathrm{mS} / \mathrm{cm}$

Tabla 6.18. Composición del lactosuero dulce. $\mathrm{T}=16^{\circ} \mathrm{C} ; \mathrm{pH}=6,1 ; \kappa=$

6,30 mS/cm ..................................................................... 175

Tabla 6.19. Condiciones de operación del protocolo 1 de limpieza 183

Tabla 6.20. Resumen de los resultados del protocolo 1 ....................... 185

Tabla 6.21. Condiciones de operación del protocolo 2 de limpieza 188

Tabla 6.22. Resumen de los resultados del protocolo 2 de limpieza. 189

Tabla 6.23. Composición del permeado del suero UF (PUF). .............. 192

Tabla 6.24. Densidad de flujo de soluto. Membrana NF200. $T=16^{\circ} \mathrm{C}$, $Q_{R}=400 \mathrm{~L} / \mathrm{h}$.

Tabla 6.25. Densidad de flujo de soluto. Membrana Ds-5 DL. T $=16^{\circ} \mathrm{C}$,

$Q_{R}=400 \mathrm{~L} / \mathrm{h}$.

Tabla 6.26. Densidad de flujo de soluto. $T=16 \pm 1^{\circ} \mathrm{C}, Q_{R}=400 \mathrm{~L} / \mathrm{h}$..... 201

Tabla 6.27. Densidad de flujo de soluto. $T=16 \pm 1^{\circ} \mathrm{C}, Q_{R}=500 \mathrm{~L} / \mathrm{h} \ldots . .201$

Tabla 6.28. Índice de rechazo y factor de concentración para un . 208

Tabla 6.29. Índice de rechazo y factor de concentración. $F R V=2$. $\Delta \mathrm{P}=2 \mathrm{MPa} . \mathrm{pH}=6,26 ; \kappa=5,0 \mathrm{mS} / \mathrm{cm}$

Tabla 6.30. Variación de $\mathrm{R}(\%)$ durante la diafiltración. $\Delta \mathrm{P}=2 \mathrm{MPa} . .211$ 
Tabla 6.31. Variación de R durante la diafiltración. $\Delta P=1$ MPa......... 212

Tabla 6.32. Variación de la concentración durante la diafiltración.

$\Delta \mathrm{P}=1 \mathrm{MPa}$

213

Tabla 6.33. Variación de la concentración durante la diafiltración. $\Delta \mathrm{P}=2 \mathrm{MPa}$

Tabla 6.34. Comparación de la DQO del alimento y permeado durante la operación de concentración.

Tabla 6.35. Valores de la DQO durante la diafiltración.

Tabla 6.36. Valores de los números adimensionales y de $\mathrm{K}_{\mathrm{TM}}$

Tabla 6.37. Rechazos reales de la lactosa $(50 \mathrm{~g} / \mathrm{L})$

Tabla 6.38. Radios de poro $\left(r_{p}\right)$ y relación entre el espesor/porosidad $\left(\Delta x / A_{k}\right)$.

Tabla 6.39. Costes de los equipos necesarios para la desmineralización y concentración del lactosuero.

Tabla 6.40. Inversión total del proceso de desmineralización y concentración del lactosuero.

Tabla 6.41. Costes de operación del proceso de desmineralización y concentración del lactosuero.

Tabla 6.42. Rentabilidad del proceso de desmineralización y concentración del lactosuero.

\section{ÍNDICE DE FIGURAS}

Figura 1.1. Producción en el sector agroalimentario.................................2

Figura 4.1. Elaboración del queso............................................................ 20

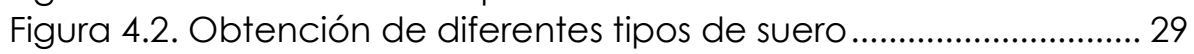

Figura 4.3. Principio básico de operación de una membrana............. 30

Figura 4.4. Diferencias entre filtración estática y dinámica. .................. 31

Figura 4.5. Rangos de presión, según el tamaño de partícula ............. 34

Figura 4.6. Uso de las membranas en la industria láctea....................... 34

Figura 4.7. Principio de flujo osmótico ............................................................. 45

Figura 4.8. Transferencia de masa en membranas................................ 46

Figura 4.9. Principio de Exclusión de Donnan ........................................... 48

Figura 4.10. Exclusión dieléctrica.............................................................49

Figura 4.1 1. Mecanismo de ensuciamiento de la membrana ...............51

Figura 4.12. Consumo de membranas de Ol en espiral ..........................60 60

Figura 4.13. Consumo de membranas de UF(arrollada) ...........................61 61

Figura 5.1. Esquema de la planta experimental...................................... 75

Figura 5.2. Detalle de la Planta piloto de membranas............................. 76

Figura 5.3. Estructura de una membrana de polietersulfona................ 80 
Figura 5.4. Obtención del suero libre de proteínas ................................. 82

Figura 5.5. Ełapa de concentración. ........................................................ 89

Figura 5.6. Ełapa de diafiltración. .............................................................. 90

Figura 5.7. Esquema de trabajo desarrollado en la tesis ........................ 95

Figura 6.1. Variación de $J_{p}$, módulo plano. $1.200 \mathrm{mg} \mathrm{NaCl} / \mathrm{L}$............ 102

Figura 6.2. Variación de R, módulo plano. $1.200 \mathrm{mg} \mathrm{NaCl} / \mathrm{L}, \ldots \ldots \ldots . .103$

Figura 6.3. Variación de $\mathrm{J}_{\mathrm{p}}$, módulo plano. $2.000 \mathrm{mg} \mathrm{KCl} / \mathrm{L}$................. 106

Figura 6.4. Variación de R, módulo plano. $2.000 \mathrm{mg} \mathrm{KCl} / \mathrm{L}, \ldots \ldots \ldots . . . .107$

Figura 6.5. Variación de $\mathrm{J}_{\mathrm{p}}$, módulo plano. $750 \mathrm{mg} \mathrm{MgSO}_{4} / \mathrm{L}, \ldots \ldots \ldots . .109$

Figura 6.6. Variación de R, Módulo plano. 750 mg MgSO $/ \mathrm{L}, \ldots \ldots \ldots \ldots . .110$

Figura 6.7. Variación de $\mathrm{Jp}_{\mathrm{p}}$, módulo plano. $50 \mathrm{~g}$ lactosa/L,................. 113

Figura 6.8. Variación de R, módulo plano. $50 \mathrm{~g}$ lactosa/L,................. 114

Figura 6.9. Variación de $J_{p}$, módulo plano. Mezcla de sales............ 116

Figura 6.10. Variación de $\mathrm{R} \mathrm{Na}^{+}$, módulo plano. Mezcla de sales... 118

Figura 6.11. Variación de $\mathrm{R} \mathrm{K} \mathrm{K}^{+}$, módulo plano. Mezcla de sales...... 119

Figura 6.12. Variación de $\mathrm{R} \mathrm{Mg}^{+2}$, módulo plano. Mezcla de sales 120

Figura 6.13. Variación de $\mathrm{R} \mathrm{Cl}$, módulo plano. Mezcla de sales .... 121

Figura 6.14. Variación de $\mathrm{R} \mathrm{SO}_{4}{ }^{-2}$, módulo plano. Mezcla de sales 123

Figura 6.15. Evolución de la Jp con la presión, módulo plano........... 128

Figura 6.16. Variación de R. Sales individuales .................................... 131

Figura 6.17. Variación de $J_{p}$ con la presión. Mezcla de sales minerales

135

Figura 6.18. Variación del Índice de rechazo. Mezcla de sales ........ 139

Figura 6.19. Variación de $J_{p}$ con el tiempo. $\Delta \mathrm{P}=0,95 \mathrm{MPa}, \ldots \ldots \ldots \ldots . . .147$

Figura 6.20. Efecto del FC sobre la densidad de flujo ............................ 147

Figura 6.21. Influencia de FC sobre R ................................................. 149

Figura 6.22. Evolución de Jagua con la membrana Ds-5 DL................. 152

Figura 6.23. Variación de Jp con la presión. Disolución modelo de

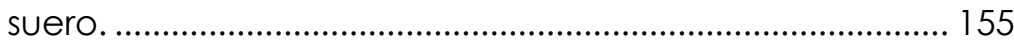

Figura 6.24. Variación de \% $\mathrm{R} \mathrm{Na}^{+1}$ con la presión ................................. 158

Figura 6.25. Variación de \% $\mathrm{K}^{+1}$ con la presión .................................. 158

Figura 6.26. Variación de \%R Cl- con la presión..................................... 159

Figura 6.27. Variación de \%R $\mathrm{Mg}^{+2}$ con la presión................................ 160

Figura 6.28. Variación de \%R SO $4^{-2}$ con la presión efectiva.................. 160

Figura 6.29. Variación de \%R Lactosa con la presión efectiva ........... 162

Figura 6.30. Variación de Jp durante la concentración....................... 163

Figura 6.31. Variación de $J_{p}$ durante la diafiltración ............................. 166

Figura 6.32. Comparación de J al agua después de completada

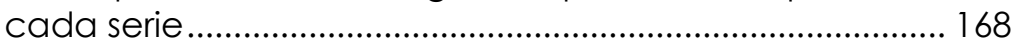

Figura 6.33. Evolución de $J_{p}$ con la presión. $Q=400$ L/h, Membrana UF

Figura 6.34. Evolución de la Jp con la presión. Membrana UF. $Q_{R}=600$ $\mathrm{L} / \mathrm{h}, \mathrm{T}=16^{\circ} \mathrm{C} ; \mathrm{pH}=6,1 ; \kappa=6,30 \mathrm{~ms} / \mathrm{cm}$. 174 
Figura 6.35. Apariencia del suero real, permeado y concentrado del proceso de UF

Figura 6.36. Distribución de las diferentes resistencias hidráulicas .... 180

Figura 6.37. Resistencia de la membrana durante la limpieza. .......... 186

Figura 6.38. Resistencia residual de la membrana ................................ 187

Figura 6.39. Resistencia de la membrana durante la limpieza .......... 189

Figura 6.40. Resistencia residual de la membrana ............................... 189

Figura 6.41. Comparación de las densidades de flujo al agua......... 191

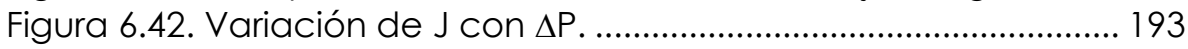

Figura 6.43. Variación de R con $\Delta \mathrm{P}$. Membranas NF200 y Ds-5 DL. .. 198

Figura 6.44. Variación de J con $\triangle \mathrm{P}$. suero UF. Ds-5 DL . ....................... 199

Figura 6.45. Variación de R con $\Delta \mathrm{P} . \mathrm{T}=16 \pm 1^{\circ} \mathrm{C}$................................... 204

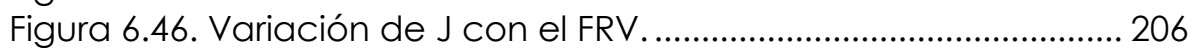

Figura 6.47. Variación de $J_{p}$ y $\kappa$ con el FD. ........................................... 210

Figura 6.48. Variación de la R con el FD. ............................................. 213

Figura 6.49. Ajuste de los Rreal y RDSPM para las membranas NF200 y 270

223

Figura 6.50. Ajuste de los Rreal y RDSPM para las membranas Ds-5 DK y DL 223

Figura 6.51 Diagrama de flujo del proceso de desmineralización del suero dulce mediante membranas 
INTRODUCCIÓN 1. 



\section{INTRODUCCIÓN}

En la fabricación de productos lácteos como el queso, se genera una elevada cantidad de suero como producto residual con alto contenido en materia orgánica y sales minerales. La materia orgánica contiene principalmente lactosa con concentraciones entre $44-52 \mathrm{~g} / \mathrm{L}$ y proteínas con concentraciones entre $6-8 \mathrm{~g} / \mathrm{L}$, ambas de gran valor nutritivo, haciendo atractiva la eliminación de las sales minerales, cuya concentración varia entre 4,3-9,5 g/L, mediante la utilización de técnicas de membranas. Dentro del proceso de fabricación de productos lácteos y recuperación de subproductos, la microfiltración, la ultrafiltración y la osmosis inversa han sido las técnicas más utilizadas. Durante los años 90, su aplicación aumentó, al bajar el precio y mejorar el rendimiento de las membranas, permitiendo cambiar los equipos viejos y disminuir el consumo energético. (Timmer J, 2001).

En esta última década, las membranas de nanofiltración han ido mejorando y se está ampliando su uso, debido a su capacidad para desmineralizar y concentrar productos procedentes de la industria láctea.

La industria agroalimentaria (I.A.A) española, por lo que respecta a ventas ocupa actualmente el quinto puesto en Europa. Las empresas de alimentación y bebidas, con el $17 \%$ del total de la producción industrial, constituyen el primer sector de la industria manufacturera en España, aportan el 12\% del valor añadido y emplean casi al $14 \%$ de la mano de obra. Estas cifras dan una idea de la importancia de una industria que, tras su integración en la Unión Europea, casi ha 
triplicado las inversiones para su modernización. En Europa, la industria de bebidas y alimentos tiene una producción alrededor de 700 mil millones de dólares. (http://www.foodproductiondaily.com)

En la figura 1.1, se muestra como esta distribuida la producción en el sector agroalimentario. (FIAB, Federación Española de industrias de alimentación y Bebidas, 2004)

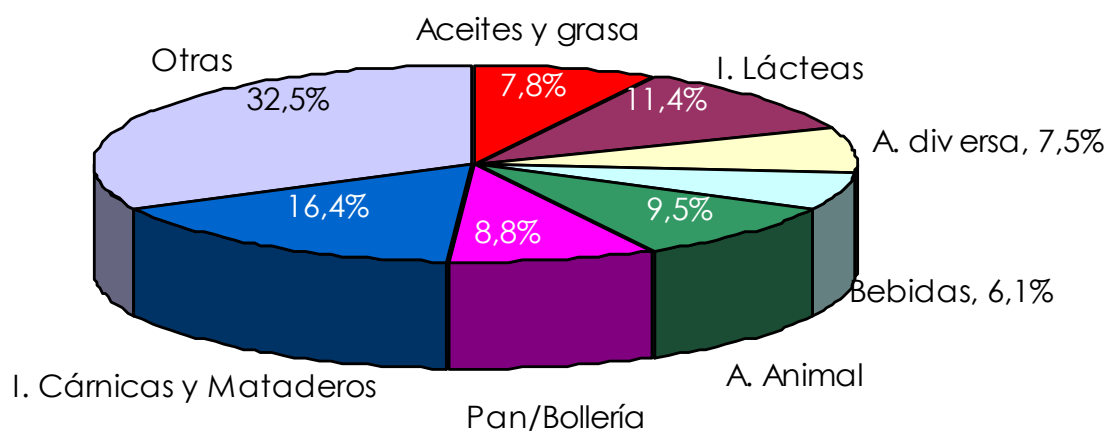

Figura 1.1. Producción en el sector agroalimentario

El respeto al medio ambiente es otro de los compromisos de la industria con el entorno. Los cambios que tiene que realizar para adaptarse a estas exigencias requieren un amplio esfuerzo de transformación con la dificultad añadida de contener los costes y mantener la competitividad. El papel de la universidad en el desarrollo de líneas de investigación que fomenten estos cambios es indispensable. La Universidad Politécnica de Valencia por medio del Grupo PROMETEO (Procesos de membrana y tratamiento de efluentes líquidos) del Departamento de Ingeniería Química y Nuclear, ya lo esta 
haciendo. El Grupo posee una amplia trayectoria en operaciones de separación por medio de técnicas de membrana, aplicadas a diversos efluentes líquidos industriales, aportando soluciones a la problemática que posee la industria en el tratamiento de los efluentes que genera en sus procesos productivos.

La presente Tesis "Estudio del proceso de nanofiltración para la desmineralización de lactosuero dulce" es la continuación de la Tesis Doctoral: "Desarrollo de membranas de nanofiltración aptas para la desmineralización del lactosuero" (Alkhatim, 1999). Ambas están enmarcadas dentro de la línea de investigación "Procesos de membrana en la industria agroalimentaria" del grupo PROMETEO. Esta línea surge como consecuencia de la problemática medioambiental de los efluentes líquidos generados en la elaboración de productos alimenticios. 
ANTECEDENTES

2. 



\section{ANTECEDENTES}

La industria láctea genera un gran volumen de agua residual, con una alta contaminación en materia orgánica compuesta principalmente por lactosa y proteínas. Una concentración de suero entre el $1-2 \%$ en el agua de los ríos produce rápidamente fermentaciones aerobias ácidas, que dificultan la actividad biológica de los ríos, debido al elevado valor de la $\mathrm{DBO}_{5}$ (Demanda Bioquímica de Oxígeno) (Morales, 1992), incrementando los costes de tratamiento en una estación depuradora de aguas residuales industriales. Se sabe que 100 litros de suero produce el mismo grado de contaminación que el agua residual domestica producida por 45 habitantes. Más del $90 \%$ de la demanda bioquímica de oxígeno generada por el lactosuero se debe a la lactosa.

Cada día la normativa medioambiental es más estricta y el coste por vertido aumenta, creándose la necesidad de optimizar al máximo los procesos en la industria. Por esto, estudiar las posibilidades de tratar y aprovechar los subproductos de una empresa y utilizarlos en otro proceso industrial, no solo facilita la protección de los recursos hídricos, sino que además conlleva a un ahorro económico.

Anteriormente, el suero era utilizado para la alimentación animal, incluso en algunos países donde las tecnologías de membrana son demasiado costosas y la regulación ambiental no es muy estricta siguen teniendo este uso o son vertidos sin tratamiento previo. Las tecnologías de membrana permiten que las proteínas y la lactosa, 
presentes en estos vertidos, se puedan separar de los componentes no deseables y reaprovecharlos nuevamente. Estos pueden ser utilizados en la producción de bebidas, helados, confitería, bollería, alimentos infantiles, productos farmacéuticos, etc.

Las sustancias bioactivas del suero son de gran aplicación en la industria alimentaria (quesos, bebidas, sopas, preparados dietéticos e infantiles) y la farmacéutica. Generando beneficios importantes para el sector quesero, al verse revalorizado un subproducto que presentaba graves problemas medioambientales. Recientemente se ha encontrado en el suero (ácido y dulce), la presencia de determinados compuestos con capacidad antioxidante, como proteínas, enzimas, péptidos, aminoácidos, tocoferoles, carotenoides, citratos, fosfatos, entre otros. (http://www.if.csic.es)

La industria láctea ha sido una de las grandes partidarias de usar los sistemas por membranas para el fraccionamiento de las proteínas del suero así como para el tratamiento de sus aguas residuales. En los años 60, las operaciones con membranas se utilizaban para clarificar, concentrar, fraccionar y purificar. En los 80, los investigadores empezaron a utilizarlas para concentrar la leche y en la producción de quesos no estandarizados. En los últimos años, la mejora de estas tecnologías hace más atractivo su uso, debido principalmente al bajo consumo de energía y a la conservación de la materia prima y productos durante su tratamiento.

La filtración con membranas ha abierto las puertas a una gran variedad de nuevos e innovadores productos lácteos, adquiriendo 
importancia en este sector. Hoy se pueden separar cada uno de los principales componentes de la leche mediante el uso de membranas. La microfiltración, la ultrafiltración, la nanofiltración y la osmosis inversa, están haciendo posible elaborar productos con propiedades únicas y a bajos costes de operación y energía.

La nanofiltración en lo últimos años ha empezado a ser estudiada para la desmineralización y concentración del lactosuero, así como para el fraccionamiento de las proteínas con resultados favorables. (Jeantet et al. (1996), Wijers et al. (1998), Alkhatim et al. (1999), Jeantet et al. (2000), Balannec et al, (2002), Rector et al. (2004), Jaffrin et al. (2004).

Jeantet et al, (1996) encontró que al utilizar membranas de nanofiltración para la producción de lactosuero en polvo desmineralizado (40-48\% en peso), obtuvieron menores pérdidas de proteínas que con otras técnicas de tratamiento como la electrodiálisis o el intercambio iónico, además de un ahorro energético del $44 \%$.

Wijers et al. (1998) desmineralizó mezclas de péptidos trípticos hidrolizados $(\mathrm{TH})$ presentes en el lactosuero mediante membranas cargadas, con tasas de desmineralización satisfactorias. Sin embargo, la más apropiada para la desmineralización fue una membrana de poliamida con la permeabilidad más alta para las sales y la menor pérdida de material peptídico.

Alkhatim (1999), en su tesis doctoral "Desarrollo de membranas de nanofiltración aptas para la desmineralización del lactosuero" utilizó tanto membranas comerciales como membranas fabricadas en el 
laboratorio. De todas ellas, los mejores resultados se obtuvieron con la membrana: ACE-3-93-TY (capa activa: acetato de celulosa, soporte: Tyvek) y la membrana comercial NF-45. Las mejores densidades de flujo se obtuvieron a $\mathrm{pH} \leq 4$ y las mejores permeabilidades a $\mathrm{pH} \geq 4,5$. Finalmente el mejor intervalo de pH para la desmineralización del suero fue de 4,5 a 5,2. Tanto la membrana ACE-3-93-TY como la NF-45 mostraron buenos resultados en la desmineralización del suero utilizado. La membrana NF-90 presentó altos rechazos de sales en todos los intervalos de pH, descartándose para esta aplicación.

Räsänen E. et al. (2002) estudiaron la concentración y desmineralización de un suero dulce con las membranas Desal-5 DK, NF45 y Koch SR1, utilizando módulos planos y de arrollamiento en espiral. Los resultados obtenidos respecto al índice de rechazo fueron similares para cada uno de los módulos utilizados. Además, con el módulo plano se obtuvo una densidad de flujo más alta que con la de arrollamiento en espiral. Este comportamiento fue justificado por los autores asumiendo que el módulo de arrollamiento en espiral es más propenso a la polarización por concentración ó a un uso ineficiente del área de la membrana.

Jaffrin et al. (2004) proponen un sistema combinado de filtración vibratoria (VSEP) con membranas de nanofiltración y osmosis inversa. Las aguas residuales procedentes de una industria lechera fueron diluidas hasta un valor de DQO de $36000 \mathrm{mg} \mathrm{O} / \mathrm{L}$. Con la membrana NF-Filmtec obtuvieron en el permeado un valor de DQO de $94 \mathrm{mg}$

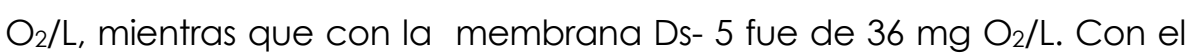
sistema VSEP y la membrana Ds-5 se obtuvieron los mejores resultados. 
Esto puede atribuirse a una reducción de la concentración de lactosa sobre la membrana. Como se esperaba la DQO en el permeado fue reducida a menos de $22 \mathrm{mg} \mathrm{O} / \mathrm{L}$ al usar la membrana de osmosis inversa.

Rektor et al. (2004) desarrollaron un sistema de filtración para el procesado del suero del proceso de obtención de la mozarella. El suero fue microfiltrado y ultrafiltrado antes de pasar por el modulo de nanofiltración y de osmosis inversa. El modulo de microfiltración retuvo el $67 \%$ de proteínas, el $98 \%$ de grasas y una pérdida de lactosa del 19.5\%. La ultrafiltración retuvo completamente la materia grasa, la retención de proteínas fue del $75 \%$ y la pérdida de lactosa del $41 \%$. Los permeados procedentes de los módulos de microfiltración y ultrafiltración se nanofiltró mostrando la misma formación de la capa gel sobre la membrana que las obtenidas con la MF y la UF. Con la unidad de osmosis inversa y un alimento con poco contenido en grasas, proteínas y lactosa no se observó formación de la capa gel. Por otra parte, los autores concluyeron que el contenido de materia grasa tuvo menor influencia sobre la disminución del flux que las proteínas y lactosa.

Suarez et al (2005), estudiaron la desmineralización parcial del lactosuero y del permeado obtenido por ultrafiltración de leche, para lo que utilizaron la membrana de nanofiltración Ds-5 DK. La reducción en el contenido salino de estos alimentos fue del orden del $30 \%$ y dependía de las condiciones de operación y del factor de reducción volumen utilizado. De todos los iones presentes, los monovalentes presentaron índices de rechazo más bajos que los divalentes. Los 
índices de rechazo más altos se obtuvieron con el lactosuero. Sin embargo, las densidades de flujo más elevadas se obtuvieron con el permeado de ultrafiltración de leche.

Un método utilizado para desmineralizar es la diafiltración, que permite obtener elevadas tasas de purificación tanto de macrosolutos como de microsolutos, proporcionando densidades de flujo aceptables. Los primeros trabajos de diafiltración fueron realizados por Blat et al (Cheryan et al, 1998) con membranas de ultrafiltración en el campo alimentario.

La diafiltración con membranas de nanofiltración es efectiva para la separación de sales de solutos orgánicos. Bowen y Mohammad (1998) desarrollaron el proceso de diafiltración para la separación de una disolución de colorantes, basado en la ecuación de NernstPlanck y la incorporación de la polarización por concentración. Algunos trabajos realizados con suero lácteo, han utilizado la diafiltración para el fraccionamiento de las proteínas presentes en el suero (Tolkach y Kulozik, 2005; Cheang y Sydney, 2004; De la Fuente, M.A. y otros, 2002, entre otros). Debido a los resultados obtenidos por estos autores, se considera interesante profundizar en este modo de operación para la desmineralización de la lactosa en esta tesis doctoral. 
OBJ ETIVOS

3. 



\section{OBJ ETIVOS}

\subsection{OBJETIVO GENERAL}

Optimizar el proceso de nanofiltración para la desmineralización y concentración de un lactosuero dulce procedente de una quesería con objeto de revalorizar la lactosa y minimizar su impacto medioambiental.

\subsection{OBJETIVOS ESPECÍFICOS}

- Caracterizar las membranas comerciales NF200, NF270, Ds-5 DK, Ds$5 \mathrm{DL}$ con disoluciones modelo.

- Determinar la influencia de la presión sobre la tasa de desmineralización de las membranas ensayadas.

- Estudiar el comportamiento de las membranas NF200 y Ds-5 DL mediante suero dulce.

- Determinar la influencia de las etapas de concentración y de diafiltración respecto de las especies presentes en el lactosuero dulce. 
- Establecer el proceso de ultrafiltración como un pretratamiento de la etapa de nanofiltración del lactosuero dulce real.

- Obtener un concentrado en lactosa, parcialmente desmineralizado para su posterior revalorización, con la consiguiente minimización del impacto medioambiental.

- Estudiar un modelo matemático que permita predecir el índice de rechazo de la lactosa en membranas de nanofiltración.

- Evaluar la viabilidad tanto técnica y económica del proceso de desmineralización del lactosuero dulce mediante nanofiltración. 
MARCO TEÓRICO 4. 



\section{MARCO TEÓRICO}

\subsection{ELABORACIÓN DEL QUESO}

El proceso de elaboración del queso, consiste en romper el equilibrio de los distintos componentes de la leche, mediante la transformación de la lactosa en ácido láctico y en la aglomeración de la cuajada (proteínas no solubles, caseína) utilizando diferentes procesos de acuerdo al tipo de queso a fabricar.

En la figura 4.1. se encuentra expuesta de forma breve la elaboración del queso. En ella se observa que hay tantas variedades de elaboración, como tipos de queso. Las etapas de la fabricación de queso se pueden dividir en:

- Recepción y tratamientos previos de la leche, entre los que se incluyen: refrigeración, higienización, pasteurización y bactofugación.

- Coagulación y separación parcial del suero.

- Llenado de moldes y prensado previo.

- Moldeado.

- Prensado.

- Salado.

- Maduración.

- Control de calidad y distribución. 

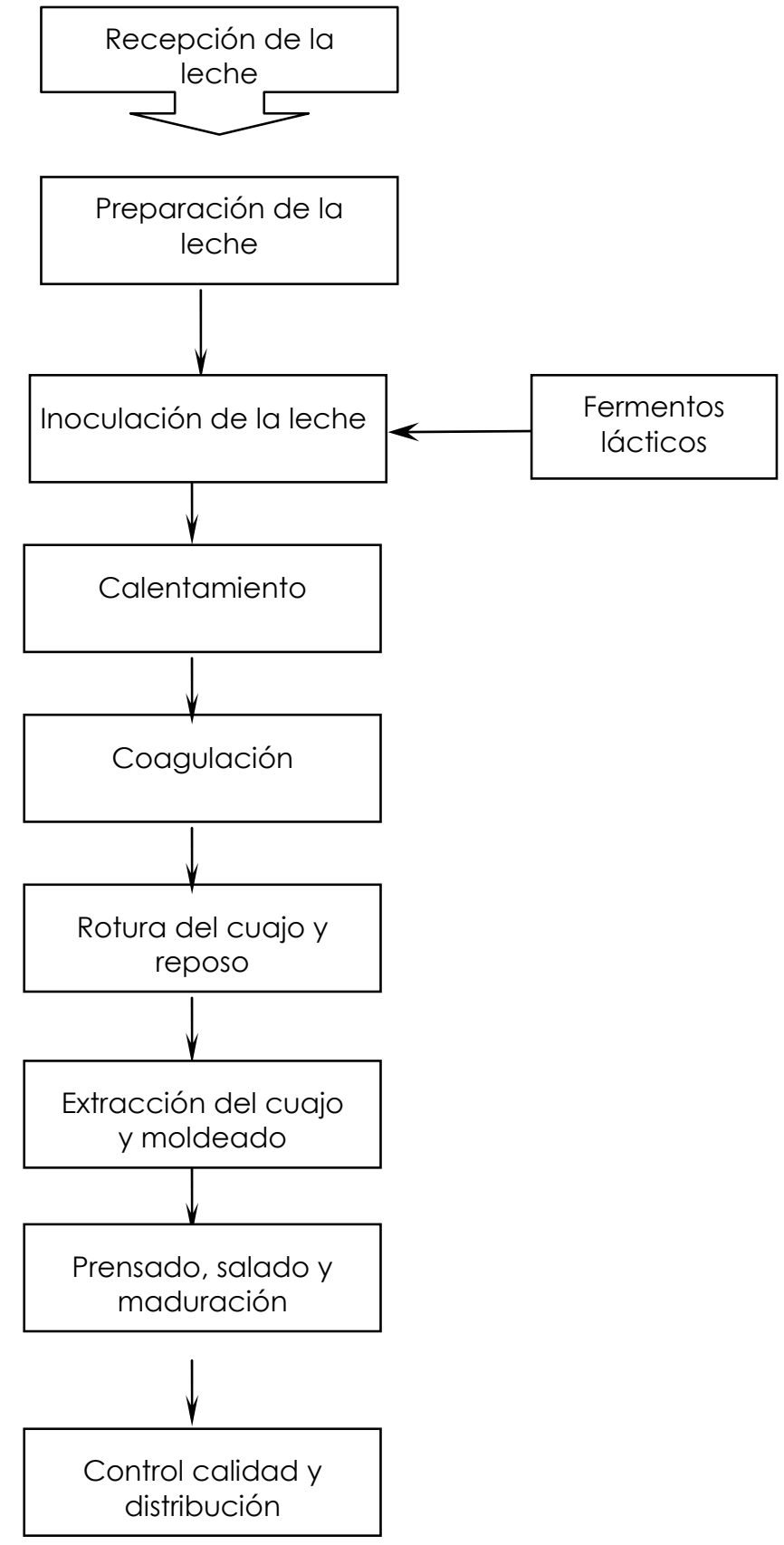

Figura 4.1. Elaboración del queso 


\section{Recepción de la leche}

La leche que se recibe en la quesería debe ser de buena calidad y con un bajo contenido bacteriano. Si es posible se debe recibir refrigerada entre $4-6^{\circ} \mathrm{C}$ en cisternas, que se descargan en tanques de acero inoxidable, donde se mantiene entre $3-4^{\circ} \mathrm{C}$.

Aunque la leche recibida sea de buena calidad, siempre es susceptible de contaminación, por lo que la quesería debe ser limpia y la leche se debe centrifugar para eliminar las impurezas sólidas. Después es pasteurizada entre $70-80^{\circ} \mathrm{C}$ (dependiendo del queso a fabricar), durante unos segundos para eliminar los microbios patógenos que puedan perjudicar la salud del consumidor.

Al pasteurizar la leche se obtienen quesos menos aromáticos, sin embargo es mejor renunciar a algunos aromas antes que correr riesgos que afecten la salud humana.

Preparación de la leche

El calentamiento de la leche elimina ciertos microorganismos que forman esporas, por ejemplo, las bacterias clostridium, que son resistentes a la pasteurización a 72 - $75{ }^{\circ} \mathrm{C}$, necesitándose temperaturas mucho más altas para su destrucción, pero no se aplican porque dañarían las calidades del queso obtenido. Así que en esta etapa se calienta la leche a una temperatura comprendida entre 65 - $75{ }^{\circ} \mathrm{C}$ para que disminuya su viscosidad y luego se centrífuga para separar las clostridium de la leche.

Inoculación con suero o fermentos lácticos En esta etapa se le añade a la leche: 
- Cultivo de bacterias lácticas, que transforman la lactosa (azúcar de la leche) en ácido láctico, lo que hace que la leche se acidifique, coagulando más fácilmente. La adición de cultivos lácticos se suele realizar a una temperatura entre $25-30^{\circ} \mathrm{C}$ y se les deja crecer durante unos minutos.

- Cloruro cálcico, añadido a la leche contribuye a su acidificación y de esta forma se acelera el proceso de coagulación. Se suele añadir cantidades entre 5 y $20 \mathrm{~g}$ de cloruro de calcio por cada $100 \mathrm{~L}$ de agua.

- Nitrato potásico, inhibe el crecimiento de bacterias. En la leche, las bacterias producen gases que afectan el sabor y el aroma del futuro queso. Se añade en dosis máximas de $20 \mathrm{~g}$ por cada $100 \mathrm{~kg}$ de leche.

- Colorantes naturales autorizados

- Mohos, que ayudan a desarrollar aromas y sabores durante la maduración.

Calentamiento

En esta etapa se lleva a cabo el calentamiento a la temperatura de coagulación de la leche. Normalmente la etapa de coagulación se realiza entre $30-32{ }^{\circ} \mathrm{C}$, aunque la temperatura óptima es a $40^{\circ} \mathrm{C}$. El trabajar a temperaturas más bajas $\left(30-32{ }^{\circ} \mathrm{C}\right)$ permite utilizar la mayor proporción de cuajo (de 20 a $30 \mathrm{~mL}$ por cada $100 \mathrm{~mL}$ de leche), siendo beneficioso para la maduración del queso, además de producir un coágulo de leche no demasiado duro. 
Coagulación

Es la transformación de la leche en queso, por la adición del cuajo. La caseina (principal proteína de la leche) coagula con gran parte de la grasa y otros componentes de la leche.

Rotura del cuajo y reposo Una vez acabada la coagulación se procede a la rotura del cuajo con utensilios de cuchillas dentro de la propia cuba quesera, con lo que el suero atrapado puede escapar. El corte reduce las partículas de coágulo a las dimensiones que se quiera (desde décimas de milímetro hasta tamaños entre $10-12 \mathrm{~mm}$ ). Si se pretende que el queso resultante tenga poca humedad se corta en tamaños pequeños, para que el suero se separe mejor. Si por el contrario se prefiere con más humedad se corta en tamaños más grandes en cuyo interior quedará retenida una cantidad importante de suero, muy rico en agua (entre 93 - 95\% de composición). El cuajo puede mantenerse en suspensión o en reposo. Con la agitación, los granos se hacen más compactos y después de unos minutos de agitación y corte se puede drenar el suero sin que se desintegren dichos granos $y$ escapen junto con el suero. Este drenaje se puede realizar sin necesidad de parar la agitación, aunque generalmente durante el drenaje del suero se paran estos dispositivos.

Extracción del cuajo y moldeado

El suero drenado se pasa por un tamiz, para retener los granos de cuajada que hubiesen podido escapar. También, se suele calentar la masa coagulada para acelerar el desuerado. Este calentamiento se suele realizar entre 30 y $48^{\circ} \mathrm{C}$, acompañado de agitación, para evitar que los trozos de coagulo se fundan unos con otros y se forme una pasta. Dependiendo de la temperatura utilizada en esta etapa se 
tendrán quesos más o menos secos. Si la temperatura es alta, escapará mucho suero y se tendrán quesos duros. Aumentando la temperatura a $44^{\circ} \mathrm{C}$ se puede llegar a destruir las bacterias lácticas que se añaden en etapas anteriores, deteniendo el proceso de acidificación. A temperaturas entre $35-36^{\circ} \mathrm{C}$ se empieza a inhibir su desarrollo. Este calentamiento se puede realizar de dos formas:

- Adición de agua caliente

- Calentamiento de la cuba con un serpentín.

\section{Prensado, salado y maduración}

Según el tipo de queso que se quiera fabricar, el prensado previo será más o menos intenso. Así, en el caso de quesos blandos, no se aplica presión alguna, dejando que el peso del propio queso actúe de prensa.

Si el prensado se realiza de manera que quede aire atrapado entre los granos o que los granos queden bañados en suero, los granos se fundirán durante la maduración y se formaran burbujas.

Después del prensado se procede a salar los quesos, bien por inmersión directa en baños de salmuera o por salado directo. Se puede hacer el salado cuando los granos aún están en la cuba, pero esto significa que se salaría también el suero, limitando sus usos. La adición de la sal ayuda a conservar el queso más tiempo, además de realzar sus aromas.

La maduración puede durar unas horas para quesos frescos y hasta meses y años para quesos duros. Durante la maduración deben 
cuidarse las condiciones de aireación, humedad y temperatura de las cámaras o cavas.

Finalmente, el queso es sometido a un control de calidad para luego ser distribuido al consumidor final.

\subsubsection{Suero de queserías}

La definición del lactosuero según el Código Alimentario, engloba a sueros de diferentes procedencias y se define como un líquido amarillento resultante tras la separación de gran parte de la caseína y la grasa durante la elaboración de diferentes productos lácteos (Morales, 1992). Como efluente representa un $83 \%$ del volumen total de la leche tratada. Dependiendo del proceso de fermentación se tienen dos tipos de suero, el suero dulce o al cuajo procede de los quesos y de la caseína al cuajo y el suero ácido de los quesos tipo quarg y el tipo cottage, entre otros. La composición del suero es variable según la procedencia (vaca, oveja y cabra, principlamente), la alimentación y la época del año.

La leche que se utiliza para la fabricación del queso, esta compuesta por:

Grasas, en forma de mono - di y triglicéridos, ácidos grasos, esteroles y carotenoides entre otros.

Proteínas, como las caseínas y las seroproteínas. Las caseínas son micelas en suspensión que difunden la luz y dan a la leche el aspecto 
blanco opaco, éstas se encuentran en mayor proporción en la leche. Las proteínas del suero o seroproteínas formadas por la lactoglobulina y lactoalbúmina, siendo esta última predominante en el suero, son proteínas de excelente calidad, con los aminoácidos esenciales en cantidades necesarias para el organismo humano y son fácilmente digeribles.

Lactosa, único azúcar que se encuentra en la leche en cantidad apreciable, está presente en forma de $\alpha$ - y $\beta$-lactosa. El porcentaje de lactosa en el suero es variable, ayuda al crecimiento de bacterias lácticas beneficiosas, pues limitan o impiden el crecimiento de bacterias patógenas.

Sales minerales, presentes en el lactosuero (calcio, sodio, potasio, magnesio, fosfatos, cloruros, citratos y caseinatos entre otros) se encuentran disueltas o en forma de complejos con la caseína. De todas, el calcio es un nutriente esencial que no esta disponible en muchos productos de consumo habitual.

\subsubsection{Composición del lactosuero}

La composición del lactosuero varía con la composición de la leche utilizada de partida y el tipo de queso a fabricar. Dependiendo de que la cuajada se consiga por acidificación o por adición de cuajo, se obtiene una variación importante en el contenido de las sales minerales. El suero dulce, obtenido por adición de cuajo, contiene poco calcio, ya que se produce por el desdoblamiento del complejo caseína-calcio. En el caso del suero obtenido por acidificación, el 
ácido láctico se convierte en lactato cálcico que aparece en el suero. En la tabla 4.1 se pueden observar las concentraciones típicas de estos tipos de suero.

Tabla 4.1. Composición del lactosuero.

\begin{tabular}{|c|c|c|}
\hline \multirow[b]{2}{*}{ Componente } & \multicolumn{2}{|c|}{ Composición \% } \\
\hline & Suero dulce & Suero ácido \\
\hline Sólidos totales & 6,40 & 6.50 \\
\hline Aqua & 93,60 & 93,50 \\
\hline Grasa & 0,05 & 0,04 \\
\hline Proteína & 0,55 & 0,55 \\
\hline NNP* & 0,18 & 0,18 \\
\hline Lactosa & 4,80 & 4,90 \\
\hline Cenizas (sales minerales) & 0,50 & 0,80 \\
\hline Calcio & 0,043 & 0,120 \\
\hline Fósforo & 0,040 & 0,065 \\
\hline Sodio & 0,050 & 0,050 \\
\hline Potasio & 0,160 & 0,160 \\
\hline Cloruro & 0,110 & 0,110 \\
\hline Ácido láctico & 0,050 & 0,400 \\
\hline
\end{tabular}

*Nitrógeno no proteico. Manual de industrias lácteas, (2003)

\subsubsection{Productos derivados del suero}

Los derivados del suero, son utilizados en una gran variedad de productos: bollería (galletas, dulces, panes, pasteles), dulces (caramelos, chocolates), productos lácteos (margarinas, quesos, 
yogures), bebidas (zumos de frutas, bebidas energéticas), helados, jarabes, productos cárnicos, salsas y aderezos de ensaladas.

A continuación, en la figura 4.2, se encuentran esquematizados, los diferentes procesos que dan lugar a los diferentes productos obtenidos a partir del suero. Se ha comprobado que la concentración por evaporación a vacio del suero para su posterior desecación o cristalización es más económica si éste es ultrafiltrado (Jeantet et al, 1996).

En el caso de productos con alta pureza es necesario eliminar las sales minerales no deseadas, por intercambio iónico y/o electrodiálisis, necesitándose altos costes de inversión, con generación de grandes volúmenes de vertido y de contaminantes. La nanofiltración es una alternativa a los procesos anteriores con la ventaja añadida de que permite obtener un suero con menor contenido salino a costes más bajos. 
Marco teórico

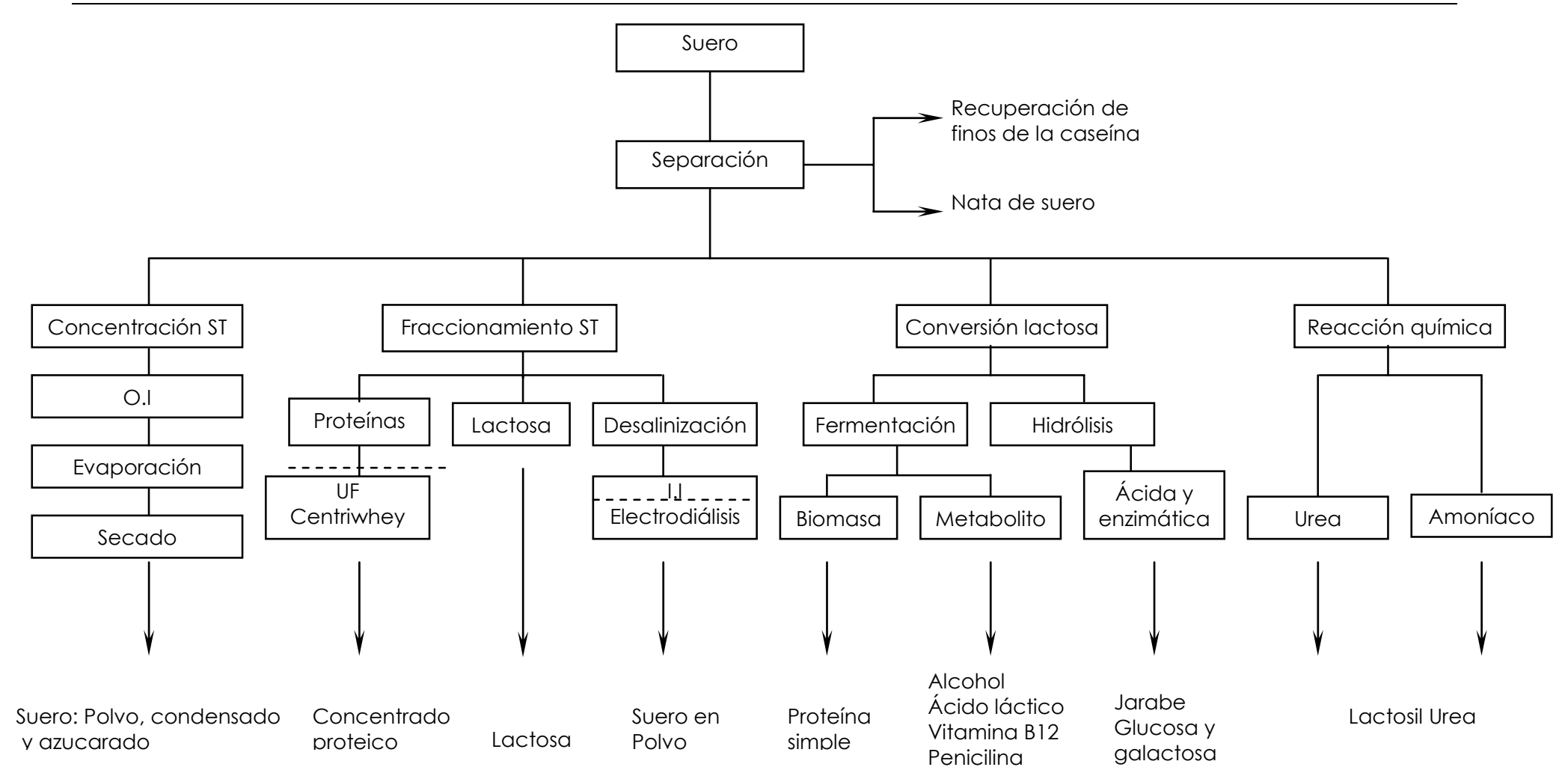

Figura 4.2. Obtención de diferentes tipos de suero 


\subsection{TECNOLOGÍAS DE MEMBRANA}

\subsubsection{Introducción a las operaciones de membrana}

Una membrana es una película delgada (fina) que separa dos fases y actúa como una barrera selectiva al transporte de materia, debido a un gradiente de potencial químico entre las dos fases situadas a ambos lados de la misma. A una membrana entra una corriente de alimento y salen dos corrientes, permeado y concentrado. La corriente de permeado esta compuesta por las especies que pasan a través de la membrana y el concentrado es la corriente formada por las especies que no logran atravesarla.

En la figura 4.3, se encuentra esquematizado el funcionamiento general de un proceso de separación por membranas, así como cada una de sus corrientes.

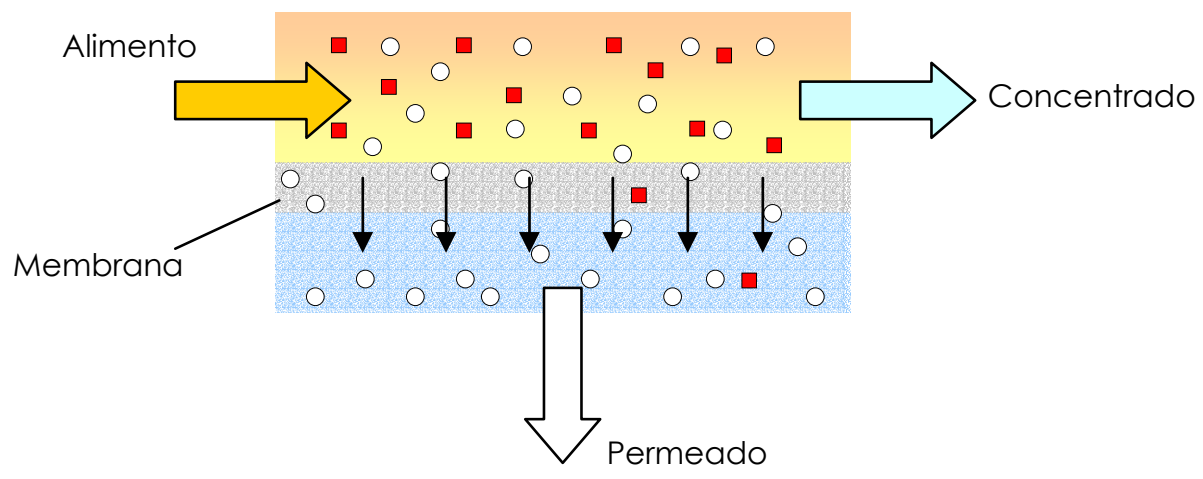

Figura 4.3. Principio básico de operación de una membrana 
Los procesos de filtración convencional, tipo filtros de carbón activo, arena y antracita, etc. operan bajo el principio de la filtración estática. Se caracterizan por que la fuerza impulsora es la gravedad, la presión solo se aplica para acelerar el proceso y la dirección del flujo es perpendicular al medio filtrante, mientras que los procesos de membranas lo hacen con la filtración dinámica. La presión es la fuerza impulsora de este proceso de separación y para evitar la colmatación de las membranas el flujo debe ser tangencial a la superficie de las mismas, tal como se muestra en la figura 4.4.
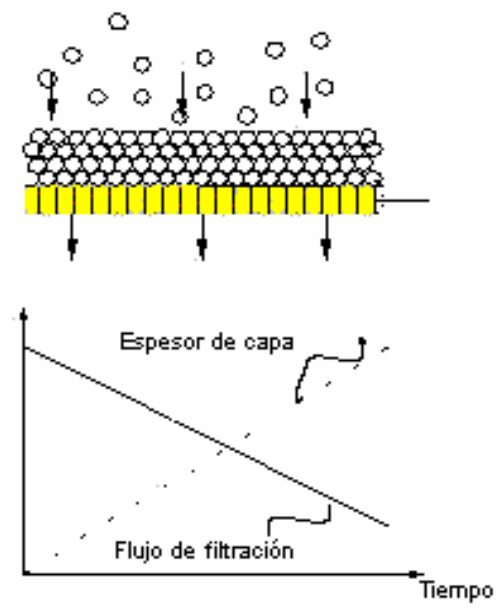

Filtración convencional

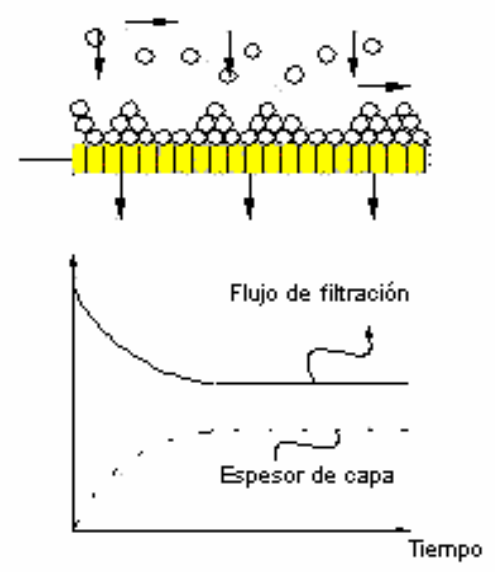

Filtración tangencial

Figura 4.4. Diferencias entre filtración estática y dinámica. 


\subsubsection{Clasificación general de las operaciones de membrana}

\subsubsection{Tipos de operación cuando la fuerza impulsora es la presión}

1. Microfiltración (MF), este tipo de membranas poseen un tamaño de poro mayor de $50 \mathrm{~nm}$. El rango de presiones de operación está por debajo de los 0,2 MPa. La microfiltración es usada principalmente para separar partículas y bacterias.

2. Ultrafiltración (UF), esta membrana posee un tamaño de poro entre 50 y $2 \mathrm{~nm}$. El rango de presiones de operación está entre 0,1 y $1 \mathrm{MPa}$. La ultrafiltración es utilizada para separar contaminantes microbiológicos, coloides (proteínas) y en general moléculas de gran tamaño.

3. Nanofiltración (NF), este tipo de membranas poseen un tamaño de poro menor de $2 \mathrm{~nm}$. El rango de presiones de operación está entre 0,5 y $4 \mathrm{MPa}$. La nanofiltración permite separar los azúcares de otras moléculas orgánicas, así como sales minerales multivalentes de moléculas orgánicas, y sales multivalentes de las monovalentes, debido a los efectos de exclusión iónica y estérica. Es usada para concentrar y desmineralizar parcialmente el suero lácteo.

4. Ósmosis inversa, esta membrana posee el nivel más fino de la filtración, pues no posee poros. Actúa como una barrera selectiva a todos los iones disueltos y a moléculas orgánicas con un peso molecular superiores a 100 Da. En cambio las moléculas de agua pasan libremente a través de la membrana. Es usada para concentrar el suero o la leche desnatada. 
En las tres últimas operaciones anteriores la presión va aumentando progresivamente desde la ultrafiltración hasta la osmosis inversa. En ninguno de los procesos anteriores la separación se lleva a cabo con cambio de fase, lo que constituye una ventaja desde el punto de vista económico, pues el consumo energético no es elevado.

En la tabla 4.2, se muestra un resumen de las operaciones de membrana cuando la fuerza impulsora es la presión.

Tabla 4.2. Tipo de operación de membranas a presión.

\begin{tabular}{lll}
\hline Operación & $\begin{array}{l}\text { Mecanismo de } \\
\text { separación }\end{array}$ & $\begin{array}{l}\text { Estructura de } \\
\text { membrana }\end{array}$ \\
\hline MF & Cribado & Macroporos \\
UF & Cribado & Mesoporos \\
NF & Cribado + disolución/difusión +exclusión & Microporos \\
OI & Disolución/difusión +exclusión & Densa \\
\hline
\end{tabular}

*American Water Works Association (AWWA) Research Foundation, (1998).

La figura 4.5, permite observar los diferentes rangos de presión así como el tamaño de las especies que permiten separar los procesos de membrana nombrados anteriormente. Así como el espectro de las separaciones por membranas utilizadas en la industria láctea, como se muestra en la figura 4.6. 


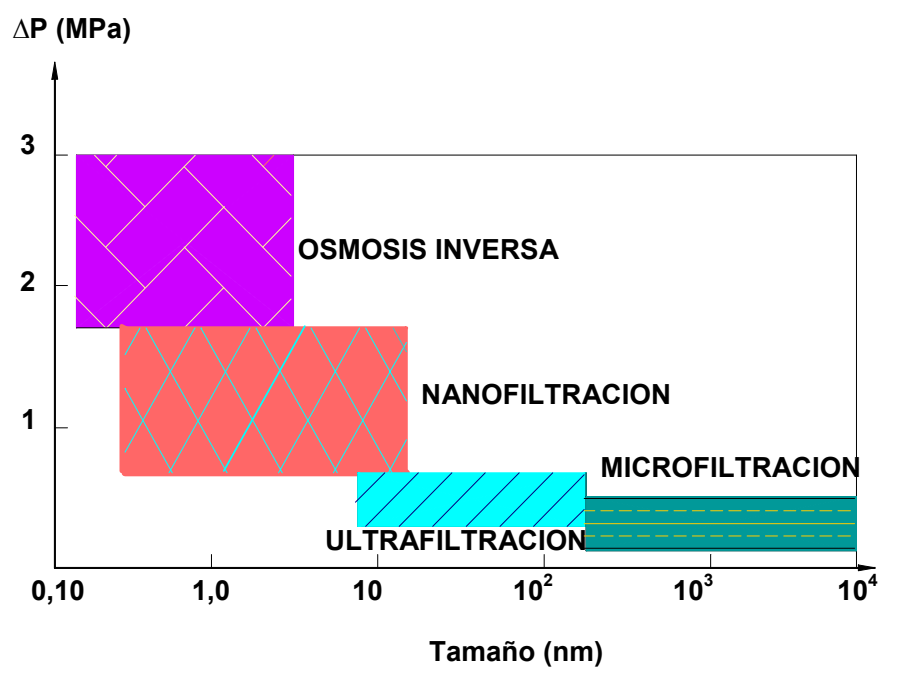

Figura 4.5. Rangos de presión, según el tamaño de partícula

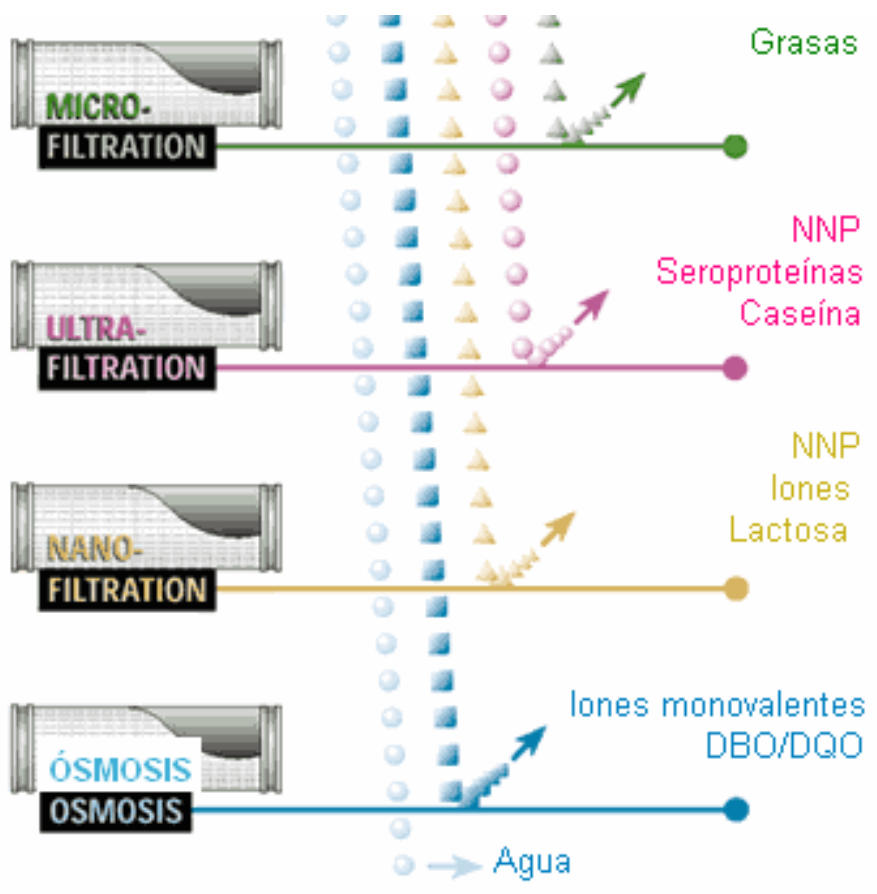

Figura 4.6. Uso de las membranas en la industria láctea 
4.2.2.2. Tipos de operación según el mecanismo de separación de la membrana

El mecanismo de separación depende de alguna propiedad específica de los componentes que serán separados selectivamente por la membrana. Básicamente hay tres mecanismos de separación:

1. Separación debida a grandes diferencias de tamaño (mecanismo de cribado). En este tipo de separación se pueden clasificar las operaciones de membrana en: microfiltración, ultrafiltración y en parte nanofiltración.

2. Separación basada en las diferencias de solubilidad y difusividad de los materiales de las membranas (mecanismo de disolucióndifusión). En este tipo de separación están los procesos de ósmosis inversa y nanofiltración.

3. Separación basada en las diferencias de carga de las especies a separar (efecto Donnan), característico de membranas de nanofiltración.

\subsubsection{Estructura, configuración y materiales de membranas.}

\subsubsection{Estructura}

Las membranas que tienen como fuerza impulsora la presión, poseen una estructura asimétrica para disminuir la pérdida de carga. Esta estructura asimétrica a su vez esta compuesta de dos capas: 
- Capa activa: esta capa es la responsable de los valores que se obtienen respecto a la densidad de flujo y al índice de rechazo de la membrana.

- Soporte: es una estructura microporosa sobre la cual esta depositada la capa activa. Su función es facilitar el drenaje de la corriente de permeado, de forma que la pérdida de carga sea baja y así obtener grandes densidades de flujo de permeado. Además, proporciona estabilidad mecánica al módulo de membrana.

\subsubsection{Configuración del módulo}

El módulo es el compartimento donde se encuentran ubicadas las membranas, debe aportar resistencia mecánica para las condiciones de operación utilizadas. Cada módulo posee una entrada para la alimentación, una salida para la corriente de concentrado y otra para la corriente de permeado, ésta a su vez, puede tener varias salidas, dependiendo del número de membranas que se puedan colocar en el modulo. La velocidad tangencial del fluido es un factor importante a la hora de minimizar el efecto de la polarización por concentración.

Las configuraciones más comunes para membranas a escala industrial son las de arrollamientos en espiral (densidad de flujo constante, mínimo ensuciamiento y fácil limpieza), fibra hueca (se produce más fácil el ensuciamiento, imposible limpieza). Las de tipo placa y marco son las más utilizados a escala de laboratorio para desarrollar y caracterizar nuevas membranas. 
- Modulo plano: Son los primeros módulos que se utilizaron. Están constituidos por membranas en forma de lámina. Su diseño se deriva de los filtros prensa. En esta configuración las membranas se colocan dentro de un marco cuadrado, rectangular o circular. Se pueden colocar varias membranas simultáneamente. Éstos módulos trabajan generalmente con pequeñas áreas de membrana, proporcionando bajos caudales de permeado. Las membranas pueden desmontarse fácilmente, facilitando su limpieza.

- Módulo de arrollamiento en espiral: Esta formado por varias membranas planas enrolladas, separadas unas de otras por un espaciador dentro de un tubo. Los espaciadores no solo mantienen abierto un canal de flujo para la alimentación, sino que también proporcionan turbulencias y de esta forma reducen el efecto de la polarización por concentración. El módulo de arrollamiento en espiral es más sensible a la obstrucción que los módulos planos.

- Módulo de fibra hueca: esta formado por un haz de varios miles incluso millones de fibras huecas. El flujo de alimentación puede realizarse bien por dentro de las fibras, (configuración interiorexterior) o bien por fuera de las fibras (configuración exterior-interior). Estos módulos son muy compactos, proporcionando grandes densidades de flujo de permeado. Su desventaja radica en la dificultad de limpieza in situ.

- Módulo tubular: Es la configuración más simple, pues la membrana se moldea sobre la pared interior de un soporte poroso. Estos módulos no necesitan una prefiltración fina y son de fácil limpieza. Su principal desventaja es que son poco compactos.

\subsubsection{Materiales de la membrana}


Los materiales de las membranas pueden ser orgánicos (materiales poliméricos como polisulfonas, polieter sulfonas, polivinil alcohol, acetatos de celulosa y derivados, poliacrilonitrilo, y poliamidas aromáticas) e inorgánicos (óxidos, carburos de aluminio, circonio, titanio, entre otros). Los materiales orgánicos a partir de los que se fabrican las membranas son esencialmente hidrofílicos; es decir, buena afinidad del material de membrana con el agua.

En la industria láctea se utilizan tanto membranas de acetato de celulosa como de poliamida aromática. Las de acetato de celulosa (mezcla de ésteres de celulosa con diferente grado de acetilación) presentan la desventaja de ser muy susceptibles a la hidrólisis tanto a pH bajos como altos, acelerandose si se trabaja fuera del rango de $\mathrm{pH}$ de 4,0 a 6,5, debido a su condición de polisacárido y éster. Además toleran bajas dosis de cloro residual, poseen bajo umbral de temperatura $\left(<30^{\circ} \mathrm{C}\right)$ y son susceptibles a la degradación biológica. Sin embargo las de triacetato y las mezclas de acetato de celulosa/triacetato de celulosa son hidrolíticamente más estables.

Las membranas de poliamida aromática tienen excelentes propiedades de rechazo, rango de $\mathrm{pH}$ más amplios de 4,0 a 9,0 y son estables a la degradación bacteriana. No obstante, las membranas de acetato de celulosa tienen mayor rendimiento de caudal y son más resistentes a la degradación por oxidación que las de poliamida. 


\subsubsection{Ultrafiltración}

En esta tesis, la unidad de ultrafiltración se utilizó como un tratamiento previo a la unidad de nanofiltración. Con la ultrafiltración se consigue separar las proteínas presentes en el suero, de aquí la corriente de permeado se lleva a la unidad de nanofiltración para continuar con el proceso de separación de la lactosa de las sales minerales. En algunas ocasiones un pretratamiento del suero es necesario con el fin de eliminar la grasa y los sólidos suspendidos antes de entrar a la unidad de ultrafiltración.

La ultrafiltración solo se reconoció como una técnica nueva y eficiente de separación a nivel industrial a partir de los años 60, principalmente en la industria láctea. Esta técnica se caracteriza por separar sustancias de elevado peso molecular o macromoléculas, así como sustancias coloidales. Una de las características más importantes de las membranas de UF es la formación de una capa gel máxima determinada sobre la superficie de la membrana que limita la densidad de flujo. Los cortes moleculares de las membranas de UF varían entre 1 y 300 kDa.

La industria láctea es la que más ha fomentado el uso de membranas de UF dentro de sus procesos, principalmente en la fabricación del queso, obtención de concentrados proteicos, etc.

El índice de rechazo es otro parámetro que se utiliza para caracterizar las membranas. En membranas de ultrafiltración, este parámetro se puede predecir a partir del corte de peso molecular de la membrana y el peso molecular del soluto a ultrafiltrar. Desafortunadamente, esta 
simple relación no puede describir exactamente el rendimiento de la membrana por varias razones:

- Una membrana con poca uniformidad en la distribución del tamaño del poro da índices de rechazo difusos. Las membranas disponibles tienen un amplio rango de tamaño de poros, lo que limita el uso de la UF en la eliminación de las diferentes proteínas.

- El corte de peso molecular (cut-off) normalmente se estima en términos de series homólogas de dextranos, pero su comportamiento no se puede aproximar al de las proteínas. Mcgregor, 1986 encontró grandes diferencias entre el cut-off de membranas de UF determinadas experimentalmente y las suministradas por los fabricantes. El corte de peso molecular de una membrana no siempre determina el límite de separación, pues la forma de las partículas a separar también influye.

- El fenómeno de polarización por concentración, también afecta el índice de rechazo al formarse la capa gel sobre la superficie de la membrana.

- En algunas disoluciones, el aumento de la presión hace que se incremente el índice de rechazo. También el incrementar la velocidad tangencial hace que el índice de rechazo de lactosa aumente, según Kiviniemi, 1977.

- El cambio de pH o de la fuerza iónica, también afectan al índice de rechazo de macromoléculas.

Los principales factores que determinan la capacidad de separación son:

- La resistencia de la membrana, que viene determinada por el diámetro de poro, el espesor y el área superficial. 
- Resistencia al transporte, por efecto de la polarización por concentración o el ensuciamiento. Esto da lugar a que se forme un depósito sobre la superficie de la membrana, por ejemplo: las grasas y las proteínas se transportan por convección hacia la membrana de forma perpendicular a la dirección del flujo.

\subsubsection{Nanofiltración}

La nanofiltración (NF) es una técnica que combina características de ultrafiltración y ósmosis inversa, pues su mecanismo de separación se basa tanto en diferencias de tamaños, propio de la ultrafiltración, como en el modelo de disolución - difusión, tal como ocurre en ósmosis inversa.

La NF es una operación de media - baja presión, que deja pasar solo las partículas de tamaño menores de 1 nanometro ( $10 \AA$ A), de aquí el término de nanofiltración. Las membranas de nanofiltración operan en rangos más altos de corte de peso molecular (300 - $500 \mathrm{~g} / \mathrm{mol}$ ) que las de osmosis inversa, mientras que las membranas de osmosis inversa son menos permeables que las de nanofiltración. Otra propiedad de las membranas de nanofiltración es la ligera carga superficial que poseen. La interacción de la carga juega un papel importante, y este principio sirve para separar iones de diferente valencia.

En la tabla 4.3 se pueden ver, las distintas aplicaciones de las membranas de nanofiltración en diversos procesos industriales. 
Tabla 4.3. Aplicaciones industriales de las membranas de NF

\begin{tabular}{ll}
\hline Industria & Aplicación \\
\hline Alimentaría & Desmineralización parcial del lactosuero \\
& Concentración de proteínas \\
& Desmineralización de disoluciones azucaradas \\
& Reciclado de nutrientes en procesos fermentativos \\
& Separación de solventes de aceites vegetales \\
& Recuperación de soluciones de limpieza \\
& Purificación de ácidos orgánicos \\
& Concentración de zumos \\
\hline Textil & Separación de aminoácidos \\
& Eliminación del color de los efluentes de tintado \\
& Recuperación de agua y de sales \\
& Recuperación de las aguas de blanqueo \\
\hline Papelera & Eliminación de lignina, lignosulfatos y derivados clorados \\
& Recuperación de agua \\
\hline Química & Eliminación de sulfatos \\
& Obtención de bromuro \\
Recuperación de sosa
\end{tabular}


Finalmente, puede concluirse que las membranas de nanofiltración se caracterizan por:

- Carga iónica: los iones divalentes son mejor rechazados que los monovalentes, haciendo posible separar iones de diferentes valencias y tamaños. Siendo muy útil en ablandamiento de aguas, eliminación de nitratos y desmineralización del lactosuero.

- Peso molecular: especies de alto peso son mejor rechazados que los de bajo peso molecular.

- Grado de disociación: ácidos débiles como el ácido láctico es mejor rechazado a valores altos de pH, donde la disociación es completa.

- Polaridad: las sustancias menos polares son mejor rechazadas.

- Grado de hidratación: Especies altamente hidratadas son mejor rechazadas que las menos hidratadas (entalpía de hidratación).

La selectividad de las membranas de nanofiltración depende de la naturaleza química del material polimérico del que están compuestas. Algunos polímeros pueden ser hidrófobos o hidrófilos, las membranas más recomendables para trabajar con disoluciones acuosas son las que presentan características hidrófilas, puesto que membranas con características hidrofóbicas tienden a ensuciarse más rápidamente.

El índice de rechazo, es otro parámetro que permite cuantificar el grado de selectividad de una membrana respecto de un determinado soluto, el cual nunca alcanza el 100\%. Un porcentaje muy bajo de soluto pasará con la corriente de permeado de acuerdo con su coeficiente de reparto (afinidad del soluto por el material de la membrana) así como del 
coeficiente de difusión del soluto en la membrana. También el efecto Donnan influye en la selectividad de la membrana. (AWWA, 1998)

En nanofiltración una parte del mecanismo de transferencia de masa se basa en la disolución - difusión, y el cual está intrínsecamente relacionado con el fenómeno de presión osmótica. A continuación se explica brevemente en que consiste dicho fenómeno.

\subsubsection{Influencia de la Presión osmótica}

La figura 4.7, muestra en la posición inicial a) dos fluidos diferentes separados mediante una membrana semipermeable en condiciones isotérmicas. Donde, la fase diluida (agua) posee mayor potencial químico que la fase concentrada (salmuera). En la posición b) se origina un flujo de disolvente de la fase diluida a la fase concentrada hasta que los potenciales químicos se igualan en ambos lados de la membrana alcanzando el equilibrio ósmotico. La diferencia de presión hidrodinámica se denomina diferencia de presión osmótica $(\Delta \pi)$. En la posición c) se observa que para vencer la presión osmótica es necesario aplicar una diferencia de presión mayor que la presión osmótica y de esta forma se obliga al disolvente a pasar de la fase más concentrada a la fase diluida, también llamada ósmosis inversa. 

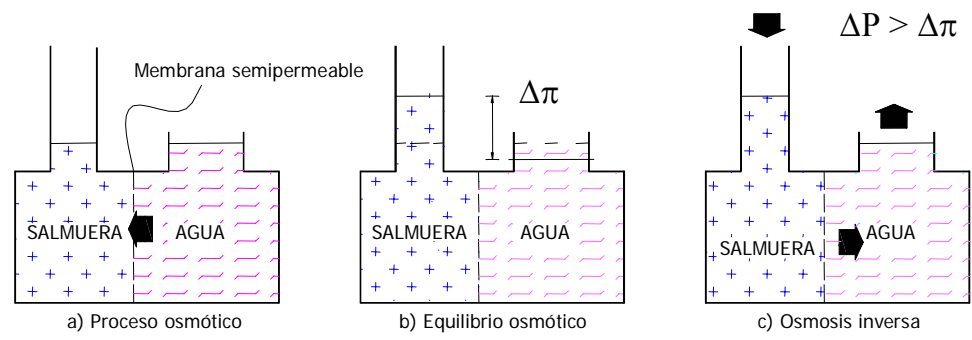

Figura 4.7. Principio de flujo osmótico

\subsubsection{Polarización por concentración}

En procesos de membrana cuando el disolvente atraviesa la membrana se incrementa la concentración de soluto en el concentrado, cerca de la cara anterior de la membrana, creándose un fenómeno de polarización por concentración. De esta forma la eficiencia de la membrana no solo depende de sus propiedades, sino también de las condiciones de operación. La hidrodinámica del sistema tiene influencia directa en la reducción de la resistencia de transporte en la interfase de la membrana. El diseño del sistema juega un papel muy importante en la distribución del flujo en la interfase de la membrana, ayudando a disminuir el efecto que la polarización por concentración tiene sobre el rendimiento. En la figura 4.8 se encuentra esquematizado dicho fenómeno. 


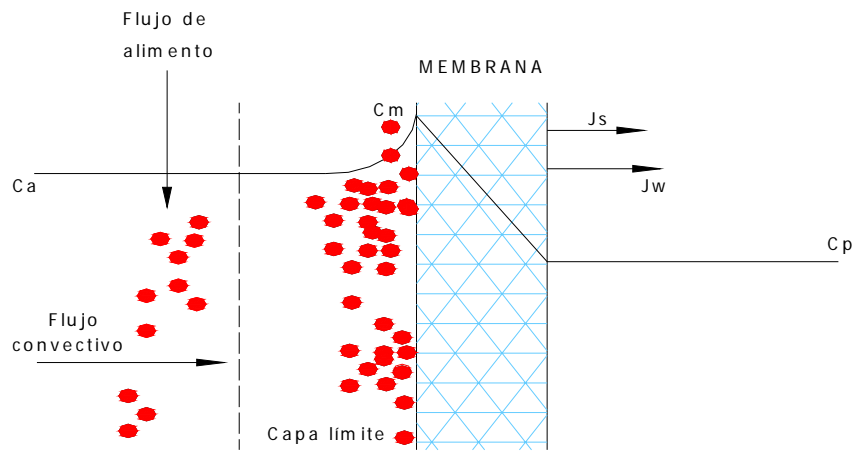

Figura 4.8. Transferencia de masa en membranas

Al aplicar una presión externa a la corriente de alimentación con una concentración $\mathrm{Ca}$, sobre la cara de la membrana, el disolvente pasará a través de esta. Una parte del soluto es rechazado, el cual se irá acumulando en la superficie, creándose un perfil de concentración. Este fenómeno se denomina polarización por concentración. El soluto distribuido en la interfase membrana/disolución, será transportado a través de la membrana tanto por el mecanismo convectivo como por el de disolución-difusión. En la cara del permeado, un segundo proceso de distribución ocurrirá y aparecerá una concentración final de soluto en la corriente de permeado $C p$.

En procesos de nanofiltración, la distribución de solutos no cargados en la interfase capa límite/membrana se debe al mecanismo de exclusión por tamaño. Este mecanismo también aparece en procesos de microfiltración y ultrafiltración. Debido a su tamaño un soluto solo tiene acceso a una parte del área total de la superficie de un poro. Esto causa la exclusión del soluto por la superficie de la membrana. Una separación entre diferentes solutos solo se dará si estos tienen diferencias significativas de tamaño. 
En el caso de solutos cargados se conocen dos mecanismos de transferencia:

\subsubsection{Mecanismo de exclusión de Donnan}

El principio de exclusión de Donnan, tiene un efecto pronunciado sobre el mecanismo de transporte cuando la superficie de la membrana está cargada (membranas de intercambio iónico, electrodiálisis, membranas con carga superficial, principalmente). Si la membrana posee una carga superficial, los solutos con carga opuesta a la de la membrana (contraiones) son atraídos, mientras que los solutos con la misma carga que la membrana (co-iones) son repelidos. En la superficie de la membrana se producirá una distribución de contra y co-iones, causando de este modo una separación adicional de los solutos cargados.

El principio de electroneutralidad debe cumplirse, por lo que co-iones y contra-iones deben pasar en proporción estequiométrica. Los iones de peso molecular superior al cut-off de la membrana son retenidos por efectos estéricos. Así mismo, se ha observado un rechazo preferente de iones multivalentes frente a iones monovalentes. Incluso, si la relación de concentraciones entre especies monovalentes y divalentes es lo suficientemente alta puede haber más concentración de co-iones en el permeado que en el alimento, dando lugar a valores de rechazos negativos. En la figura 4.9, se esquematiza este comportamiento para una membrana cargada negativamente. 


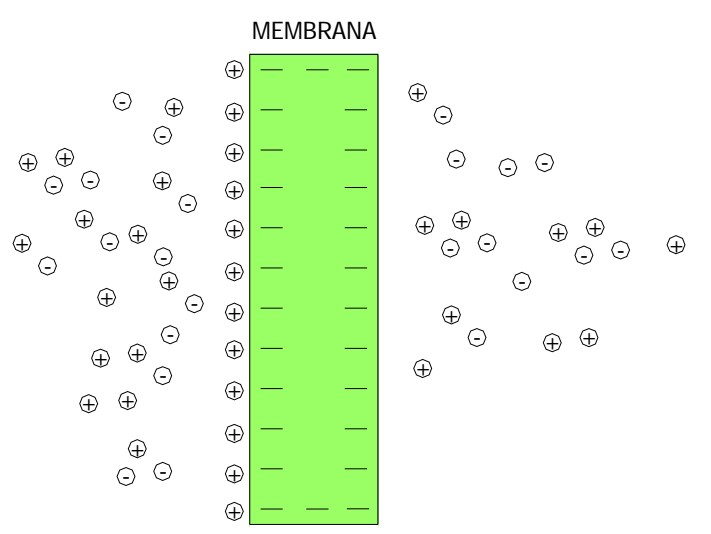

Figura 4.9. Principio de Exclusión de Donnan

\subsubsection{Mecanismo de exclusión dieléctrica}

Esta exclusión, se debe a la carga superficial de la membrana y al momento dipolar del agua, las moléculas de agua muestran una polarización dentro del poro. Dicha polarización ejerce una disminución de la constante dieléctrica, haciendo que sea menos favorable para un soluto cargado entrar. Sin embargo, en condiciones en las que la constante dieléctrica dentro del poro es igual a la constante dieléctrica del agua, se produce un cambio en la energía libre electrostática del ión al ser transferido desde el seno de la disolución hasta el poro, dando como resultado su exclusión.(Glueckauf, 1976). Este comportamiento se muestra en la figura 4.10. 


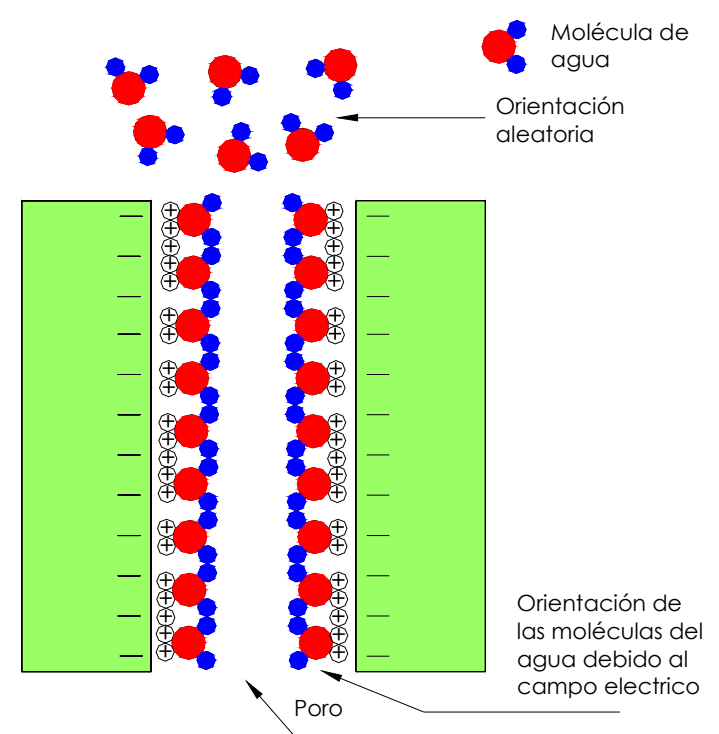

Figura 4.10. Exclusión dieléctrica

Dentro de la teoría de exclusión dieléctrica, se tiene que el agua al estar influenciada por un campo eléctrico no actúa como tal, el poro adquiere propiedades similares a un disolvente hidrofóbico (la constante dieléctrica disminuye). Forzar a un ión que entre dentro del poro es energéticamente desfavorable, por lo que el ión tiene que deshacerse del agua de solvatación.

La importancia de estos dos mecanismos de transporte, en procesos de nanofiltración es aún punto de debate en la comunidad científica (Hagmeyer 1998, Yaroshchuk 2000). En la mayoría de la literatura estudiada, se utiliza el principio de exclusión de Donnan para comprender mejor el mecanismo de transporte en membranas de nanofiltración. 
Para describir el mecanismo de transporte en membranas de nanofiltración se han utilizado modelos como: modelo de Theorell y Meyers y Sievers (TMS), modelo de carga superficial (SC), ecuación Extendida de Nernst Planck (ENP), entre otras.

\subsubsection{Ensuciamiento de las membranas en la industria láctea.}

Algunos autores definen el ensuciamiento por proteínas como una red compleja de muchas proteínas. Algunas fotografías de microscopia electrónica, sugieren que el ensuciamiento ocurre cuando los constituyentes más grandes del suero incluidos los microorganismos precipitan sobre la membrana formando una red cristalina. Entre todas las proteínas, la $\alpha$-lactoalbumina tiene una tendencia más fuerte a la formación de una capa gel y la albúmina de suero bovina la que menos, mientras que la $\beta$-lactoglobulina es la que más afecta al ensuciamiento.

Los finos de la caseina y la coagulación incompleta de esta contribuyen al ensuciamiento. De ahí, que el suero fresco con frecuencia provoque mayor ensuciamiento que otro que ha sido almacenado durante unas horas. Los Lípidos, pequeños glóbulos de grasa, también contribuyen al ensuciamiento de la membrana.

De todos los constituyentes inorgánicos presentes en el suero, es el calcio el que más problemas puede ocasionar respecto al ensuciamiento de la membrana. El calcio puede estar presente de dos formas en el suero, una fracción ermeable y otra impermeable. La 
última esta presente como fosfato coloidal unido a la $\beta$-lactoglobulina del suero. Cuando la concentración de fosfato cálcico en el concentrado excede su índice de solubilidad, este tiende a cristalizar formando depósitos sobre la membrana que contribuyen al ensuciamiento. El incremento del contenido de calcio del suero a un $\mathrm{pH}$ alrededor de 6, incrementa el ensuciamiento de la membrana. (Kessler, 1982).

Los resultados de Hickey, 1980 indican sin embargo, que la formación de una capa gel no reduce las tasas de permeación a menos que las condiciones permitan la formación de una capa gel dentro de los poros de la membrana. El papel del calcio en el ensuciamiento de la membrana ha sido verificado por Merin y Cheryan (1980) y Kessler (1982), determinaron que el calcio depositado sobre la membrana puede producir una capa gel de gran dureza, que además aumenta con la presión. En la figura 4.11, se encuentran resumidos, los tipos de ensuciamiento más comunes.

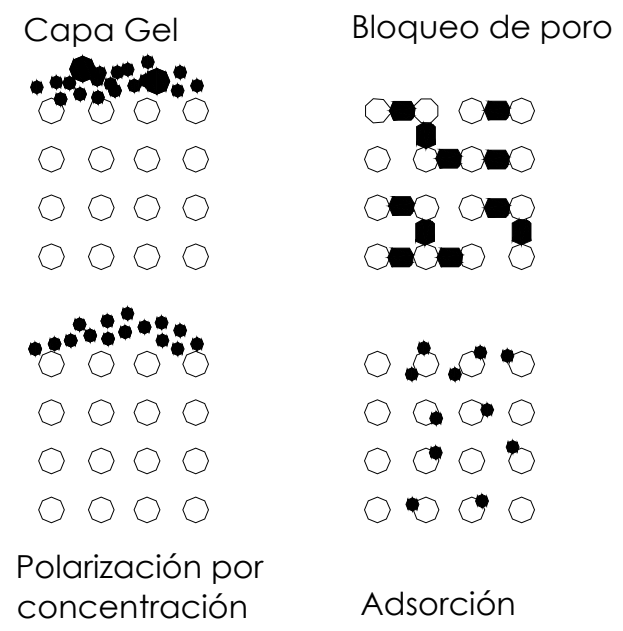

Figura 4.1 1. Mecanismo de ensuciamiento de la membrana 
La formación de un deposito ó precipitado de la proteína debido a la convección a través del material poroso es mucho más difícil de caracterizar. La desnaturalización y agregación de las proteínas puede dar lugar a diferentes tipos de acumulación comparada con las proteínas nativas. En cuanto a otros tipos de solutos, el ensuciamiento por proteínas ha sido tradicionalmente caracterizado midiendo el índice de rechazo y la densidad de flujo. Hay otras técnicas que permiten analizar la superficie ensuciada, como la microscopia electrónica, rayos $X$, el potencial zeta de la membrana, etc.

La adsorción de proteínas es considerada como la principal causa de ensuciamiento en UF y además, éstas no son fácilmente eliminadas con limpieza química. La morfología de los depósitos de proteínas depende fuertemente del pH y de su concentración en la disolución. Las características hidrofóbicas de la membrana también afectan al ensuciamiento de la membrana. La adsorción de las proteínas da lugar a la redistribución de la carga al haber sobreposición de la doble capa eléctrica de las proteínas y de la superficie de la membrana.

Las interacciones proteína-proteína pueden contribuir al ensuciamiento de la membrana al ir aumentando la capa de proteína adsorbida o al alterarse el tamaño de las proteínas. James et al (2003). Tanto la adsorción de la proteína como las interacciones pueden estrechar o taponar los poros de la membrana, de ahí la disminución de las proteínas en el permeado. Aunque también pueden acumularse partículas sobre la superficie de la membrana debido a su baja difusión dando lugar a la polarización por concentración. 
Adicionalmente, la química de la superficie de la membrana, la morfología y la estructura interna juegan un papel importante en el ensuciamiento y en el rendimiento de la separación

Cuando existe una fuerza iónica alta, las repulsiones electrostáticas tienen menor efecto sobre la difusión de las proteínas a través de la membrana. La comparación de la difusión de las proteínas a mayor y menor fuerza iónica muestra la importancia de la exclusión de carga sobre el transporte de la proteína. Estos efectos de carga dependen de las propiedades de la proteína adsorbida sobre la pared del poro. (Causserand et al, 1994).

Para incrementar la eficiencia y vida útil de las membranas, es conveniente realizar un pretratamiento del agua de alimentación, la selección de este tratamiento maximizará la eficiencia y vida de la membrana, minimizando el ensuciamiento, la precipitación de sustancias y la degradación de la membrana. Optimizando el caudal de permeado, el índice de rechazo, los costes de operación y el mantenimiento.

\subsubsection{Limpieza de las membranas}

Hay diferentes tipos de limpieza, según la naturaleza de los componentes que originan el ensuciamiento, como son:

Enjuague, después de detectarse el ensuciamiento lo primero que se hace es un enjuague para eliminar los restos de la disolución que ocasiona el ensuciamiento y de esta forma arrastrar las partículas que 
se encuentren depositadas sobre la superficie de la membrana. El enjuague se realiza también después de cada una de las respectivas limpiezas, con el fin de eliminar los restos de productos químicos y poder determinar la cantidad de flujo recuperado, un agua de excelente calidad es vital a la hora de minimizar el tiempo durante la limpieza de la membrana.

Limpieza Química, en esta etapa se utilizan productos químicos de carácter básico y/o ácido para que reaccionen con las partículas que causan el ensuciamiento. Si el ensuciamiento es originado por compuestos de tipo orgánico, las disoluciones de limpieza de carácter básico son las más adecuadas. Si por el contrario el ensuciamiento es de tipo inorgánico, las disoluciones ácidas son las más eficaces. Incluso se pueden utilizar agentes desinfectantes como el hipoclorito de sodio, el peroxido de hidrógeno, entre otros.

Limpieza con tensioactivos, es aquel tipo de limpieza en la que se utilizan productos químicos que forman micelas con las sustancias causantes del ensuciamiento de la membrana.

Limpieza enzimática, se basa en eliminar el ensuciamiento mediante reacciones químicas catalizadas por enzimas, las cuales pueden ser proteasas o peptonas.

\subsubsection{Caracterización de membranas}

Para caracterizar las membranas se deben tener en cuenta los parámetros que más información proporcionan sobre sus propiedades, 
dependiendo si las membranas son de naturaleza porosa o no porosa. Entre las cuales se encuentran: la distribución y el tamaño de poro, la selectividad, la permeabilidad, las propiedades de superficie y las propiedades eléctricas.

Distribución y tamaño del poro, estos parámetros se relacionan con el rechazo de solutos y el flujo de permeado. Para la medición del tamaño de poro así como su distribución se pueden utilizar diferentes métodos como: medida de la permeabilidad (punto de burbuja, porosimetría de mercurio, permeación de gases y permoporosimetría), los de termoporometría y los de adsorción/desorción. Estos métodos están limitados por la tensión superficial, el ángulo de contacto, y en el caso de membranas con poros muy pequeños por las elevadas presiones, puesto que puede alterar la morfología de la membrana.

Propiedades de superficie, estas proporcionan información sobre la morfología de la membrana, el espesor de la capa activa, la rugosidad, el carácter hidrófilo o hidrófobo de la membrana y la polarización por concentración en la cara de la membrana.

La microscopia electrónica de barrido permite observar ciertas propiedades de las membranas como tamaño de poro, su distribución, la morfología de su estructura, el espesor de la capa activa, etc. Para determinar la imagen de la membrana que se quiere observar, esta se coloca sobre el equipo donde un haz de electrones con una elevada energía cinética se divide en dos, uno es el que incide (primario) y otro el que se refleja (secundario). Este último es el responsable de capturar la imagen del objeto observado. El haz de 
electrones que incide sobre la membrana posee calor, por lo tanto se debe tener mucho cuidado en el momento de elegir las condiciones de operación del microscopio para evitar daños en la estructura de la membrana. Una desventaja de esta técnica es que los resultados varían dependiendo de la forma en que se prepare la muestra.

Propiedades eléctricas, estas propiedades son muy importantes en el caso de membranas de nanofiltración, pues ayudan a explicar los mecanismos de separación y transporte. Dentro de estas propiedades están la densidad de carga y el potencial de corriente lefecto Donnan).

Propiedades mecánicas, químicas y térmicas, estas propiedades aunque pueden parecer muy elementales, juegan un papel muy importante en el momento de elegir el tipo de membrana y establecer las condiciones de operación.

Hay otros parámetros que pueden ser de utilidad a la hora de analizar los resultados obtenidos, los cuales se definen a continuación.

\section{Densidad de flujo de permeado $(J p)$}

Se calcula midiendo el volumen de permeado recogido en un intervalo de tiempo determinado, por unidad de área según la siguiente ecuación:

$$
J p=\frac{Q p}{A m}
$$


siendo, $Q p$ : Caudal de permeado (L/h)y $A m$ : Área efectiva de la membrana $\left(\mathrm{m}^{2}\right)$.

Índice de rechazo $\left(R_{i}\right)$

La selectividad o índice de rechazo, determina la preferencia de la membrana por un soluto o solutos, así como la naturaleza de la membrana. Se calcula midiendo la concentración de soluto en la corriente de permeado y en la del alimento.

$$
R_{i}(\%)=\frac{C a_{i}-C p_{i}}{C a_{i}} \cdot 100
$$

Donde: $R_{i}$ es el índice de rechazo, $C a_{i}$ y $C p_{i}$ son las concentraciones de la especie i en el alimento y en el permeado respectivamente.

\section{Densidad de flujo de soluto $\left(J_{i}\right)$}

La densidad de flujo de soluto proporciona información sobre la cantidad de soluto que pasa a través de la membrana. Este parámetro ayuda a cuantificar la capacidad desmineralizadora de la membrana. $J_{s}$, se determina a partir de la ecuación (4.3).

$$
J_{s_{i}}=J_{p} \cdot\left(1-R_{i}\right) C a_{i}=J_{p} \cdot C_{p_{i}}
$$

Donde: $J_{s}$ es la densidad de flujo de soluto i $\left(\mathrm{g} / \mathrm{m}^{2} \mathrm{~h}\right)$ 


\section{Presión transmembranal}

La presión transmembranal se calcula de la siguiente manera:

$$
\Delta P=\frac{P_{e}+P_{s}}{2}-P_{p}
$$

Donde:

$P_{e}$ es la presión de entrada del alimento, $P_{s}$ es la presión de salida del concentrado y ${ }^{P_{p}}$ es la presión de salida del permeado.

\section{Presión osmótica}

La presión osmótica de las disoluciones es estimada a partir de la ecuación de Van't Hoff.

$$
\Delta \pi=\underset{i}{Z i \sum_{i}}\left(C a_{i}-C p_{i}\right) \cdot R \cdot T
$$

Donde $\pi$ es la presión osmótica, Zi la carga del ión, $C a_{i}$ y $C_{p i}$ la concentración molar del ión en la corriente de alimentación y permeado respectivamente $(\mathrm{mol} / \mathrm{L}), \mathrm{R}$ la constante de los gases perfectos y $\mathrm{T}$ la temperatura absoluta $(\mathrm{K})$. Las presiones osmóticas calculadas a partir de esta ecuación se ajustan bastante bien para el caso de disoluciones diluidas.

\section{Fuerza iónica}

La fuerza iónica, l, es una medida de la concentración total de los iones en disolución. Cuanto mayor es la carga de un ión, más contribuye a ella. Se define mediante la siguiente expresión: 


$$
I=\frac{1}{2} \sum_{i} C_{i} Z_{i}{ }^{2}
$$

Donde:

$C_{i}$ es la concentración molar de la especie i y $Z_{i}$ es la carga de la especie i, el sumatorio se extiende a todos los iones en disolución.

Las sales compuestas de iones monovalentes se disocian casi completamente cuando se preparan disoluciones de baja concentración $(<0.1 \mathrm{M}$ ), a estos electrólitos se les llama electrólitos fuertes. Las sales que contienen cationes y aniones con carga $\geq 2$ están mucho menos disociados, incluso en disoluciones diluidas. Por esta razón los valores de fuerza iónica calculados para el magnesio y sulfatos no son del todo exactos pero sirven de modo orientativo.

\subsubsection{Perspectivas de las membranas en el sector lácteo.}

La importancia de los procesos de membrana puede ser juzgada de acuerdo a la cantidad de membranas utilizadas en varios sectores industriales.

Las figuras 4.12 y 4.13 , muestran las áreas de membrana instaladas en equipos de ósmosis inversa y de ultrafiltración en el sector lácteo. Durante los años 90, la instalación de estos equipos era constante y de repente su consumo se incrementó. Dicho aumento se vió favorecido principalmente por la reducción de los precios de las membranas, pudiéndose reemplazar los equipos viejos, contribuyendo a que las compañías lecheras mejoraran el consumo energético por unidad de producto, lo que repercutió en una mejora económica y el desarrollo de nuevos mercados. 


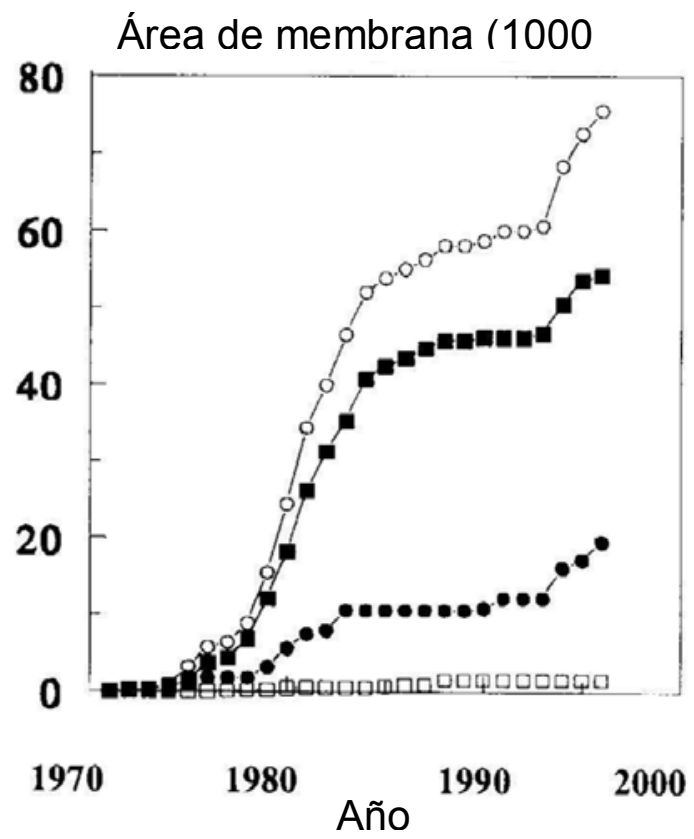

Figura 4.12. Consumo de membranas de Ol en espiral

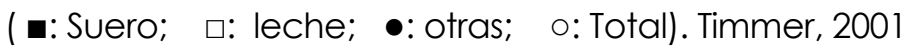

En la figura 4.12, se puede observar que la cantidad de área de membranas de ósmosis inversa de arrollamiento en espiral, instaladas en la industria láctea tuvo un aumento notorio para aplicaciones del suero desde 1980 hasta 1985. A partir de 1985 su consumo no presento grandes variaciones hasta que de repente en 1994 su consumo se incremento de nuevo. Este hecho es explicado por Timmer (2001) como consecuencia de los precios más bajos de los sistemas de membrana. Mientras que, para aplicaciones de la leche no se observan cambios significativos durantes los años señalados. 


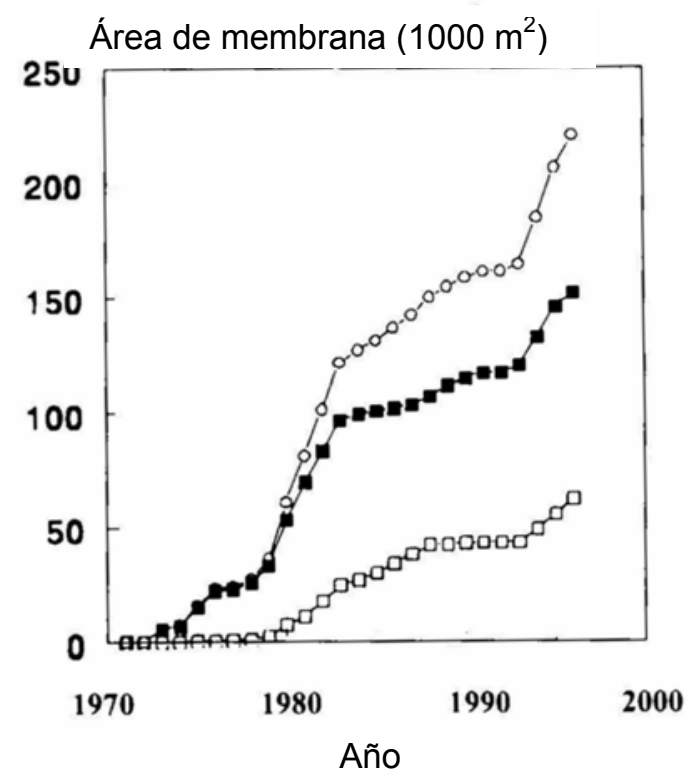

Figura 4.13. Consumo de membranas de UF(arrollada)

(a: Suero; $\square$ : leche; o: Total)

Como puede observarse en la figura 4.13, el uso de membranas de ultrafiltración ha aumentado más en el tratamiento del suero que con la leche, seguramente debido al interés de revalorizar las proteínas presentes en el suero.

Un estudio detallado sobre la evolución del mercado de las tecnologías de membranas y sus materiales ha sido publicado recientemente por el Grupo Freedonia (Membrana Technology, 2002).

En Estados Unidos, se prevé que la demanda de los materiales de membrana crecerá un $7.4 \%$ por año valorándose en US\$2110 millones 
para el 2006. Según el grupo Freedonia, el crecimiento será impulsado, en parte por la elevada calidad de los materiales, a pesar de sus precios.

La demanda de estos materiales se espera se incremente en 118 millones de $\mathrm{m}^{2}$ en 2006, de acuerdo a la tabla 4.4. Los investigadores de las compañías dicen que la demanda total de los sistemas de membrana (incluyendo bombas, tuberías, tanques, etc.) alcanzará US\$3300 millones en 2006. Durante el 2001, la gran cantidad de materiales de membrana fueron poliméricos.

Tabla 4.4. Crecimiento del uso de membranas (en millones de dolares)

\begin{tabular}{|c|c|c|c|c|c|c|}
\hline \multirow{2}{*}{$\begin{array}{l}\text { Proceso de } \\
\text { membrana }\end{array}$} & \multicolumn{4}{|c|}{ Año } & \multicolumn{2}{|c|}{ Crecimiento (\%) } \\
\hline & 1996 & 2001 & 2006 & 2011 & $01 / 96$ & $06 / 01$ \\
\hline MF & 520 & 740 & 980 & 1290 & 7,3 & 5,8 \\
\hline Ol & 180 & 310 & 490 & 740 & 11,5 & 9,6 \\
\hline UF & 150 & 270 & 420 & 630 & 12,5 & 9,2 \\
\hline Otras & 100 & 160 & 220 & 280 & 28,8 & 15,5 \\
\hline $\begin{array}{l}\text { Consumo } \\
\text { total }\end{array}$ & 950 & 1480 & 2110 & 2940 & 9,3 & 7,4 \\
\hline US $\$ / m^{2}$ & 15,59 & 16,67 & 17,74 & 18,82 & 13,98 & 13,98 \\
\hline Miles de $m^{2}$ & 62 & 88 & 118 & 154 & 7,5 & 6,0 \\
\hline
\end{tabular}

The Freedonia Group Inc (Membrana Technology, 2002)

El consumo de materiales poliméricos se incrementará en un $7.1 \%$ por año hasta alcanzar los dos mil millones de dólares en el 2006, según informe del grupo Freedonia. Además, El volumen de la demanda crecerá un $6 \%$ por año a 111,5 millones de $m^{2}$. 
Las membranas de MF son las que mayor consumo experimentan debido a que se utilizan como pretratamiento para los demás procesos de membrana. Le sigue la ósmosis inversa, debido a su capacidad para proporcionar agua de elevada pureza y a que se ha incrementado su demanda en los hogares, en el procesado de bebidas y en el tratamiento de aguas residuales, tal como dice este estudio.

Por lo que respecta a la nanofiltración como técnica de tratamiento no aparece de forma concreta en la tabla 4.4, ya que se ha englobado en el termino otras.

Tabla 4.5. Utilización de las membranas según el proceso industrial.

\begin{tabular}{lccccc}
\hline Proceso & \multicolumn{5}{c}{ Año } \\
\cline { 2 - 6 } industrial & 1992 & 1996 & 2001 & 2006 & 2011 \\
\hline Tratamiento de agua y A.R. & 397 & 535 & 820 & 1165 & 1605 \\
Bebidas y alimentos & 144 & 200 & 325 & 470 & 665 \\
Farmacéutica & 51 & 79 & 130 & 200 & 305 \\
Producción química & 27 & 41 & 70 & 105 & 150 \\
Gases industriales & 31 & 40 & 50 & 60 & 65 \\
Otros mercados & 40 & 55 & 85 & 110 & 150 \\
US $\$ \mathrm{~m}^{2}$ & 14 & 16 & 17 & 18 & 19 \\
Mill m $^{2}$ & 49 & 61 & 88 & 118 & 154 \\
\hline
\end{tabular}

En la tabla 4.5, se observa que el uso de membranas esta más extendido en el tratamiento de agua y aguas residuales, seguido de la bebidas y alimentos e industria farmacéutica principalmente. 


\subsection{MODELO MATEMÁTICO PARA MEMBRANAS DE NF}

Para explicar el transporte de solutos a través de las membranas de nanofiltración, varios autores han utilizado diferentes modelos (KedemSpiegler, Donnan Steric Partitioning Pore Model, la ecuación Extendida de Nerst Planck, Teorell Meyers y Sievers, exclusión dieléctrica, y el modelo de carga superficial, entre otros)

En esta tesis, se tienen en cuenta los artículos publicados, así como la información obtenida con los ensayos experimentales a la hora de elegir el modelo (Donnan Steric Partitioning Pore Model) DSPM (Schaep, 1999; Labbez, 2003), y el soluto elegido es la lactosa, con el fin de obtener información sobre el radio de poro y la relación entre el espesor efectivo y la porosidad de cada una de las membranas ensayadas. Conocidos estos valores se puede obtener una ecuación matemática para predecir el índice de rechazo en función de la densidad de flujo de permeado.

A continuación se desarrollan las ecuaciones propuestas por el modelo para obtener una expresión matemática del índice de rechazo para la lactosa.

\subsection{1 Índice del rechazo real para la lactosa.}

Para determinar el índice de rechazo real a partir de los datos experimentales es necesario hacer una serie de aproximaciones a la hora de realizar los cálculos. 
Para determinar los rechazos reales se tiene en cuenta el efecto de polarización por concentración, la expresión que se utiliza viene dada por la ecuación (4.7).

$$
R_{\text {real }}=\frac{R_{\exp } \exp \left(\frac{J_{p}}{K_{T M}}\right)}{1-R_{\exp }\left[1-\exp \left(\frac{J_{p}}{K_{T M}}\right)\right]}
$$

siendo $R_{\exp }$ el rechazo medido experimentalmente, $K_{T M}$ el coeficiente de transferencia de materia en $\mathrm{m} / \mathrm{s}$ y $J_{p}$ la densidad de flujo de permeado $\mathrm{m}^{3} / \mathrm{m}^{2} \cdot \mathrm{s}$.

Para obtener el coeficiente de transferencia de materia se utilizó la ecuación:

$$
K_{T M_{-} \text {soluto }}=S h \_ \text {soluto } \frac{D_{-} \text {soluto }}{d_{h}}
$$

Esta ecuación es función del número de Sherwood, la difusividad y el diámetro hidráulico.

El número de Sherwood se determinó mediante la expresión (4.9) que depende del número de Reynolds y del número de Schmidt.

$$
\text { Sh_soluto }=0,017 \operatorname{Re}^{0,875} S_{-} \text {soluto }^{0,296}
$$

El número de Reynolds (Re) y el de Schmidt (Sc) se determinan a partir de las ecuaciones (4.10) y (4.11) respectivamente:

$$
\operatorname{Re}=\frac{\rho d_{h} v_{x}}{\mu}=4344
$$




$$
\text { Sc soluto }=\frac{\mu}{\rho \cdot D_{-} \text {soluto }}
$$

donde el $d_{h}$ es el diámetro hidráulico en metros, $v_{x}$ es la velocidad media y se determina a partir del flujo de alimentación $Q\left(\mathrm{~m}^{3} / \mathrm{s}\right)$ y $A$ el área de membrana $\left(\mathrm{m}^{2}\right), D$ la difusividad del soluto $\left(\mathrm{m}^{2} / \mathrm{s}\right)$.

El cálculo del diámetro hidráulico esta dado por:

$$
d_{h}=\frac{4 \cdot A}{\text { perimetro mojado }}
$$

\subsubsection{Modelo DSPM (Donnan Steric Partioning Pore model)}

El modelo DSPM está basado en la teoría de carga eléctrica fija propuesta por Teorell, Meyers y Sievers, en combinación con la ecuación extendida de Nernst-Planck. Los experimentos de rechazo con solutos no cargados (lactosa) sirven para caracterizar la membrana en términos del radio de poro y de la relación entre el espesor y la porosidad de la membrana.

Labbez y otros; 2003, hacen las siguientes aproximaciones a la hora de aplicar el modelo DSPM:

- La membrana consiste en un haz de poros cilíndricos idénticos de radio $r_{p} y$ longitud $\Delta x$ (con $\left.\Delta x>>r_{p}\right)$.

- Uno de los componentes móviles, denominado disolvente, está presente en exceso.

- Los flujos molares de los componentes (iones o solutos neutros) (ji), la concentración del componente i en la 
membrana $(\mathrm{c} i, \mathrm{~m})$, y el flujo volumétrico de permeado $(\mathrm{p})$ están perfectamente definidos en términos de magnitudes promediadas.

- El flujo volumétrico en el interior de los poros sigue un perfil parabólico definido por la ecuación de Hagen-Poiseuille.

\section{Ecuaciones básicas del modelo DSPM}

Ecuación extendida de Nernst-Planck (ENP)

$$
j_{i}=-D_{i, p} \frac{d c_{i}^{m}}{d x}-z_{i} c_{i}^{m} D_{i, p} \frac{F}{R T} \frac{d \psi}{d x}+K_{i, c} c_{i}^{m} J_{p}
$$

donde $D_{i, p}=D_{i, \infty} K_{i, d}$ y $J_{p}=\frac{j_{i}}{C_{i, p}}$

El primer término se debe al transporte difusivo, el segundo al transporte eléctrico y el tercero al transporte convectivo. $K_{i, d}$ y $K_{i, c}$ son los factores de retardo para la difusión y la convección, respectivamente, y se definen como:

$$
\begin{gathered}
K_{i, d}=1.0-2.3 \lambda_{i}+1.154 \lambda_{i}^{2}+0.224 \lambda_{i}^{3} \\
K_{i, c}=\left(2-\phi_{i}\right)
\end{gathered}
$$

$\phi i$ es el coeficiente de partición de equilibrio, tiene en cuenta el tamaño finito del componente i, y está definido por el perfil de concentración que se da en el proceso de acuerdo a la siguiente expresión:

$$
\phi_{i}=\frac{c_{i, x=0}}{C_{i, m}}=\frac{c_{i, x=\Delta x}}{C_{i, p}}=\left(1-\frac{r_{i}}{r_{p}}\right)^{2}=\left(1-\lambda_{i}\right)^{2}
$$


El índice de rechazo esta definido como:

$$
R_{i}=1-\frac{C_{i, p}}{C_{i, m}}
$$

Reemplazando los términos de concentración de soluto en el permeado $\left(C_{i, p}\right)$ y en la membrana $\left(C_{i, m}\right)$, el índice de rechazo obtenido por el modelo queda de la siguiente manera,

$$
R_{i}=1-\frac{K_{i, c} \phi_{i}}{1-\exp (-P e)\left(1-\phi_{i} K_{i, c}\right)}
$$

donde el número de Peclet se define como

$$
P e=\frac{K_{i, c}}{K_{i, d}} \frac{J_{v} \Delta x}{D_{i, \infty} A_{k}}
$$

Si se reemplaza la ecuación 4.19 en la 4.18, la expresión del índice de rechazo predicho por el modelo es función del flujo de permeado Jp tal como puede apreciarse en la ecuación 4.20

$$
R_{i}=1-\frac{\left(2-\phi_{i}\right) \cdot \phi_{i}}{1-\exp \left[-\frac{\left(2-\phi_{i}\right) \cdot J_{p} \cdot\left(\frac{\Delta x}{A_{k}}\right)}{\left(1-2,3 \cdot \lambda_{i}+1,154 \cdot \lambda_{i}{ }^{2}+0,224 \cdot \lambda_{i}{ }^{3}\right)}\right] \cdot\left[1-\phi_{i} \cdot\left(2-\phi_{i}\right)\right]}
$$

Para calcular el índice de rechazo a partir de la ecuación anterior es necesario conocer los valores de $\lambda_{i}$ y $\phi_{i}$. Para obtener estos valores se supone que para un flujo de permeado infinito, el índice de rechazo se transforma en el coeficiente de reflexión de soluto y la ecuación 4.18 queda en términos del factor de retardo convectivo y del coeficiente de partición, tal como se muestra en la ecuación 4.21:

$$
\sigma_{i}=1-K_{i, c} \phi_{i}
$$


Si se reemplazan las ecuaciones 4.15 y 4.16 en la 4.21 , se obtiene la siguiente expresión:

$$
\sigma_{i}=1-\left\lfloor 2-\left(1-\lambda_{i}\right)^{2}\right\rfloor \cdot\left(1-\lambda_{i}\right)^{2}
$$

Los valores de $\lambda_{i}$ y $\phi_{i}$ se pueden calcular de forma iterativa a partir de las ecuaciones 4.16 y 4.21 .

El valor de $\lambda_{i}$ se relaciona con el radio de Stokes y el radio de poro de la membrana, de acuerdo con la ecuación 4.22.

$$
\lambda_{i}=\frac{r_{i}}{r_{p}}
$$

Siendo $r_{p}$ el radio de poro y $r_{i}$ el radio de Stokes del componente i. Este último viene dado por la ecuación (4.24), donde k es la constante de Boltzman (T es la temperatura en grados Kelvin, $D_{i, \infty}$ es la difusividad del soluto i a dilución infinita, $\mu$ es la viscosidad dinámica.

$$
r_{i}=\frac{k T}{6 \pi \mu D_{i, \infty}}
$$

Conocido el radio del poro, se puede aplicar la ecuación de HagenPoiseville para despejar $\Delta \mathrm{x} / \mathrm{A}_{\mathrm{k}}$. Esta ecuación muestra la relación que existe entre el flujo de agua pura $J_{w}$ y la presión aplicada a lo largo de la membrana.

$$
J_{w}=\frac{r_{p}^{2} \Delta P}{8 \mu\left(\Delta x / A_{k}\right)}
$$

Después de obtener la expresión de rechazo según el modelo, este debe compararse con el rechazo real obtenido experimentalmente. 
METOdOLOGÍA 5 . 



\section{METODOLOGÍA}

\subsection{REVISIÓN BIBLIOGRÁFICA}

Para la realización de esta tesis se realizó previamente una extensa búsqueda bibliográfica con el fin de conocer los trabajos de investigación realizados hasta la fecha, teniendo en cuenta principalmente los publicados en los últimos cinco años.

Para apoyar el trabajo de laboratorio y el diseño de experimentos se ha recurrido a las técnicas de laboratorio normalizadas y a las aplicadas en la industria láctea.

Se realizó una revisión y análisis constante del material bibliográfico y de la literatura existente relacionada con este tema, por intermedio de las bibliotecas de las diferentes universidades que realizan estudios en este campo, centros de documentación y a través de los servicios de redes nacionales e internacionales, con el fin de recopilar y actualizar la información sobre el tema de interés.

\subsection{PLANTA PILOTO}

Para la realización del trabajó experimental, se utilizó la planta piloto de NF/UF diseñada en el Departamento de Ingeniería Química y Nuclear (DIQN) de la Universidad Politécnica de Valencia. Esta planta permite trabajar tanto con módulos de planos, como con 
módulos de arrollamiento en espiral. El módulo plano, trabaja simultáneamente con dos membranas en serie con un área de 90 $\mathrm{cm}^{2}$ cada una. Las membranas de NF utilizadas fueron NF200, NF270, Ds-5 DK, Ds-5 DL y la membrana de UF SD-polietersulfona.

Las membranas se cortaron para adaptarlas al tamaño de la placa del módulo $\left(8 \times 18 \mathrm{~cm}^{2}\right)$, que es de acero inoxidable. La superficie activa de la membrana está en contacto con la entrada del alimento y la capa no activa esta en contacto con un soporte poroso recolector de permeado y esta a su vez sobre la placa perforada. Entre placa y placa se colocó una junta de teflón para garantizar el sellado del módulo.

La planta de nanofiltración utilizada, tiene la posibilidad de trabajar con un modulo plano o con un modulo de arrollamiento en espiral, si bien éste último se utilizó en la fase final de la tesis.

La planta piloto dispone de dos manómetros uno a la entrada y otro a la salida del módulo. En este proceso la temperatura se mantuvo constante (próxima a los $22^{\circ} \mathrm{C}$ ). Para tal fin se instaló un sistema de refrigeración controlado electrónicamente que ayudaba a mantener la disolución a la temperatura deseada, tal como se encuentra esquematizado en la figura 5.1 


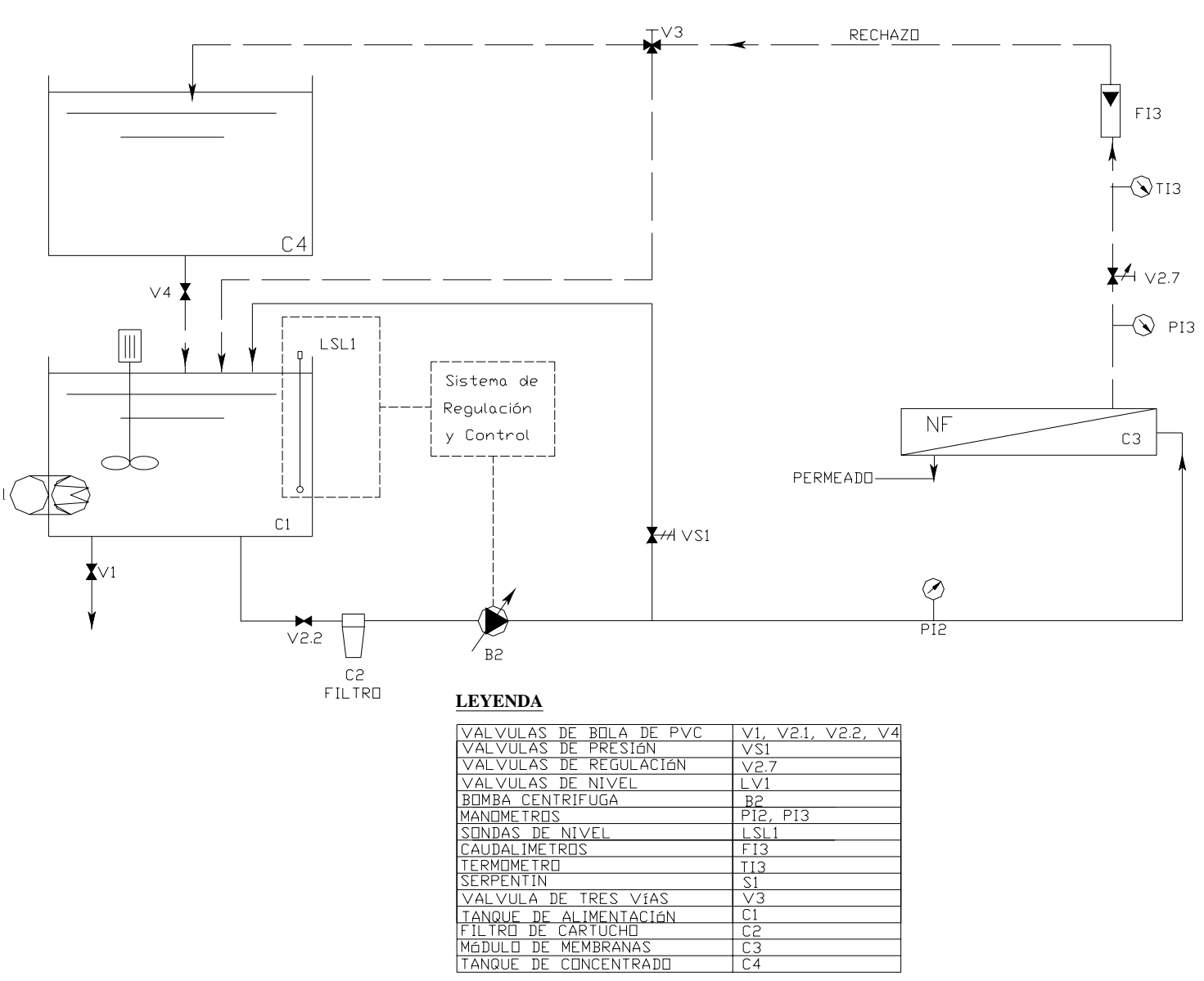

Figura 5.1. Esquema de la planta experimental

\section{Puesta en marcha de la instalación}

La puesta en marcha de la instalación piloto se inicia con el arranque de la bomba de alimentación (B2), antes de llegar a la bomba y al módulo de membranas, la disolución pasa a través de un filtro de cartucho de $20 \mu \mathrm{m}$ (C2), que retiene las partículas de mayor tamaño, esto se hace para proteger tanto a la bomba como a la membrana. La bomba impulsa el alimento a una presión dada (en esta línea hay 
un manómetro (PI2) que mide la presión del alimento) que luego pasa al módulo de membranas (C3). A la salida de este módulo hay dos corrientes: el permeado y el concentrado. En la línea de conducción de la corriente de concentrado se encuentra un manómetro (PI3) y un caudalimetro (FI3) que permiten controlar la presión y el caudal de trabajo, respectivamente. Para ajustar la presión, la instalación cuenta con una válvula de regulación (V2.7) y el ajuste de caudal se hace con el variador de velocidad que se encuentra en el cuadro de mandos de la instalación. La instalación cuenta además con una válvula de seguridad (VS1) ubicada a la salida de la bomba, de tal forma que la bomba no sobrepase la presión máxima admitida.

En la figura 5.2 se muestra una fotografía de la planta piloto con el módulo plano y el arrollamiento en espiral.

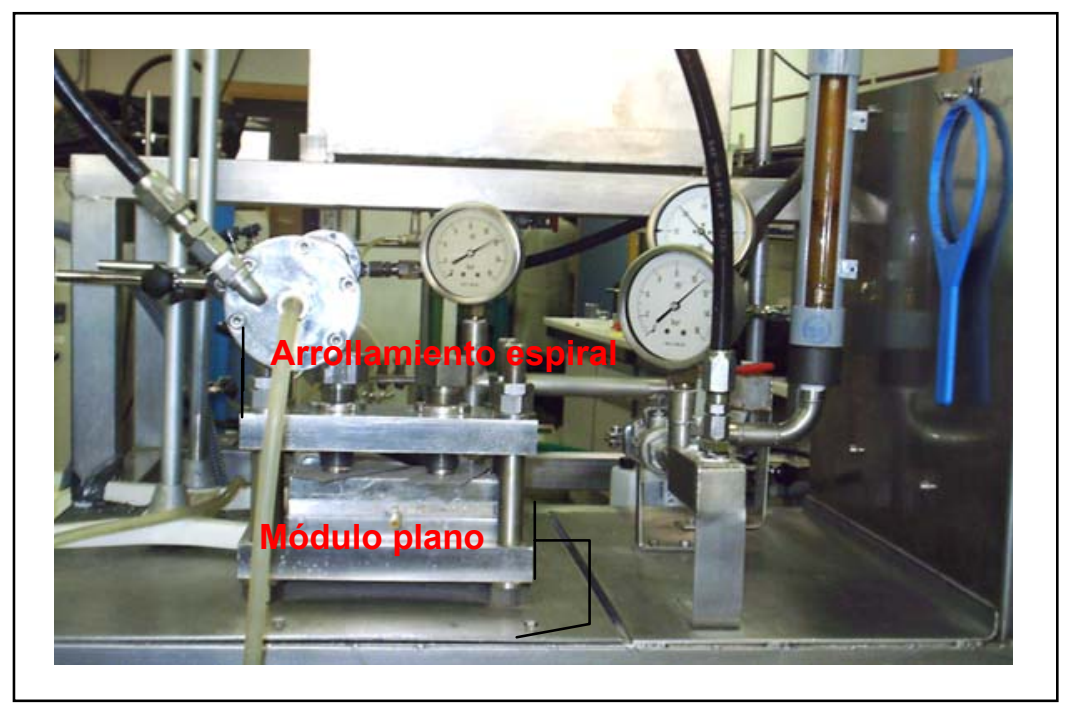

Figura 5.2. Detalle de la Planta piloto de membranas 


\subsection{MATERIALES}

Las condiciones de operación facilitadas por los fabricantes de las membranas aparecen en la tabla 5.1. Las fichas técnicas se encuentran en los anexos 11.1.1, 11.1.2, 11.1.3.

\subsubsection{Membranas utilizadas en la tesis.}

Las características más importantes suministradas por los fabricantes se encuentran en la tabla 5.1. Se trabajó con cuatro membranas de nanofiltración suministradas por Dow-Filmtec y Osmonic-GE, la membrana de ultrafiltración fue suministrada por PTI Advanced Filtration.

Tabla 5.1. Características de las membranas utilizadas.

\begin{tabular}{llllll}
\hline Condiciones & \multicolumn{5}{c}{ Membranas } \\
\cline { 2 - 6 } de operación & NF200 & NF270 & Ds-5 DK & Ds-5 DL & SD \\
\hline Fabricante & Dow & Dow & GE & GE & PTI \\
Material & PA & PA & PA & PA & PES \\
Tipo & TFC & TFC & TFC & TFC & UF \\
Cut-off (Da) & $200-300$ & $200-300$ & $150-300$ & $150-300$ & 10.000 \\
Rango de pH & $3-10$ & $3-10$ & $2-11$ & $2-11$ & $3-10$ \\
Presión máx. (MPa) & 4,1 & 4,1 & 3,45 & 3,45 & 1,03 \\
Temp. Máx. $\left({ }^{\circ} \mathrm{C}\right)$ & 45 & 45 & 50 & 50 & 50 \\
Cloro (mg/L) & $<0,1$ & $<0,1$ & $<0,1$ & $<0,1$ & 180 \\
$\%$ R MgSO 4 & 974 & 974 & 985 & 985 & - \\
\hline
\end{tabular}

4: $2000 \mathrm{mg} / \mathrm{L} \mathrm{MgSO}_{4}, 0,48 \mathrm{MPa}, 25^{\circ} \mathrm{C}$ y $15 \%$ de recuperación; $\quad$ 5: $2000 \mathrm{mg} / \mathrm{L} \mathrm{MgSO}$, 0,69 MPa, $25^{\circ} \mathrm{C}$ y $10 \%$ de recuperación; PA: Poliamida Aromática; PES: Polietersulfona; TFC: Thin film composite (compuesta) 
En los siguientes párrafos, la información aportada sobre las membranas estudiadas es tomada de los autores Mäntäri y otros (2004); Gorenflo (2003) y Her y otros (2000).

Las propiedades de las cuatro membranas (NF200, NF270, Ds-5 DK y Ds-5 DL) fueron caracterizadas midiendo el ángulo de contacto (índice de hidrofobicidad), potencial zeta (indicador de la carga), corte de peso molecular, composición y grupos funcionales. Mäntäri y otros (2004); Gorenflo (2003) y Her y otros (2000).

\subsubsection{Membranas NF200 y NF270}

Ambas membranas están compuestas por tres capas: una capa superior ultrafina, un soporte microporoso y un soporte de poliéster de tipo no tejido. (Her y otros, 2000 y Gorenflo 2003).

La capa superior, de amida polipiperacina (PA) controla las propiedades de semipermeabilidad (densidad de flujo e índice de rechazo). La polipiperacina contiene ácidos carboxilicos, cetonas y aminas terciarias, que contribuyen a una baja hidrofobicidad de la membrana.

El soporte microporoso o capa intermedia es de polisulfona, contiene anillos aromáticos conectados por carbonos y dos grupos metilo, oxigeno y grupos sulfónicos. (Her y otros, 2000 y Gorenflo 2003).

El soporte es de poliéster no tejido, de carácter hidrofílico proporciona la máxima resistencia y compresión combinada con la mínima resistencia al flujo de permeado. 


\subsubsection{Membranas Ds-5}

Las membranas Ds-5DK y DL están compuestas por cuatro capas: una capa de poliamida (PA), un soporte microporoso de polisulfona y dos capas de marca registrada. Estas membranas presentan carga negativa y carácter hidrofílico. Las densidades de flujo fueron mucho mas bajas que las obtenidas con las membranas de la serie NF, tal como puede observarse en el capitulo de resultados, por lo que se necesitan presiones mayores para conseguir las mismas densidades de flujo que las membranas de la serie NF. (Nyström y otros, 2004)

En la tabla 5.2, se muestra un resumen de las propiedades más importantes de las membranas.

Tabla 5.2. Caracterización de las membranas estudiadas

\begin{tabular}{lcccc}
\hline Membrana & NF200 & NF270 & Ds-5 DK & Ds-5 DL \\
\hline Material & Tres capas & Tres capas & $\begin{array}{c}\text { Cuatro } \\
\text { capas }\end{array}$ & $\begin{array}{c}\text { Cuatro } \\
\text { capas }\end{array}$ \\
\%R lactosa & $98-99$ & $98-99$ & $97-98$ & $97-98$ \\
LP (L/m $\left.{ }^{2} \cdot \mathrm{h}^{+} \mathrm{MPa}\right)^{+}$ & 43,92 & 52,70 & 35,54 & 39,03 \\
Potencial zeta & $-16 \mathrm{mV}$ & $-16 \mathrm{mV}$ & Negativo & $-5 \mathrm{mV}$ \\
PIE, pH & $(\mathrm{pH}=7)$ & $(\mathrm{pH}=7)$ & $4,3)$ & 4,0 \\
Ángulo de & 4,3 & 4,3 & 4,0 & $46 \pm 3^{\circ}$ \\
contacto & $30,3^{\circ}$ & $30^{\circ}$ & N.D. &
\end{tabular}

${ }^{+}$: Determinado en esta tesis con el modulo plano N.D.: No Disponible *50 g/L, $22 \pm 2^{\circ} \mathrm{C}$

A partir de la tabla 5.2, se observa que el potencial zeta para todas las membranas es negativo; lo que sugiere que puedan darse repulsiones electrostáticas con los iones cargados negativamente. 
Los ángulos de contacto de las membranas NF200 y NF270 son muy similares, así como relativamente bajos comparados con los de la membrana Ds-5 DL, por lo que las membranas de la serie NF considerarse pueden más hidrofílicas.

\subsubsection{Membrana de ultrafiltración SD}

La membrana de ultrafiltración utilizada esta hecha de polietersulfona con un corte de peso molecular de umbral límite de $10 \mathrm{KDa}$ y un área de $3 \mathrm{~m}^{2}$, suministrada por PTI Advanced filtration de EE.UU.

La estructura molecular de una membrana de polietersulfona se muestra en la figura 5.3. Dicho polímero esta formado de un anillo de fenileno conectado a un grupo sulfona $\left(\mathrm{SO}_{2}\right)$ y/o unido a un éter (-O-) para formar el polímero.

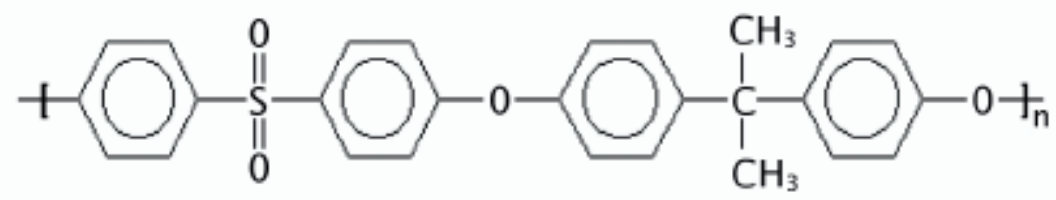

Figura 5.3. Estructura de una membrana de polietersulfona

\subsubsection{Disoluciones modelo}

Las materias primas utilizadas en la preparación de las diferentes disoluciones modelo utilizadas en las etapas inicial e intermedia de la presente tesis fueron las siguientes. 
Tabla 5.3. Productos químicos utilizados

\begin{tabular}{llc}
\hline Reactivo & Marca & Riqueza \% \\
\hline Cloruro de sodio $(\mathrm{NaCl})$ & Panreac PA. & 99 \\
Cloruro de potasio $(\mathrm{KCl})$ & Panreac PA. & 99 \\
Sulfato de magnesio $(\mathrm{MgSO})$ & Panreac PA. & 99 \\
Lactosa monohidratada $\left(\mathrm{C}_{12} \mathrm{H}_{22} \mathrm{O}_{11} \cdot \mathrm{H}_{2} \mathrm{O}\right)$ & Panreac PA. & 99 \\
\hline
\end{tabular}

\subsubsection{Disolución de suero real}

El suero utilizado proviene de una empresa quesera ubicada en la Comunidad Valenciana. Dentro de su proceso productivo, generan diferentes tipos de suero, dependiendo del tipo de queso a fabricar, en este caso se eligió el suero que tenia la más alta carga contaminante, siendo la del lactosuero dulce, su composición se muestra en la tabla 5.8.

\subsection{DESCRIPCIÓN DE LAS EXPERIENCIAS}

\subsubsection{Caracterización de las membranas}

Para la caracterización de las membranas, se partió de una disolución modelo de lactosuero, exenta de proteínas, pues el rendimiento de la membrana puede verse alterado por la adsorción de proteínas sobre la superficie de la membrana y por las interacciones proteína-proteína (Lucas et al, 1998). Para evitar problemas de ensuciamiento las proteínas fueron eliminadas previamente por ultrafiltración, obteniéndose una corriente de permeado libre de proteínas, compuesta principalmente por lactosa 
y sales minerales. Esta corriente es la que se tomó como base en este trabajo para el estudio de la desmineralización del lactosuero.

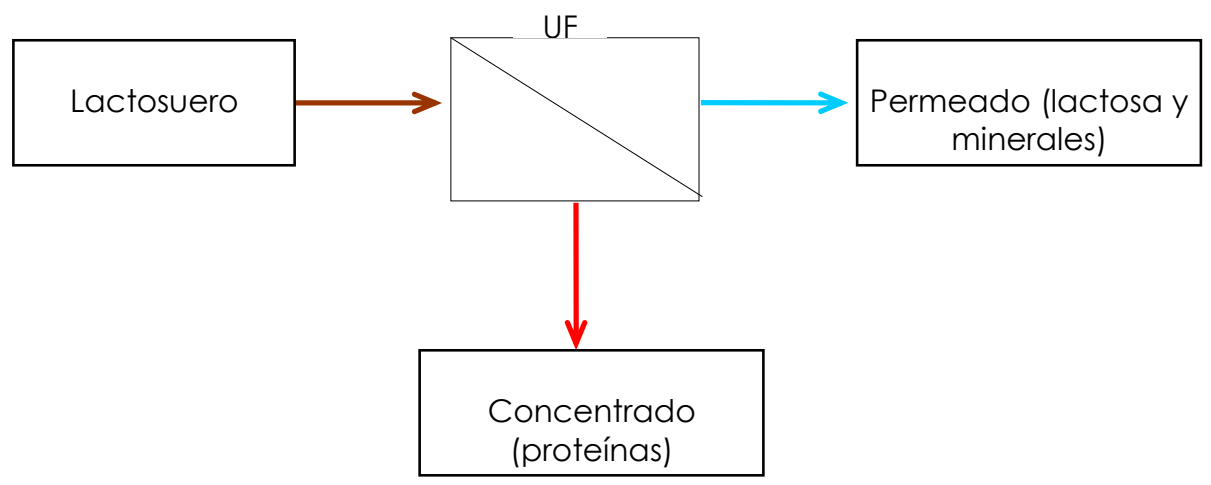

Figura 5.4. Obtención del suero libre de proteínas

\subsubsection{Fase inicial}

Una vez elegida la disolución modelo de partida y las membranas de trabajo la siguiente etapa fue su caracterización, para conocer su comportamiento en el tiempo con respecto a la densidad de flujo y al índice de rechazo. Las disoluciones ensayadas fueron:

- Disolución modelo de cada una de las sales individuales.

- Disolución modelo de la mezcla de sales minerales.

\subsubsection{Disolución modelo de sales individuales}

Este ensayo se realizó para determinar el comportamiento de la permeabilidad y de la selectividad de la membrana frente a las diferentes condiciones de operación. En una primera etapa se utilizaron disoluciones modelo de cada una de las sales presentes en 
el lactosuero como: cloruro de sodio, cloruro de potasio, sulfato de magnesio, así como con lactosa a una concentración similar a la que se encuentra en el suero. Todas preparadas en el laboratorio a partir de reactivos comerciales. La composición de las disoluciones utilizadas se muestra en la tabla 5.2.

\subsubsection{Disolución modelo de la mezcla de sales minerales}

Este ensayo se realizó para determinar el comportamiento de la permeabilidad y de la selectividad de la membrana frente a las diferentes condiciones de operación con la mezcla completa de sales. Las condiciones de operación empleadas con esta disolución fueron las mismas que las utilizadas para las disoluciones individuales, tal como se detalla en la tabla 5.4.

Tabla 5.4. Fase inicial. $\mathrm{pH}=6,7 ; \mathrm{T}=22 \pm 1^{\circ} \mathrm{C} y \dagger=8 \mathrm{~h}$.

\begin{tabular}{|c|c|c|}
\hline Alimento & $\begin{array}{c}\text { Concentración } \\
\text { (g/L) }\end{array}$ & $\begin{array}{c}\Delta \mathrm{P} \\
(\mathrm{MPa})\end{array}$ \\
\hline \multicolumn{3}{|c|}{ Sales por separado } \\
\hline $\mathrm{NaCl}$ & 1,20 & \\
\hline $\mathrm{KCl}$ & 2,00 & \\
\hline $\mathrm{MgSO}_{4}$ & 0,75 & 0,51 a 1,30 \\
\hline Lactosa (g/L) & $50 \pm 0,5$ & \\
\hline \multicolumn{3}{|c|}{ Mezcla de sales minerales } \\
\hline $\mathrm{Na}+$ & 0,48 & \\
\hline $\mathrm{K}^{+}$ & 1,04 & \\
\hline $\mathrm{Cl}^{-}$ & 1,70 & 0,51 a 1,30 \\
\hline $\mathrm{Mg}^{+2}$ & 0,15 & \\
\hline $\mathrm{SO}_{4}^{-2}$ & 0,60 & \\
\hline
\end{tabular}




\subsubsection{Fase intermedia}

\subsubsection{Módulo plano}

Después de caracterizadas las membranas estudiadas, el siguiente paso fue elegir la membrana con el menor índice de rechazo que resultó ser la membrana Ds-5 DL. Con esta membrana se realizaron los ensayos de concentración del alimento hasta el valor máximo permitido por la planta piloto, Debido a que en el módulo plano no es posible concentrar la disolución alimento hasta el valor deseado. Se hicieron experiencias de ocho horas cada una, al cabo de las cuales se cambiaba la disolución alimento por otra más concentrada. Partiendo de una concentración en lactosa del 5\% $\mathrm{p} / \mathrm{v}, 1200 \mathrm{mg} / \mathrm{L}$ de cloruro de sodio, $2000 \mathrm{mg} / \mathrm{L}$ de cloruro de potasio y $750 \mathrm{mg} / \mathrm{L}$ de sulfato de magnesio hasta llegar a una concentración del $15 \% \mathrm{p} / \mathrm{v}$ en lactosa, $3600 \mathrm{mg} / \mathrm{L}$ de cloruro de sodio, $6000 \mathrm{mg} / \mathrm{L}$ de cloruro de potasio y $2250 \mathrm{mg} / \mathrm{L}$ de sulfato de magnesio (lo que supone alcanzar un factor de concentración de 3). No se pudo trabajar con un factor de concentración mayor de 3, ya que, a partir de estas concentraciones la densidad de flujo fue muy baja. La tabla 5.5, resume las condiciones de ensayo utilizadas en esta fase. 
Tabla 5.5. Fase intermedia. $\Delta \mathrm{P}=0,95 \mathrm{MPa} ; \mathrm{pH}=6,5 ; \mathrm{T}=22 \pm 1^{\circ} \mathrm{C}$ y $t=8 \mathrm{~h}$

\begin{tabular}{lrrcccc}
\hline Exp. & \multicolumn{5}{c}{ Concentración (g/L) } \\
\cline { 2 - 7 } $\mathrm{N}^{\circ}$ & Lactosa & $\mathrm{Na}^{+}$ & $\mathrm{K}^{+}$ & $\mathrm{Mg}^{+2}$ & $\mathrm{Cl}^{-}$ & $\mathrm{SO}^{-2}$ \\
\hline 1 & 50,0 & 0,48 & 1,05 & 0,15 & 1,70 & 0,57 \\
2 & 66,7 & 0,64 & 1,40 & 0,20 & 2,25 & 0,80 \\
3 & 83,3 & 0,79 & 1,47 & 0,25 & 2,82 & 1,00 \\
4 & 100,0 & 0,95 & 2,10 & 0,30 & 3,38 & 1,20 \\
5 & 116,7 & 1,11 & 2,51 & 0,35 & 4,01 & 1,40 \\
6 & 133,4 & 1,27 & 2,80 & 0,41 & 4,51 & 1,60 \\
7 & 150,0 & 1,43 & 3,15 & 0,46 & 5,08 & 1,80 \\
\hline
\end{tabular}

\subsubsection{Módulo de arrollamiento en espiral}

Esta parte se llevó a cabo con un módulo de arrollamiento en espiral y una disolución modelo de suero. La membrana Ds-5 DL alcanzó el estado estacionario después de cuatro horas de operación.

Las experiencias se desarrollaron de la siguiente manera:

1) Cálculo del coeficiente de permeabilidad con agua destilada (membrana nueva).

2) Seguimiento de los valores de la densidad de flujo y el índice de rechazo de la disolución modelo de suero, compuesta de lactosa más sales minerales.

3) Concentración de la disolución alimento para evaluar su efecto sobre los parámetros de densidad de flujo e índice de rechazo.

4) Diafiltración de la disolución anterior durante cinco y ocho horas para evaluar el efecto desmineralizador que esta operación alternativa tiene con la membrana utilizada. 
Después de realizada la primera tanda de experiencias (membrana nueva), se limpió la membrana con una disolución de ácido cítrico al $0,5 \%$ durante 30 minutos y luego se enjuagó con agua destilada hasta que su conductividad fue igual al agua destilada. Inmediatamente después de esta limpieza se repitió cada una de las etapas anteriores enumeradas de 1 a 4 . Terminada esta tanda de experiencias, se procede nuevamente a limpiar la membrana, pero esta vez solo con agua destilada hasta que la conductividad de la corriente de concentrado bajó al mismo rango de valores que el agua destilada.

\section{A.1 Ensayo de la permeabilidad al agua}

El primer ensayo que se hizo con la membrana nueva de arrollamiento en espiral fue determinar su coeficiente de permeabilidad al agua (agua desionizada con una conductividad < $5 \mu \mathrm{S} / \mathrm{cm})$. Las condiciones de operación fueron: área de membrana de 2,51 $\mathrm{m}^{2}$, caudal de alimentación de $400 \mathrm{~L} / \mathrm{h}$ y presiones transmembranales de 0,45 a 1,15 MPa, la temperatura de operación se mantuvo a $22 \pm 2{ }^{\circ} \mathrm{C}$ y el tiempo de operación fue de cuatro horas.

\section{A.2 Ensayo con la disolución modelo de suero}

Se preparo una disolución modelo a partir de productos químicos comerciales, la composición de dicha disolución se muestra en la tabla 5.6. Así mismo algunas características de los iones presentes tales como, radio iónico, radio hidratado, entalpía de hidratación y fuerza iónica, se resumen en la tabla 5.7. 
Tabla 5.6. Composición y $\mathrm{pH}$ de la disolución alimento, $\mathrm{pH}=6,50$ y $\kappa=5,80-6,02 \mathrm{mS} / \mathrm{cm}$

\begin{tabular}{lc}
\hline Parámetro & Alimento \\
\hline Sodio, mg/L & $420-490$ \\
Potasio, mg/L & $752-1033$ \\
Magnesio, mg/L & $142-191$ \\
Cloruro, mg/L & $870-1610$ \\
Sulfatos, mg/L & $550-605$ \\
Lactosa, g/L & $45-50$ \\
\hline
\end{tabular}

Tabla 5.7. Características de los iones de la disolución alimento.

\begin{tabular}{lcccc}
\hline \multirow{2}{*}{ lón } & $\begin{array}{c}\text { Radio } \\
\text { iónico }\end{array}$ & $\begin{array}{c}\text { Radio } \\
\text { hidratado' }\end{array}$ & $\begin{array}{c}\text { Entalpía de } \\
\text { hidratación } \\
(\mathrm{kJ} / \mathrm{mol}){ }^{2}\end{array}$ & $\begin{array}{c}\text { I } \\
(\mathrm{mol} / \mathrm{L})\end{array}$ \\
\cline { 2 - 3 } Sulfatos & 0,230 & 0,379 & -1138 & 0,013 \\
Cloruro & 0,181 & 0,332 & -376 & 0,024 \\
Potasio & 0,133 & 0,331 & -324 & 0,013 \\
Sodio & 0,095 & 0,358 & -407 & 0,010 \\
Magnesio & 0,065 & 0,428 & -1931 & 0,012 \\
\hline
\end{tabular}

Los iones inorgánicos interactúan con las moléculas de agua de forman electrostática, debido al momento dipolar del agua; Mientras que los solutos orgánicos y las moléculas de agua interactúan por medio de puentes de hidrógeno. La forma en que las moléculas de

\footnotetext{
${ }^{1}$ Nightingale, 1959
}

${ }^{2}$ Marcus Y, 1985 
agua se asocian a estos tipos de solutos da lugar a la formación de radios de hidratación, así como a entalpías de hidratación. Como se observa en la tabla 5.5, Los radios de hidratación son más grandes que los radios iónicos. Además, el tamaño del ión (radio) afecta la densidad de carga de éste, pues un ión con radio pequeño tendrá mayor densidad de carga y por tanto mayor campo eléctrico que un ión de mayor tamaño o superficie, lo que hará que los iones sean atraídos por los dipolos del agua, quedando "atrapados" y recubiertos por un mayor número de moléculas de agua.

\section{A.2.1 Influencia de la presión sobre la densidad de flujo y el índice de} rechazo.

Para establecer dicha influencia, se utilizó como alimento una disolución modelo de lactosa y sales minerales. En esta etapa tanto la corriente de permeado como la de concentrado se retornan al tanque de alimentación con objeto de mantener su concentración constante, también la temperatura se mantuvo entorno a los $22 \pm$ $1{ }^{\circ} \mathrm{C}$, la presión transmembranal varió entre 0,51 y 1,35 MPa.

\section{A.2.2. Ełapa de concentración.}

Esta etapa se realizó para estudiar el efecto de la concentración sobre la capacidad desmineralizadora de la membrana Ds-5 DL. EI factor de reducción volumétrica alcanzado fue, $F R V=2$. La expresión utilizada para calcularlo fue: 


$$
F R V=\frac{V_{a}}{V_{a}-V_{p}}
$$

Donde: $V_{a}$ es el volumen inicial de alimento, $V_{p}$ es el volumen de líquido permeado obtenido en el tiempo.

La figura 5.5, muestra de forma esquemática como trabajó la planta durante el proceso de concentración.

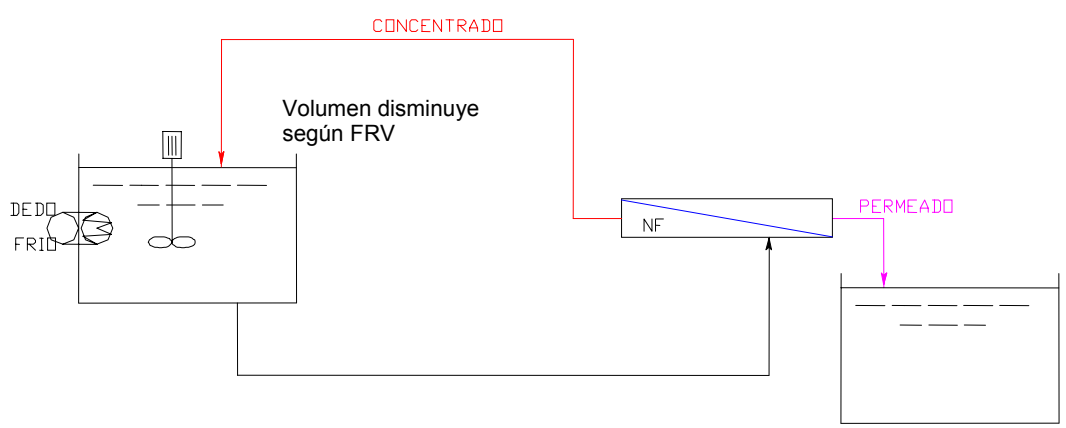

Figura 5.5. Ełapa de concentración.

\section{A.2.3. Ełapa de diafiltración.}

Después de realizada la etapa de concentración se continuó con la etapa de diafiltración, para ver si es posible mejorar el proceso de desmineralización. La dialfiltración consiste en ir agregando agua pura al tanque de alimentación para favorecer la eliminación de las sales presentes a través de la corriente de permeado.

La diafiltración puede llevarse a cabo de forma continua o discontinua. En este estudio se utilizó el modo continuo, que consiste en ir adicionando agua a unas condiciones de $\mathrm{pH}$ y temperatura constantes al tanque de alimentación, de tal forma que el caudal de 
permeado sea igual al caudal de entrada de agua al tanque de alimentación, de manera que el volumen de alimentación se mantiene constante durante todo el tiempo de operación, tal como se muestra en la figura 5.6

Los solutos permeados son eliminados a la misma velocidad que la densidad de flujo de permeado. En este caso la expresión utilizada para definir el factor de dilución es:

$$
F D=\frac{V_{p}}{V_{a}}
$$

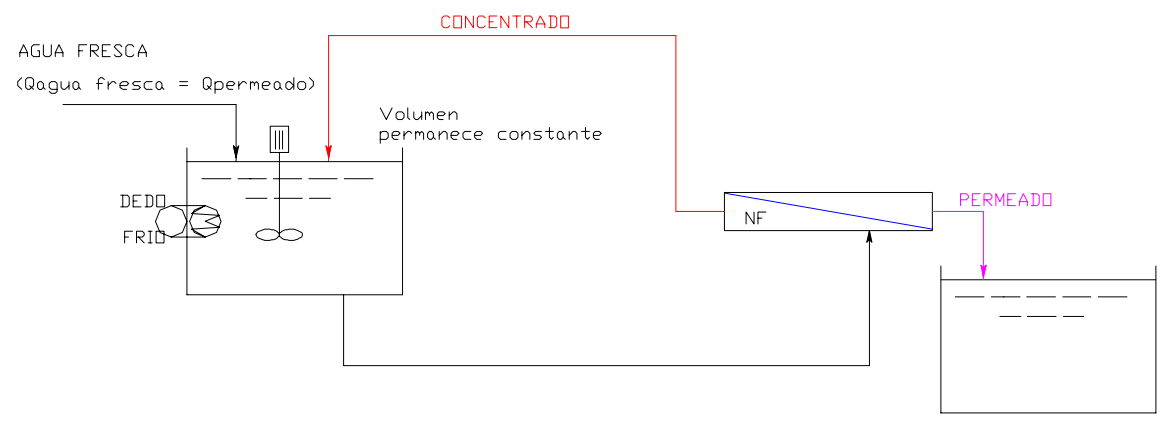

Figura 5.6. Ełapa de diafiltración.

La diafiltración con membranas de nanofiltración es efectiva en la separación de sales de solutos orgánicos. Bowen y Mohammad (1998), desarrollaron el proceso de diafiltración para la separación de una disolución de colorantes, basado en la ecuación de NernstPlanck y la incorporación del fenómeno de polarización por concentración. 


\subsubsection{Fase final}

En esta fase se trabajó con una membrana de ultrafiltración y dos membranas de nanofiltración de arrollamiento en espiral. La disolución utilizada como alimento fue suministrada por una industria quesera ubicada en la localidad de Albal (Valencia).

Para la realización de esta parte, primero se ultrafiltró el suero, generándose una corriente de concentrado rica en proteínas, de gran valor añadido y una corriente de permeado compuesta principalmente por sales minerales y lactosa. La corriente de permeado se recoge y se almacena adecuadamente para tratarla posteriormente mediante membranas de nanofiltración y poder evaluar el efecto de las variables de operación sobre el comportamiento de la membrana en cuanto a la eliminación de sales. De esta forma se pudo obtener una corriente enriquecida en lactosa con menor cantidad de sales minerales.

Las características del suero y las condiciones de operación utilizadas en los ensayos de ultrafiltración y nanofiltración se muestran en las tablas 5.8 y 5.9 respectivamente. 
Tabla 5.8. Fase Final. Ensayo de ultrafiltración. Membrana SD_10 kDa Suero real. $\mathrm{pH}=6,10 ; \kappa=6,30 \mathrm{mS} / \mathrm{cm} ; \mathrm{T}=16 \pm 1{ }^{\circ} \mathrm{C} ; \Delta \mathrm{P}=0,3$ a $0,6 \mathrm{MPa}$ y $Q_{R}=600 \mathrm{~L} / \mathrm{h}$

\begin{tabular}{lc}
\hline Alimento & Concentración (\%) \\
\hline Proteínas & 1,20 \\
Lactosa & 5,88 \\
Grasas & 0,50 \\
Extracto seco & 8,13 \\
\hline
\end{tabular}

Tabla 5.9. Fase final. Membranas NF200 y Ds-5 DL. Suero real. $\mathrm{pH}=$ $6,10-6,50 ; \kappa=5,88-, 4,30 \mathrm{mS} / \mathrm{cm} ; \mathrm{T}=16 \pm 2{ }^{\circ} \mathrm{C} . \Delta \mathrm{P}=0,5$ a $2,5 \mathrm{MPa}$ y $Q_{R}=400$ y $500 \mathrm{~L} / \mathrm{h}$.

\begin{tabular}{lc}
\hline Alimento & Concentración (g/L) \\
\hline Proteínas & $2,0-2,2$ \\
Lactosa & $36,6-56,0$ \\
Grasas & 0,0 \\
Cloruros & $1,40-1,01$ \\
Sodio & $0,45-0,30$ \\
Potasio & $1,60-1,20$ \\
Magnesio & $0,10-0,07$ \\
Sulfatos & $0,10-0,07$ \\
Fosfatos & $0,80-0,50$ \\
\hline
\end{tabular}




\subsubsection{Modelización matemática}

Para la modelización del proceso de nanofiltración se utilizaron los resultados obtenidos con la disolución alimento de lactosa y el módulo plano. Las ecuaciones del modelo utilizados fueron Donnan steric partioning, tal como se describieron en el apartado 4.3.

\subsubsection{Análisis económico}

Para determinar la viabilidad económica del proceso de desmineralización del lactosuero mediante membranas, se realizo un análisis del proceso teniendo en cuenta los resultados obtenidos experimentalmente, así como hizo información obtenida de fuentes bibliográficas. Para obtener finalmente, el tiempo de recuperación de la inversión.

\subsection{MÉTODOS ANALÍTICOS}

A continuación en la tabla 5.10, se muestra un breve resumen de los métodos utilizados para determina la composición analítica de las corrientes tratadas. La descripción detallada de los métodos analíticos utilizados en la cuantificación de cada uno de los parámetros de interés al ser bastante extenso se incluye en el anexo 11.2 de esta tesis. 
Tabla 5.10. Resumen de los métodos analíticos empleados

\begin{tabular}{lll}
\hline Análisis & Determinación & Método \\
\hline $\mathrm{pH}$ & $\mathrm{pH}$-metro & $\mathrm{pH}$-metro Crison \\
Conductividad & Conductímetro & Conductímetro Crison \\
Extracto seco & Estufa & Norma UNE 34-824-83 \\
Lactosa & Cloramina T-yoduro potásico & Norma UNE 34-826-83 \\
Nitrógeno total & Kjeldahl & Norma UNE-EN ISO \\
Grasas & Método Gerber. & 8968-2/3 \\
Proteínas & Nitrógeno total x 6,38 & Norma UNE 34-898-86 \\
Sulfatos & Método turbidimétrico fotométrico & 4500-SO4-2E. \\
Cloruros & Método nitrato mercúrico & Norma FIL 20A/1986 \\
& $\begin{array}{l}\text { Cromatografía iónica y/o } \\
\text { absorción atómica }\end{array}$ & Standard Methods \\
\hline
\end{tabular}




\subsection{RESUMEN DE LA METODOLOGÍA}
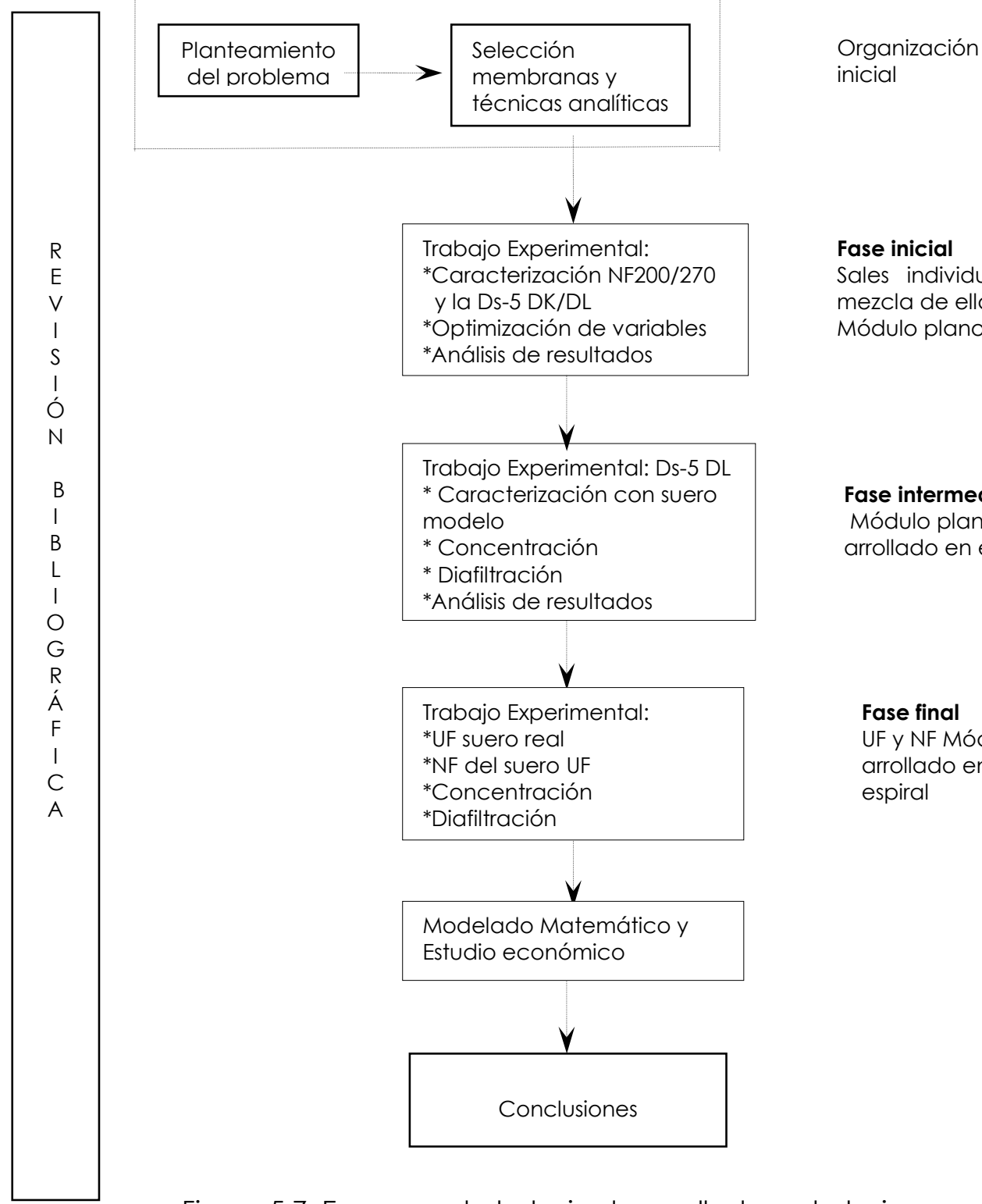

Trabajo Experimental:

*Caracterización NF200/270

y la Ds-5 DK/DL

*Optimización de variables

*Análisis de resultados

Sales individuales y mezcla de ellas

Módulo plano

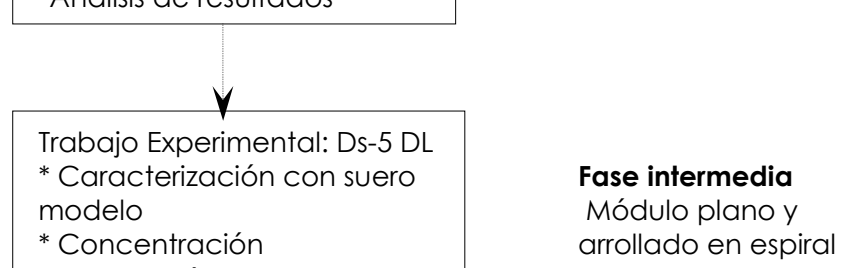

* Diafiltración

*Análisis de resultados

arrollado en espira

\section{Fase final}

Trabajo Experimental:

*UF suero real

*NF del suero UF

*Concentración

UF y NF Módulo

arrollado en

*Diafiltración

espiral

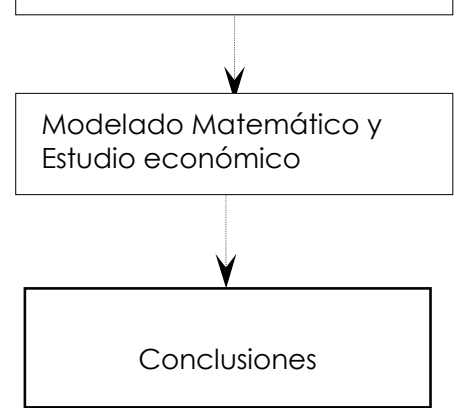

Figura 5.7. Esquema de trabajo desarrollado en la tesis 
RESULTADOS Y

DISCUSIÓN

6. 



\section{RESULTADOS Y DISCUSIÓN}

\subsection{FASE INICIAL}

\subsubsection{Estado estacionario de la disolución modelo de sales individuales}

Para la caracterización de las membranas de nanofiltración con las disoluciones de sales individuales, se utilizan las membranas: NF200, NF270, Ds-5 DK y Ds-5 DL.

En la tabla 5.4, se muestra un resumen de las condiciones experimentales de los ensayos realizados en esta fase. Con estas experiencias se pretende determinar el estado estacionario (EE) de las membranas; es decir, partir de que tiempo de operación las membranas se estabilizan, para tomar los valores del índice de rechazo y la densidad de flujo como parámetros fiables de comportamiento a la hora de analizar los resultados obtenidos.

Ésta fase se dividió en dos etapas:

1. Caracterización de las membranas con disoluciones modelo de las sales individuales más representativas del lactosuero.

2. Caracterización de las membranas con una disolución modelo de la mezcla completa de sales minerales en el lactosuero. 


\subsubsection{Disolución de cloruro de sodio}

Se prepara con una disolución modelo de cloruro de sodio de concentración $1.200 \mathrm{mg} / \mathrm{L}$ y presión osmótica de 0,10 MPa. Los resultados obtenidos con esta disolución a las diferentes presiones aplicadas $(0,53 ; 0,92$ y $1,3 \mathrm{MPa})$ y con todas las membranas ensayadas se muestran en las figuras 6.1 y 6.2. En ellas se puede observar que para las membranas NF200 y NF270, el estado estacionario se alcanza a partir de las seis horas de operación, mientras que para las membranas Ds-5 DK y Ds-5 DL es a partir de las 4 horas. Tanto con la membrana NF200 como con la NF270, se observa que para la presión de 0,53 MPa una vez alcanzado el estado estacionario presentan valores de densidad de flujo y rechazo muy similares (aprox. $60 \mathrm{~L} / \mathrm{m}^{2} \mathrm{~h}$ y $29 \%$ ).

Sin embargo, a esta misma presión (0,53 MPa) y una vez alcanzado el estado estacionario la densidad de flujo de la membrana Ds-5 DL es el doble con respecto a la Ds-5 DK, mientras que el índice de rechazo es muy similar para ambas membranas (alrededor del 33\%).

En la figura 6.1 se observa que para la presión aplicada de 0,92 MPa, al alcanzar al estado estacionario los valores de densidad de flujo presentan pequeñas diferencias $\left(156\right.$ y $138 \mathrm{~L} / \mathrm{m}^{2} \mathrm{~h}$ para la NF 200 y la NF 270 respectivamente). Sin embargo, respecto al índice de rechazo no se aprecian diferencias significativas estando alrededor del $40 \%$ para ambas membranas, como puede verse en la figura 6.2. 
En el caso de la presión de 1,3 MPa, se observa un comportamiento similar, mostrando índices de rechazo muy próximos para ambas membranas a las mismas condiciones de operación.

A la presión de 0,92 MPa, las densidades de flujo de las membranas Ds-5 se diferencian poco $\left(22\right.$ y $29 \mathrm{~L} / \mathrm{m}^{2} \mathrm{~h}$ para la DK y la DL respectivamente), en cambio en el índice de rechazo si hay diferencias apreciables alrededor del $46 \%$ para la DK y $36 \%$ para la DL. Mientras que, a la presión de 1,3 MPa se observan diferencias un poco más apreciables en las densidades de flujo con valores próximos a 54 y $72 \mathrm{~L} / \mathrm{m}^{2} \mathrm{~h}$ para la DK y la DL respectivamente, sin embargo en los índices de rechazo (54\% para la DK y $43 \%$ para la DL) siguen el mismo comportamiento observado con la presión anterior. 
Resultados y discusión
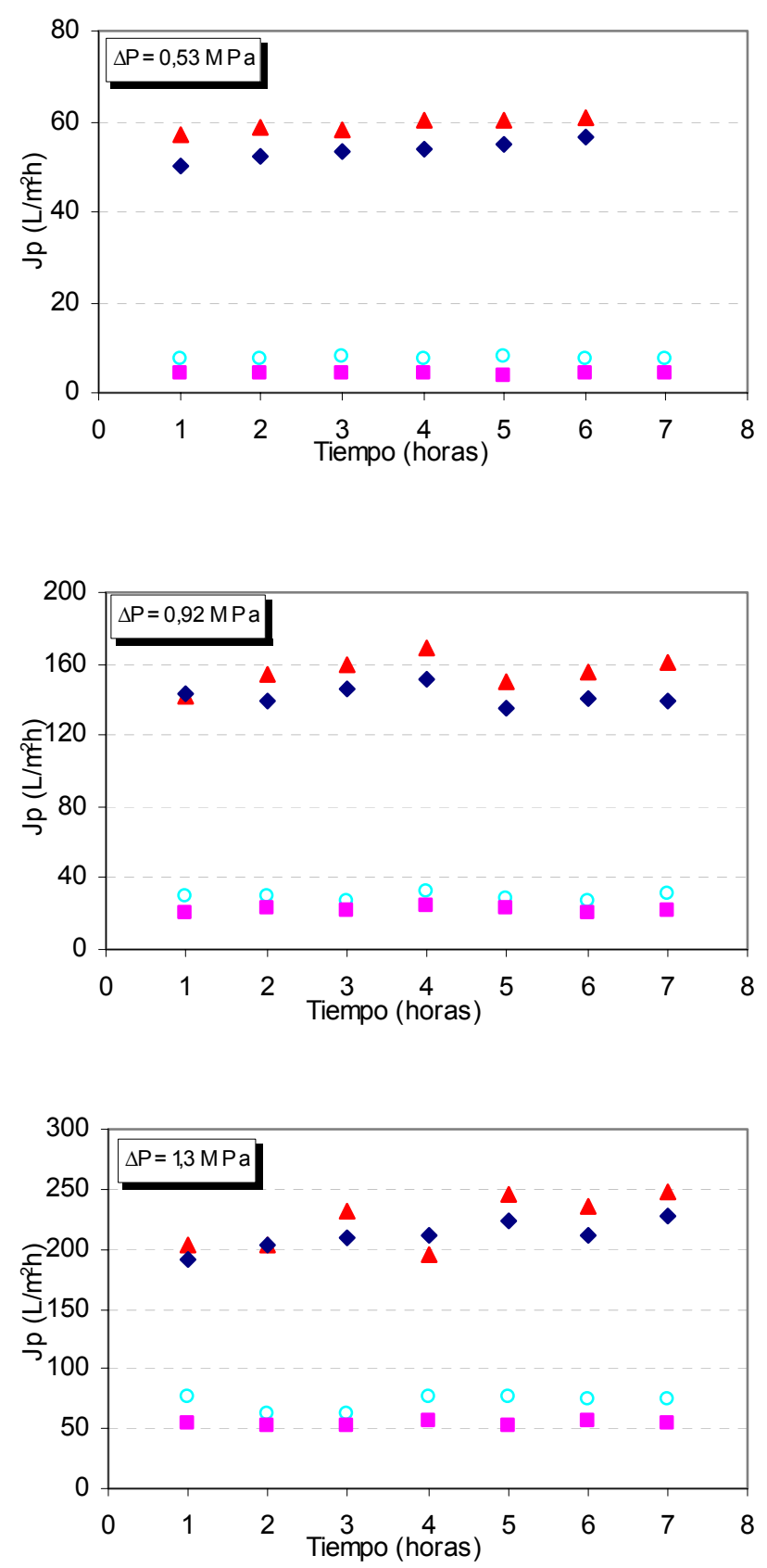

Figura 6.1. Variación de Jp, módulo plano. $1.200 \mathrm{mg} \mathrm{NaCl} / \mathrm{L}$ $\triangle N F 200 \bullet N F 270 \quad$ Ds-5DL $\triangle D s-5 D K, T=22 \pm 1^{\circ} \mathrm{C}, V_{\text {tang }}=2,04 \mathrm{~m} / \mathrm{s}$ 

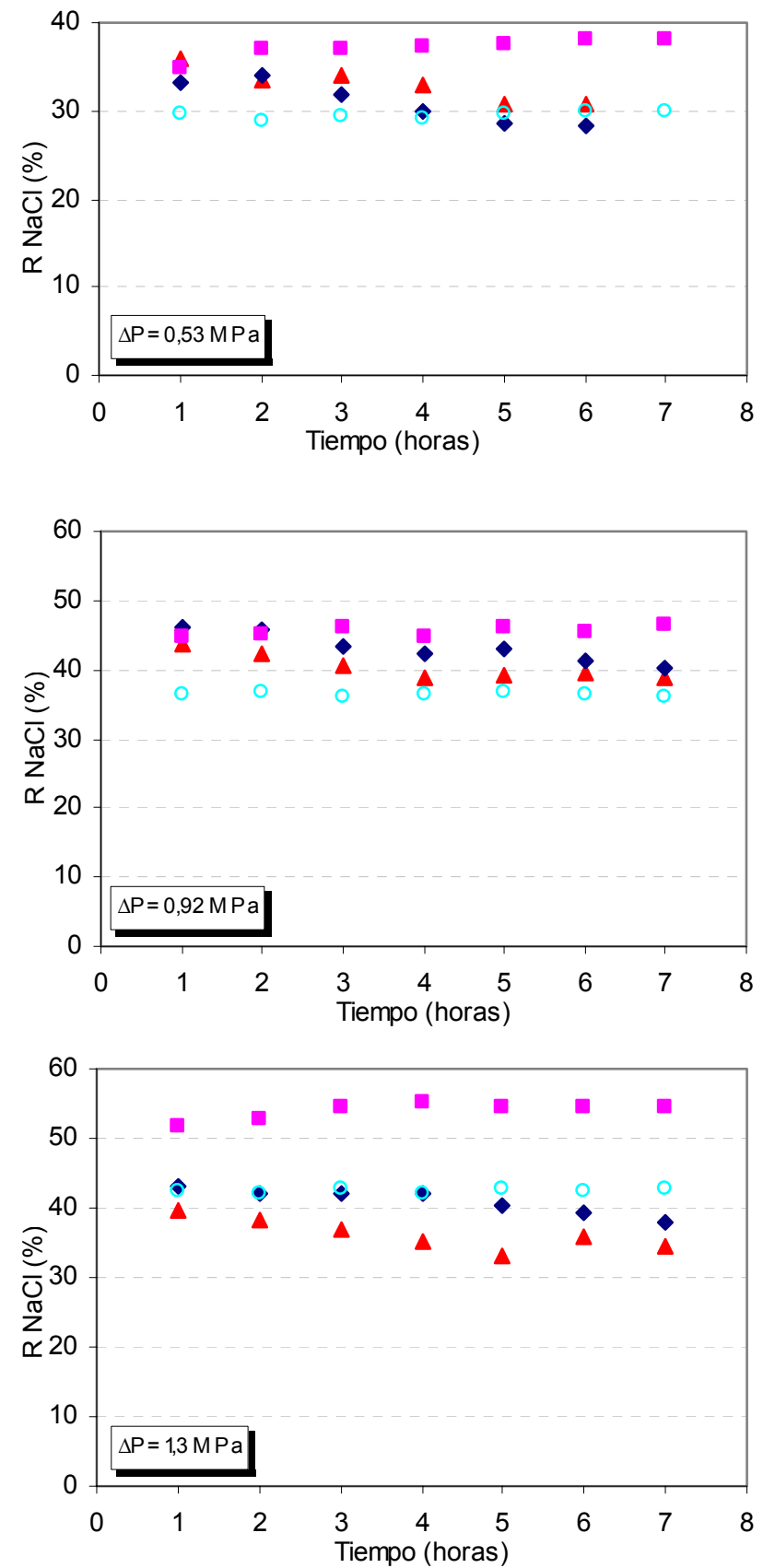

Figura 6.2. Variación de $\mathrm{R}$, módulo plano. $1.200 \mathrm{mg} \mathrm{NaCl} / \mathrm{L}$, $\triangle N F 200 \bullet N F 270$ Ds-5DL $\backsim \mathrm{Ds}-5 \mathrm{DK}, \mathrm{T}=22 \pm 1^{\circ} \mathrm{C}, \mathrm{V}_{\text {tang }}=2,04 \mathrm{~m} / \mathrm{s}$ 


\subsubsection{Disolución de cloruro de potasio}

Se prepara una disolución modelo de cloruro de potasio a una concentración de $2.000 \mathrm{mg} / \mathrm{L}$ y presión osmótica de 0,13 MPa, los resultados obtenidos con esta disolución, se observan en las figuras 6.3 y 6.4. Las membranas NF200 y NF270 con esta disolución presentan un comportamiento similar al observado con el cloruro sódico, seguramente debido al hecho de tratarse en ambos casos de sales monovalentes y a valores similares de presión osmótica.

Cabe mencionar no obstante, que las membranas NF200 y NF270 con la disolución de cloruro potásico, presentan más variaciones que con la disolución de cloruro sódico respecto a la densidad de flujo de permeado. El índice de rechazo presenta pocas fluctuaciones a lo largo de las 8 horas de experimentación. Cabe destacar, que el índice de rechazo al cloruro de potasio es más alto que al cloruro sódico. Este comportamiento es anómalo, ya que el cloruro sódico posee mayor entalpía de hidratación que el cloruro de potasio, por lo que el comportamiento esperado sería un mayor índice de rechazo al cloruro sódico.

En la figura 6.3, las membranas Ds-5 DK y Ds-5 DL presentan un aumento más significativo de la densidad de flujo que el obtenido con la disolución de cloruro de sodio. A 0,53 MPa la densidad de flujo y el índice de rechazo para ambas membranas son muy similares. Las diferencias respecto de la permeabilidad se conservan al ir aumentando la presión aplicada. 
Es importante destacar que para las mismas condiciones operación, las membranas Ds-5 DK y Ds-5 DL, presentan un comportamiento más estable respecto a la densidad de flujo y el índice de rechazo que las membranas NF200 y NF270. 
Resultados y discusión
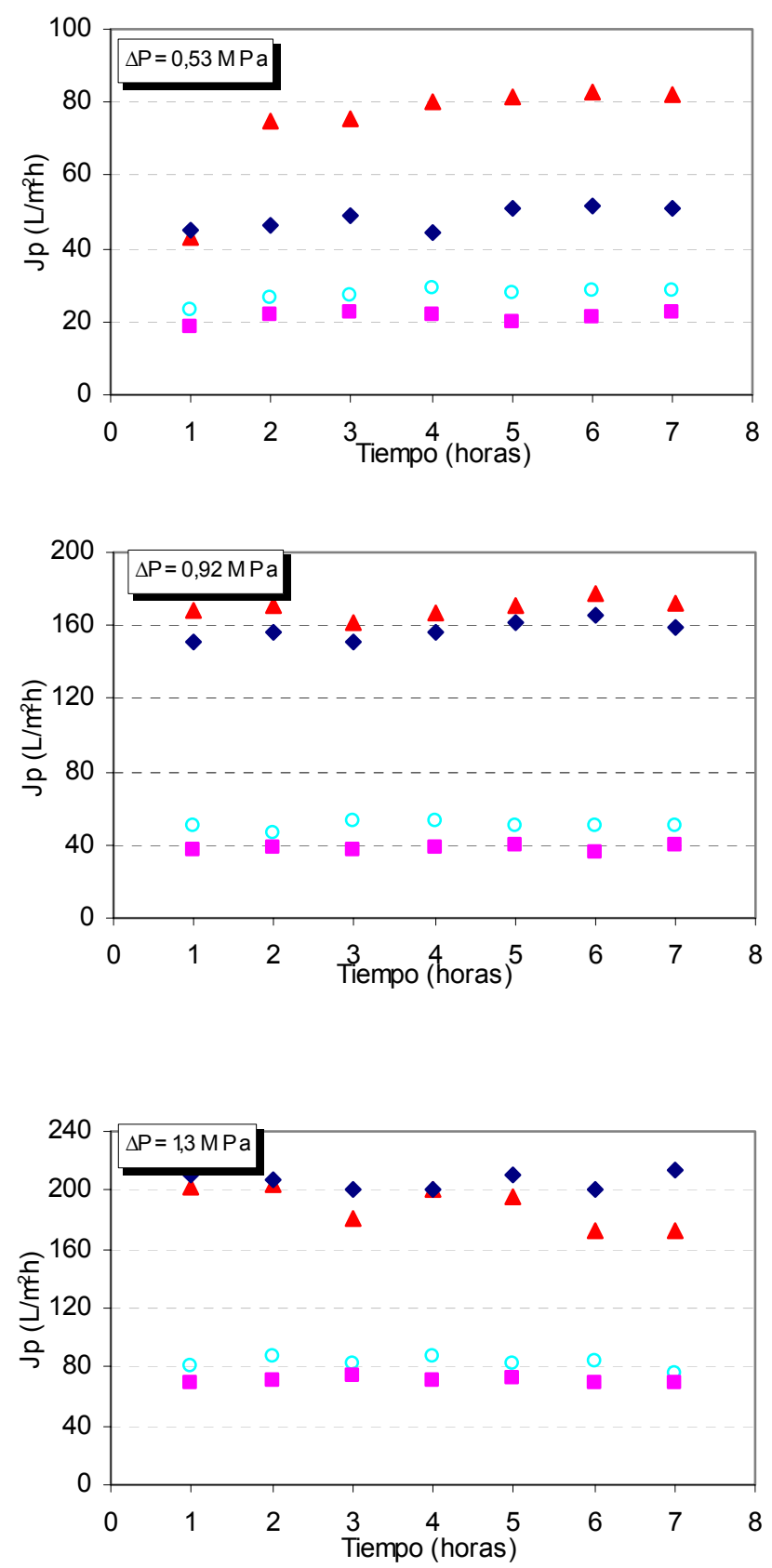

Figura 6.3. Variación de Jp, módulo plano. $2.000 \mathrm{mg} \mathrm{KCl} / \mathrm{L}$ $\triangle N F 200$ NF270 oDs-5DL $\square \mathrm{Ds}-5 \mathrm{DK}, \mathrm{T}=22 \pm 1^{\circ} \mathrm{C}, \mathrm{V}_{\text {tang }}=2,04 \mathrm{~m} / \mathrm{s}$ 

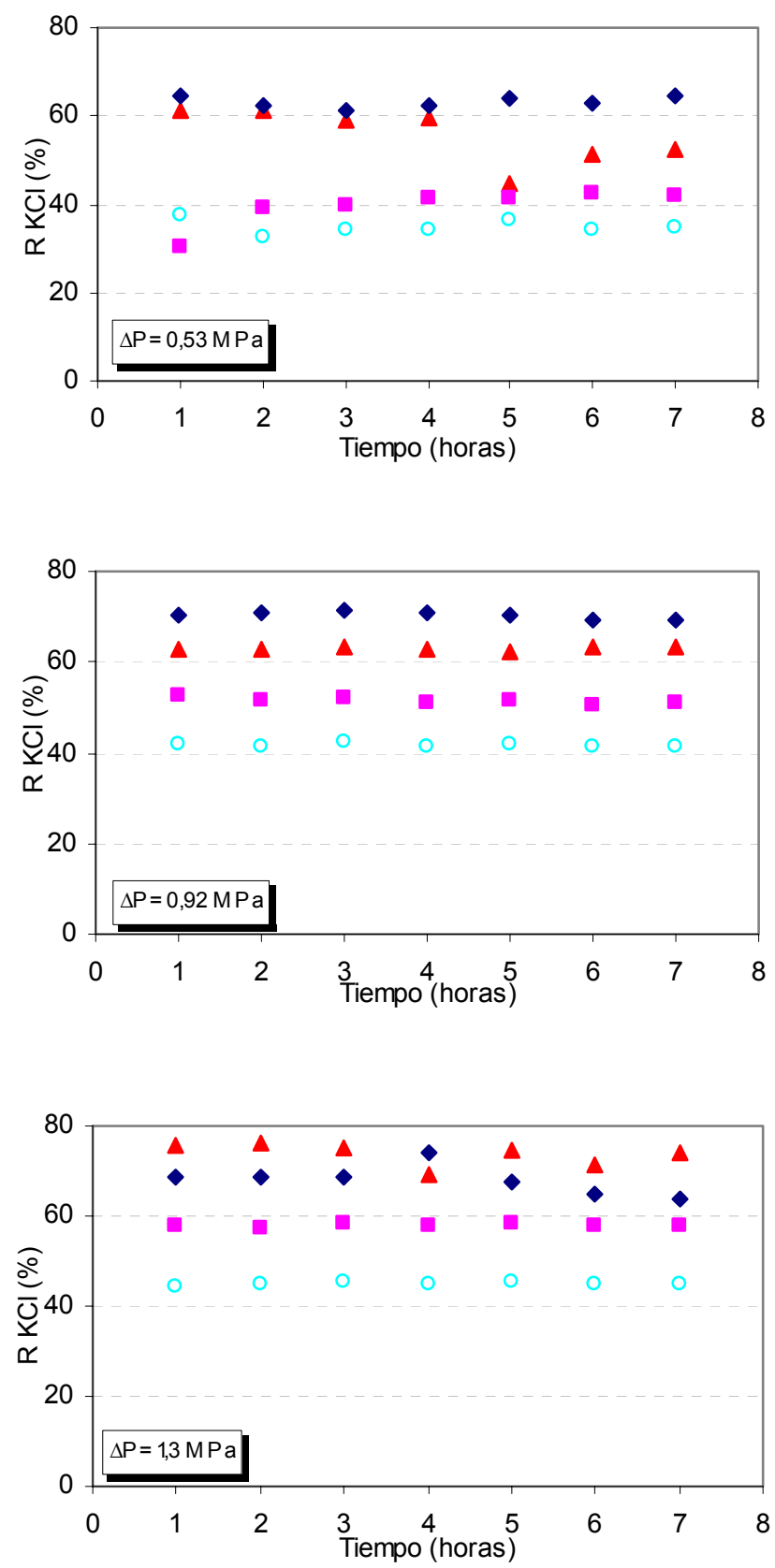

Figura 6.4. Variación de R, módulo plano. $2.000 \mathrm{mg} \mathrm{KCl} / \mathrm{L}$, $\triangle N F 200 \bullet N F 270$ Ds-5DL $\backsim \mathrm{Ds}-5 \mathrm{DK}, \mathrm{T}=22 \pm 1^{\circ} \mathrm{C}, \mathrm{V}_{\text {tang }}=2,04 \mathrm{~m} / \mathrm{s}$ 


\subsubsection{Disolución de sulfato de magnesio}

Se prepara una disolución modelo de sulfato de magnesio a una concentración de $750 \mathrm{mg} / \mathrm{L}$ y presión osmótica de 0,03 MPa. Los resultados obtenidos con cada una de las membranas (NF200, NF270, Ds-5 Dk y Ds-5 DL), muestran un comportamiento esperado a medida que aumenta la presión aplicada, la densidad de flujo también aumentó. Sin embargo el índice de rechazo se mantiene constante en el rango de presiones aplicadas, tal como se puede apreciar en las figuras 6.5 y 6.6 .

Cabe mencionar que las membranas NF200, NF270, Ds-5 DK y Ds-5 DL con la disolución de sulfato de magnesio, presentan un índice de rechazo alrededor del 94-98\%, tal como, se observa en las gráficas. Con esta disolución las membranas presentan valores muy estables respecto al índice de rechazo y muestran un aumento proporcional de la densidad de flujo acorde con cada una de las presiones aplicadas.

Los elevados valores del índice de rechazo de sulfato de magnesio que se obtienen respecto del cloruro sódico y del cloruro potásico, es un comportamiento característico de las membranas de nanofiltración. 

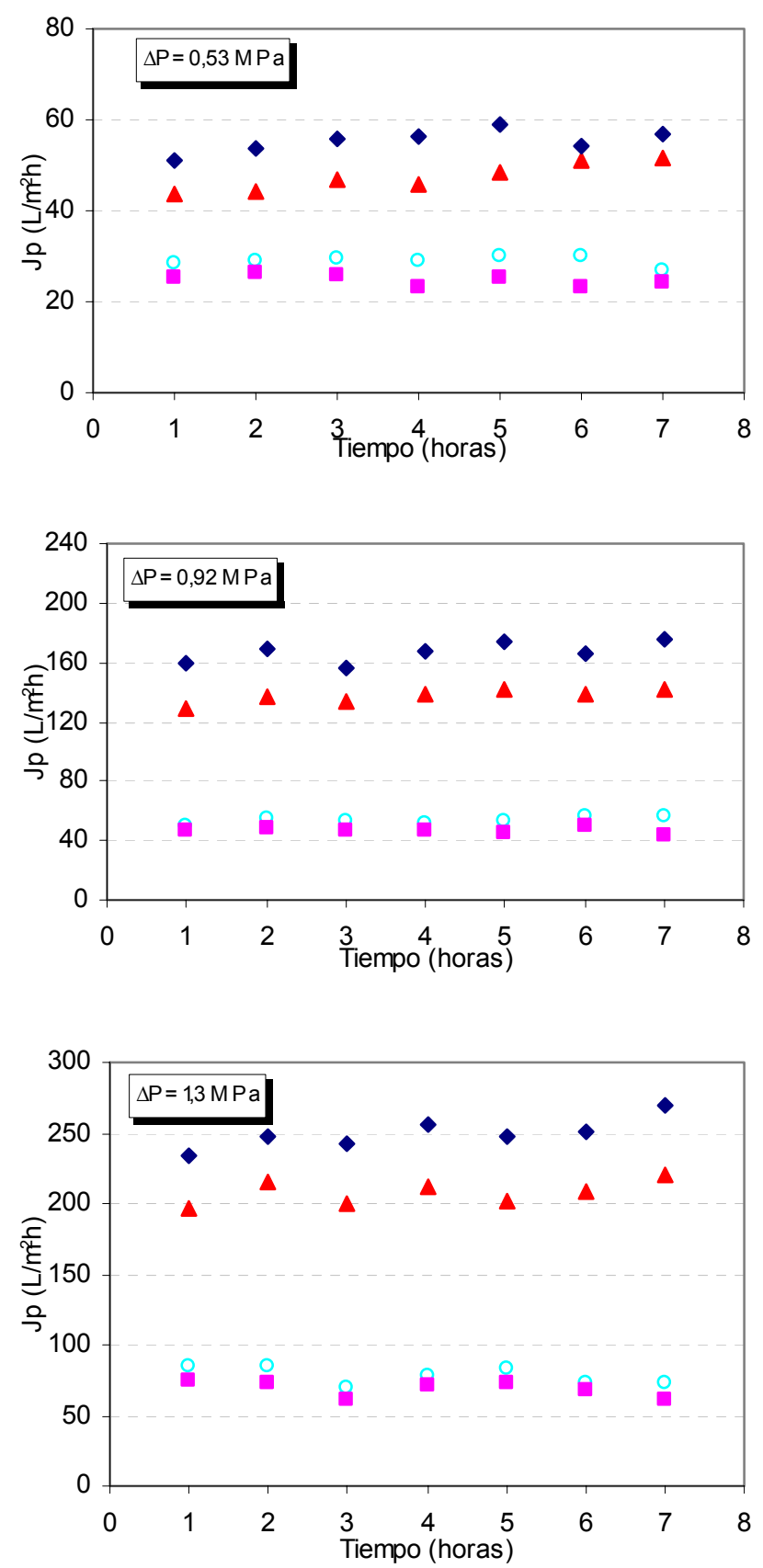

Figura 6.5. Variación de $\mathrm{Jp}_{\mathrm{p}}$, módulo plano. $750 \mathrm{mg} \mathrm{MgSO} / \mathrm{L}$, $\triangle N F 200 \bullet N F 270$ Ds-5DL $\backsim \mathrm{Ds}-5 \mathrm{DK}, \mathrm{T}=22 \pm 1^{\circ} \mathrm{C}, \mathrm{V}_{\text {tang }}=2,04 \mathrm{~m} / \mathrm{s}$ 

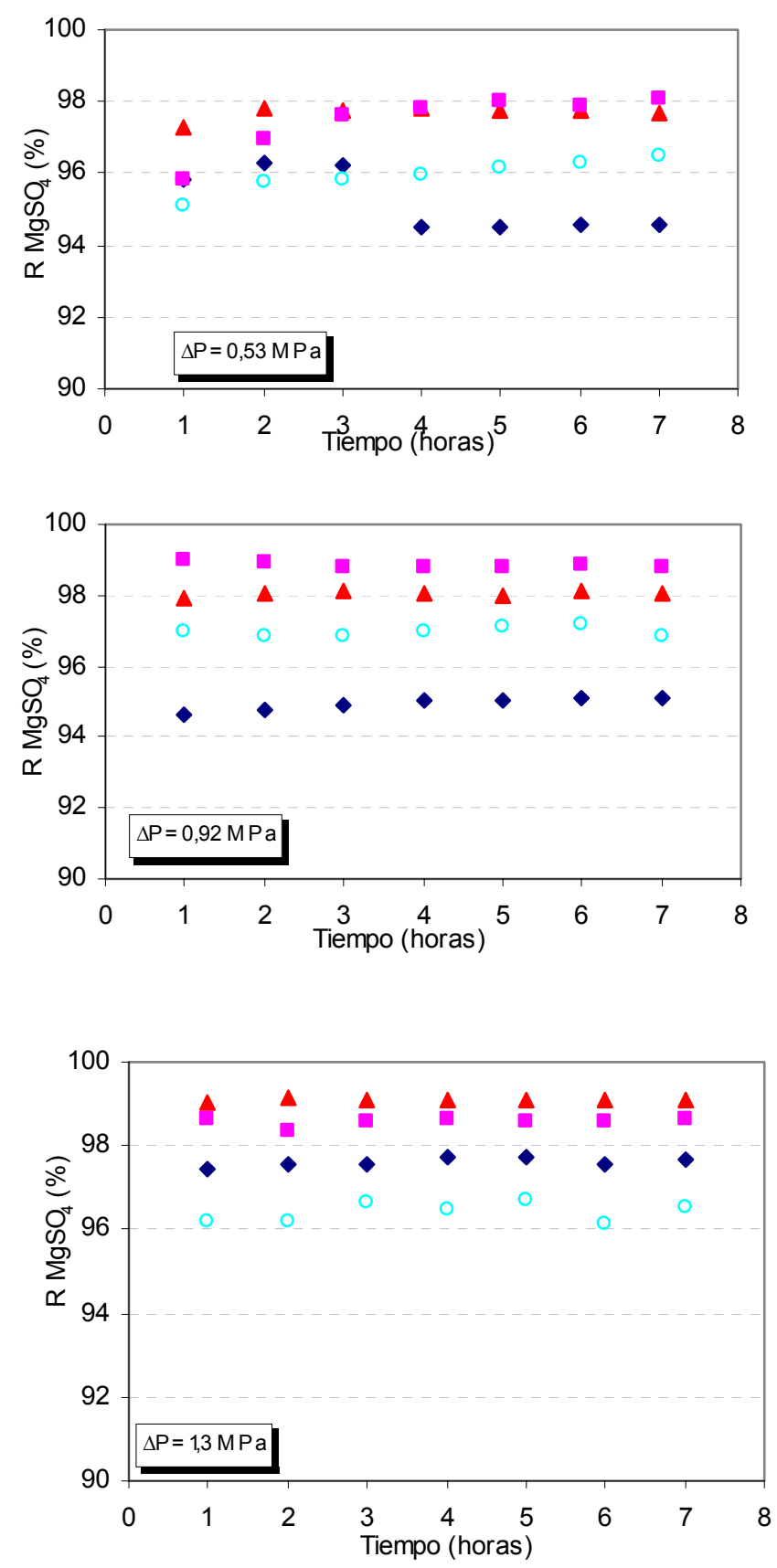

Figura 6.6. Variación de R, Módulo plano. $750 \mathrm{mg} \mathrm{MgSO}_{4} / \mathrm{L}$, $\triangle N F 200 \bullet N F 270$ Ds-5DL - Ds-5 DK, T $=22 \pm 1^{\circ} \mathrm{C}, V_{\text {tang }}=2,04 \mathrm{~m} / \mathrm{s}$ 


\subsubsection{Disolución de lactosa}

Se prepara una disolución modelo de lactosa de $50 \mathrm{~g} / \mathrm{L}$, lo que equivale a una presión osmótica aproximada de 0,35 MPa. Los resultados obtenidos con cada una de las membranas (NF200, NF270, Ds-5 DK y Ds-5 DL) muestran un comportamiento muy similar a los obtenidos con el sulfato de magnesio. Siendo válido para la disolución de lactosa lo expuesto en el apartado de la disolución de sulfato de magnesio. (Ver las figuras 6.7 y 6.8).

Cabe mencionar, que las membranas NF200, NF270, Ds-5 DK y Ds-5 DL con la disolución de lactosa, presentan un índice de rechazo alrededor del $96 \%$. Valores que están dentro del rango de selectividad de estas membranas para solutos orgánicos.

Si se comparan los valores obtenidos con el sulfato de magnesio y la lactosa, respecto a la densidad de flujo, se ve que los más altos se obtiene con la disolución de sulfato de magnesio, esto es lógico debido a la mayor presión osmótica de la disolución de lactosa, pues a menor presión efectiva menor densidad de flujo. Sin embargo, con las membranas Ds-5 DK y Ds-5 DL estas diferencias no fueron apreciables.

Con esta disolución la mayor densidad de flujo se obtiene con la membrana NF200, seguida de la NF270 y las membranas Ds-5 DL y Ds5 DK. Las membranas presentan valores estables respecto al índice de rechazo y un aumento proporcional de la densidad del flujo respecto a la presión aplicada, acorde con lo que cabria esperar. 
A la luz de los resultados obtenidos con las sales minerales y la lactosa, puede llegar a suponerse que las membranas NF200 y NF270 tienen mayor número de poros, con una distribución y tamaño más homogénea, frente a las membranas Ds-5. 

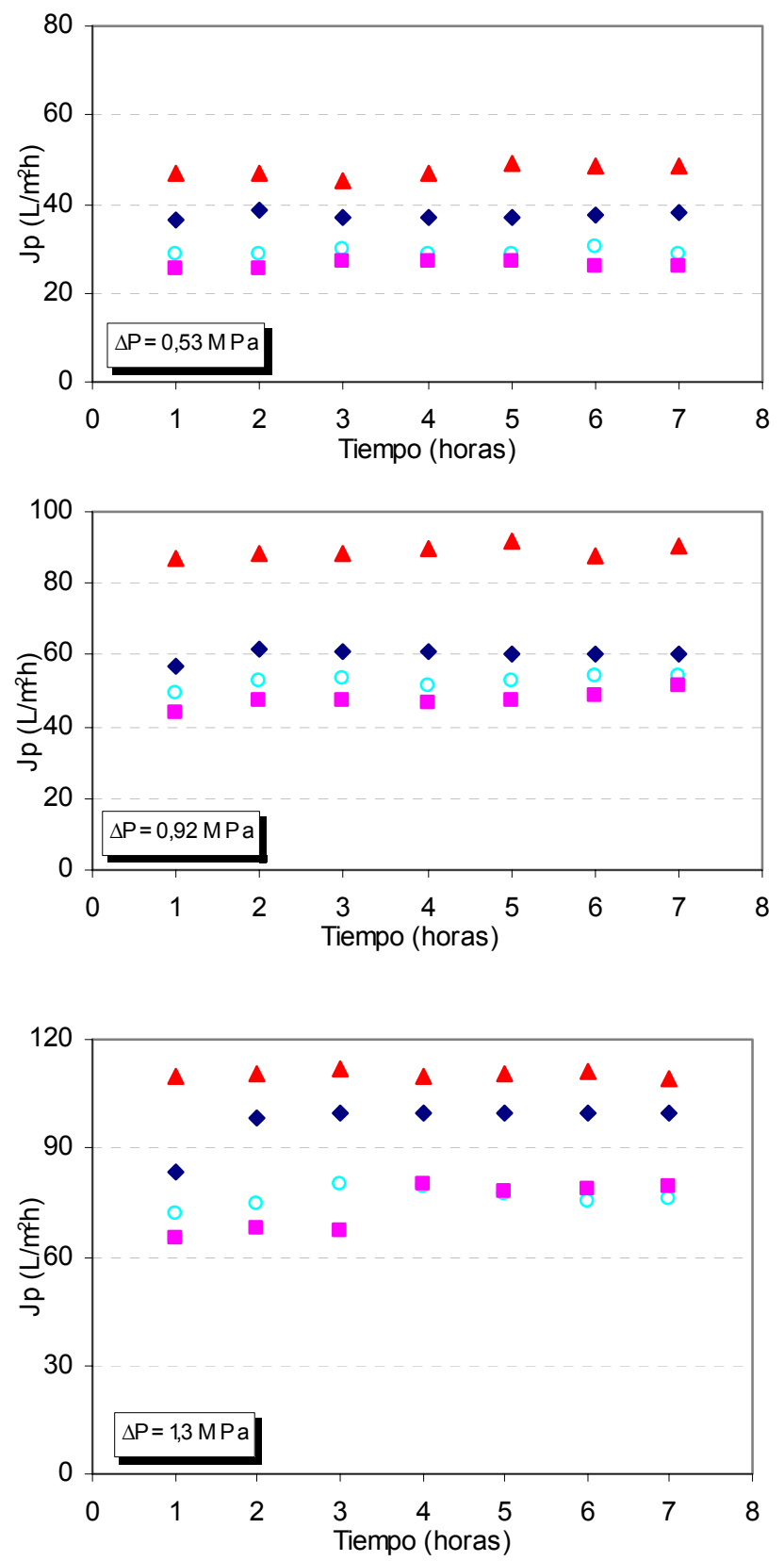

Figura 6.7. Variación de $\mathrm{J}_{\mathrm{p}}$, módulo plano. $50 \mathrm{~g}$ lactosa/L, $\triangle N F 200 \bullet N F 270$ Ds-5DL - Ds-5 DK, T $=22 \pm 1^{\circ} \mathrm{C}, V_{\text {tang }}=2,04 \mathrm{~m} / \mathrm{s}$ 


\section{Resultados y discusión}
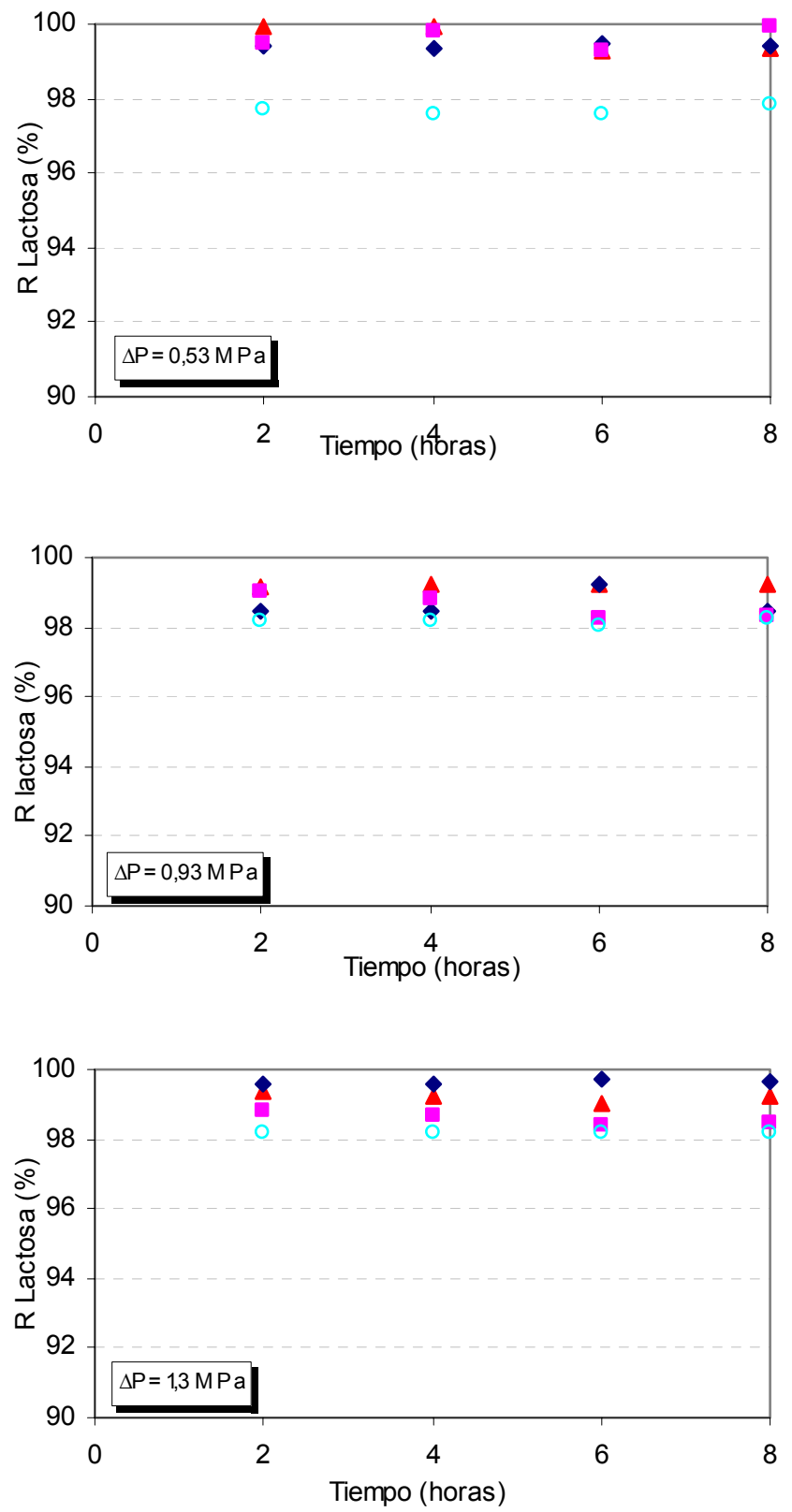

Figura 6.8. Variación de R, módulo plano. $50 \mathrm{~g}$ lactosa/L, $\triangle N F 200 \bullet N F 270$ oDs-5DL $\square$ Ds-5 DK, T $=22 \pm 1^{\circ} \mathrm{C}, V_{\text {tang }}=2,04 \mathrm{~m} / \mathrm{s}$ 


\subsubsection{Estado estacionario de la disolución modelo de mezcla de sales minerales}

La composición de la disolución modelo se muestra en la tabla 5.2. Las figuras 6.9 y 6.10 , reflejan los resultados obtenidos a las diferentes presiones aplicadas $(0,530,92$ y 1,3 MPa). Se puede observar que el estado estacionario se alcanza a partir de las 4 horas con las membranas Ds-5, tiempo en el cual se estabiliza el índice de rechazo y la densidad de flujo de estas membranas.

Además se observa que a una presión aplicada de 0,53 MPa y alcanzado el estado estacionario, los valores de densidad de flujo son muy similares para las membranas NF200 y NF270 (aprox. 50 $\mathrm{L} / \mathrm{m}^{2} \mathrm{~h}$ ). Sin embargo, para las membranas Desal-5 (DK y DL), la densidad de flujo es la mitad del valor obtenido con las NF200 y NF270. A la presión de 1,3 MPa, las diferencias en las densidades de flujo de las membranas NF (200 y 270 ) son del 18\%, siendo la membrana NF 200 la que presenta mayor densidad de flujo. Mientras que para las membranas Ds-5 esta desviación es de 1 14\%. De los resultados anteriores, puede decirse que las membranas NF200 y NF270 producen caudales de permeado e índices de rechazo mayores a los de las membranas Ds-5.

Como se puede observar en la figura 6.9, el orden de la densidad de flujo obtenido es el siguiente: NF200 > NF270 > Ds-5 DL > Ds-5 DK 

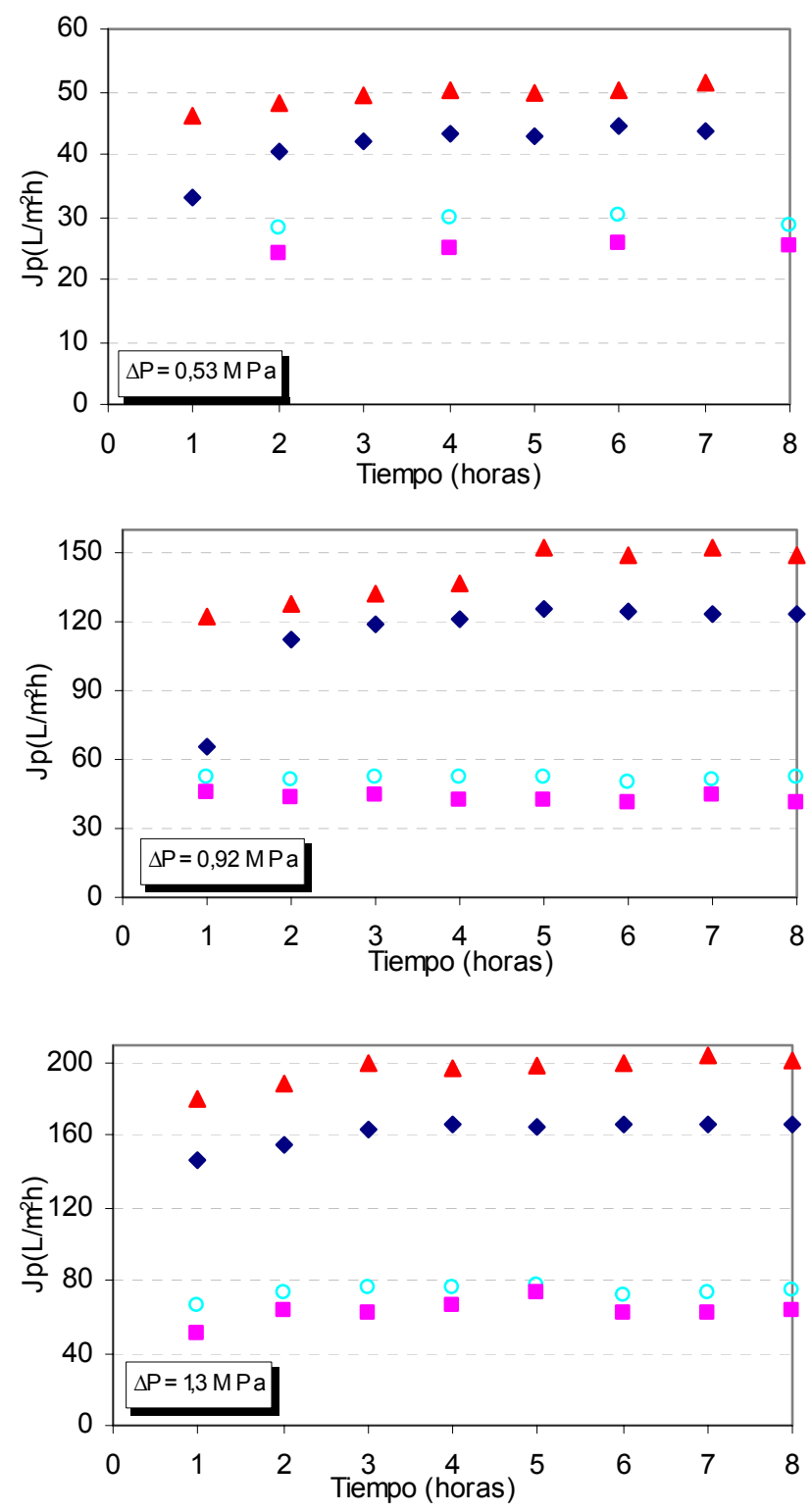

Figura 6.9. Variación de $J_{p}$, módulo plano. Mezcla de sales.

$\triangle N F 200 \triangleleft N F 270$ Ds-5DL $\square$ Ds-5 DK, T $=22 \pm 1{ }^{\circ} \mathrm{C}, V_{\text {tang }}=2,04 \mathrm{~m} / \mathrm{s}$ 
Las membranas Ds-5 presentan un comportamiento muy estable durante todo el tiempo de operación, lo contrario a las membranas NF200 y NF270.

A continuación se muestran los valores de índices de rechazo obtenidos para cada uno de los iones presentes en la disolución.

Para el ión sodio, los índices de rechazo más altos son los obtenidos con la membrana NF270 y los más bajos los de la membrana Ds-5 DL, tal como puede apreciarse en la figura 6.10.

Para el ión potasio, los índices de rechazo más altos se obtienen con las membranas NF200 y NF270 y del mismo orden e magnitud. Los valores obtenidos con las membranas de la serie Ds-5 son también muy similares al alcanzar el estado estacionario, pero inferiores a los de la membrana NF (200 y 270), tal como se muestra en la figura 6.11.

Para el ión magnesio, tal como se muestra en la figura 6.12, los valores de índice de rechazo están entre el $84-98 \%$ para todas las membranas ensayadas.

Para el ión cloruro, tal como se aprecia en la figura 6.13 las membranas NF200 y NF270 presentan los índices de rechazos alrededor del 50-66\%, mientras que los de las membranas Ds-5 están alrededor del $30-45 \%$. 

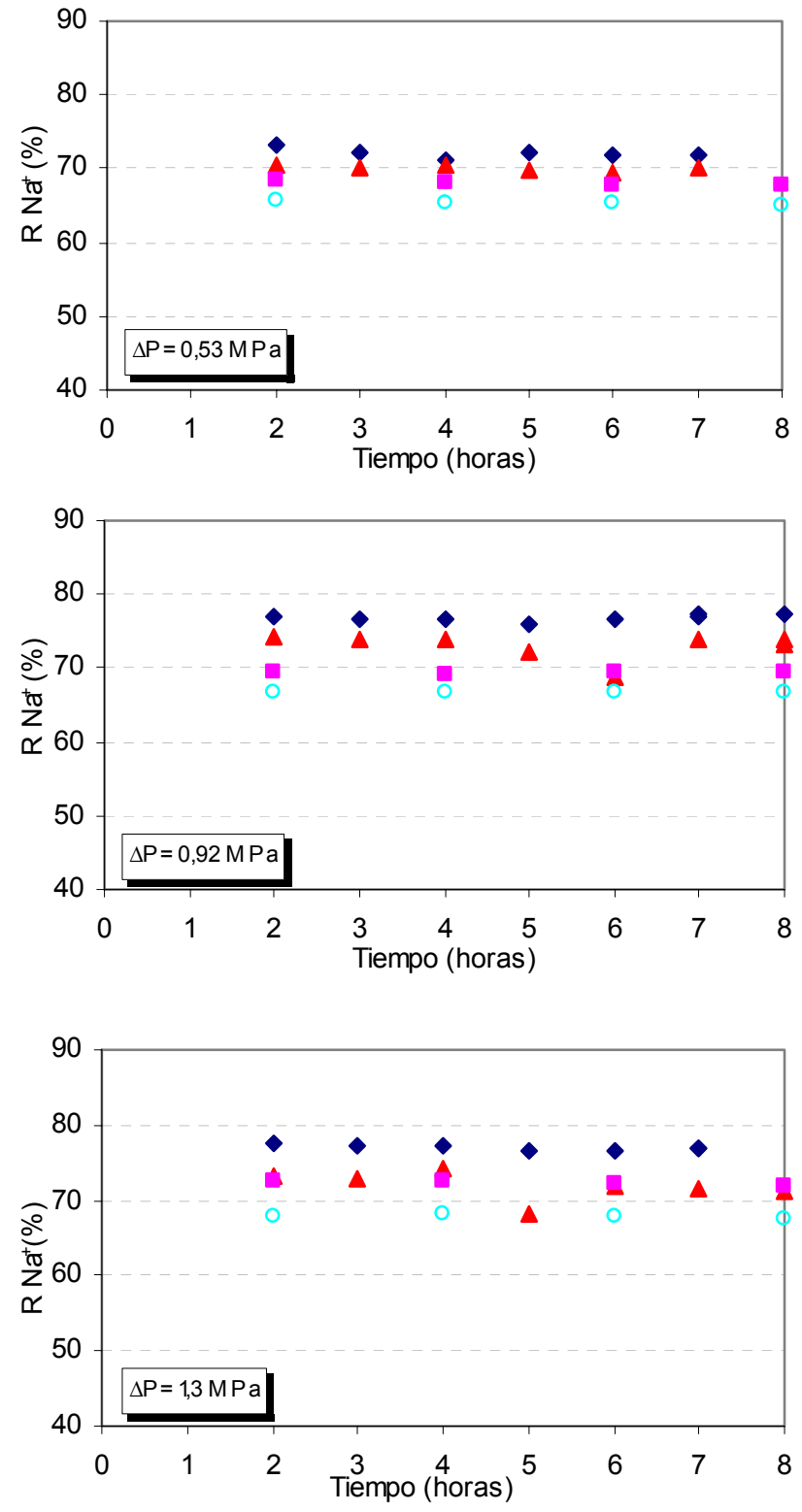

Figura 6.10. Variación de $\mathrm{R} \mathrm{Na}^{+}$, módulo plano. Mezcla de sales $\triangle N F 200 \bullet N F 270$ Ds -5DL $\square \mathrm{Ds}-5 \mathrm{DK}, \mathrm{T}=22 \pm 1^{\circ} \mathrm{C}, \mathrm{V}_{\text {tang }}=2,04 \mathrm{~m} / \mathrm{s}$ 

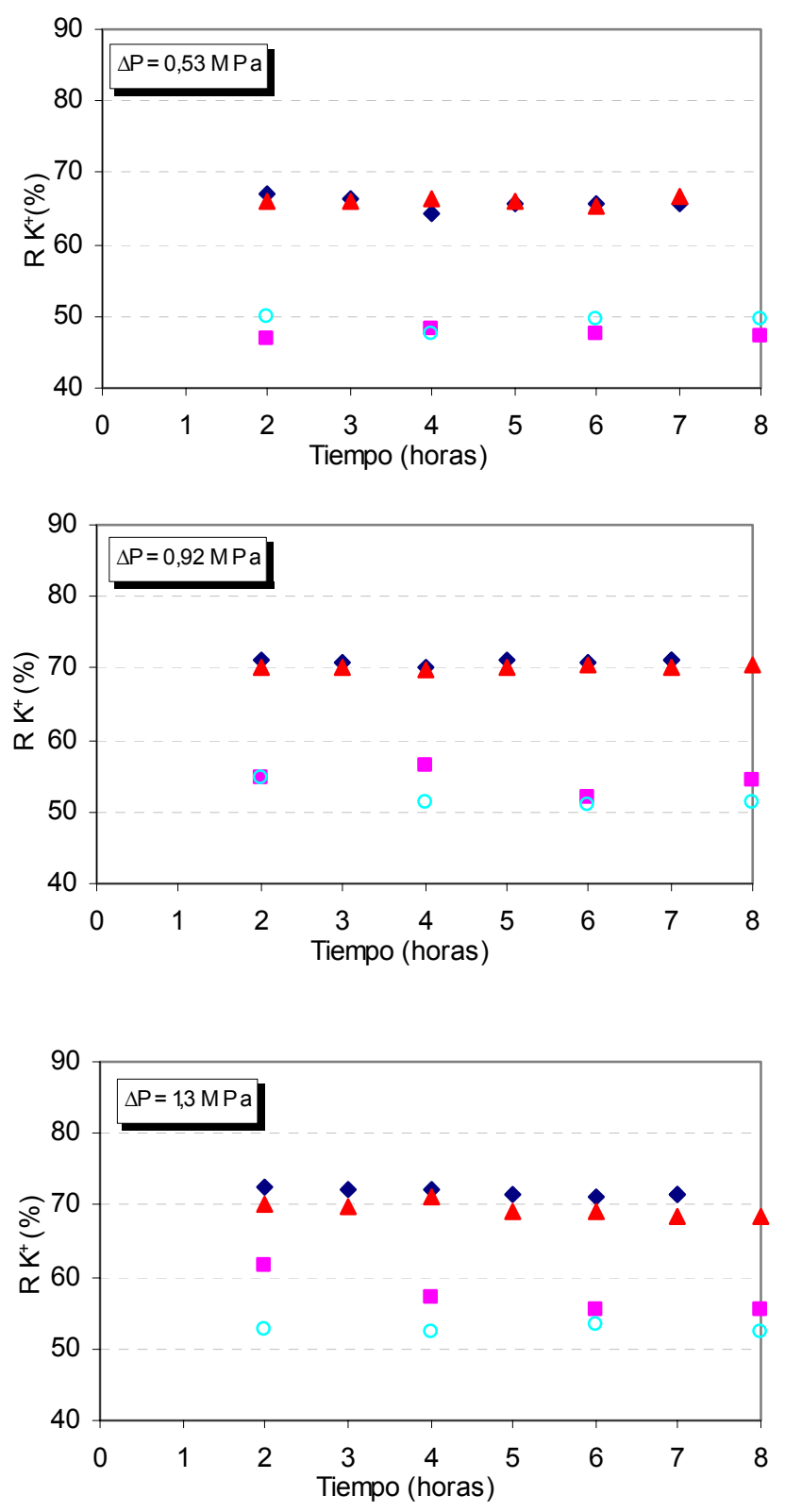

Figura 6.11. Variación de R K+, módulo plano. Mezcla de sales $\triangle N F 200 \triangleleft N F 270$ Ds-5DL $\square \mathrm{Ds}-5 \mathrm{DK}, \mathrm{T}=22 \pm 1^{\circ} \mathrm{C}, \mathrm{V}_{\text {tang }}=2,04 \mathrm{~m} / \mathrm{s}$ 

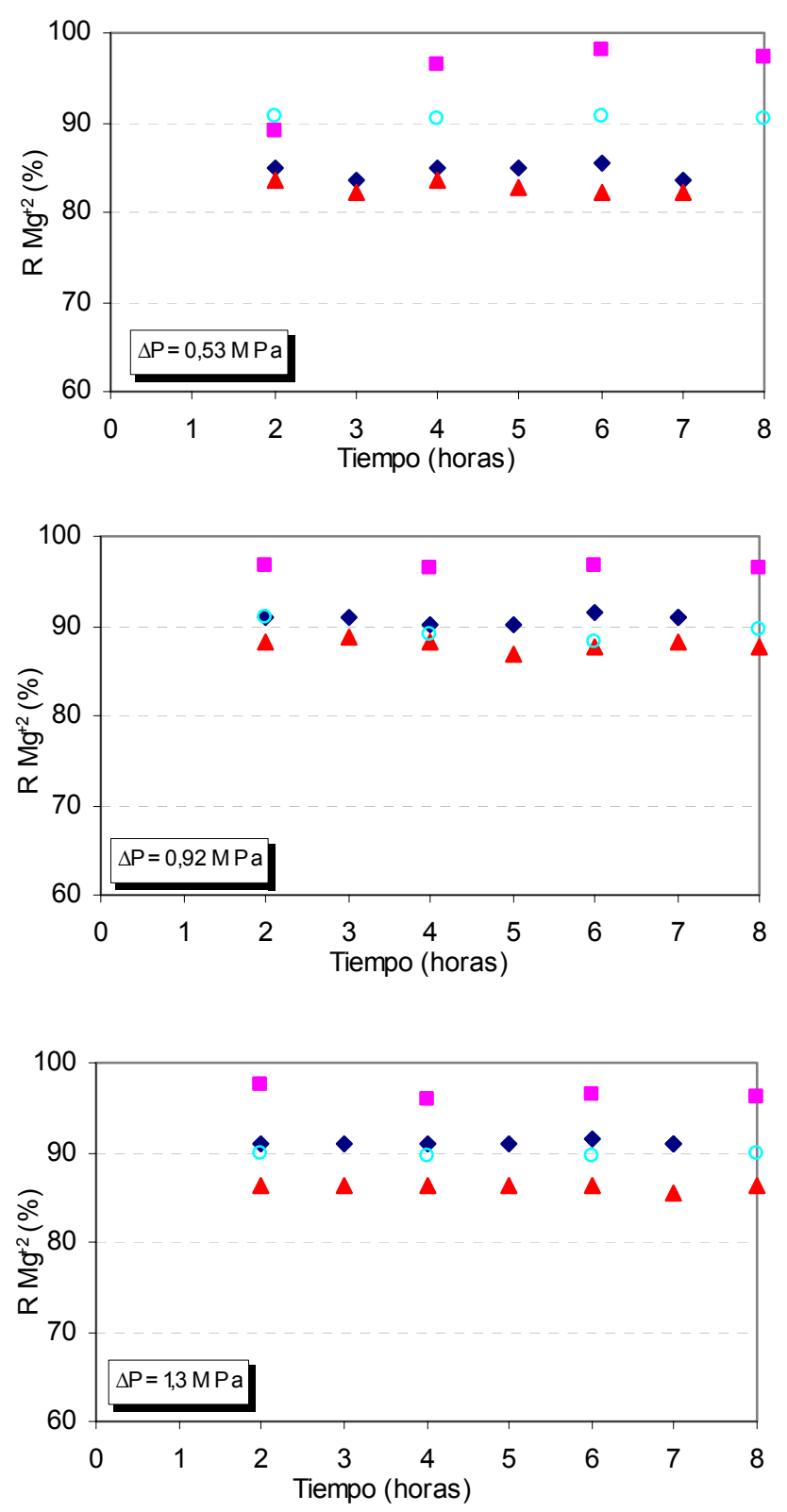

Figura 6.12. Variación de $\mathrm{R} \mathrm{Mg}^{+2}$, módulo plano. Mezcla de sales $\triangle N F 200$ NF270 oDs-5DL $\because \mathrm{Ds}-5 \mathrm{DK}, \mathrm{T}=22 \pm 1^{\circ} \mathrm{C}, \mathrm{V}_{\text {tang }}=2,04 \mathrm{~m} / \mathrm{s}$ 

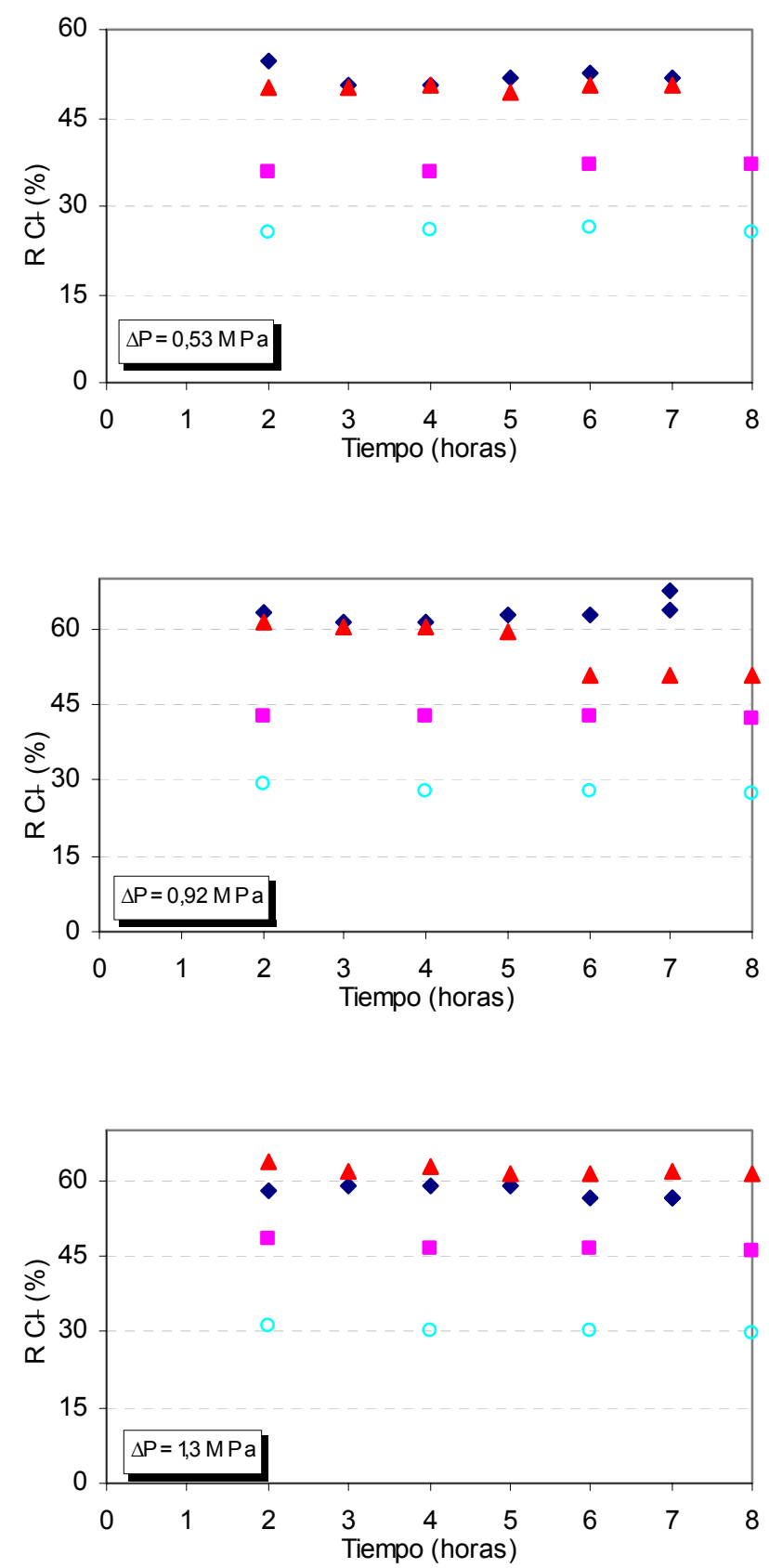

Figura 6.13. Variación de $\mathrm{R} \mathrm{Cl}^{-}$, módulo plano. Mezcla de sales $\triangle N F 200 \bullet N F 270$ Ds-5DL $\backsim \mathrm{Ds}-5 \mathrm{DK}, \mathrm{T}=22 \pm 1^{\circ} \mathrm{C}, \mathrm{V}_{\text {tang }}=2,04 \mathrm{~m} / \mathrm{s}$ 
Para el ión sulfato, los resultados obtenidos se muestran en la figura 6.14, de todas las membranas ensayadas son las membranas Ds-5 las que presentan los valores más altos de índice de rechazo respecto de las NF200 y NF270. Los índices de rechazo varían entre el 94-99\%. 

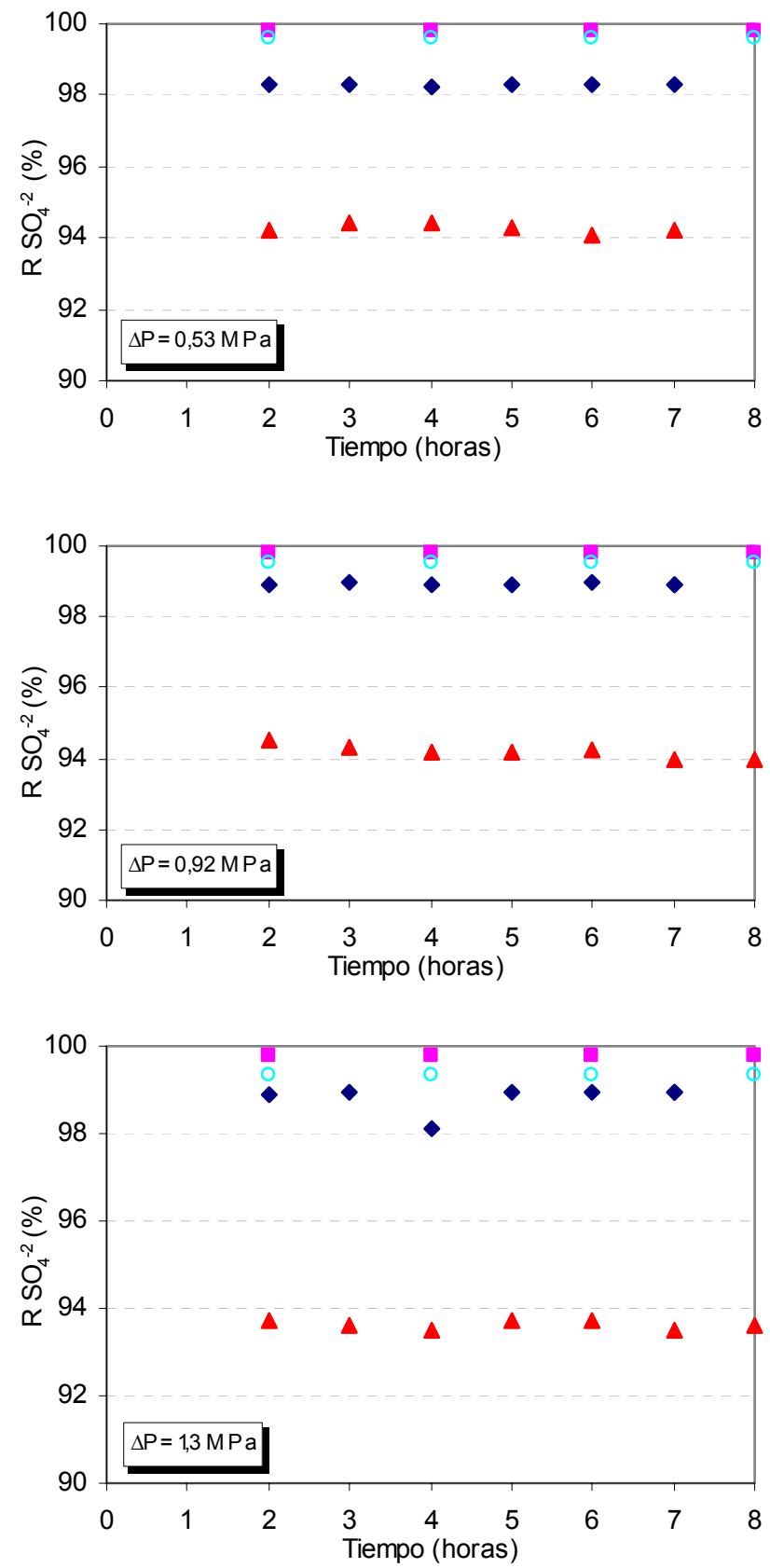

Figura 6.14. Variación de $\mathrm{R} \mathrm{SO}_{4}^{-2}$, módulo plano. Mezcla de sales $\triangle N F 200 \backsim N F 270$ Ds-5DL $\square$ Ds-5 DK, T $=22 \pm 1{ }^{\circ} \mathrm{C}, V_{\text {tang }}=2,04 \mathrm{~m} / \mathrm{s}$ 


\subsubsection{Influencia de la presión sobre la densidad de flujo de permeado y el índice de rechazo}

\subsubsection{Disolución modelo de sales individuales}

\section{Densidad de flujo de permeado}

En la figura 6.15 ( $a, b, c$ y d) se representan los valores de densidad de flujo obtenidos para las diferentes presiones aplicadas con cada una de las membranas NF200, NF270, Ds-5 DK y Ds-5 DL. A partir de dichos resultados se pueden hacer las siguientes observaciones.

La presión aplicada y la densidad de flujo son directamente proporcionales siempre que se opera a concentración constante. Este incremento se produce para cada una de las disoluciones de sales analizadas dentro del rango de presiones utilizadas.

En el caso de las disoluciones de cloruro de sodio y lactosa, bajo las mismas condiciones de operación, tal como se muestra en la figura 6.15 la densidad de flujo es ligeramente mayor para la membrana NF 200 que para la NF 270. Mientras que, la membrana NF270 presenta mayor densidad de flujo que la membrana NF200, con las disoluciones de cloruro potásico y sulfato magnésico.

La mayor densidad de flujo se obtiene para la disolución de cloruro de sodio con la membrana NF 200 (253 L/m²h) y la menor densidad 
de flujo se obtiene con las membranas NF200 y NF270 para la disolución de lactosa ( 110 y $95 \mathrm{~L} / \mathrm{m}^{2} \mathrm{~h}$ respectivamente).

En el caso de las membranas Ds-5 y las mismas condiciones de operación, la densidad de flujo es mayor para la membrana DL en comparación con la DK, lo cual cabía esperar pues la membrana DL, según las especificaciones técnicas posee mayor densidad de flujo. Para las disoluciones de cloruro de potasio y sulfato de magnesio, las densidades de flujo son bastantes parecidas. Con la membrana DK la mayor densidad de flujo se obtiene con las disoluciones de cloruro de potasio y sulfato de magnesio y la menor densidad de flujo con la disolución de cloruro de sodio.

A la máxima presión aplicada la diferencia de la densidad de flujo entre las membranas NF200 y NF270 no es significativa, presentando la máxima variación entorno al $7 \%$ con la disolución de cloruro de sodio ( $1.200 \mathrm{mg} / \mathrm{L})$, dicha diferencia no es significativa, tal como se aprecia en la figura 6.15.

A la máxima presión aplicada las densidades de flujo entre las membranas NF200, NF270, así como entre las membranas Ds-5 DK y Ds-5 DL son del $15 \%$ respectivamente con la disolución de cloruro de potasio (2000 mg/L). Dicha diferencia es significativa, sin embargo conviene destacar que en la ficha técnica de las membranas, las densidades de flujo para elementos individuales de una membrana pueden variar en este porcentaje, haciendo esta diferencia no significativa. 
Densidades de flujo similares se obtienen con las membranas de la serie NF (NF200, NF270), así como entre las membranas de la serie Ds5 (Ds-5 DK y Ds-5 DL) con las disoluciones de cloruro de potasio y sulfato de magnesio respecto a la densidad de flujo a la máxima presión, siendo la diferencia entre las densidades de flujo del 15\% para las membranas de la misma serie. Estas diferencias se encuentran dentro de los márgenes de variación dados por el fabricante.

La diferencia de densidad de flujo a la máxima presión aplicada, con las membranas NF200 y NF270, con la disolución de lactosa (5\%), presenta el mismo comportamiento que la de cloruro de potasio y la de sulfato de magnesio, del 15\%, dicha diferencia no es significativa, por las razones expuestas anteriormente. Sin embargo las membranas Ds-5 Dk y Ds-5 DL presentan valores muy similares, no notándose diferencias en este aspecto.

Bajo las mismas condiciones de operación y con las membranas Ds-5 DK y Ds-5 DL, la densidad de flujo más baja se obtuvo con la disolución de cloruro de sodio y la más alta con la disolución de sulfato de magnesio. Sin embargo comparando las densidades de flujo entre todas las membranas estudiadas la membrana NF200 presenta densidades de flujo muy superiores a las obtenidas por las membranas Ds-5 DK y Ds-5 DL. 


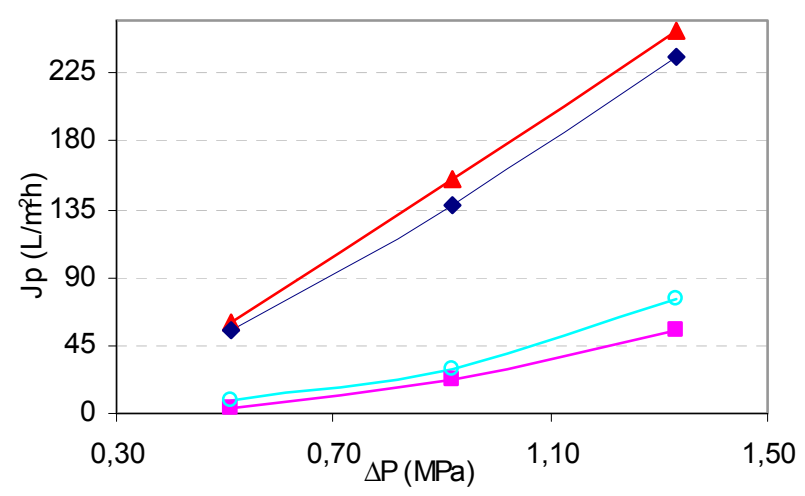

Figura 6.15a. Disolución de $1.200 \mathrm{mg} \mathrm{NaCl} / \mathrm{L}$

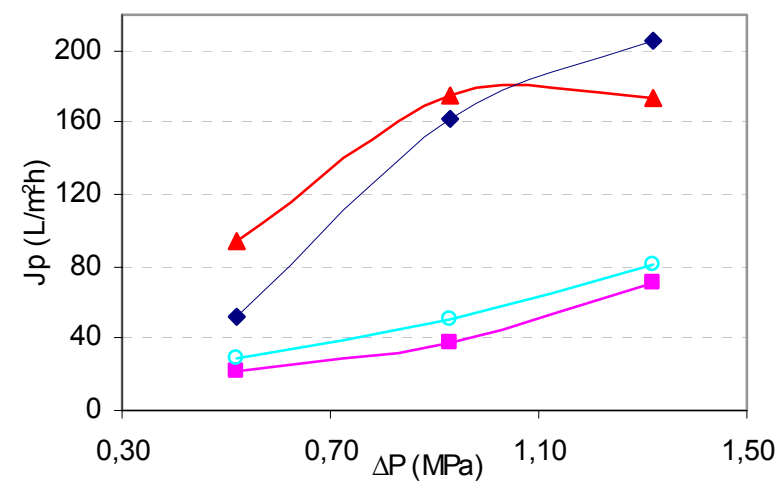

Figura 6.15b. Disolución de $2000 \mathrm{mg} \mathrm{KCl} / \mathrm{L}$

$\triangle N F 200 \backsim N F 270$ Ds-5DL $\square \mathrm{Ds}-5 \mathrm{DK}, \mathrm{T}=22 \pm 1^{\circ} \mathrm{C}, \mathrm{V}_{\text {tang }}=2,04 \mathrm{~m} / \mathrm{s}$ 


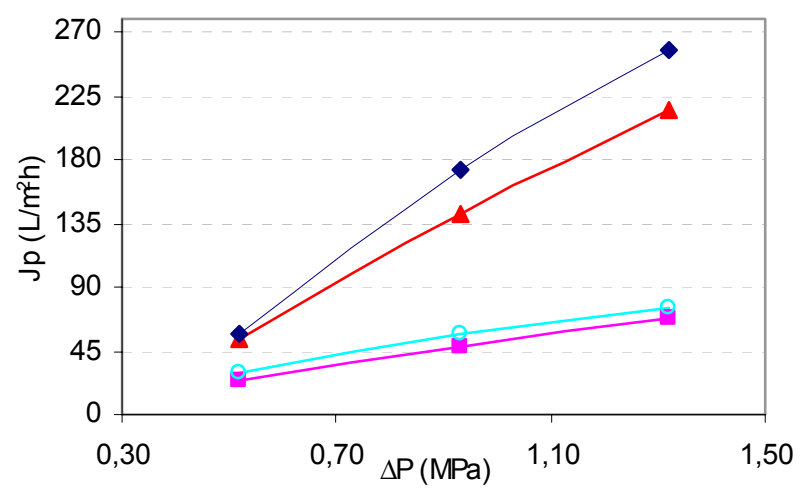

Figura 6.15c. Disolución de $750 \mathrm{mg} \mathrm{MgSO} 4 / \mathrm{L}$

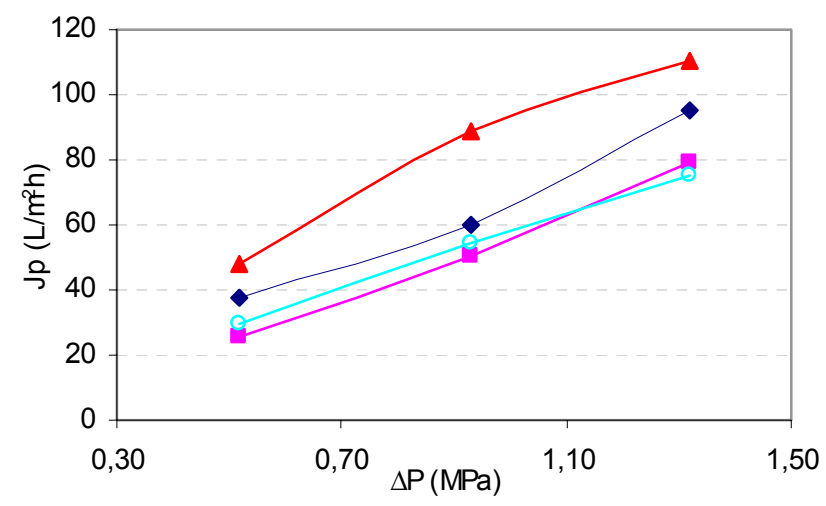

Figura 6.15d. Disolución de $50 \mathrm{~g}$ lactosa/L

Figura 6.15. Evolución de la Jp con la presión, módulo plano.

$\triangle N F 200$-NF270 oDs-5DL $\backsim D s-5 D K, T=22 \pm 1^{\circ} \mathrm{C}, V_{\text {tang }}=2,04 \mathrm{~m} / \mathrm{s}$ 
En la tabla 6.1, se muestran los valores de la densidad de flujo y la presión osmótica de cada una de las disoluciones modelo para todos los intervalos de presión.

Tabla 6.1. Resumen de $J_{p}$ y $\Delta \pi$ de las sales individuales.

\begin{tabular}{llcccccccc}
\hline $\begin{array}{l}\Delta \mathrm{P} \\
(\mathrm{MPa})\end{array}$ & Membrana & \multicolumn{2}{c}{ Lactosa } & \multicolumn{2}{c}{$\mathrm{KCl}$} & \multicolumn{2}{c}{$\mathrm{NaCl}$} & \multicolumn{2}{c}{$\mathrm{MgSO}_{4}$} \\
& & $\begin{array}{c}\mathrm{J}_{\mathrm{p}} \\
\left(\mathrm{L} / \mathrm{m}^{2} \mathrm{~h}\right)\end{array}$ & $\begin{array}{c}\Delta \pi \\
(\mathrm{MPa})\end{array}$ & $\begin{array}{c}\mathrm{J}_{\mathrm{p}} \\
\left(\mathrm{L} / \mathrm{m}^{2} \mathrm{~h}\right)\end{array}$ & $\begin{array}{c}\Delta \pi \\
(\mathrm{MPa})\end{array}$ & $\begin{array}{c}\mathrm{J}_{\mathrm{p}} \\
\left(\mathrm{L} / \mathrm{m}^{2} \mathrm{~h}\right)\end{array}$ & $\begin{array}{c}\Delta \pi \\
(\mathrm{MPa})\end{array}$ & $\begin{array}{c}\mathrm{J}_{\mathrm{p}} \\
\left(\mathrm{L} / \mathrm{m}^{2} \mathrm{~h}\right)\end{array}$ & $\begin{array}{c}\Delta \pi \\
(\mathrm{MPa})\end{array}$ \\
\hline 0,53 & $\mathrm{NF200}$ & 47,72 & 0,335 & 84,05 & 0,058 & 60,35 & 0,025 & 52,54 & 0,031 \\
0,53 & $\mathrm{NF270}$ & 37,39 & 0,334 & 51,68 & 0,071 & 55,11 & 0,023 & 56,62 & 0,030 \\
0,53 & Ds-5 DK & 25,87 & 0,331 & 21,11 & 0,047 & 12,04 & 0,030 & 24,44 & 0,031 \\
0,53 & Ds-5 DL & 29,94 & 0,328 & 28,40 & 0,039 & 16,48 & 0,024 & 28,80 & 0,031 \\
& & & & & & & & & \\
0,92 & $\mathrm{NF200}$ & 88,57 & 0,333 & 175,27 & 0,070 & 155,29 & 0,032 & 142,74 & 0,031 \\
0,92 & $\mathrm{NF270}$ & 60,12 & 0,331 & 162,63 & 0,077 & 138,06 & 0,033 & 173,28 & 0,030 \\
0,92 & Ds-5 DK & 50,54 & 0,331 & 38,21 & 0,056 & 21,79 & 0,037 & 48,28 & 0,031 \\
0,92 & Ds-5 DL & 54,27 & 0,330 & 50,03 & 0,046 & 29,04 & 0,029 & 56,30 & 0,031 \\
& & & & & & & & & \\
1,33 & NF200 & 110,50 & 0,333 & 173,80 & 0,080 & 253,71 & 0,031 & 215,81 & 0,032 \\
1,33 & NF270 & 95,10 & 0,335 & 205,09 & 0,071 & 235,87 & 0,032 & 258,52 & 0,031 \\
1,33 & Ds-5 DK & 79,19 & 0,331 & 70,42 & 0,064 & 55,52 & 0,044 & 67,55 & 0,031 \\
1,33 & Ds-5 DL & 75,14 & 0,330 & 80,88 & 0,050 & 74,98 & 0,034 & 76,02 & 0,031 \\
\hline
\end{tabular}

La presión transmembranal y la osmótica están relacionadas por la siguiente ecuación:

$$
J_{p}=L_{p} \cdot(\Delta P-\Delta \pi)
$$

Donde: $L_{p}$ es el coeficiente de permeabilidad al agua de la membrana. Esta ecuación muestra la densidad de flujo como función de la presión transmembranal y la presión osmótica.

La presión osmótica, tal como se ha descrito en el apartado 4.28 depende tanto de la concentración del soluto en la disolución, como de la masa molecular del mismo. Un incremento de la presión osmótica, supone una disminución de la densidad de flujo. 
En este sentido, teniendo en cuenta ambos parámetros, se ha obtenido la siguiente secuencia de las diferentes disoluciones:

$$
\Delta \pi\left(\text { Lactosa }>\mathrm{KCl}>\mathrm{MgSO}_{4}>\mathrm{NaCl}\right)
$$

\section{Índice de rechazo}

En la figura 6.16 (a, b, c, d) se pueden observar los valores obtenidos del índice de rechazo para cada una de las sales estudiadas. En esta gráfica se puede apreciar un comportamiento similar para los electrolitos individuales, observándose que el índice de rechazo aumenta con la presión aplicada para todas las membranas estudiadas. Excepto para las membranas NF200 y NF270 con la disolución de cloruro sódico, donde los índices de rechazo fueron muy similares para los dos últimos valores de presión, tal como se aprecia en al figura 6.16.a.

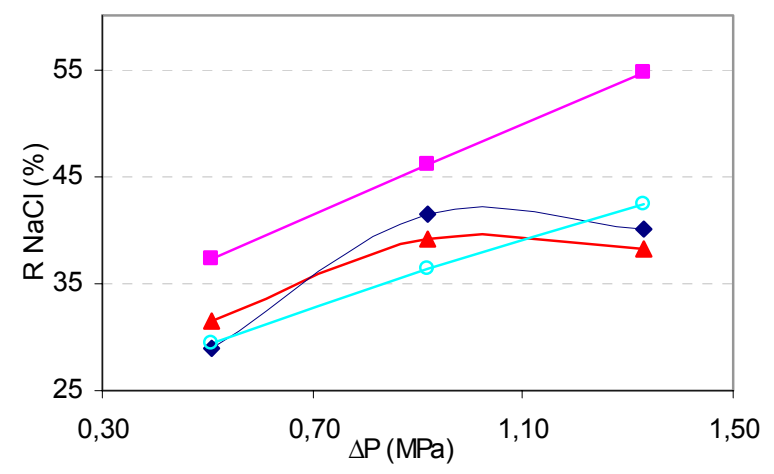

Figura 6.16a. Disolución de $1.200 \mathrm{mg} \mathrm{NaCl} / \mathrm{L}$ 


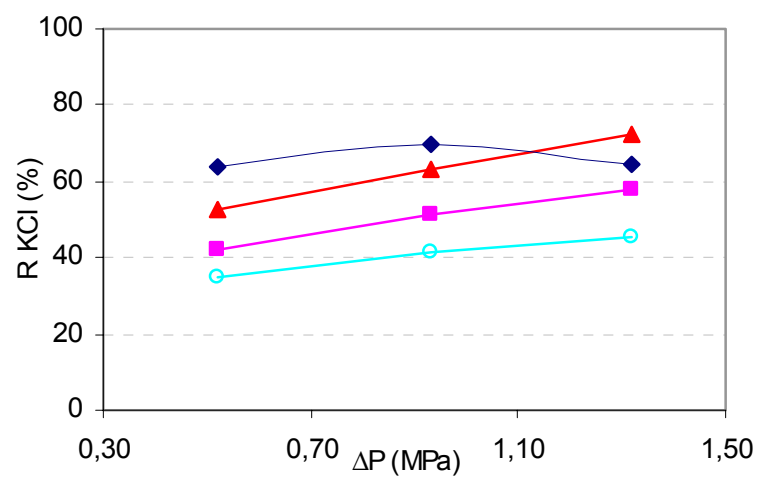

Figura 6.16b. Disolución de $2.000 \mathrm{mg} \mathrm{KCl} / \mathrm{L}$

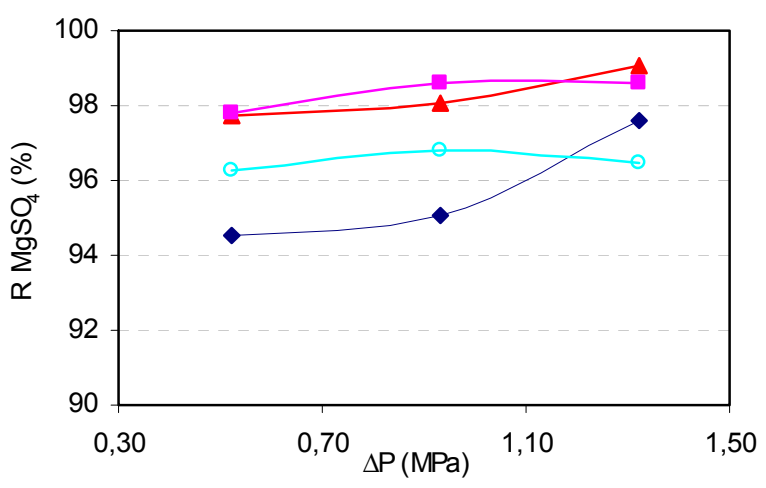

Figura 6.16c. Disolución de 750mg $\mathrm{MgSO}_{4} / \mathrm{L}$

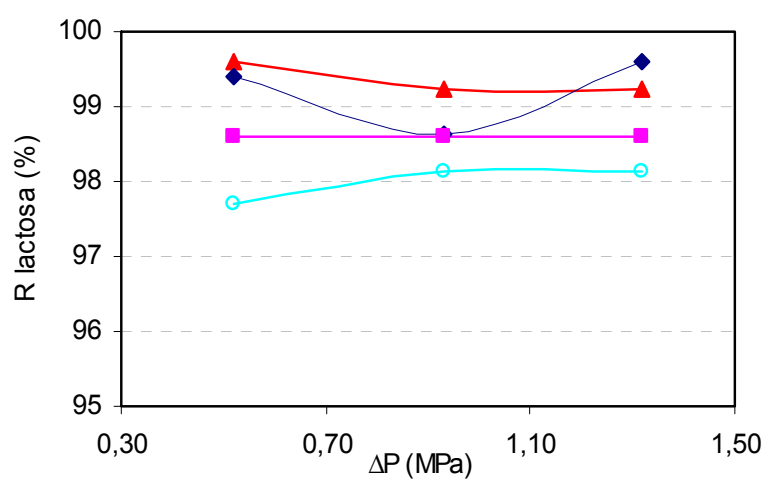

Figura 6.16d. Disolución de $50 \mathrm{~g}$ lactosa/L

Figura 6.16. Variación de R. Sales individuales

$\triangle N F 200 \backsim N F 270$ oDs-5DL $\square \mathrm{Ds}-5 \mathrm{DK}, \mathrm{T}=22 \pm 1^{\circ} \mathrm{C}, \mathrm{V}_{\text {tang }}=2,04 \mathrm{~m} / \mathrm{s}$ 
La ligera tendencia del índice de rechazo a disminuir en algunos casos, puede ser que el paso de soluto (Js), va aumentando hasta compensarse con el paso de disolvente (JW). Este paso de soluto, puede verse favorecido por el aumento de la deformación elástica de los microporos.

Según los resultados de las figuras 6.16 (a, b, c, d) se tiene la siguiente secuencia respecto al índice de rechazo:

$$
\mathrm{R} \text { Lactosa } \approx \mathrm{R} \mathrm{MgSO}_{4}>\mathrm{R} \mathrm{KCL}>\mathrm{R} \mathrm{NaCl}
$$

Estos resultados están de acuerdo con los principios de transporte que gobiernan el proceso de nanofiltración, donde las membranas tienen una alta capacidad para retener moléculas orgánicas, así como iones divalentes frente a los monovalentes. Una secuencia similar también fue obtenida por Wang et al (2002) con la membrana NF45, con ligeras diferencias respecto a las disoluciones de cloruro de sodio y de potasio, pues estos autores obtuvieron el mismo orden de magnitud, comentando que era debido a las repulsiones electrostáticas entre los electrolitos y la carga de la membrana. Sin embargo esta explicación no es del todo completa, pues además de estas interacciones, los efectos estéricos también ejercen un efecto importante sobre el índice de rechazo, ya que el transporte de estos dos electrólitos esta altamente influenciado por sus entalpías de hidratación. La entalpía de hidratación del cloruro de potasio es menor $(-700 \mathrm{~kJ} / \mathrm{mol})$ que la del cloruro de sodio $(-783 \mathrm{~kJ} / \mathrm{mol})$, con lo cual cabria esperar una ligera diferencia respecto a sus índices de rechazo, siendo el del cloruro de potasio mayor a el del cloruro de sodio. 
El índice de rechazo aumenta y luego disminuye con la presión aplicada, tal como se aprecia en la figura 6.16a, 6.16b. Esto puede deberse a que las interacciones electrostáticas de los iones entre si reducen el potencial químico de estos iones generando una disminución en su índice de rechazo (Teoría de Debye-Hückel). Resultados similares también han sido obtenidos por Pontalier et al, 1999 y Paugam et al, 2004. Estos autores comentan que este incremento del rechazo con la presión se debe a que los solutos son retenidos por las fuerzas superficiales y estas fuerzas son independientes de la presión aplicada. Las fuerzas de superficie pueden ser insignificantes hasta un valor límite de presión.

Mucchetti et al, 2000, ensayaron membranas de nanofiltración con una disolución de lactosa de concentración $45 \mathrm{~g} / \mathrm{L}$, en el rango de presiones de 0,9 a 1,5 MPa, obteniendo índices de rechazo entorno al 95\%. Al comparar estos resultados con los obtenidos en esta tesis, se puede observar que los rechazos alcanzados en la misma son más altos y además presentan menores pérdidas de lactosa que los obtenidos por Mucchetti.

\subsubsection{Disolución modelo de la mezcla de sales minerales}

La disolución alimento utilizada para este apartado contiene los componentes iónicos representativos de un suero lácteo dulce. Su composición se presenta en la tabla 6.2. 
Tabla 6.2 . Composición de la disolución alimento, $\mathrm{pH}=6,51 ; \kappa=5,98$ $\mathrm{mS} / \mathrm{cm}$

\begin{tabular}{lc}
\hline lón & $\mathrm{mg} / \mathrm{L}$ \\
\hline $\mathrm{Na}+$ & 476,00 \\
$\mathrm{~K}^{+}$ & $1.043,20$ \\
$\mathrm{Cl}^{-}$ & $1.700,00$ \\
$\mathrm{Mg}^{2+}$ & 147,77 \\
$\mathrm{SO}_{4}^{2-}$ & 600,23 \\
\hline
\end{tabular}

\section{Densidad de flujo de permeado}

En la figura 6.17, se representa la densidad de flujo de permeado de las cuatro membranas ensayadas con dicha disolución como alimento modelo. La diferencia de densidad de flujo a la máxima presión aplicada con cada una de las membranas estudiadas presenta la misma tendencia que la mostrada con cada una de las sales estudiadas de forma individual. Aquí concretamente cabe comentar que la diferencia en la densidad de flujo con las membranas de la serie NF es del $16 \%$, este mismo valor se obtiene al comparar las densidades de flujo de las membranas de la serie Ds-5. 


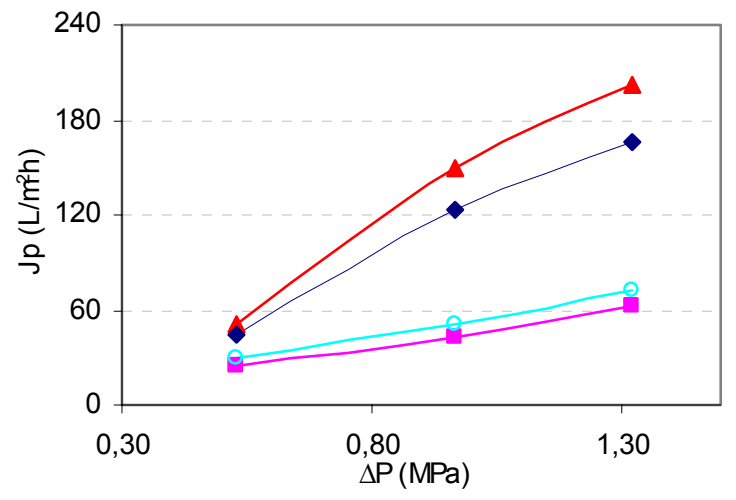

Figura 6.17. Variación de Jp con la presión. Mezcla de sales minerales $\triangle N F 200$ NF270 oDs-5DL $\| \mathrm{Ds}-5 \mathrm{DK}, \mathrm{T}=22 \pm 1^{\circ} \mathrm{C}, \mathrm{V}_{\text {tang }}=2,04 \mathrm{~m} / \mathrm{s}$

La densidad de flujo de permeado se incrementó con la presión transmembranal, tanto para las sales individuales como la mezcla de estas, siendo su comportamiento característico de todos los procesos de membranas. Sin embargo, los valores de densidad de flujo en la mezcla fueron ligeramente más bajos debido al efecto de la presión osmótica de la disolución, en los que ejerce una gran influencia la fuerza iónica de la disolución.

En la tabla 6.3, se puede observar que el incremento de la presión osmótica para cada una de las disoluciones es muy parecido en todos los intervalos de presión. Con lo cual puede decirse que los valores de densidades de flujo estarán más influenciados por la presión transmembranal que por la osmótica. 
Tabla 6.3. Densidades de flujo de la mezcla de sales minerales

\begin{tabular}{cccc}
\hline$\Delta \mathrm{P}(\mathrm{MPa})$ & Membrana & $\mathrm{Jp}_{\mathrm{p}}\left(\mathrm{L} / \mathrm{m}^{2} \mathrm{~h}\right)$ & $\begin{array}{c}\Delta \pi \\
(\mathrm{MPa})\end{array}$ \\
\hline 0,53 & $\mathrm{NF200}$ & 50,53 & 0,30 \\
0,53 & $\mathrm{NF270}$ & 43,73 & 0,31 \\
0,53 & Ds-5 DK & 25,48 & 0,27 \\
0,53 & Ds-5 DL & 29,43 & 0,25 \\
0,92 & $\mathrm{NF200}$ & 149,78 & 0,32 \\
0,92 & $\mathrm{NF270}$ & 123,70 & 0,34 \\
0,92 & Ds-5 DK & 42,25 & 0,29 \\
0,92 & Ds-5 DL & 50,93 & 0,26 \\
1,33 & $\mathrm{NF200}$ & 201,89 & 0,33 \\
1,33 & $\mathrm{NF270}$ & 166,27 & 0,33 \\
1,33 & Ds-5 DK & 62,75 & 0,30 \\
1,33 & Ds-5 DL & 72,94 & 0,26 \\
\hline
\end{tabular}

\section{Índice de rechazo}

Analizando los resultados obtenidos respecto de cada uno de los iones presenta, se observa que para el ión cloruro, el índice de rechazo obtenido es del 51\%, con la membrana NF200 a la presión más baja. Sin embargo, con la membrana Ds-5 DL este valor esta entorno al 30\%, tal como, puede apreciarse en la figura 6.18.a. 


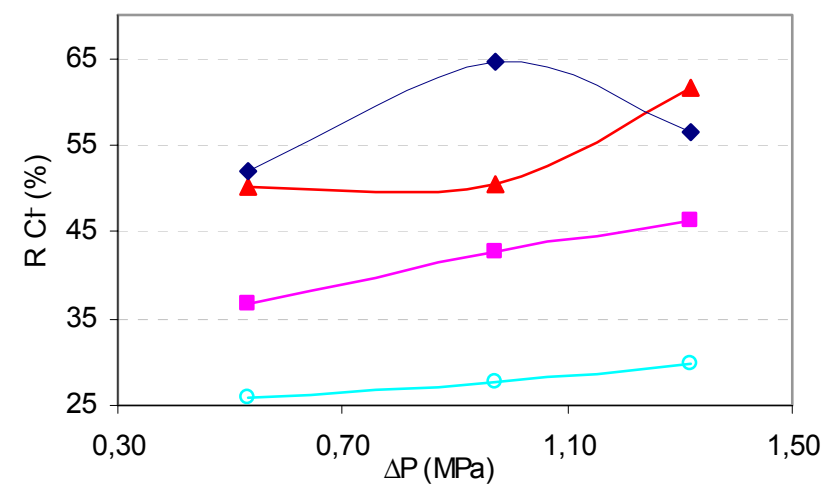

Figura 6.18a. Índice de rechazo del ión cloruro.

$\triangle N F 200 \backsim N F 270$ Ds-5DL $\square \mathrm{Ds}-5 \mathrm{DK}, \mathrm{T}=22 \pm 1^{\circ} \mathrm{C}, \mathrm{V}_{\text {tang }}=2,04 \mathrm{~m} / \mathrm{s}$

En la figura 6.18.b, se observa que el índice de rechazo del ión potasio obtenido esta entorno al $70 \%$, con las membranas de la serie NF. Sin embargo con las membranas de la serie Ds-5 está alrededor del $55 \%$.

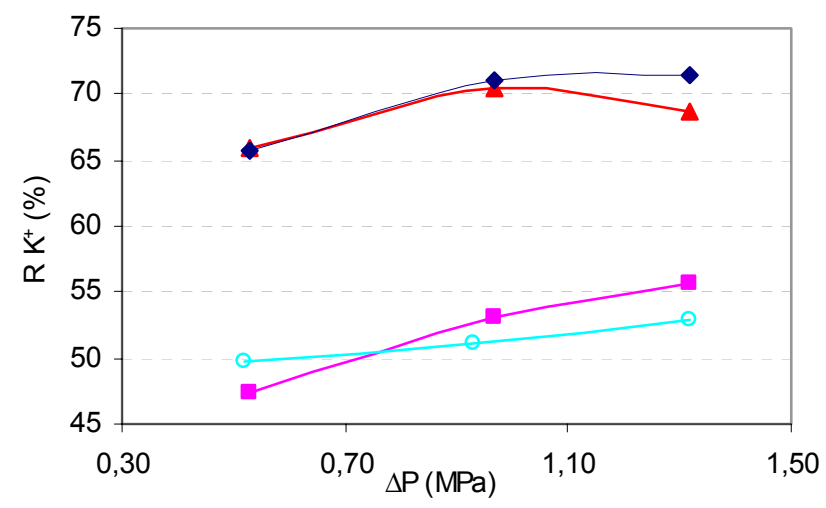

Figura 6.18b. Índice de rechazo del ión potasio.
a NF200
-NF270 Ds-5DL $=\mathrm{Ds}-5 \mathrm{DK}, \mathrm{T}=22 \pm 1{ }^{\circ} \mathrm{C}, \mathrm{V}_{\text {tang }}=2,04 \mathrm{~m} / \mathrm{s}$ 
Para el ión sodio el mayor índice de rechazo está entorno al 75\%, con la membrana NF 270. Mientras que, con la membrana Ds-5 DL este valor está alrededor del 65\%, tal como se muestra en la figura 6.18.c.

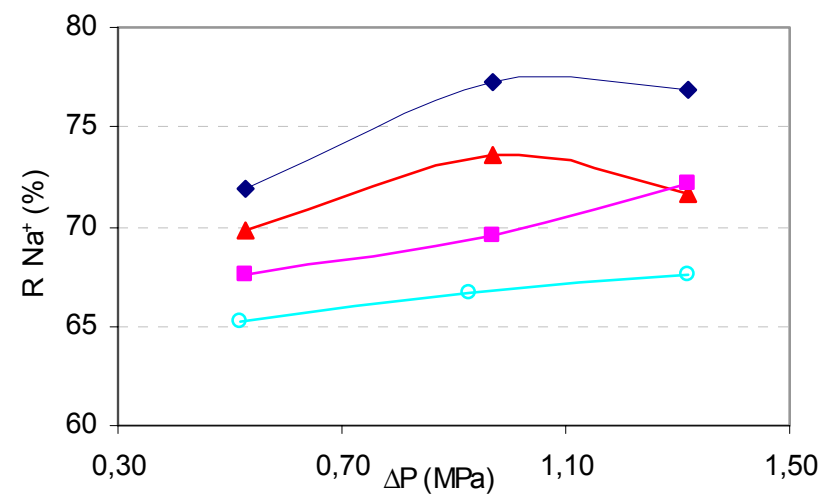

Figura 6.18c. Índice de rechazo de sodio.

$\triangle$ NF200 NF270 oDs-5DL Ds-5 DK, T $=22 \pm 1^{\circ} \mathrm{C}, V_{\text {tang }}=2,04 \mathrm{~m} / \mathrm{s}$

En la figura 6.18.d se muestra los índices de rechazo obtenidos para el ión magnesio, el valor mas bajo está entorno al 85\% (membrana NF200), con valores muy similares con las membranas de la serie NF. Para las membranas Ds-5 DK y Ds-5 DL este valor esta alrededor del 90\%. Las membranas de nanofiltración se caracterizan por presentar altos índices de rechazos de sales multivalentes.

En la figura 6.18.e, se observa que para el ión sulfato el índice de rechazo obtenido con la membrana NF200 está alrededor del 94\%, mientras que para la membrana NF270 está entorno al 98\%. Para las membranas de la serie Ds-5 está alrededor del 99\%. Estos valores son característicos de las membranas de nanofiltración, como se comentó anteriormente. 


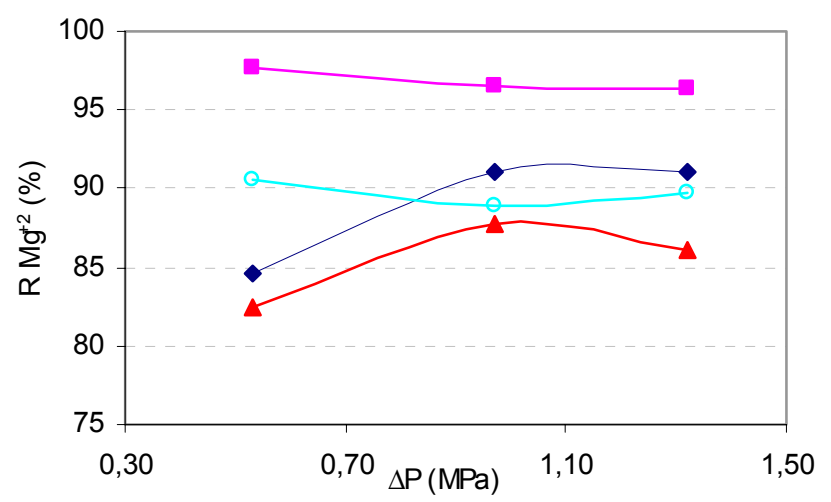

Figura 6.18d. Índice de rechazo del ión magnesio.

$\triangle N F 200$ NF270 oDs-5DL $\square \mathrm{Ds}-5 \mathrm{DK}, \mathrm{T}=22 \pm 1^{\circ} \mathrm{C}, \mathrm{V}_{\text {tang }}=2,04 \mathrm{~m} / \mathrm{s}$

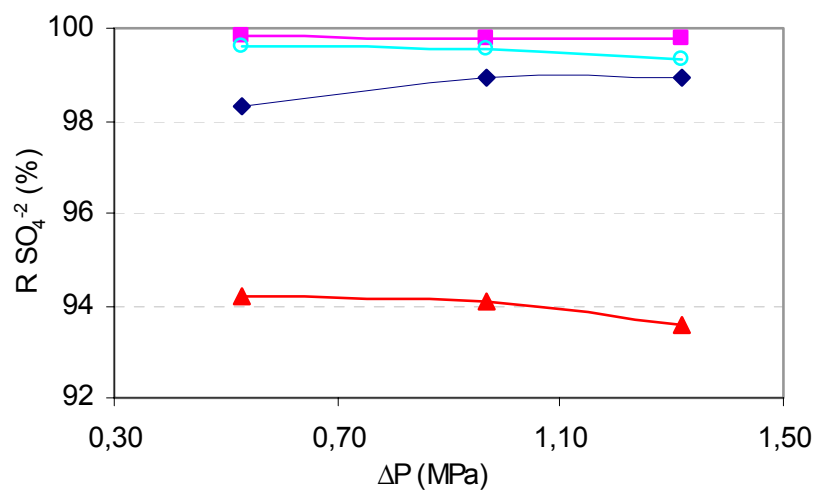

Figura 6.18e. Índice de rechazo de sulfato.

$\Delta$ NF200 NF270 DDs-5DL $\because \mathrm{Ds}-5 \mathrm{DK}, \mathrm{T}=22 \pm 1^{\circ} \mathrm{C}, \mathrm{V}_{\text {tang }}=2,04 \mathrm{~m} / \mathrm{s}$

Figura 6.18. Variación del Índice de rechazo. Mezcla de sales

En general se puede decir, que en todos los casos los índices de rechazo con la disolución modelo de sales son mayores a los obtenidos con las disoluciones individuales. Esto puede deberse al efecto de los iones divalentes sobre los monovalentes. Además, para 
mantener el principio de electroneutralidad (equilibrio Donnan), es necesario que una mayor proporción de iones monovalentes sean rechazados para contrarrestar el efecto del sulfato y del magnesio que quedan retenidos en la corriente de concentrado.

La serie liotrópica (Sourirajan, 1970) predice que el rechazo de cationes, se puede comportar de acuerdo a la siguiente secuencia: $\mathrm{Mg}^{2+}>\mathrm{Na}^{+}>\mathrm{K}^{+}$.

De modo similar para los aniones, el rechazo se comportaría de la siguiente manera: $\mathrm{SO}_{4}^{2-} \mathrm{Cl}^{2}$. (Sourirajan, 1970)

Algunos autores han observado excepciones a la secuencia de estas series al trabajar con ciertos solutos. Además, este orden puede no darse, si hay interacciones de los iones, formación de complejos, además de interacciones disolución-soluto, soluto-soluto y solutomembrana.

Si se consideran los efectos estéricos, característicos de las membranas de nanofiltración debido al tamaño de sus poros, los radios iónicos, así como los radios de hidratación (tamaño efectivo de un ión en una disolución acuosa) de cada uno de los solutos, estos pueden influir en el orden de las secuencias presentadas anteriormente. A continuación en la tabla 6.4, se muestra la relación entre los radios hidratados, las entalpías de hidratación, así como los índices de rechazo obtenidos con cada uno de los cationes ensayados. 
Tabla 6.4. Pesos atómicos, radios iónicos y entalpías de hidratación de cationes.

\begin{tabular}{lcccccc}
\hline \multirow{2}{*}{ lón } & $\begin{array}{c}\text { Peso } \\
\text { atómico } \\
(\mathrm{g} / \mathrm{mol})\end{array}$ & \multirow{2}{*}{$\begin{array}{c}\text { Radio iónico } \\
(\mathrm{nm})\end{array}$} & $\begin{array}{c}\text { Radio } \\
\text { hidratado } \\
(\mathrm{nm})\end{array}$ & \begin{tabular}{c} 
Entalpía de \\
hidratación \\
\cline { 7 - 8 }
\end{tabular} & & \multicolumn{2}{c}{$\mathrm{KJ} / \mathrm{mol})$} & $\mathrm{NF} 200-270$ & $\mathrm{Ds}-5$ \\
\hline $\mathrm{K}^{+}$ & 39 & 0,133 & 0,331 & -324 & $65-70$ & $45-55$ \\
$\mathrm{Na}^{+}$ & 23 & 0,095 & 0,358 & -407 & $70-77$ & $65-75$ \\
$\mathrm{Mg}^{+2}$ & 24 & 0,065 & 0,428 & -1931 & $82-91$ & $90-97$ \\
\hline
\end{tabular}

Analizando la tabla anterior, se puede inferir que el efecto del radio iónico sobre el radio hidratado, la entalpía de hidratación, así como el índice de rechazo presenta una relación inversa. Puede pensarse que el ión con el menor radio iónico pasará preferentemente a través de los poros de la membrana y el de mayor radio iónico será el más rechazado. Sin embargo sucede todo lo contrario, pues los iones al estar en un medio acuoso se solvatan, atrayendo más moléculas de agua el ión de mayor valencia y aumentando de esta forma su radio de hidratación.

Lo contrario sucede con iones de radios mayores, pues al ser su densidad de carga más difusa, atrae menos moléculas de agua y disminuye su radio de hidratación. El ión con mayor radio de hidratación; es decir con la mayor energía de hidratación es el que presenta el índice de rechazo más alto. Pues a mayor entalpía de hidratación (mayor tendencia de hidratación) mayor índice de rechazo.

En la tabla 6.5 se muestran los resultados obtenidos para los aniones, sobre los que se puede hacer un análisis similar al anterior. 
Tabla 6.5. Pesos atómicos, radios iónicos y entalpías de hidratación de aniones.

\begin{tabular}{|c|c|c|c|c|c|c|}
\hline \multirow{2}{*}{ lón } & \multirow{2}{*}{$\begin{array}{c}\text { Peso } \\
\text { atómico } \\
\text { (gr/mol) }\end{array}$} & \multirow{2}{*}{$\begin{array}{l}\text { Radio } \\
\text { iónico } \\
(\mathrm{nm}) \\
\end{array}$} & \multirow{2}{*}{$\begin{array}{c}\text { Radio } \\
\text { hidratado } \\
(\mathrm{nm})\end{array}$} & \multirow{2}{*}{$\begin{array}{c}\text { Entalpía de } \\
\text { hidratación } \\
\mathrm{KJ} / \mathrm{mol}\end{array}$} & \multicolumn{2}{|c|}{$R(\%)$} \\
\hline & & & & & NF 200-270 & Ds-5 \\
\hline $\mathrm{Cl}^{-}$ & 35 & 0,181 & 0,332 & -376 & $50-62$ & $25-45$ \\
\hline $\mathrm{SO}_{4}^{-2}$ & 96 & 0,230 & 0,379 & -1138 & $94-99$ & 99 \\
\hline
\end{tabular}

El radio hidratado (directamente proporcional a la entalpía de hidratación) tiene gran influencia sobre la selectividad de la membrana, pero no es el único factor a considerar, pues las fuerzas de superficie y las interacciones electrostáticas también influyen sobre el mecanismo de transporte.

Se puede observar que el ión sodio presenta un incremento en el índice de rechazo, superior al conseguido cuando la sal de cloruro de sodio fue tratada como único soluto en el alimento. Este mismo comportamiento se obtiene con cada una de las membranas estudiadas y los iones de magnesio y cloruro. Sin embargo, los valores respecto al ión potasio y sulfato permanecen casi invariables. El índice de rechazo para el ión sodio pasa del $40 \% \mathrm{R} \mathrm{NaCl}$ (sales individuales) al $70 \% \mathrm{R} \mathrm{Na}^{+}$aproximadamente (mezcla de sales). En el caso del magnesio varia del $98 \% R \quad \mathrm{MgSO}_{4}$ al $88 \% \mathrm{R} \quad \mathrm{Mg}^{+2}$ aproximadamente para todas las membranas excepto con la membrana Ds-5 DK, donde se observa que no hay una variación significativa entre la sal individual y la de la mezcla de sales.

Con la membrana NF270 se observa, una disminución anómala del índice de rechazo del ión cloruro fue observada cuando se incrementa la presión transmembranal de 0,95 MPa a 1,3 MPa. Este 
hecho puede explicarse a las posibles interacciones electrostáticas entre el ión cloruro y otros iones de la disolución, reduciéndose el potencial químico del ión cloruro (Teoría de Debye-Hückel). Otros autores (XU X et al, 1997 y Paugam L., 2004) también han observado este comportamiento, al estudiar disoluciones con elevadas concentraciones de nitratos. Xu et al, atribuyen este comportamiento al aumento del fenómeno de polarización por concentración por efecto del incremento de la presión y las bajas velocidades tangenciales empleadas.

En el caso de los aniones, el índice de rechazo está entorno al 34\% para el ión cloruro y entorno al $94 \%$ para el ión sulfato. Con los cationes el índice de rechazo fue de un 53\% para el potasio, seguido del sodio con un $67 \%$ y del magnesio con un $90 \%$. Estos resultados están de acuerdo con la serie liotrópica predicha por Sourirajan y la entalpía de hidratación de los iones.

Además de la influencia de la presión sobre el índice de rechazo, otro factor a considerar es el pH de la disolución alimento. Varios investigadores han coincidido sobre este hecho. Todos están de acuerdo en que si el pH de la disolución está por encima del punto isoeléctrico (PIE) de la membrana, la carga de ésta es negativa, si por el contrario el pH de la disolución está por debajo del PIE, la carga de la membrana será positiva y si el pH de la disolución coincide con el PIE de la membrana, la carga de ésta será neutra. (Tanninen et al, 2002; Freger et al, 2000; Hagmeyer et al, 1998). Además de estas consideraciones Labbez et al (2003) sugieren que la adsorción de ciertos iones también puede afectar la carga de la membrana. 
Teniendo en cuenta las referencias bibliográficas y los datos suministrados por el fabricante, la membrana NF200 y NF270 tiene su PIE a pH de 4,3 (suministrado por el fabricante). Para la membrana Ds-5 su PIE está entorno pH =4,0. (Freger et al, 2000 y Hagmeyer et al, 1998).

En esta tesis al trabajar con un pH de 6,51 para la disolución de la mezcla de sales (que se corresponde con el pH de un suero dulce real), y teniendo en cuenta lo comentado anteriormente, puede asumirse que a este valor de $\mathrm{pH}$, la carga de las membranas ensayadas será negativa y el transporte se verá influenciado por los efectos estéricos y la carga superficial de la membrana. Por tanto, la carga superficial de la membrana tenderá a dejar pasar los iones de carga opuesta (contra-iones) y rechazar a los de su misma carga (co-iones), siempre que el tamaño de los poros de la membrana lo permita.

El magnesio es el catión que presenta mayor carga y además posee mayor entalpía de hidratación, dando como resultado un alto índice de rechazo, típico de membranas cargadas negativamente. Para los iones sodio y potasio, al tener ambos la misma carga, juegan un papel más importante sus entalpías de hidratación, siendo la del sodio $(407 \mathrm{~kJ} / \mathrm{mol})$ más alta, lo que contribuye a que éste sea más lentamente transportado en comparación con el potasio (324 $\mathrm{kJ} / \mathrm{mol})$. 


\subsection{FASE INTERMEDIA}

Una vez analizados los resultados obtenidos en el apartado de caracterización de membranas, el siguiente paso a seguir es elegir la membrana que mejor se adaptase a los objetivos de esta tesis. En este sentido se elige la membrana Ds-5 DL, dado que es la membrana con la que se obtienen los menores índices de rechazo para los iones monovalentes, lo cual es uno de los objetivos perseguidos por este trabajo de investigación. Cabe anotar que el caudal de permeado es de los más bajos si se compara con los obtenidos con las membranas de la serie NF. Sin embargo, se espera que con la utilización del módulo de arrollamiento en espiral estos valores mejoren de forma ostensible ya que dicha configuración posee una mayor superficie de membrana.

\subsubsection{Módulo plano}

Influencia del factor de concentración sobre algunas propiedades permeselectivas de la membrana Ds-5 DL

Para realiza éste estudio, se realizaron ensayos de concentración con la disolución alimento modelo empleando el módulo plano. Debido al bajo caudal del permeado que se obtiene con dicho módulo es imposible concentrar la disolución hasta el valor deseado que en principio. Para ello se hacen experiencias de ocho horas cada una y tras cada experiencia se cambia el alimento por otro de mayor concentración de forma progresiva. Se partió de una disolución modelo del $5 \% \mathrm{p} / \mathrm{v}$ de lactosa, $1.200 \mathrm{mg} / \mathrm{L}$ de cloruro de sodio, 2.000 
$\mathrm{mg} / \mathrm{L}$ de cloruro de potasio y $750 \mathrm{mg} / \mathrm{L}$ de sulfato de magnesio hasta llegar a una concentración tres veces más concentrada respecto de cada compuesto (tal como se muestra en la tabla 6.6), pues a partir de dicha concentración la densidad de flujo obtenida es muy baja.

Tabla 6.6. Composición de la disolución alimento para cada experiencia. $\mathrm{pH}=6,5$.

\begin{tabular}{lrrrrrrr}
\hline \multirow{7}{*}{$\begin{array}{l}\text { Exp. } \\
\mathrm{N}^{0}\end{array}$} & \multicolumn{7}{c}{ Concentración (g/L) } \\
\cline { 2 - 6 } & Lactosa & $\mathrm{Na}^{+}$ & $\mathrm{K}^{+}$ & $\mathrm{Mg}^{+2}$ & $\mathrm{Cl}^{-}$ & $\mathrm{SO}^{-2}$ & $\mathrm{FC}$ \\
\hline 1 & 50,0 & 0,48 & 1,05 & 0,15 & 1,70 & 0,57 & 1,00 \\
2 & 66,7 & 0,64 & 1,40 & 0,20 & 2,25 & 0,80 & 1,33 \\
3 & 83,3 & 0,79 & 1,47 & 0,25 & 2,82 & 1,00 & 1,67 \\
4 & 100,0 & 0,95 & 2,10 & 0,30 & 3,38 & 1,20 & 2,00 \\
5 & 116,7 & 1,11 & 2,51 & 0,35 & 4,01 & 1,40 & 2,33 \\
6 & 133,4 & 1,27 & 2,80 & 0,41 & 4,51 & 1,60 & 2,67 \\
7 & 150,0 & 1,43 & 3,15 & 0,46 & 5,08 & 1,80 & 3,00 \\
\hline
\end{tabular}

Los resultados de densidad de flujo de permeado obtenidos con cada de las disoluciones alimento ensayadas y la membrana Ds-5 DL se muestran en la figura 6.19. Tal como puede apreciarse las densidades de flujo muestran un comportamiento muy estable y con la misma tendencia con cada una de los ensayos a lo largo de las 8 horas de operación. 


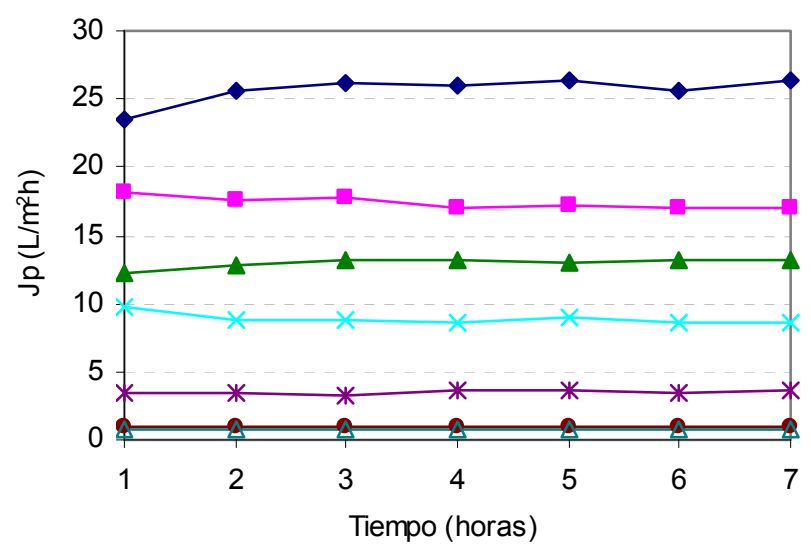

Figura 6.19. Variación de $\mathrm{J}_{\mathrm{p}}$ con el tiempo. $\Delta \mathrm{P}=0,95 \mathrm{MPa}$,

$\mathrm{T}=22 \pm 1^{\circ} \mathrm{C}, V_{\text {tang }}=2,04 \mathrm{~m} / \mathrm{s} . \quad 1 ;=1,33 ; \Delta 1,67 ; \times 2 ; \quad * 2,33 ; \bullet 2,67 ; \Delta 3$

En la figura 6.20, se observa una disminución gradual de la densidad de flujo (que tiende prácticamente a cero) al ir aumentando la concentración de cada una de las disoluciones alimento. Esto es de esperar, pues cada vez la fuerza impulsora es más pequeña, debido al aumento de la presión osmótica entre el alimento y el permeado.

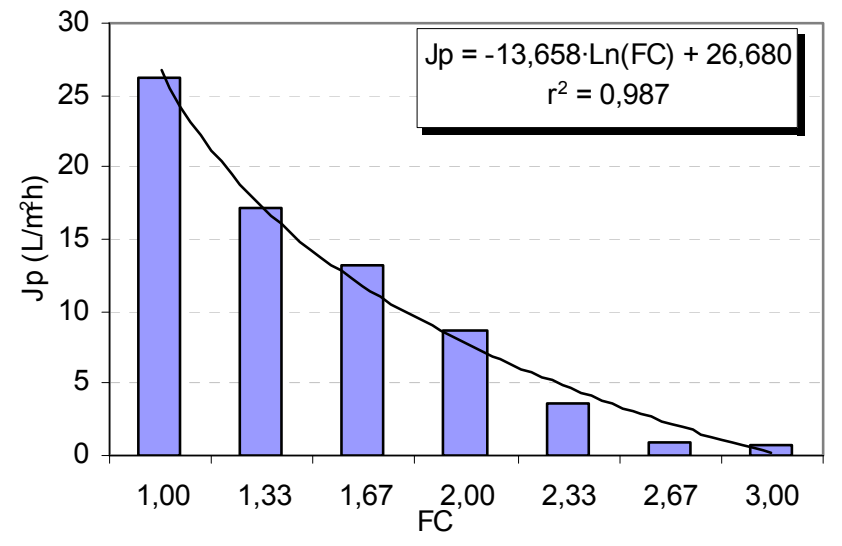

Figura 6.20. Efecto del FC sobre la densidad de flujo $\Delta \mathrm{P}=0,95 \mathrm{MPa}, \mathrm{T}=22 \pm 1^{\circ} \mathrm{C}, \mathrm{V}_{\text {tang }}=2,04 \mathrm{~m} / \mathrm{s}$ 
Los resultados obtenidos presentan una tendencia logarítmica con un error cuadrático cercano a 1, comprobándose experimentalmente que al aumentar la concentración de la disolución alimento, su presión osmótica también aumenta, lo que implica que a la misma presión aplicada la densidad de flujo disminuye. Resultados similares han sido obtenidos por otros investigadores (Wang et al, 2002).

El soluto que ejerce una presión osmótica más alta es la lactosa, como cabe esperar dada su elevada concentración en la disolución alimento y en el concentrado.

En la figura 6.21 se puede observar que los índices de rechazo van disminuyendo conforme va aumentando la concentración de la disolución alimento (compuesta de lactosa y sales). En esta experiencia se logran obtener los índices de rechazo más bajos, con respecto a las experiencias anteriores (fase inicial). La disminución del índice de rechazo con el aumento de la concentración alimento (mayor fuerza iónica) esta de acuerdo con el principio de exclusión de Donnan, dando como resultado una disminución en la carga de la membrana. Este comportamiento ha sido observado por muchos autores y todos ellos coinciden en explicarlo como un hecho característico de membranas cargadas negativamente (Peeters et al, 1998). 

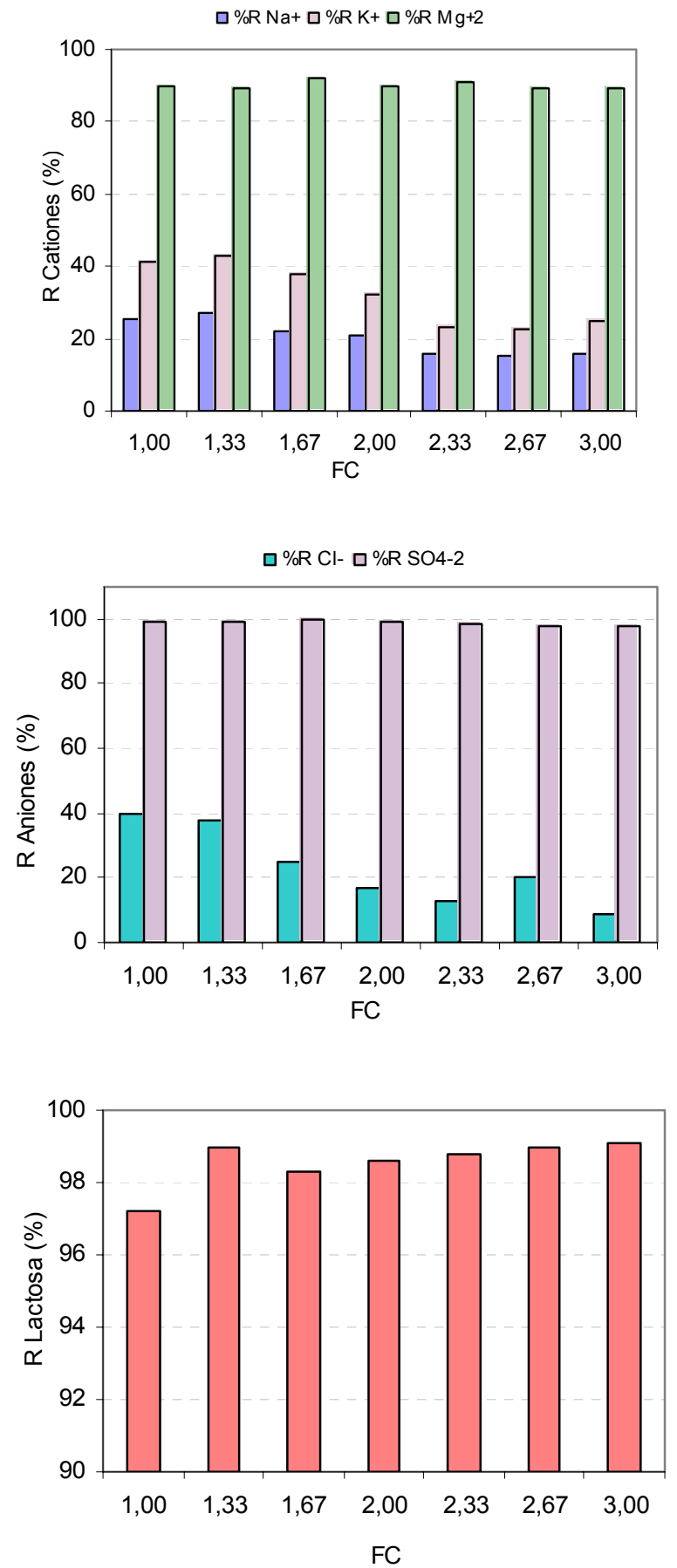

Figura 6.21. Influencia de FC sobre $R$ $\Delta \mathrm{P}=0,95 \mathrm{MPa}, \mathrm{T}=22 \pm 1^{\circ} \mathrm{C}, \mathrm{V}_{\text {tang }}=2,04 \mathrm{~m} / \mathrm{s}$ 
Otros investigadores también han observado esta tendencia. (Paugam et al, 2004, Freger et al, 2000; Gilron et al, 2001, entre otros). Dicho comportamiento es característico de membranas cargadas y generalmente interpretado como un fenómeno de apantallamiento. El incremento de la concentración de la disolución alimento da lugar a la formación de una pantalla por parte de los cationes, neutralizando lentamente la carga negativa de la membrana. Esto hace que disminuyan las fuerzas de repulsión entre los aniones y algunas zonas de la membrana con carga negativa.

Sin embargo, a bajas concentraciones el efecto es más débil, siendo importante la repulsión de los aniones por parte de la membrana, dando lugar a elevados índices de rechazo. Cuando la concentración es mayor, este efecto se incrementa y la carga de la membrana se debilita, como consecuencia, la repulsión entre la membrana y los aniones disminuye y estos pueden atravesar la membrana más fácilmente, con el consiguiente descenso del índice de rechazo.

Los índices de rechazo más bajos se obtuvieron para los iones sodio, potasio y cloruro con valores entre el 20-30\% aproximadamente y como cabe esperar para los iones magnesio, sulfato y también para la lactosa se obtienen índices de rechazo mayores entre el 90-98\% aproximadamente. Estos últimos no se ven influenciados por el incremento de la concentración de la disolución alimento ni por la presión transmembranal. 


\subsubsection{Módulo de arrollamiento en espiral}

Realizados los ensayos con el módulo plano, el siguiente paso es trabajar con un módulo de arrollamiento en espiral con el fin de continuar los ensayos con las disoluciones de suero modelo y suero real.

\subsubsection{Ensayo de la permeabilidad al agua}

A continuación se muestran los resultados obtenidos con la membrana Ds-5 DL. Lo primero que se hace con esta membrana es hacerla funcionar durante una hora sin tomar muestras ni hacer mediciones, como procedimiento previo recomendado por el fabricante cuando la membrana es nueva y va a ser utilizada por primera vez. Luego, se pone en marcha durante cuatro horas de operación, tiempo en el cual las densidades de flujo permanecen constantes. Este ensayo se realiza por duplicado. El caudal de alimentación se fija en 400 L/h y la temperatura del agua es de $20 \pm$ $1^{\circ} \mathrm{C}$, con una conductividad de $4 \mu \mathrm{S} / \mathrm{cm}$.

En la figura 6.22, se muestran los resultados obtenidos con el agua desmineralizada en función de la presión. 


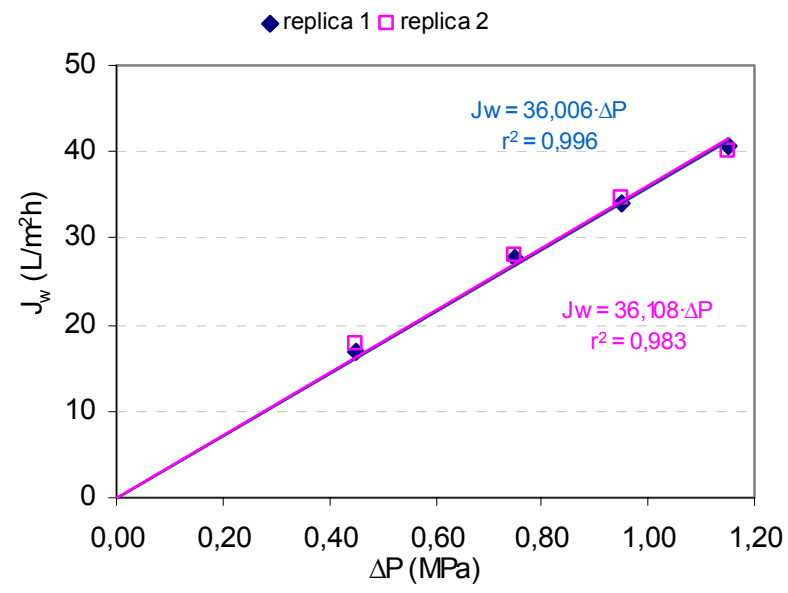

Figura 6.22. Evolución de Jagua con la membrana Ds-5 DL.

Como se puede observar en la figura 6.22, los valores de las densidades de flujo de las réplicas 1 y 2 son muy similares. Como se comentó anteriormente, la densidad de flujo es función de la presión transmembranal y la presión osmótica, pero al tratarse de agua pura no tiene efecto la presión osmótica. El resultado que cabe esperar es el de una línea recta que pasa por el origen, tal como se aprecia en la figura anterior. La pendiente representa el coeficiente de permeabilidad al agua de la membrana $(L p)$ Ds-5 DL, en este caso presenta un valor promedio de 36,06 L/( $\left.\mathrm{m}^{2} \cdot \mathrm{h} \cdot \mathrm{MPa}\right)$.

En este apartado se muestran los resultados obtenidos respecto al índice de rechazo y densidad de flujo. La composición de la disolución modelo (lactosa + sales minerales) se muestra en la tabla 6.7. Los resultados son los obtenidos después de cuatro horas de funcionamiento para cada una de las presiones ensayadas. 
Tabla 6.7. Composición del suero modelo

\begin{tabular}{lr}
\hline Parámetro & \multicolumn{1}{c}{ Alimento } \\
\hline$\kappa, \mathrm{mS} / \mathrm{cm}$ & $5,80-6,02$ \\
$\mathrm{pH}$ & 6,50 \\
Sodio, $\mathrm{mg} / \mathrm{L}$ & $420-490$ \\
Potasio, $\mathrm{mg} / \mathrm{L}$ & $752-1033$ \\
Magnesio, mg/L & $142-191$ \\
Cloruro, mg/L & $870-1610$ \\
Sulfatos, mg/L & $550-605$ \\
Lactosa, $\mathrm{g} / \mathrm{L}$ & $45-50$ \\
\hline
\end{tabular}

Las condiciones de los ensayos realizados en este apartado se hacen variando las condiciones de operación, pues cada una de las series se hace por triplicado y para pasar de una serie se hacen diferentes protocolos de limpieza con el fin de estudiar el efecto de estos sobre el comportamiento de la membrana. Cada serie hace alusión dos tipos de ensayo, el primero se hace a concentración constante (tanto la corriente de concentrado como la de permeado retornan al tanque), al que le siguen el de concentración (se descarta la corriente de permeado) y por último el de diafiltración (se descarta el caudal de permeado y se añade agua pura para mantener el volumen de alimento constante), la notación utilizada para referirnos a cada una de ellas será la siguiente:

- Serie 1 (membrana nueva): hace referencia a los resultados obtenidos con la membrana nueva. 
- Serie 2 (membrana limpiada con ácido cítrico): hace referencia a los resultados obtenidos después de haber realizado la primera tanda de experiencias (serie 1) y limpiar la membrana con ácido cítrico.

- Serie 3 (membrana limpiada con agua destilada): corresponde a los resultados obtenidos después de haber realizado la segunda tanda de experiencias (serie 2) y limpiar la membrana con agua.

A continuación se muestran los resultados obtenidos con cada una de las series para los diferentes modos de operación.

\subsubsection{Etapa a concentración constante.}

\section{Densidad de flujo de permeado}

A continuación, en la tabla 6.8, se muestra un resumen de los resultados obtenidos con cada una de las series.

Tabla 6.8. Relación entre la densidad de flujo de permeado y el incremento de presión osmótica a concentración constante.

\begin{tabular}{|c|c|c|c|c|c|c|}
\hline \multirow[b]{2}{*}{$\begin{array}{c}\Delta \mathrm{P} \\
\mathrm{MPa}\end{array}$} & \multicolumn{2}{|c|}{ Serie 1} & \multicolumn{2}{|c|}{ Serie 2} & \multicolumn{2}{|c|}{ Serie 3} \\
\hline & $\begin{array}{c}\Delta \pi \\
\mathrm{MPa} \\
\end{array}$ & $\begin{array}{c}J_{p} \\
L / m^{2} h \\
\end{array}$ & $\begin{array}{c}\Delta \pi \\
\mathrm{MPa} \\
\end{array}$ & $\begin{array}{c}J_{p} \\
L / m^{2} h\end{array}$ & $\begin{array}{c}\Delta \pi \\
\mathrm{MPa} \\
\end{array}$ & $\begin{array}{c}J_{p} \\
L / m^{2} h\end{array}$ \\
\hline 0,55 & 0,38 & 4,84 & 0,37 & 4,96 & 0,37 & 4,70 \\
\hline 0,75 & 0,39 & 8,55 & 0,38 & 8,84 & 0,38 & 8,63 \\
\hline 0,96 & 0,40 & 11,86 & 0,38 & 12,30 & 0,38 & 11,30 \\
\hline 1,15 & 0,40 & 13,83 & 0,39 & 15,13 & 0,39 & 14,23 \\
\hline 1,35 & 0,41 & 16,42 & 0,39 & 17,11 & 0,39 & 16,39 \\
\hline
\end{tabular}


Tal como se puede apreciar en la tabla anterior y en los resultados comentados en otros apartados, la densidad de flujo aumentó con la presión aplicada para todas las experiencias

Al trabajar siempre con la misma composición de la disolución alimento para cada uno de los ensayos (serie 1, 2 y 3), la presión osmótica para cada uno de los intervalos de presión es muy parecida, sin que haya mucha desviación en la composición de la disolución alimento en cada caso.

Las densidades de flujo obtenidas después de cada uno de los diferentes protocolos de limpieza con la disolución modelo de suero, son muy similares.

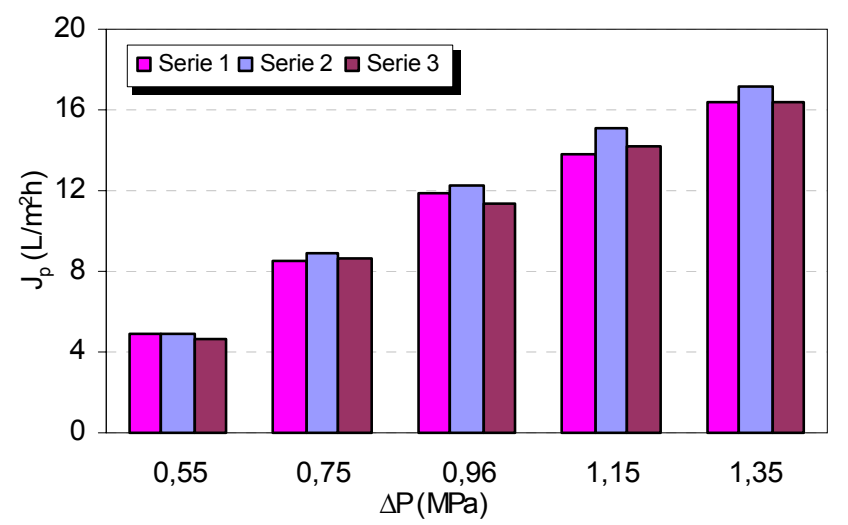

Figura 6.23. Variación de Jp con la presión. Disolución modelo de suero. 


\section{Densidad de flujo de soluto}

Las densidades de flujo de soluto presentadas en las tablas 6.9 a 6.11, corresponden a un mismo orden de magnitud. Los valores más altos son para el ión cloruro, mostrando las tasas más altas de desmineralización, seguido del potasio, el sodio, el magnesio y el sulfato.

Tabla 6.9. Densidad de flujo de soluto. Serie 1.

\begin{tabular}{ccccccc}
\hline & \multicolumn{6}{c}{$\mathrm{Js}\left(\mathrm{g} / \mathrm{m}^{2} \mathrm{~h}\right)$} \\
\cline { 2 - 7 } $\mathrm{MPa}$ & Lactosa & $\mathrm{K}^{+}$ & $\mathrm{Na}^{+}$ & $\mathrm{Mg}^{+2}$ & $\mathrm{Cl}^{-}$ & $\mathrm{SO}_{4}^{-2}$ \\
\hline 0,55 & 1,75 & 3,91 & 2,11 & 0,08 & 6,92 & 0,03 \\
0,75 & 3,32 & 6,67 & 3,67 & 0,14 & 11,79 & 0,02 \\
0,96 & 4,29 & 8,74 & 4,89 & 0,20 & 15,79 & 0,04 \\
1,15 & 3,12 & 10,28 & 5,53 & 0,22 & 17,04 & 0,04 \\
1,35 & 3,64 & 11,82 & 6,40 & 0,30 & 20,23 & 0,05 \\
\hline
\end{tabular}

Tabla 6.10. Densidad de flujo de soluto. Serie 2.

\begin{tabular}{ccccccc}
\hline & \multicolumn{7}{c}{$\mathrm{Js}\left(\mathrm{g} / \mathrm{m}^{2} \mathrm{~h}\right)$} \\
\cline { 2 - 7 } $\mathrm{MPa}$ & Lactosa & $\mathrm{K}^{+}$ & $\mathrm{Na}^{+}$ & $\mathrm{Mg}^{+2}$ & $\mathrm{Cl}^{-}$ & $\mathrm{SO}_{4}^{-2}$ \\
\hline 0,55 & 1,72 & 3,43 & 1,94 & 0,09 & 6,85 & 0,02 \\
0,75 & 3,44 & 5,75 & 3,34 & 0,12 & 11,34 & 0,02 \\
0,96 & 4,62 & 7,87 & 4,56 & 0,16 & 15,48 & 0,04 \\
1,15 & 5,69 & 9,08 & 5,59 & 0,18 & 18,67 & 0,07 \\
1,35 & 3,70 & 10,27 & 6,22 & 0,19 & 21,11 & 0,05 \\
\hline
\end{tabular}


Tabla 6.11. Densidad de flujo de soluto. Serie 3.

\begin{tabular}{ccccccc}
\hline & \multicolumn{6}{c}{$\mathrm{Js}\left(\mathrm{g} / \mathrm{m}^{2} \mathrm{~h}\right)$} \\
\cline { 2 - 7 } $\begin{array}{c}\Delta P \\
\mathrm{MPa}\end{array}$ & Lactosa & $\mathrm{K}^{+}$ & $\mathrm{Na}^{+}$ & $\mathrm{Mg}^{+2}$ & $\mathrm{Cl}^{-}$ & $\mathrm{SO}^{-2}$ \\
\hline 0,55 & 1,69 & 3,19 & 1,96 & 0,03 & 6,47 & 0,02 \\
0,75 & 3,38 & 5,09 & 3,55 & 0,04 & 11,46 & 0,04 \\
0,96 & 4,28 & 6,78 & 4,58 & 0,07 & 14,70 & 0,04 \\
1,15 & 5,12 & 7,97 & 5,51 & 0,06 & 17,80 & 0,05 \\
1,35 & 3,61 & 9,01 & 6,13 & 0,04 & 20,91 & 0,05 \\
\hline
\end{tabular}

Como se ha comentado en otros apartados la densidad de soluto es función de la densidad de flujo y el índice de rechazo, a medida que aumenta la presión también lo hace la densidad de flujo, sin embargo el índice de rechazo tiende a estabilizarse al ir aumentado la presión, con lo cual el efecto predominante sobre este parámetro es la densidad de flujo. Por ejemplo, en el caso de la lactosa podemos apreciar que su índice de rechazo esta alrededor del 99\%, sin embargo a medida que va aumentando la densidad de flujo, la perdida de lactosa se incrementa. Comportamientos similares son observados para el resto de los iones estudiados.

\section{Índice de rechazo.}

Se puede observar que no hay diferencias significativas respecto al índice de rechazo de iones divalentes y lactosa; dichos valores son típicos de membranas de nanofiltración. Por el contrario para los iones monovalentes se encuentran algunas diferencias en cada una de las tres series realizadas. Al aumentar la presión aplicada los 
índices de rechazo aumentan para cada uno de los iones en disolución, excepto para las dos últimas presiones.

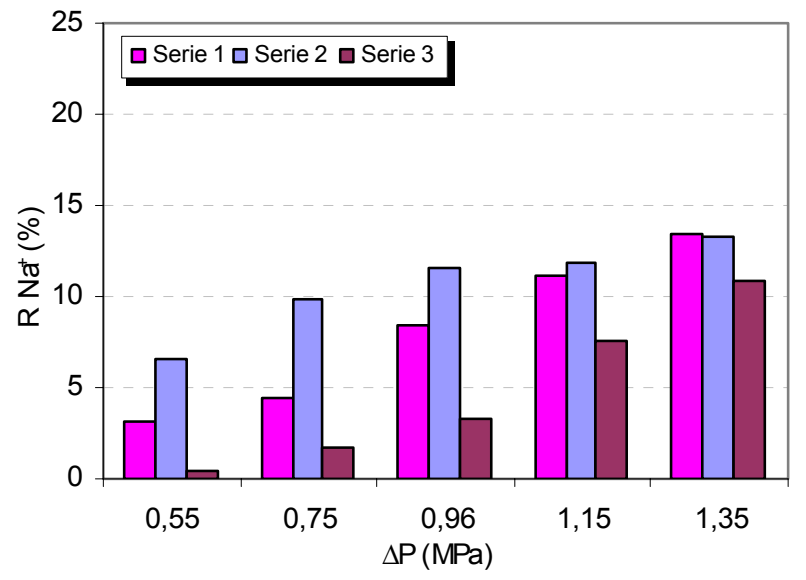

Figura 6.24. Variación de \% $\mathrm{R} \mathrm{Na}^{+1}$ con la presión

Para la membrana limpiada con agua destilada (serie 3) y a la presión de 0,55 MPa, el índice de rechazo del sodio disminuye en relación con el del potasio que aumenta, equilibrando las cargas a ambos lados de la membrana por efecto Donnan.

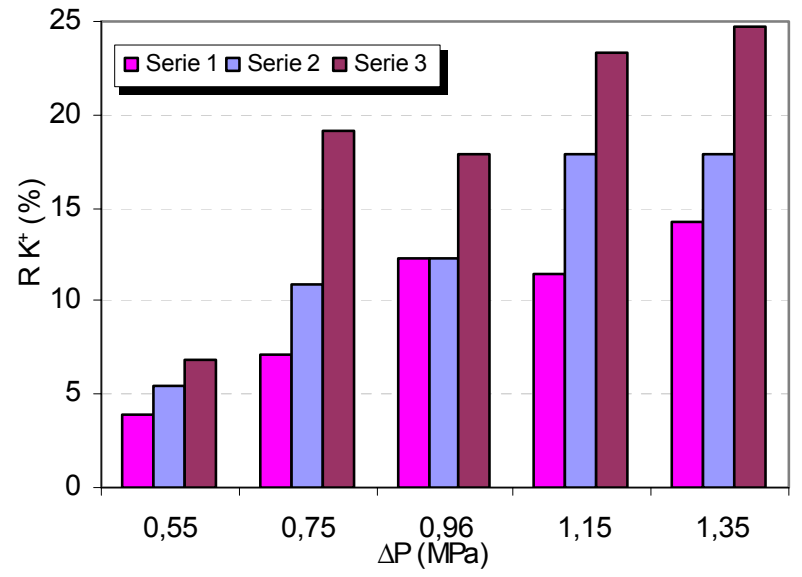

Figura 6.25. Variación de \%R K+1 con la presión 
Respecto al ión cloruro, su índice de rechazo aumenta al incrementarse la presión aplicada y a los valores más altos permanece casi constante, excepto para la serie 1 que se mantiene constante esto puede deberse a que mantiene sus características esenciales en el rango de presiones de trabajo.

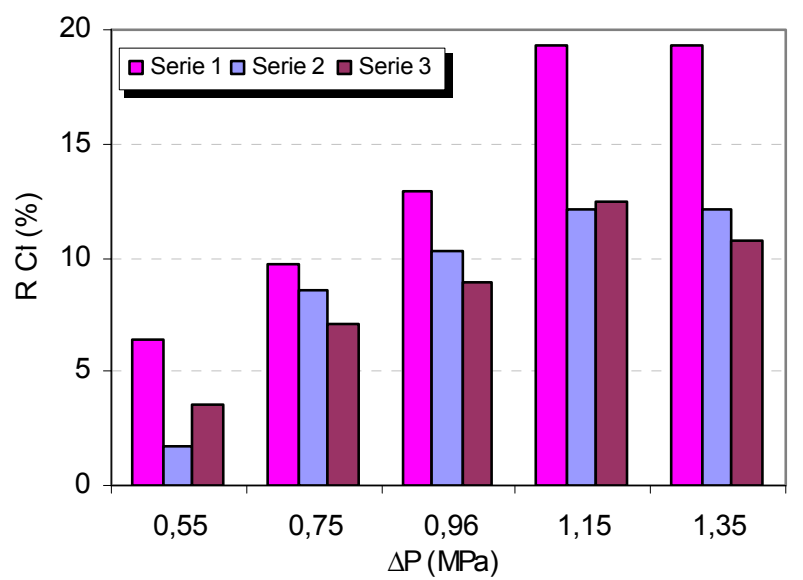

Figura 6.26. Variación de \% $\mathrm{Cl}^{-}$con la presión

De todos los iones presentes en la disolución alimento, el magnesio y el sulfato tienen un efecto más notable en la separación, ya que al ser iones polivalentes enmascaran la carga de la membrana y tienden a no disociarse totalmente (fuerza iónica) por lo que son fácilmente excluidos por el poro de la membrana. 


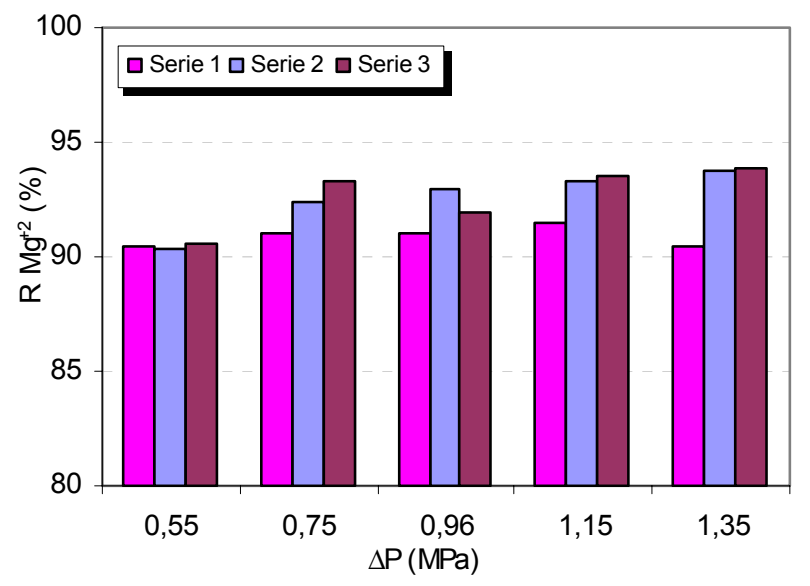

Figura 6.27. Variación de \%R $\mathrm{Mg}^{+2}$ con la presión

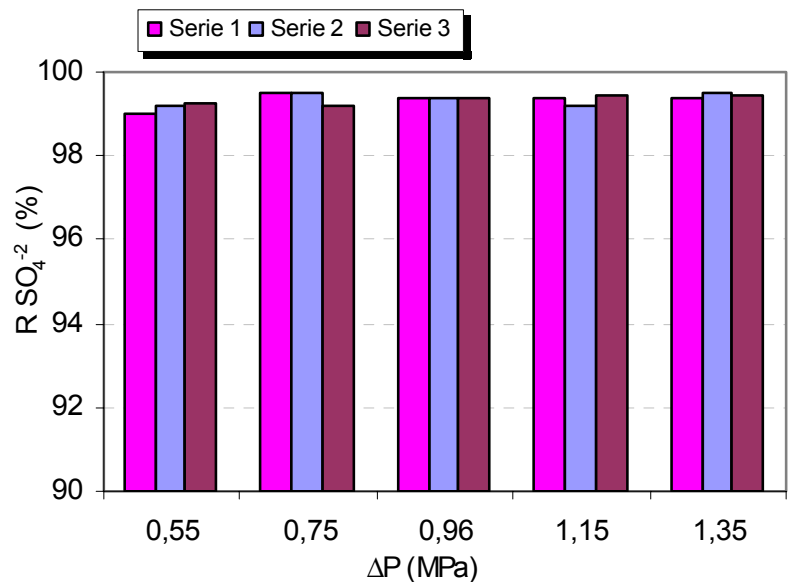

Figura 6.28. Variación de \% $\mathrm{SO}_{4}{ }^{-2}$ con la presión efectiva

Para verificar el principio de electroneutralidad, se hace un balance de cargas entre aniones y cationes en la corriente de permeado. 
Tabla 6.12. Balance de cargas en la corriente de permeado.

\begin{tabular}{|c|c|c|c|c|c|c|c|c|c|}
\hline$\Delta \mathrm{P}$ & \multicolumn{3}{|c|}{ Serie 1} & \multicolumn{3}{|c|}{ Serie 2} & \multicolumn{3}{|c|}{ Serie 3} \\
\hline \multirow[t]{2}{*}{$\mathrm{MPa}$} & Ecation & Eanion & Des & ition & Eanion & \multirow{2}{*}{$\begin{array}{c}\text { Desv. } \\
\%\end{array}$} & ition & Eanion & \multirow{2}{*}{$\begin{array}{c}\text { Desv. } \\
\%\end{array}$} \\
\hline & \multicolumn{2}{|c|}{ (eq/L) } & $\%$ & \multicolumn{2}{|c|}{ (eq/L) } & & \multicolumn{2}{|c|}{ (eq/L) } & \\
\hline 0,55 & 0,0410 & 0,0404 & 1,47 & 0,0361 & 0,0389 & 7,84 & 0,0371 & 0,0389 & 4,99 \\
\hline 0,75 & 0,0400 & 0,0389 & 2,66 & 0,0342 & 0,0362 & 5,79 & 0,0340 & 0,0375 & 10,05 \\
\hline 0,96 & 0,0381 & 0,0376 & 1,44 & 0,0335 & 0,0355 & 5,87 & 0,0343 & 0,0367 & 7,17 \\
\hline 1,15 & 0,0377 & 0,0348 & 7,71 & 0,0324 & 0,0348 & 7,53 & 0,0323 & 0,0353 & 9,47 \\
\hline 1,35 & 0,0369 & 0,0348 & 5,66 & 0,0321 & 0,0348 & 8,47 & 0,0313 & 0,0360 & 14,91 \\
\hline
\end{tabular}

Como se puede observar de la tabla 6.12, la ley de electroneutralidad se cumple, pues los porcentajes de desviación entre cationes y aniones con cada una de las presiones aplicadas son bajos ( $\leq 10 \%$ ), excepto para la serie 3 a la presión de 1,35 MPa donde el porcentaje de desviación está entorno al 15\%.

Tabla 6.13. Fuerza iónica (I) del permeado.

\begin{tabular}{cccc}
\hline$\Delta \mathrm{P}$ & \multicolumn{3}{c}{$\sum \mathrm{I}_{\mathrm{p}}(\mathrm{mol} / \mathrm{L})$} \\
\cline { 2 - 4 } $\mathrm{MPa}$ & Serie 1 & Serie 2 & Serie 3 \\
\hline 0,55 & 0,041 & 0,038 & 0,039 \\
0,75 & 0,040 & 0,036 & 0,036 \\
0,96 & 0,039 & 0,035 & 0,034 \\
1,15 & 0,037 & 0,034 & 0,034 \\
1,35 & 0,037 & 0,034 & 0,034 \\
\hline - La fuerza iónica en el alimento para cada una de las experiencias es: \\
\multicolumn{2}{c}{ 0.068 M; 0.065M; 0.066M. }
\end{tabular}

El cálculo de la fuerza iónica ayuda a comprender mejor cual es el comportamiento de los diferentes iones presentes en la disolución. Como se puede apreciar en la corriente de permeado, los valores de 
la fuerza iónica para cada uno de los iones son bastante similares, mostrando que el comportamiento de la membrana es bastante similar con cada una de las repeticiones.

El índice de rechazo para la lactosa está entorno al 98-99\% en cada una de las series realizadas, tal como puede observarse en la figura 6.29 .

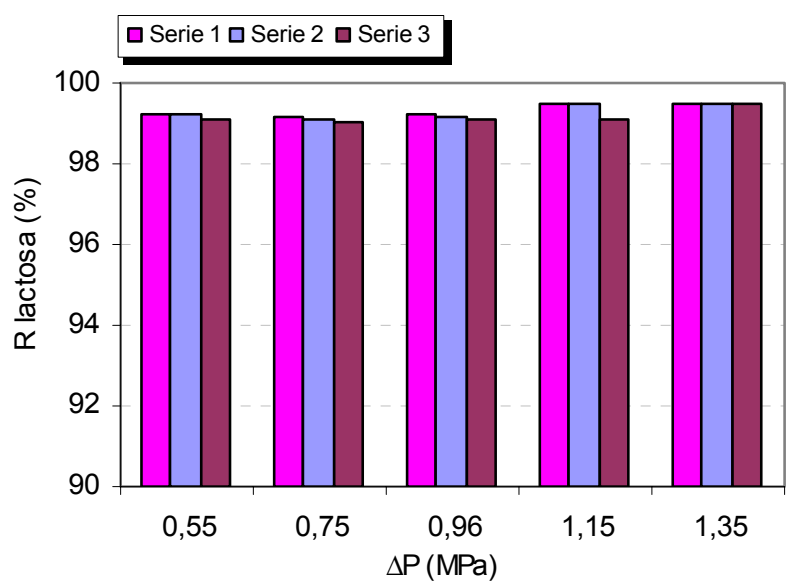

Figura 6.29. Variación de \%R Lactosa con la presión efectiva

\subsubsection{Etapa de concentración - diafiltración.}

A continuación se muestran los resultados obtenidos en la etapa de concentración-diafiltración para cada una de las series estudiadas, tal como se comento al inicio del apartado 6.2.2.

\section{Concentración}

Los resultados obtenidos en la etapa de concentración se recogen en la figura 6.30: 


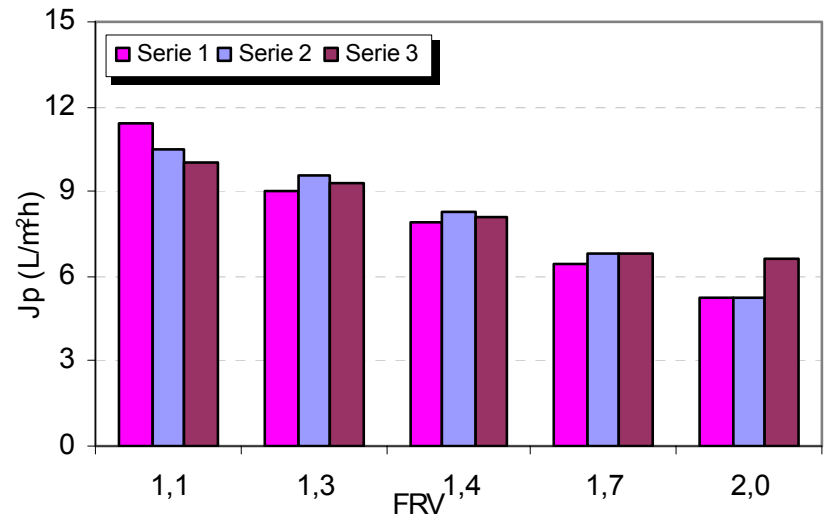

Figura 6.30. Variación de Jp durante la concentración

Si se comparan los resultados obtenidos en la etapa de concentración con el módulo plano y el de arrollamiento en espiral, se observa que al aumentar la concentración de la disolución alimento, tanto la densidad de flujo como el índice de rechazo disminuyen para ésta última. Los valores de densidad de flujo obtenidos son más bajos con el módulo arrollado en espiral, esto puede ser debido a que la pérdida de carga de este módulo es mayor a la del módulo plano. Räsänen et al, 2002, explicaron este comportamiento apoyándose en que el módulo de arrollamiento en espiral es más propenso a la polarización por concentración ó a la existencia de zonas muertas que ocasionan un uso ineficiente del área de membrana. 
Tabla 6.14. Índice de rechazo para FRV = 2

\begin{tabular}{lcll}
\hline & \multicolumn{3}{c}{$\% \mathrm{R}$} \\
\cline { 2 - 4 } Soluto & Serie 1 & Serie 2 & Serie 3 \\
\hline lactosa & 99,23 & 99,00 & 99,50 \\
$\mathrm{~K}^{+}$ & 1,23 & $-3,75$ & $-4,41$ \\
$\mathrm{Mg}^{2+}$ & 84,00 & 85,00 & 87,60 \\
$\mathrm{Na}^{+}$ & $-0,15$ & $-0,31$ & $-3,49$ \\
$\mathrm{SO}_{4}{ }^{2-}$ & 99,20 & 99,50 & 99,60 \\
$\mathrm{Cl}^{-}$ & $-22,28$ & $-0,01$ & $-0,02$ \\
\hline
\end{tabular}

En casi todas las experiencias (véase tabla 6.14), se obtienen índices de rechazo negativos, para los iones sodio, potasio y cloruro. Esto puede ser debido a interacciones electrostáticas altas (efecto Donnan), tal como se ha explicado anteriormente. Estas interacciones pueden incrementar la transferencia de electrólitos monovalentes al repeler los polivalentes, obteniéndose rechazos negativos, estos resultados también han sido obtenidos por otros investigadores (Mohammad A. W., Takriff M.S., 2003; Szoke S et al. 2002; Tanninen J., Nyström M., 2002; Gilron J. et al. 2001; Freger V. et al., 2000).

Respecto al índice de rechazo, también se observan diferencias entre los obtenidos en el módulo plano y el arrollado en espiral. Aunque el factor de concentración no es el mismo, pues con el módulo plano se llego hasta un valor de 3 y con el arrollado se aproxima a 2. Con el módulo de arrollamiento en espiral, se obtienen índices de rechazo negativos. Sin embargo, este comportamiento no es observado con el módulo plano, en el que se llegaron a obtener los valores más bajos para el ión cloruro, pero en ningún momento 
concentraciones mayores de soluto en la corriente de permeado respecto al alimento.

Por otro lado, en los ensayos con el módulo plano, el alimento siempre variaba en la misma proporción en cada una de las experiencias numeradas de la 1 a la 7 . Mientras que, con el módulo arrollado, al ser la membrana la que iba concentrando el alimento más en iones polivalentes que en monovalentes, la proporción de los respectivos iones cambiaba. Además en el módulo plano, se observa que a partir de cierto nivel de concentración el índice de rechazo de cloruros fue muy similar, posiblemente debido a la polarización por concentración o que al ser el área de membrana menor, la carga de la membrana se neutraliza, sin que influya la carga de la membrana sobre el paso del ión pero si su tamaño.

Mohammad et al, 2003, utilizaron una disolución de cloruro de sodio y sulfato de magnesio, obteniendo índices de rechazos de cloruro de sodio negativos a bajas densidades de flujo, pudiendo ser debido a la presencia de altas concentraciones de sulfatos en el alimento.

\section{Diafiltración.}

El objetivo de la diafiltración es favorecer la permeación de los iones monovalentes, adicionando agua fresca de alta calidad, de tal forma que disminuya la concentración de aquellos. Mientras que, con los iones divalentes es más difícil conseguir esta separación. La capacidad desmineralizadora de la membrana se ve favorecida, lográndose porcentajes de eliminación altos. 
En esta etapa, se diafiltró el alimento resultante tras concentrar el alimento hasta un factor de reducción volumétrica de dos con cada una de las series. Se toman muestras del alimento a diferentes intervalos de tiempo de diafiltración (cero, cinco y ocho horas). Los resultados obtenidos se muestran en la figura 6.31 y la tabla 6.15.

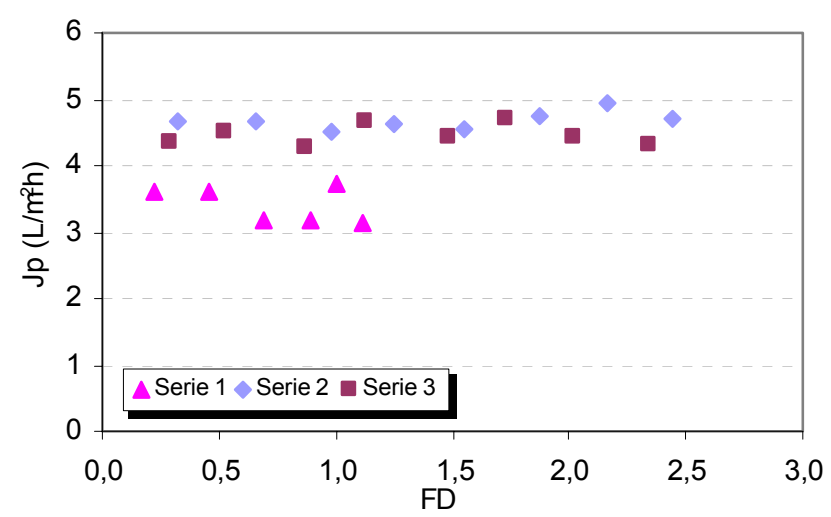

Figura 6.31. Variación de Jp durante la diafiltración

Durante la diafiltración, la densidad de flujo permanece aproximadamente constante durante las ocho horas de duración. Los valores de conductividad de la corriente de alimento, disminuyen en un 30, 63 y $73 \%$ después de 2, 5 y 8 horas de operación respectivamente. La diferencia obtenida entre las 5 y ocho horas de operación no es muy grande. 
Tabla 6.15. Composición de la disolución alimento antes y después de diafiltrar

\begin{tabular}{lccccccccc}
\hline & \multicolumn{3}{c}{ Serie 1 } & \multicolumn{3}{c}{ Serie 2 } & \multicolumn{3}{c}{ Serie 3 } \\
\cline { 2 - 10 } Conc. (g/L) & $\mathrm{K}^{+}$ & $\mathrm{Na}^{+}$ & $\mathrm{Cl}^{-}$ & $\mathrm{K}^{+}$ & $\mathrm{Na}^{+}$ & $\mathrm{Cl}^{-}$ & $\mathrm{K}^{+}$ & $\mathrm{Na}^{+}$ & $\mathrm{Cl}^{-}$ \\
\hline Inicial & 0,81 & 0,42 & 1,35 & 0,80 & 0,45 & 1,50 & 0,68 & 0,54 & 1,53 \\
DF 5 h & 0,38 & 0,25 & 0,69 & 0,29 & 0,20 & 0,46 & 0,25 & 0,22 & 0,46 \\
DF 8 h & - & - & - & 0,15 & 0,09 & 0,19 & 0,20 & 0,11 & 0,31 \\
\%Elimin. (5h) & 53,1 & 39,1 & 49,1 & 64,3 & 55,8 & 69,7 & 63,97 & 59,24 & 70,00 \\
\%Elimin. (8h) & - & - & - & 81,9 & 80,1 & 87,1 & 70,44 & 78,85 & 80,00 \\
\hline
\end{tabular}

Para la serie 1 y después de 5 horas de diafiltración, el volumen de dilución es de 1,12. Para la serie 2 y después de 5 y 8 horas de diafiltración los volúmenes de dilución son 1,55 y 2,44 respectivamente. Para la serie 3 y después de 5 y 8 horas de diafiltración los volúmenes de dilución son 1,49 y 2,34 respectivamente.

Los valores de desmineralización alcanzados en cada una de las series son bastante similares, por lo que los diferentes protocolos de limpieza no modifican de forma apreciable el comportamiento de la membrana.

Al analizar los resultados obtenidos en la etapa de concentracióndiafiltración, se observa que al concentrar la disolución alimento, hay una disminución en el índice de rechazo y en la densidad de flujo. La ventaja del modo de concentración es la de optimizar el proceso de diafiltración, reduciendo sus tiempos y la cantidad de agua utilizada a la vez que permite concentrar el soluto a valorizar, en este caso la lactosa. La combinación de estos dos modos de operación da lugar 
a altas densidades de flujo de soluto y por consiguiente a elevadas tasas de desmineralización.

Bowen y Mohammad, en 1998 trabajaron con una membrana de nanofiltración (CA30) diafiltrando en continuo disoluciones de cloruro de potasio, cloruro de sodio y cloruro de litio y solutos no cargados (tinte) con valores de $\mathrm{pH}$ entre 5,8-6,0. De sus experiencias concluyeron que la presión osmótica de la disolución es significativa en presencia del soluto orgánico (tinte), así como la variación de la concentración de $44 \mathrm{~mol} / \mathrm{m}^{3}$ hasta conseguir una disminución de 6 $\mathrm{mol} / \mathrm{m}^{3}$. Los mejores resultados fueron cuando el proceso fue operado en dos fases, preconcentración y diafiltración.

Después de finalizar los ensayos correspondientes a cada una de las series, se comparan las densidades de flujo con agua pura, tal como se muestra en la figura 6.32, verificándose en todos los casos que son prácticamente constantes.

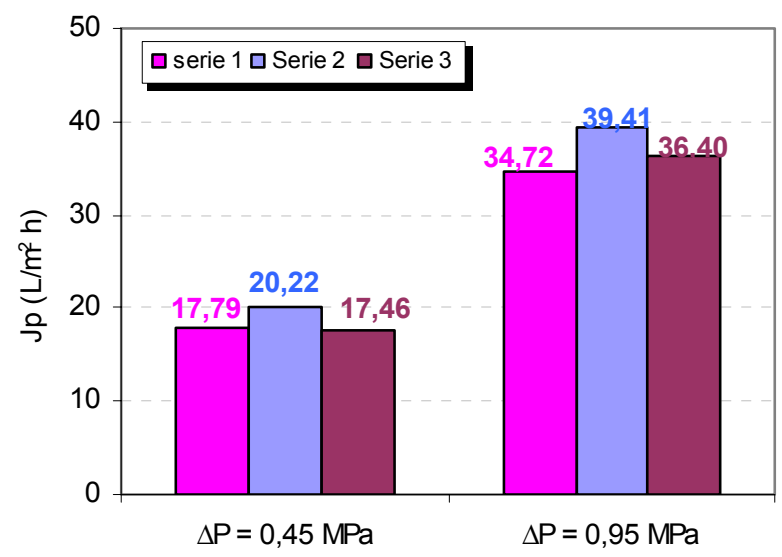

Figura 6.32. Comparación de J al agua después de completada cada serie 


\subsection{FASE FINAL}

Para esta fase final se utilizó el suero dulce procedente de una quesería ubicada en la Comunidad Valenciana. Primero se ultrafiltró el suero para evitar problemas de ensuciamiento debido a la precipitación, adsorción o concentración de las proteínas sobre la superficie de la membrana.

\subsubsection{Ensayos de Ultrafiltración}

Los ensayos realizados fueron:

1. Caracterización de la membrana de UF con agua pura para determinar su coeficiente de permeabilidad y su resistencia.

2. Ultrafiltración del suero real para separar las proteínas presentes, de tal forma que la corriente de concentrado se retorna al tanque de alimentación y la del permeado se separa llevándola a otro tanque, como el volumen de alimentación va disminuyendo al no retornar la corriente de permeado, se añade suero fresco al tanque de alimentación para mantener el volumen constante. La corriente de concentrado, rica en proteínas puede ser aprovechada en la fabricación de quesos y en preparados proteicos. La corriente de permeado se lleva a la unidad de NF para separar la lactosa de las sales minerales.

3. Protocolo de limpieza realizado para limpiar la membrana e intentar recuperar el flujo original. 
La membrana seleccionada para esta parte es de polietersulfona (PES) de $10 \mathrm{kDa}$ de corte molecular, con el fin de retener la mayor cantidad de proteínas de este tamaño y mayores a este valor.

La solubilidad de una proteína es mínima en su punto isoeléctrico, ya que su carga neta es cero y desaparece cualquier fuerza de repulsión electrostática que pudiera dificultar la formación de agregados. Así mismo, a la hora de operar el proceso de UF es importante conocer un poco sobre las características más importantes de las proteínas, las cuales se encuentran resumidas en la tabla 6.16.

Tabla 6.16. Características de las proteínas típicas del suero lácteo

\begin{tabular}{|c|c|c|c|c|}
\hline Proteína & $\begin{array}{l}\text { P.M. } \\
\text { KDa }\end{array}$ & $\begin{array}{c}\text { Diámetro } \\
(\mu \mathrm{m})\end{array}$ & PIE & Estabilidad al calor \\
\hline$\beta$-lactoglobulina & 18,40 & $3,9 \times 10^{-3}$ & $5,35-5,49$ & Muy inestable \\
\hline$\alpha$-lactoalbumina & 14,20 & $2,9 \times 10^{-3}$ & $4,20-4,50$ & Ligeramente inestable \\
\hline Inmunoglobulinas & $\begin{array}{l}80,00- \\
900,00\end{array}$ & - & $5,50-8,30$ & Muy inestable \\
\hline Albúmina de & & & & \\
\hline $\begin{array}{l}\text { Suero Bovina } \\
\text { (BSA) }\end{array}$ & 66,30 & $4,9 \times 10^{-3}$ & 5,10 & Inestable \\
\hline Proteosa-peptona & $4,00-8,00$ & - & $5,10-6,00$ & Estable \\
\hline Caseina soluble & 24,00 & $\begin{array}{l}2,5 \times 10^{-2}- \\
3,3 \times 10^{-1}\end{array}$ & 4,70 & Estable \\
\hline $\begin{array}{l}\text { Proteínas } \\
\text { minoritarias }\end{array}$ & $\begin{array}{l}30,00- \\
100,00\end{array}$ & - & - & - \\
\hline
\end{tabular}

PIE: Punto isoeléctrico de la proteína.

P.M.: Peso molecular 
Los resultados obtenidos con las membranas de ultrafiltración y las de nanofiltración seleccionadas en esta etapa se muestran a continuación. La metodología seguida es la expuesta en el apartado 5.4.4.

\subsubsection{Ensayo de la permeabilidad al agua de la membrana de UF}

Lo primero que se hace con la membrana nueva es medir la densidad de flujo a diferentes valores de presión. El caudal de alimentación es de $400 \mathrm{~L} / \mathrm{h}$, la temperatura del agua pura es de $20 \pm$ $1{ }^{\circ} \mathrm{C}$ con una conductividad de $1,9 \mu \mathrm{S} / \mathrm{cm}$.

A continuación se muestran los resultados obtenidos con la membrana de UF de polietersulfona (cutoff $=10 \mathrm{KDa})$.

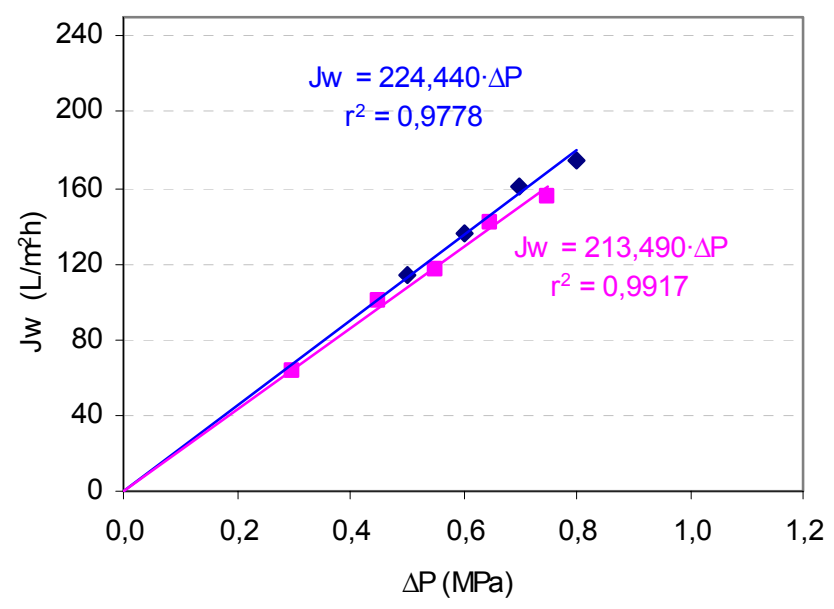

Figura 6.33. Evolución de Jp con la presión. Q = 400 L/h, Membrana UF - replica 1; r replica 2. 
Como se puede observar los valores de las densidades de flujo al agua son muy similares.

La densidad de flujo en ultrafiltración de acuerdo a la ecuación de Darcy es directamente proporcional a la presión aplicada e inversamente proporcional a la viscosidad. A partir de estos resultados y de acuerdo a la ecuación de Darcy, se obtiene de forma gráfica la permeabilidad de la membrana, representada por la pendiente, tal como se muestra en la figura 6.33, haciendo una media de el valor obtenido en las replicas 1 y 2 , se obtiene un valor de $218,97 \mathrm{~L} /\left(\mathrm{m}^{2} \cdot \mathrm{h} \cdot \mathrm{MPa}\right)$ y su inversa la resistencia de la membrana, $R_{m}=0,164 \times 10^{14} \mathrm{~m}^{-1}$.

\subsubsection{Caracterización de la membrana de UF con el suero real}

Mediante estos ensayos se determinan tanto la densidad de flujo como el índice de rechazo de proteínas para un rango de presiones entre 0,3 y 0,6 MPa, con objeto de establecer las condiciones de operación óptimas.

La composición del lactosuero dulce utilizado se muestra en la Tabla 6.17 y los métodos analíticos empleados para su caracterización se indican en el anexo 11.2 . 
Tabla 6.17. Composición del lactosuero dulce. $\mathrm{pH}=6,10$ y $\kappa=6,30$ $\mathrm{mS} / \mathrm{cm}$

\begin{tabular}{lc}
\hline Componente & Concentración $(\% \mathrm{p} / \mathrm{p})$ \\
\hline Proteínas & 1,20 \\
Lactosa & 5,88 \\
Grasas & 0,50 \\
Extracto seco & 8,13 \\
Agua & 84,29 \\
\hline
\end{tabular}

\section{Densidad de flujo}

En estos ensayos se estudian diferentes condiciones de operación para ver su efecto sobre el índice de rechazo de proteínas y la densidad de flujo. Después de un tiempo de operación, la densidad de flujo de la membrana disminuyó, debido seguramente a la polarización por concentración, al ensuciamiento de la superficie de la membrana por la adsorción de contaminantes, el bloqueo del poro o a la formación de una capa gel. Adicionalmente, el efecto de la presión sobre la densidad de flujo aumenta en un $30 \%$ al pasar duplicar el valor de presión, tal como puede observarse en la figura 6.34 . 


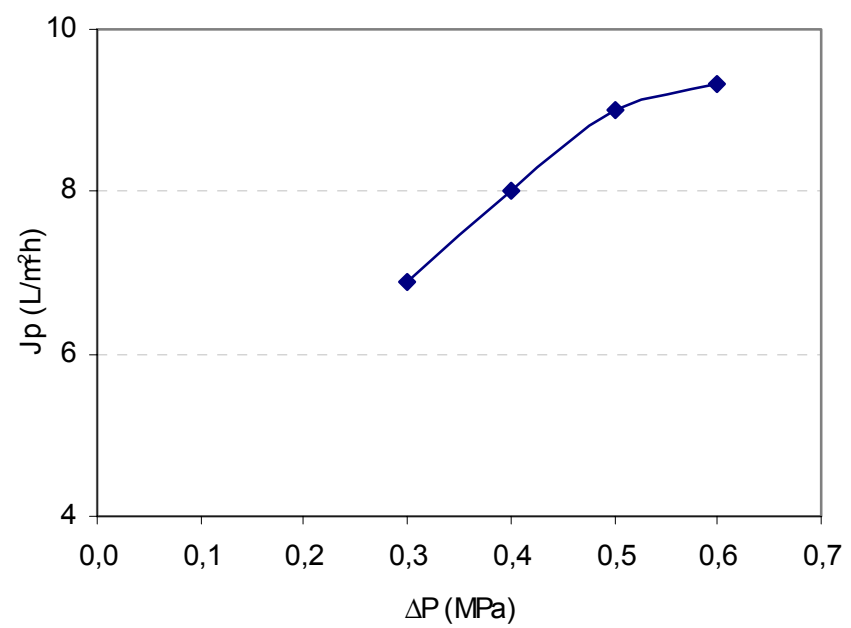

Figura 6.34. Evolución de la Jp con la presión. Membrana UF. $Q_{R}=600$ $\mathrm{L} / \mathrm{h}, \mathrm{T}=16^{\circ} \mathrm{C} ; \mathrm{pH}=6,1 ; \kappa=6,30 \mathrm{~ms} / \mathrm{cm}$.

Analizando los resultados de la figura 6.34, se observa que la densidad de flujo muestra dos zonas, una primera lineal, para el primer tramo de presiones y luego otra cuasi-constante con el aumento de presión. Esto puede ser debido no solo a las características de la disolución alimento (suero lácteo dulce), sino también a las interacciones de éste con la membrana y el efecto sobre el mecanismo de transporte, que algunos autores han intentado explicar a partir de diferentes modelos: el modelo de transferencia de masa basado en el fenómeno de polarización por concentración y la formación de la capa gel, el modelo de la presión osmótica y el modelo de resistencias en serie principalmente.

En la realización de estos ensayos, al cambiar de una presión a otra, es necesario limpiar la membrana, ya que se observa una reducción 
importante en la densidad de flujo. Para la etapa de limpieza se utilizan, si bien, diferentes productos comerciales, teniendo en cuenta procedimientos poco agresivos para no afectar el rendimiento de la membrana en cuanto a densidad de flujo, índice de rechazo y vida útil. Los detalles de los diferentes protocolos se indican más adelante en el apartado 6.3.1.3

\section{Índice de rechazo}

Se notan ligeras diferencias respecto a la densidad de flujo al cambiar el caudal de circulación. Sin embargo, el índice de rechazo de proteínas no varia significativamente para ninguna de las presiones y caudales ensayados, obteniéndose valores entre el 7578\%. La grasa es eliminada totalmente y la cantidad de extracto seco disminuye, tal como puede apreciarse en la tabla 6.18.

Tabla 6.18. Composición del lactosuero dulce. $\mathrm{T}=16^{\circ} \mathrm{C} ; \mathrm{pH}=6,1 ; \kappa=$ $6,30 \mathrm{~ms} / \mathrm{cm}$

\begin{tabular}{lccc}
\hline & \multicolumn{2}{c}{ Concentración (\%) } & \\
Componente & Antes de UF & Después de UF & R (\%) \\
\hline Proteínas & 1,05 & 0,21 & 78 \\
Lactosa & 5,88 & 5,12 & 13 \\
Grasas & 0,50 & 0,00 & 100 \\
Extracto seco & 8,13 & 5,65 & 35 \\
\hline
\end{tabular}


Teniendo en cuenta los argumentos anteriores y que el suero ultrafiltrado luego pasa a una segunda etapa con membranas de nanofiltración, se decidió trabajar a pH constante, con el fin de no modificar las concentraciones en sales minerales del suero real para las etapas posteriores.

Si se tiene en cuenta el peso molecular de las proteínas y el cut off de la membrana utilizada (10 KDa), las especies de tamaño superior a éste, deberían quedar retenidas, pasando aquellas de menor tamaño como las peptonas - proteasas (tabla 6.16). Sin embargo, muchos autores han documentado que el $\mathrm{pH}$ del suero puede modificar su tamaño. De igual modo, el fenómeno de polarización por concentración ayuda a aumentar el porcentaje de proteína rechazada. Sydney et al (2004). Estos argumentos pueden explicar los índices de rechazo obtenidos en esta tesis (alrededor del 78\%).

A continuación en la figura 6.35, se muestra una fotografía de diferentes muestras las corrientes de alimento, permeado y concentrado obtenidas mediante los ensayos de ultrafiltración. El lactosuero resultante de la elaboración del queso tiene un color amarillento, como resultado de separar la caseína de la leche (responsable del color blanco opaco), tal como puede apreciarse en la fotografia. 


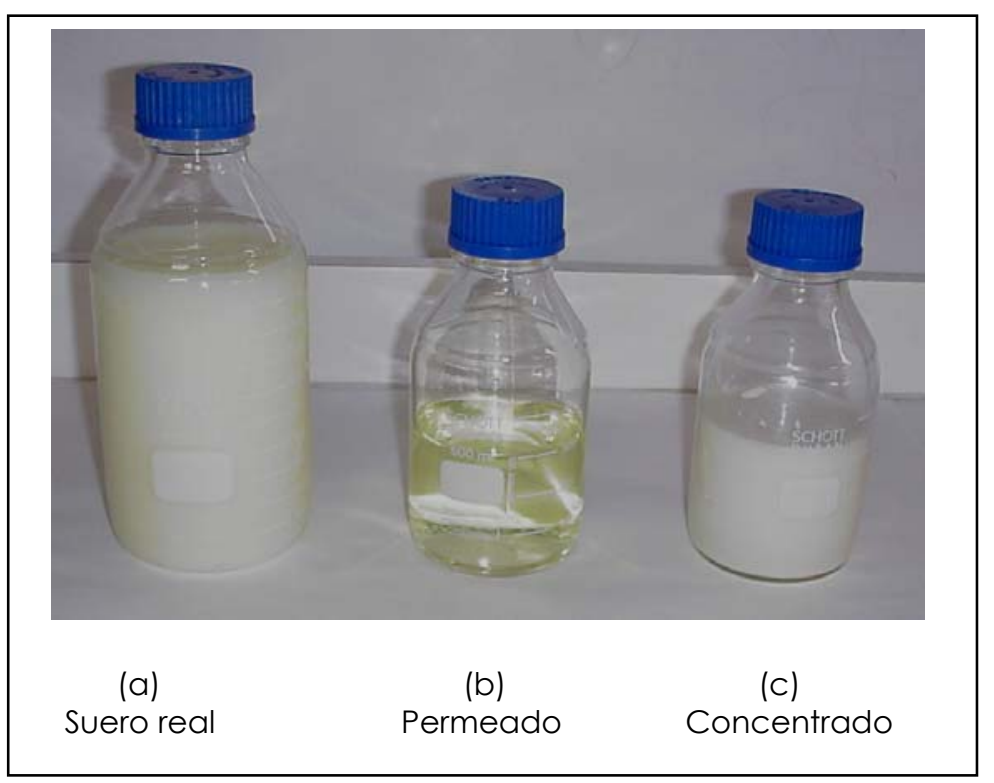

Figura 6.35. Apariencia del suero real, permeado y concentrado del proceso de UF

\subsubsection{Protocolos de limpieza}

Tal como se ha comentado anteriormente, después de cada presión ensayada la membrana se limpia utilizando diferentes protocolos de limpieza básica, ácida y enzimática, obteniéndose finalmente recuperaciones de la densidad de flujo entre el 95 y $100 \%$.

En esta etapa se tiene en cuenta la influencia de parámetros como: el pH, la concentración, el tiempo de limpieza, el caudal de recirculación, la presión y la temperatura, con objeto de establecer el protocolo óptimo que permita máximas recuperaciones respecto a la de la membrana. 
El fabricante de la membrana recomienda efectuar la limpieza a altas presiones (0,4 - 0,5 MPa), mientras que, en la mayoría de las referencias bibliográficas consultadas las presiones utilizada son más bajas (0,5-2,0 MPa). (Bartlett et al, 1995).

Se ensayan diferentes protocolos de limpieza, variando el orden de limpieza de los reactivos comerciales y los parámetros de operación con el fin de observar con cuales se obtienen los mejores resultados en cuanto a la densidad de flujo recuperado y a la resistencia de la membrana.

Para evaluar la efectividad de cada una de las etapas de limpieza se utiliza el término factor de recuperación y la resistencia hidráulica de la membrana.

\section{Factor de recuperación:}

$$
r_{J}=\frac{J_{p}}{J_{0}} \cdot 100
$$

Siendo,

$r_{J}$ : factor de recuperación de flujo.

$J_{p}$ : densidad de flujo de permeado al agua después de cada etapa de limpieza.

$J_{0}$ : densidad de flujo de permeado al agua de la membrana original.

La densidad de flujo al agua, servirá de referencia para determinar él factor de recuperación de flujo después de cada una de las etapas de limpieza. 


\section{Resistencia de la membrana}

Para determinar la resistencia hidráulica de la membrana se utilizó la ecuación de Darcy, en función de la densidad de flujo del permeado, la viscosidad de la disolución y la presión transmembranal aplicada.

$$
R_{h}=\frac{\Delta P}{J_{p} \cdot \mu}
$$

donde:

$\Delta \mathrm{P}$ es la presión transmembranal, $\mathrm{Jp}$ la densidad de flujo de permeado, $\mu$ es la viscosidad calculada a partir de la densidad y la viscosidad cinemática.

A lo largo del protocolo de limpieza es posible obtener diferentes resistencias hidráulicas de acuerdo a la etapa realizada, utilizando las siguientes notaciones para diferenciarlas.

$R_{m}$ : Resistencia de la membrana original, calculada como el inverso del valor de la permeabilidad al agua pura $\left(0,164 \times 10^{14} \mathrm{~m}^{-1}\right)$.

$\mathrm{R}_{\mathrm{L}}$ : Resistencia de limpieza. Calculada con la disolución de limpieza.

Rf: Resistencia de la membrana calculada finalmente con el agua pura después de enjuagar la disolución de limpieza.

$R_{\text {res }}=R_{f}-R_{m}$ : resistencia residual, después de la limpieza.

En la figura 6.36, se muestra de forma esquemática la distribución de las resistencias hidráulicas durante las diferentes etapas del proceso (ultrafiltración, enjuague y limpieza). 


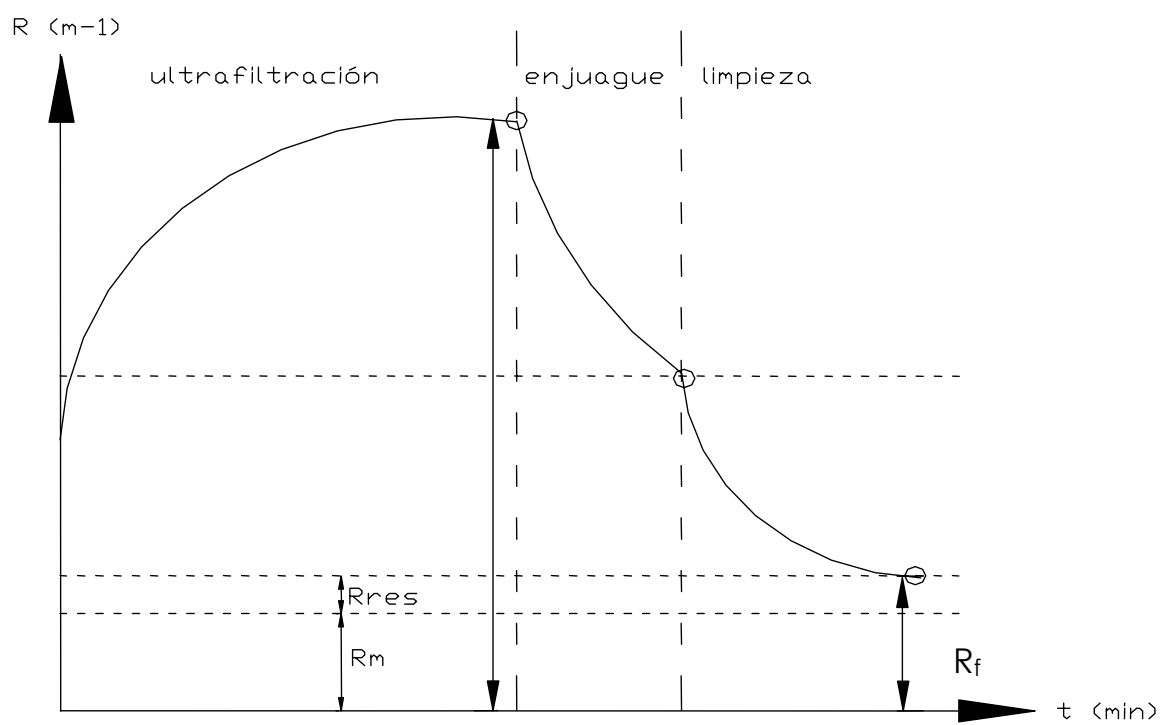

Figura 6.36. Distribución de las diferentes resistencias hidráulicas Adaptada de Argüello et al.

Daufin et al, 1991, obtuvieron una relación entre la resistencia residual de la membrana y la resistencia hidráulica de la membrana virgen para saber a partir de qué momento se podría considerar que la membrana esta limpia. En esta tesis se realiza un procedimiento similar, en el que se consideran los errores relativos aportados por cada uno de los equipos de medida (manómetros, probeta, cronometro, termómetro) para finalmente determinar cuando la membrana esta limpia. Además de esta relación también se tuvo en cuenta el término de factor de recuperación de flujo.

El error relativo aportado por cada uno de los elementos de medida es el siguiente: 


$$
\frac{\Delta R_{h}}{R_{h}} \leq \frac{\Delta P}{P}+\frac{\Delta V}{V}+\frac{\Delta t}{t}+\frac{\Delta T}{T}
$$

donde:

El término relativo a los errores aportados por los manómetros a la entrada y a la salida de la planta es: $\frac{\Delta P}{P} \leq 6,667 \%$

El término relativo al error aportado por la probeta es: $\frac{\Delta V}{V} \leq 1 \%$

El término relativo al error aportado por el cronómetro es: $\frac{\Delta t}{t} \leq 0,166 \%$

El término relativo al error aportado por el control de temperatura es: $\frac{\Delta T}{T} \leq 5 \%$

El sumatorio de todos los errores relativos a la medida de la resistencia da: $\frac{\Delta R_{h}}{R_{h}} \leq 12,68 \%$

De tal forma, que se puede considerar que la membrana esta limpia cuando la relación entre la resistencia residual y la de la membrana original es:

$\frac{R_{r e s}}{R_{m}} \leq 0,127$

Es común a todos los protocolos de limpieza, el determinar inicialmente, la resistencia de la membrana original, valor que servirá de referencia para hacer calcular el factor de recuperación de flujo y las diferentes resistencias de la membrana. 
En cada uno de los protocolos el ensuciamiento de la membrana se lleva a cabo después de 1 hora de operación, habiéndose procesado $15 \mathrm{~L}$ de un suero dulce.

\section{Protocolo 1}

Después de 1 hora de operación con el suero dulce procedente de la quesería, la densidad de flujo disminuye ostensiblemente, teniéndose que llevar a cabo la limpieza química de la membrana, y así eliminar las partículas responsables del ensuciamiento. Después de dicha limpieza química, se enjuaga la membrana con agua pura.

La secuencia de las etapas realizadas es:

1. Ensuciamiento de la membrana con el suero real

2. Enjuague con agua y medida del flujo recuperado y las resistencias

3. Limpieza básica

4. Enjuague con agua y medida del flujo recuperado y las resistencias

5. Limpieza ácida

6. Enjuague con agua y medida del flujo recuperado y las resistencias

7. Limpieza enzimática

8. Enjuague con agua y medida del flujo recuperado y las resistencias 
Tabla 6.19. Condiciones de operación del protocolo 1 de limpieza

\begin{tabular}{llll}
\hline Alimento & $\begin{array}{l}\Delta \mathrm{P} \\
(\mathrm{MPa})\end{array}$ & $\mathrm{T}\left({ }^{\circ} \mathrm{C}\right)$ & Operación \\
\hline Agua & 0,2 & 20 & $\mathrm{R}_{\mathrm{m}}$ \\
Suero real & 0,2 & 16 & Ensuciamiento \\
Agua & 0,2 & $20 / 35$ & Enjuague y cálculo $r_{J}$ \\
$\mathrm{NaOH}, \mathrm{pH}=10,5$ & 0,2 & $35 / 40$ & Limpieza \\
Agua & 0,2 & 20 & Enjuague y medida $r_{J}$ \\
$\mathrm{HCl}, \mathrm{pH}=3,0$ & 0,2 & $35 / 40$ & Limpieza \\
Agua & 0,2 & 20 & Enjuague y cálculo $r_{J}$ \\
SE-300 0,5-1,0\% & 0,2 & $35 / 40$ & Limpieza \\
y pH=9,0 & & & \\
Agua & 0,2 & 20 & Enjuague y cálculo $r_{J}$
\end{tabular}

Dichas etapas se pueden describir como:

\section{Enjuague}

Todos los enjuagues se realizaron siguiendo el mismo procedimiento, se desplazó inicialmente un volumen de agua, descartando tanto la corriente de concentrado como la de permeado hasta que las conductividades y el pH observados alcanzaron valores muy similares al agua utilizada.

\section{Limpieza básica}

Ayuda a eliminar el ensuciamiento ocasionado por la materia orgánica presente en el suero (proteínas, lactosa, citratos, etc.). Se utiliza hidróxido sódico a un pH = 10,5. Después de 22 minutos de limpieza el flujo de permeado disminuye y la disolución presenta 
cierta turbidez, por lo que se cambia dicha disolución por una nueva. Esta operación se repite tres veces, hasta la desaparición por completo de la turbidez, finalmente se enjuaga y se chequea el factor recuperación de flujo.

Como la recuperación de flujo obtenida es muy baja (38\%), tal como se muestra en la tabla 6.20, se continúa con la limpieza ácida, para intentar una mayor recuperación de flujo.

\section{Limpieza ácida}

Elimina el ensuciamiento debido principalmente a las sales minerales presentes en el suero (sodio, potasio, calcio, fosfatos, sulfatos, etc.). Como disolución de limpieza ácida, se usa una disolución de ácido clorhídrico a $\mathrm{pH}=3,0$ y temperatura de $35^{\circ} \mathrm{C}$. En este caso también fue necesario cambiar la disolución de limpieza hasta eliminar por completo la turbidez. La recuperación de flujo en este caso es del 39,4\%, valor todavía muy bajo, se continúa con la limpieza enzimática

\section{Limpieza enzimática}

Elimina el ensuciamiento debido principalmente a las proteínas presentes en el suero (LA, LG, BSA, Ig). La disolución enzimática empleada es una disolución comercial recomendada por el fabricante de la membrana, está basada en una enzima proteasa que se encarga de eliminar y degradar los restos de proteínas, mejorando la limpieza de la membrana. Se estudian dos disoluciones a concentraciones de 0,5 y $1 \%$ respectivamente a un $\mathrm{pH}$ de 9,0 , para ajustar el pH se utiliza hidróxido sódico. Después de 22 minutos de 
limpieza el flujo de permeado disminuye y también se detecta turbidez en la disolución, siendo necesario renovar la disolución.

El factor de recuperación de flujo, solo alcanzó el 50\% del valor inicial (membrana original), por lo que se decide aumentar la concentración de la disolución enzimática al 1\%. Después de ésta última limpieza enzimática y una vez enjuagada la membrana, se determina el factor de recuperación de flujo obteniéndose un valor del $95 \%$.

La tabla 6.20, así como las figuras 6.37 y 6.38 muestran los resultados obtenidos con cada una de las disoluciones de limpieza.

Tabla 6.20. Resumen de los resultados del protocolo 1

\begin{tabular}{lccc}
\hline $\begin{array}{l}\text { Operación de } \\
\text { limpieza }\end{array}$ & $r_{J}(\%)$ & $R_{\text {res }} \times 10^{-14}\left(\mathrm{~m}^{-1}\right)$ & $R_{\text {res }} / R_{m}$ \\
\hline $\mathrm{NaOH}, 35^{\circ} \mathrm{C}$ & 24,0 & 0,62 & 3,78 \\
$\mathrm{NaOH}, 40^{\circ} \mathrm{C}$ & 38,0 & 0,25 & 1,52 \\
$\mathrm{HCl}, 35^{\circ} \mathrm{C}$ & 39,4 & 0,24 & 1,46 \\
$\mathrm{SE} 3000,5 \%, 35^{\circ} \mathrm{C}$ & 49,0 & 0,16 & 0,98 \\
$\mathrm{SE} 3000,5 \%, 40^{\circ} \mathrm{C}$ & 51,0 & 0,14 & 0,85 \\
$\mathrm{SE} 3001 \%, 40^{\circ} \mathrm{C}$ & 95,0 & 0,01 & 0,06 \\
\hline
\end{tabular}

Puede observarse que los valores más bajos de resistencia se obtuvieron con la disolución enzimática al $1 \%$ y a $40^{\circ} \mathrm{C}$ al cabo del cual el flujo recuperado era del $95 \%$ y la relación entre la resistencia 
residual y la de la membrana virgen es menor al error determinado $(\leq 0,127)$.

Estos dos parámetros son bastante fiables a la hora de determinar que etapas del protocolo de limpieza, han sido más eficientes. Puede verse como la limpieza de la membrana va mejorando con cada una de las operaciones, obteniéndose los mejores resultados con la limpieza enzimática al $1 \%$ y $40^{\circ} \mathrm{C}$.

Las dificultades en la limpieza dependen del grado de ensuciamiento y si este es de tipo reversible o irreversible, de las condiciones de operación, del volumen de las disoluciones de limpieza, del área de membrana, del tipo de material, así como de la configuración de membrana.

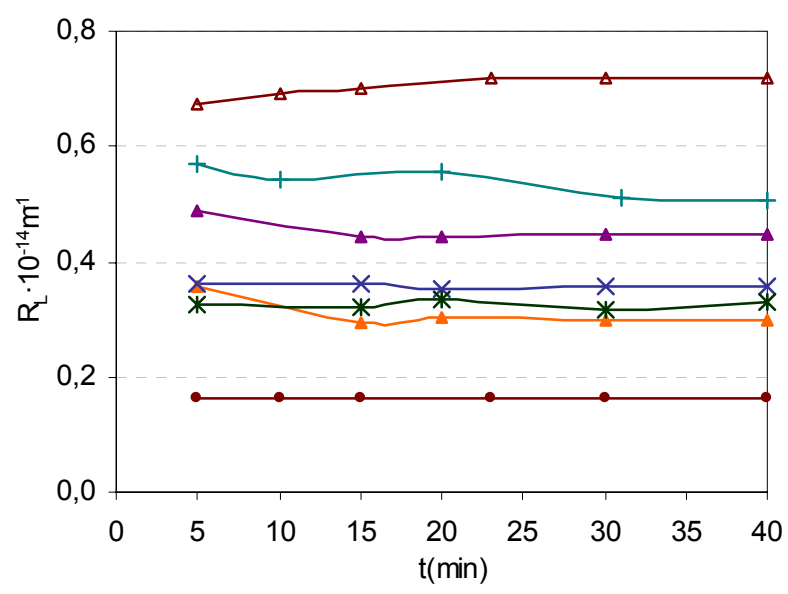

Figura 6.37. Resistencia de la membrana durante la limpieza. $\triangle \mathrm{NaOH} 35^{\circ} \mathrm{C} ;+\mathrm{NaOH}, 40^{\circ} \mathrm{C} ; \Delta \mathrm{HCl} ; \mathbf{X ~ S E ~} 0,5 \%$ y $35^{\circ} \mathrm{C}$;

SE $0,5 \%$ y $40^{\circ} \mathrm{C} ; \triangle \mathrm{SE} 1 \%$ y $40^{\circ} \mathrm{C} ;(\bullet) \mathrm{Rm}_{\mathrm{m}}$ 


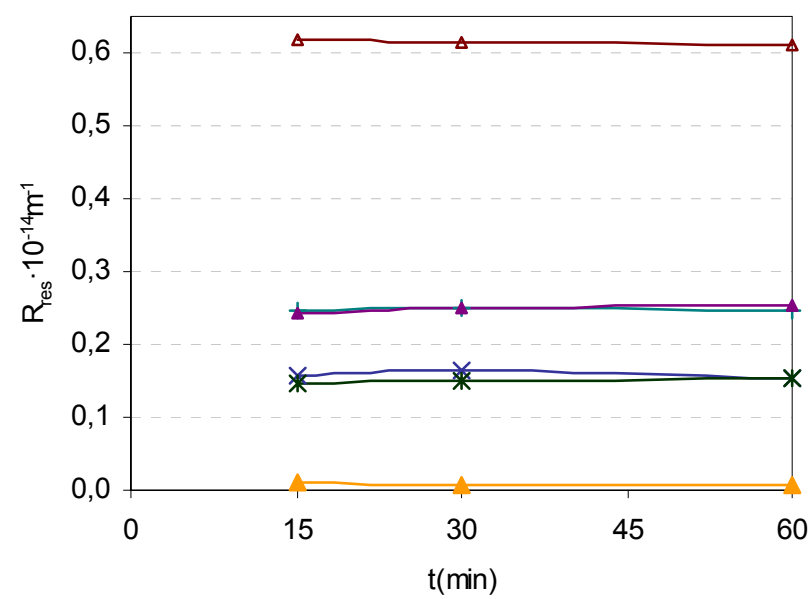

Figura 6.38. Resistencia residual de la membrana $\triangle \mathrm{NaOH} 35^{\circ} \mathrm{C} ;+\mathrm{NaOH}, 40^{\circ} \mathrm{C} ; \boldsymbol{\Delta} \mathrm{HCl} ; \times$ SE $0,5 \%$ y $35^{\circ} \mathrm{C}$;

$\%$ SE $0,5 \%$ y $40^{\circ} \mathrm{C} ; \triangle \mathrm{SE} 1 \%$ y $40^{\circ} \mathrm{C}$;

A continuación se realiza un segundo protocolo de limpieza, pero modificando la secuencia de los reactivos comerciales, con el fin de determinar con cual se obtienen los mejores resultados.

\section{Protocolo 2}

Teniendo en cuenta los resultados obtenidos con el protocolo anterior. En este ensayo se modifican algunas secuencias de limpieza con respecto al protocolo 1, con objeto de mejorar tanto la eficacia como el número de etapas de limpieza. La secuencia realizada se encuentra esquematizada en la siguiente tabla 6.21. 
Tabla 6.21. Condiciones de operación del protocolo 2 de limpieza

\begin{tabular}{llll}
\hline Alimento & $\begin{array}{l}\Delta \mathrm{P} \\
(\mathrm{MPa})\end{array}$ & $\begin{array}{l}\mathrm{T} \\
\left({ }^{\circ} \mathrm{C}\right)\end{array}$ & Operación \\
\hline Agua & 0,2 & 20 & $\mathrm{R}_{\mathrm{m}}$ \\
Suero & 0,2 & 16 & Ensuciamiento \\
Agua & 0,2 & 40 & Enjuague y medida $r_{J}$ \\
SE 300, 1\% & 0,2 & 40 & Limpieza \\
Agua & 0,2 & 20 & Enjuague y medida $r_{J}$ \\
NaOH, $\mathrm{pH}=10,5$ & 0,2 & 40 & Limpieza \\
Agua & 0,2 & 20 & Enjuague y medida $r_{J}$ \\
HCl, pH=3,0 & 0,2 & 40 & Limpieza \\
Agua & 0,2 & 20 & Enjuague y medida $r_{J}$ \\
\hline
\end{tabular}

En la tabla 6.22 y las figuras 6.39 y 6.40 se muestran los resultados obtenidos con cada una de las disoluciones de limpieza.

Se observa que a medida que transcurre la limpieza con cada una de las disoluciones la resistencia residual es cada vez menor y cercana a los valores de la membrana original.

En la última operación de limpieza con el ácido clorhídrico, se obtienen valores negativos de resistencia residual, esto puede ser debido a que el proceso de limpieza, modificará la estructura del poro de la membrana. Sin embargo, el rechazo de proteínas de la membrana no se ve afectado, tal como se observa en la tabla 6.22. 
Tabla 6.22. Resumen de los resultados del protocolo 2 de limpieza.

\begin{tabular}{lccc}
\hline Operación de limpieza & $r_{J}(\%)$ & $R_{\text {res }} \times 10^{-14}\left(\mathrm{~m}^{-1}\right)$ & $\mathrm{R}_{\mathrm{res}} / \mathrm{Rm}_{\mathrm{m}}$ \\
\hline $\mathrm{SE} 3001 \%, 40^{\circ} \mathrm{C}$ & 68 & 0,075 & 0,457 \\
$\mathrm{NaOH}, 40^{\circ} \mathrm{C}$ & 90 & 0,015 & 0,091 \\
$\mathrm{HCl}, 40^{\circ} \mathrm{C}$ & 100 & $-0,004$ & $-0,020$ \\
\hline
\end{tabular}

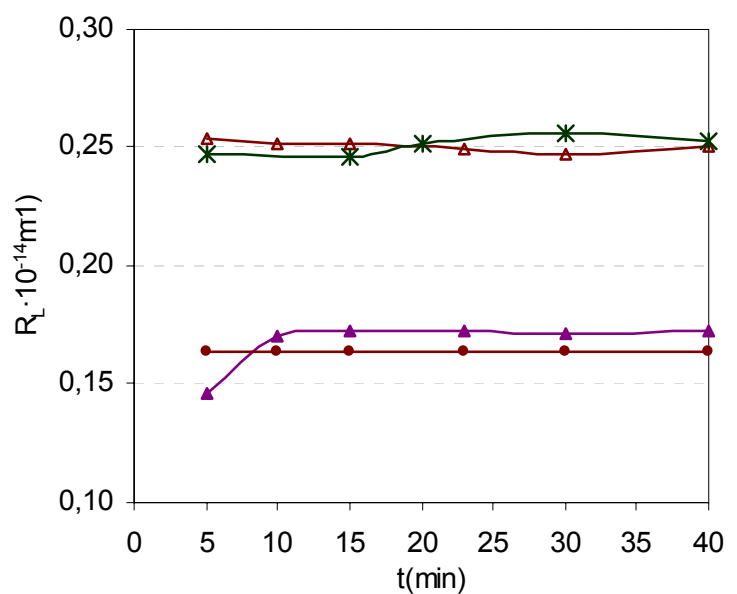

Figura 6.39. Resistencia de la membrana durante la limpieza $\triangle \mathrm{NaOH} 40^{\circ} \mathrm{C} ; \quad \triangle \mathrm{HCl} 40^{\circ} \mathrm{C}$; $* \mathrm{SE} 0,5 \%$ y $40^{\circ} \mathrm{C} ; \cdot \mathrm{Rm}$

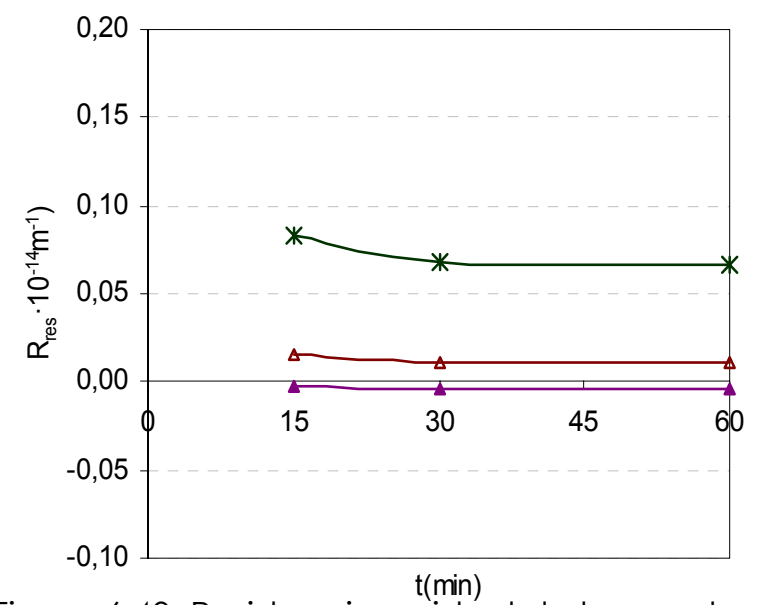

Figura 6.40. Resistencia residual de la membrana $\triangle \mathrm{NaOH} 40^{\circ} \mathrm{C} ; \quad \triangle \mathrm{HCl} 40^{\circ} \mathrm{C} ; \quad$ \% SE $0,5 \%$ y $40^{\circ} \mathrm{C}$ 
Si se comparan los resultados obtenidos entre el primer y segundo protocolo de limpieza, la menor resistencia residual se obtiene con éste último, presentando valores muy por debajo respecto al error relativo.

\subsubsection{Ensayos de nanofiltración}

En esta etapa, se trabaja con el permeado ultrafiltrado de lactosvero dulce. Las membranas seleccionadas para esta etapa son la NF200 y Ds-5 DL, de configuración arrolladas en espiral, para la desmineralización parcial del lactosuero dulce. La membrana NF200 se selecciona por poseer altas densidades de flujo y elevados índices de rechazo, mientras que la membrana Ds-5 DL se considera pese a poseer densidades de flujo intermedias y por tener bajos índices de rechazo.

Así mismo se pretende determinar que membrana es más idónea para llevar a cabo la desmineralización del lactosuero dulce. Antes de ser utilizadas con la disolución de suero real, se determina la densidad de flujo al agua de ambas membranas. Los resultados obtenidos se muestran en la figura 6.41 . 


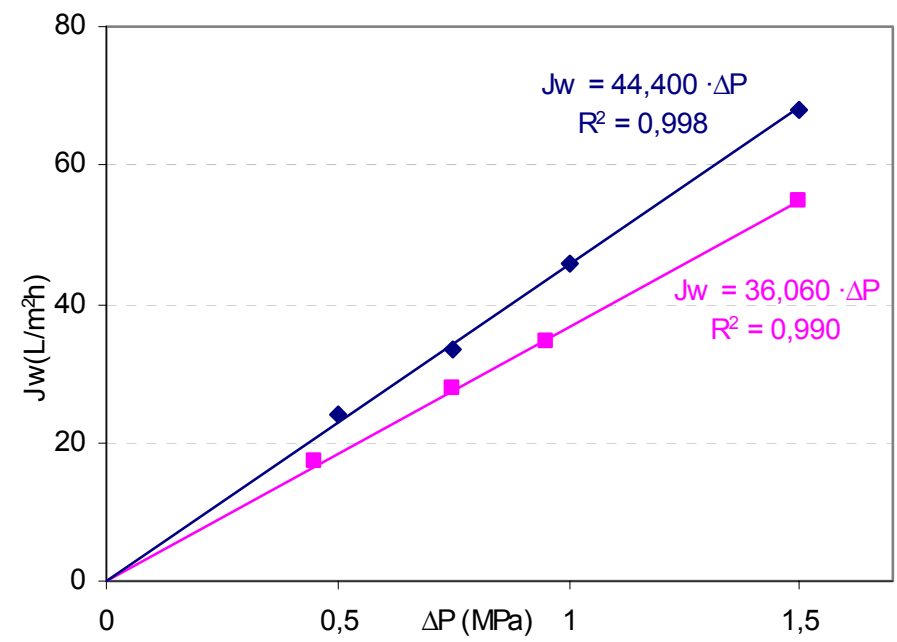

Figura 6.41. Comparación de las densidades de flujo al agua.

- Ds-5 DL; * NF200. T=20 $\pm 1^{\circ} \mathrm{C}, Q_{R}=400 \mathrm{~L} / \mathrm{h}$

En la figura 6.41, se muestran los valores de las densidades de flujo de la membrana NF200 y Ds-5 DL, con buenos coeficientes de correlación. Como se comentó en apartados anteriores, el resultado que cabe esperar es el de una línea recta que pasa por el origen, tal como se puede apreciar en la figura anterior. La pendiente representa el coeficiente de permeabilidad al agua de ambas membranas ensayadas, siendo en este caso de $44,4 \mathrm{~L} \cdot \mathrm{m}^{-2} \cdot \mathrm{h}^{-1} \cdot \mathrm{MPa}^{-1}$ para la membrana NF200 y para la membrana Ds-5DL $36,06 \mathrm{~L} \cdot \mathrm{m}^{-2} \cdot \mathrm{h}$ $1 \cdot \mathrm{MPa}^{-1}$. Se aprecia que la membrana NF200 tal como se ha comentado anteriormente proporciona mayor cantidad de densidad de flujo de permeado (un $23 \%$ más que la membrana Ds-5 DL), para la misma presión de operación. 
6.3.2.1. Comparación de las membranas NF200 y Ds-5 DL con el suero real ultrafiltrado

Antes de proceder a estudiar el comportamiento de ambas membranas con el permeado de suero dulce ultrafiltrado, se analiza la composición del mismo. Los valores obtenidos se muestran a continuación en la tabla 6.23

Tabla 6.23. Composición del permeado del suero UF (PUF).

\begin{tabular}{lc}
\hline PUF & Concentración (g/L) \\
\hline Proteínas & $2,0-2,2$ \\
Lactosa & $36,6-56,0$ \\
Grasas & 0,0 \\
Cloruro & $1,40-1,01$ \\
Sodio & $0,45-0,30$ \\
Potasio & $1,70-1,20$ \\
Magnesio & $0,10-0,07$ \\
Sulfato & $0,12-0,07$ \\
Fosfato & $0,80-0,50$ \\
pH & $6,10-6,50$ \\
$\kappa$, mS/cm & $6,40-4,30$ \\
\hline
\end{tabular}

\section{Densidad de flujo de permeado}

Las membranas NF200 y Ds-5 DL se ensayan con la disolución de suero UF, variando la presión y el caudal de recirculación. La concentración de alimentación se mantiene constante, recirculando 
la corriente de permeado y de concentrado al tanque de alimentación. Los resultados obtenidos se muestran en las siguientes figuras:

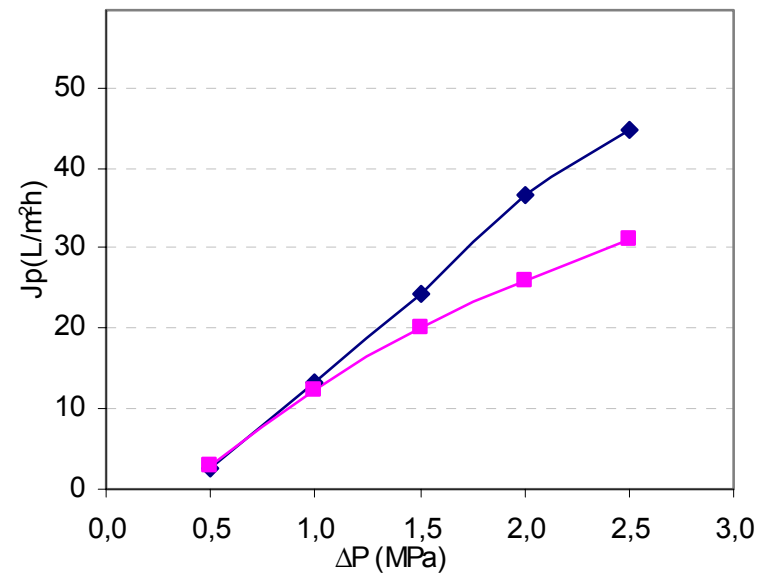

Figura 6.42. Variación de J con $\Delta P$.

- Ds-s DL, $\mathrm{pH}=6,34 ; \kappa=4,6 \mathrm{mS} / \mathrm{cm}$ y $\rightarrow \mathrm{NF} 200, \mathrm{pH}=6,30, \kappa=5,7 \mathrm{mS} / \mathrm{cm}$

Como puede observarse en la figura 6.42, los valores de densidad de flujo de las membranas NF200 y Ds-5 DL muestran diferencias a partir de 1,0 MPa de presión, mientras que las diferencias son mínimas para los valores más bajos.

\section{Densidad de flujo de soluto}

En las tablas 6.24 y 6.25 se pueden observar los resultados obtenidos para las dos membranas objeto de este estudio. Este parámetro es de gran utilidad a la hora de estudiar las condiciones con las que se obtienen las tasas de desmineralización más altas. 
Los resultados obtenidos con la membrana NF200 muestran como a medida que se aumenta la presión, también lo hace la densidad de flujo de soluto, mostrando un máximo a la presión de 2 MPa. La densidad de flujo de soluto (Js) es función de la densidad de flujo de permeado y del índice de rechazo ó de la concentración de soluto en el permeado de acuerdo con la ecuación 5.4, por lo que este máximo se debe más al aumento de flujo que al índice de rechazo, tal como se observa en la figura 6.42b, que tiende a estabilizarse con el aumento de presión.

Tabla 6.24. Densidad de flujo de soluto. Membrana NF200. $\mathrm{T}=16^{\circ} \mathrm{C}$, $Q_{R}=400 \mathrm{~L} / \mathrm{h}$.

\begin{tabular}{lcccccccc}
\hline$\Delta P$ & \multicolumn{7}{c}{$\mathrm{Js}\left(\mathrm{g} / \mathrm{m}^{2} \mathrm{~h}\right)$} \\
\cline { 2 - 9 } $\mathrm{MPa}$ & lactosa & $\mathrm{Cl}^{-}$ & $\mathrm{SO}_{4}^{-2}$ & $\mathrm{PO}_{4}^{-3}$ & $\mathrm{Na}^{+}$ & $\mathrm{K}^{+}$ & $\mathrm{Ca}^{+2}$ & $\mathrm{Mg}^{+2}$ \\
\hline 0,5 & 22,99 & 3,21 & 0,06 & 0,25 & 0,68 & 2,61 & 0,19 & 0,04 \\
1,0 & 30,43 & 6,90 & 0,09 & 0,23 & 1,52 & 5,91 & 0,26 & 0,07 \\
1,5 & 27,28 & 8,44 & 0,09 & 0,29 & 1,92 & 7,43 & 0,23 & 0,06 \\
2,0 & 44,35 & 9,90 & 0,12 & 0,47 & 2,39 & 9,13 & 0,32 & 0,09 \\
2,5 & 31,56 & 11,58 & 0,13 & 0,46 & 2,69 & 9,98 & 0,30 & 0,07 \\
\hline
\end{tabular}

De acuerdo a los resultados expuestos en la tabla anterior, se obtiene la siguiente secuencia respecto a la densidad de soluto.

$$
\mathrm{J}(\text { lactosa })>>\mathrm{J}\left(\mathrm{Cl}^{-}, \mathrm{K}^{+}\right)>\mathrm{J}\left(\mathrm{Na}^{+}\right)>\mathrm{J}\left(\mathrm{PO}^{-3}\right)>\mathrm{J}\left(\mathrm{Ca}^{+2}\right)>\mathrm{J}\left(\mathrm{SO}^{-2}, \mathrm{Mg}^{+2}\right)
$$

El mismo razonamiento hecho con la membrana NF200, cabe con la Ds-5 DL, pues ambas presentan comportamientos similares respecto al transporte de lactosa a la corriente de permeado. En este caso los máximos valores se observan a las presiones de 1,5 y 2,5 MPa, 
mientras que el índice de rechazo tiende a estabilizarse con la presión hasta alcanzar valores muy similares. A partir de los resultados obtenidos puede decirse que para membranas con índices de rechazo del mismo orden de magnitud y elevadas permeabilidades, el paso de soluto está más influenciado por éste último, como sucede en el rango de presiones 1,5 - 2,0 MPa con índices de rechazo de 97,88 y 97,69 respectivamente.

Tabla 6.25. Densidad de flujo de soluto. Membrana Ds-5 DL. T $=16^{\circ} \mathrm{C}$, $Q_{R}=400 \mathrm{~L} / \mathrm{h}$.

\begin{tabular}{lcccccccc}
\hline$\Delta \mathrm{P}$ & \multicolumn{8}{c}{$\mathrm{Js}\left(\mathrm{g} / \mathrm{m}^{2} \mathrm{~h}\right)$} \\
\cline { 2 - 9 } $\mathrm{MPa}$ & lactosa & $\mathrm{Cl}^{-}$ & $\mathrm{SO}_{4}^{-2}$ & $\mathrm{PO}^{-3}$ & $\mathrm{Na}^{+}$ & $\mathrm{K}^{+}$ & $\mathrm{Ca}^{+2}$ & $\mathrm{Mg}^{+2}$ \\
\hline 0,5 & 16,31 & 5,11 & 0,04 & 0,61 & 1,11 & 4,25 & 0,26 & 0,07 \\
1,0 & 44,76 & 16,92 & 0,09 & 1,19 & 3,66 & 14,14 & 0,66 & 0,20 \\
1,5 & 58,23 & 26,53 & 0,11 & 1,58 & 5,84 & 21,42 & 0,89 & 0,22 \\
2,0 & 48,65 & 32,42 & 0,12 & 1,64 & 7,41 & 27,38 & 0,96 & 0,25 \\
2,5 & 72,42 & 38,04 & 0,26 & 2,12 & 8,64 & 31,36 & 1,19 & 0,28 \\
\hline
\end{tabular}

De manera similar, la secuencia respecto a la densidad de soluto que se obtiene con la membrana Ds-5DL es la siguiente.

$$
\mathrm{J}(\text { lactosa })>>J\left(\mathrm{Cl}^{-}, \mathrm{K}^{+}\right)>J\left(\mathrm{Na}^{+}\right)>J\left(\mathrm{PO}_{4}^{-3}\right)>\mathrm{J}\left(\mathrm{Ca}^{+2}\right)>\mathrm{J}\left(\mathrm{SO}_{4}^{-2}, \mathrm{Mg}^{+2}\right)
$$

Al comparar los resultados obtenidos puede apreciarse como a pesar de que la membrana Ds-5 DL a valores más altos de presión (2,5 MPa) presenta más pérdidas de lactosa comparada con la NF200. Si se trabaja por debajo de $2 \mathrm{MPa}$, las diferencias se minimizan con el valor añadido de que es la membrana Ds-5 DL, la que presenta un porcentaje más alto de desmineralización. Al aumentar 
la presión, también lo hace el paso de soluto debido al aumento en la densidad de flujo, pues el índice de rechazo varía en menor proporción.

\section{Índice de rechazo}

En la figura 6.43 , se muestran los valores obtenidos para aniones y cationes. Puede observarse que a medida que aumenta la presión también lo hace el índice de rechazo. Las membranas NF200 y Ds-5 DL presentan índices de rechazo altos para los iones fosfato, sulfato, calcio y magnesio, así como para la lactosa con valores alrededor del $96 \%$.

La membrana NF200 es la que tiene los índices de rechazo más altos no solo para los iones polivalentes, sino también para los monovalentes, por lo que se puede decir que le cuesta separar unos de otros. Por otro lado, la membrana Ds-5 DL presenta índices de rechazo negativos para el ión cloruro y a medida que va aumentado el paso de disolvente este va aproximándose a valores positivos, este comportamiento es característico de membranas de NF y se le atribuye al efecto Donnan, tal como se ha comentado en apartado 4.2.5.3. Resultados similares han sido obtenidos por varios investigadores, entre ellos Szoke et al (2002) que encontraron rechazos negativos a bajas densidades de flujo y al aumentar la densidad de flujo los rechazos cambian a valores positivos. 
En esta tesis, además de los índices de rechazo de cloruro, también se obtienen valores bajos respecto a los demás iones monovalentes, mientras que los polivalentes están sobre un $90 \%$.

A la luz de los resultados anteriores (densidad de flujo de permeado, densidad de flujo de soluto e índice de rechazo) se decide sacrificar un poco de pérdida de lactosa pero con un mayor grado de desmineralización, por lo que para los apartados posteriores se continuara con la membrana Ds-5 DL.

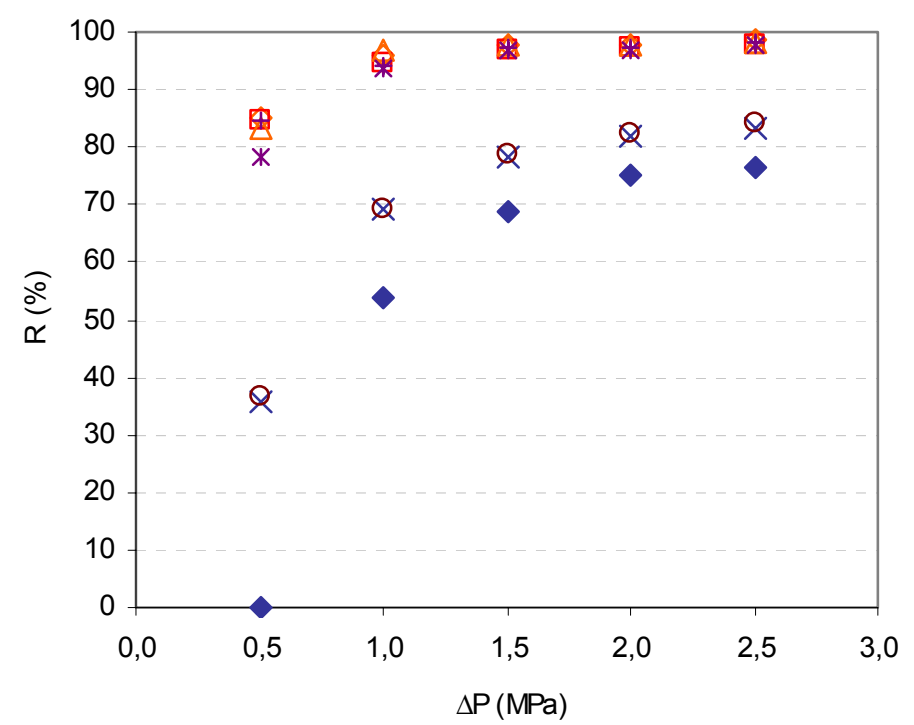

Figura 6.43a. Membrana NF200. $\mathrm{pH}=6,34 ; \mathrm{\kappa}=4,6 \mathrm{mS} / \mathrm{cm}$ 


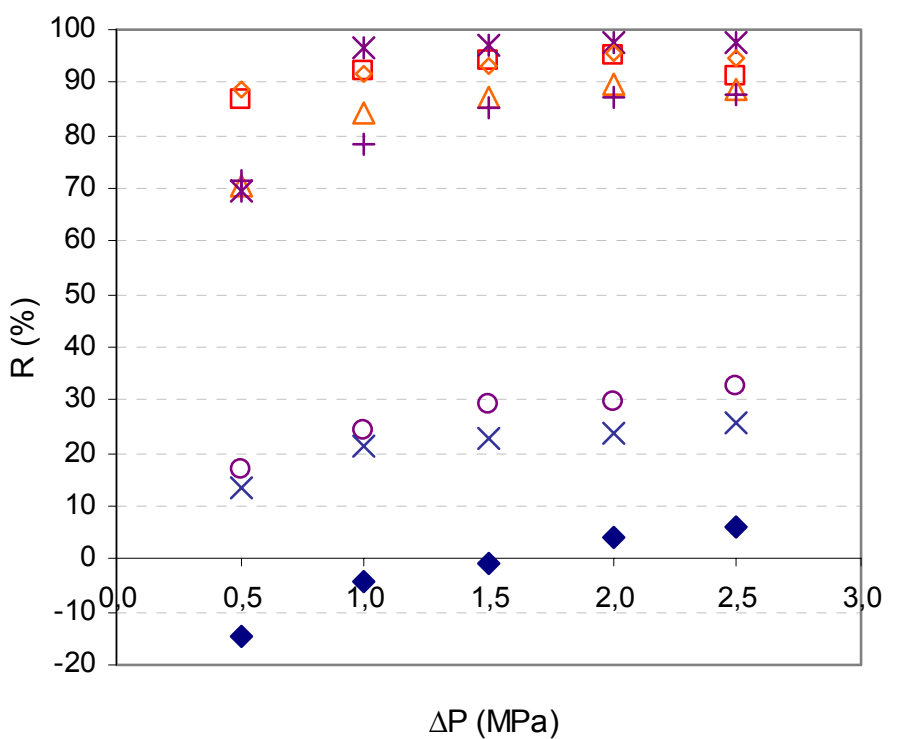

Figura 6.43b. Membrana Ds-5 DL. $\mathrm{pH}=6,30, \kappa=5,7 \mathrm{~ms} / \mathrm{cm}$

Figura 6.43. Variación de R con $\Delta \mathrm{P}$. Membranas NF200 y Ds-5 DL. $\mathrm{KCa}^{+2} ; \square \mathrm{SO}_{4}^{-2} ; \Delta \mathrm{PO}_{4}^{-3} ;+\mathrm{Mg}^{+2} ; \diamond$ lactosa; $\circ \mathrm{K}^{+} ; \times \mathrm{Na}^{+} ; \bullet \mathrm{Cl}^{-}$

6.3.2.2. Caracterización de la membrana Ds-5 DL con el suero ultrafiltrado

Después de comparación los resultados obtenidos con las membranas NF200 y Ds-5 DL, se vuelven a repetir una serie de ensayos variando algunas condiciones de operación con la membrana que aporta los mejores resultados en cuanto a tasas de desmineralización (Ds-5 DL). 


\section{Densidad de flujo de permeado}

Se realizan las experiencias a distintas presiones y caudales de recirculación para estudiar la influencia de estos sobre el comportamiento de la membrana. En la figura 6.44, se pueden observar los resultados obtenidos a dos caudales de circulación diferentes y un rango de presiones de operación entre 0,7 y 1,5 MPa

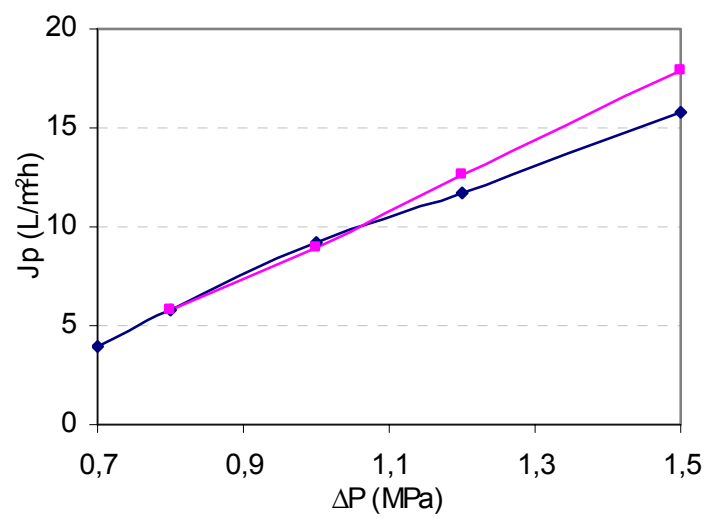

Figura 6.44. Variación de J con $\triangle \mathrm{P}$. suero UF. Ds-5 DL . $\mathrm{pH}=6,23, \mathrm{\kappa}=6,35 \mathrm{mS} / \mathrm{cm} . \quad-\mathrm{QR}=400 \mathrm{~L} / \mathrm{h} ;-\mathrm{QR}=500 \mathrm{~L} / \mathrm{h}$

De la figura anterior se observa una ligera diferencia entre los dos caudales de rechazo ensayados. Para ambos caudales no hay una diferencia significativa en el rango de presiones de 0,7 MPa a 1,2 MPa, pues sus densidades de flujo son prácticamente las mismas. Sin embargo, a presiones mayores de 1,2 MPa se empiezan a notar diferencias, ya que, un aumento en el caudal de circulación provoca un aumento en la densidad de flujo de permeado. El trabajar a mayores caudales de recirculación supone trabajar con 
conversiones más bajas de las recomendadas por el fabricante, ocasionando un gasto innecesario de energía.

Se observa que con el caudal de circulación de $500 \mathrm{~L} / \mathrm{h}$ hay una tendencia lineal en todo el rango de presiones ensayadas. Mientras que, para el caudal más bajo, a medida que aumenta la presión, la densidad de flujo tiende a una curva, seguramente debido al fenómeno de polarización por concentración.

El comportamiento asintótico es característico del fenómeno de polarización por concentración, comentado en capítulos anteriores. Muchos trabajos han documentado este hecho, pues a menor caudal de recirculación las partículas tienden a depositarse más fácilmente sobre la superficie de la membrana, creando una capa límite. Mientras que a valores más altos, esta capa tarda más en formarse.

Si se comparan los resultados obtenidos con el suero dulce y la disolución modelo ( $\mathrm{pH}=6,5$ y $\kappa=6,02 \mathrm{~ms} / \mathrm{cm}$ ) para el caudal de 400 $\mathrm{L} / \mathrm{h}$, puede observarse cómo las diferencias no son tan grandes.

\section{Densidad de flujo de soluto}

La densidad de flujo de soluto aumentó con la presión, con valores más próximos entre si para los últimos rangos de presión. Entre los dos caudales de rechazo estudiados no se observan diferencias significativas respecto de los iones, sin embargo para la lactosa si. Este hecho puede ser atribuido a que al trabajar a un caudal más 
bajo el fenómeno de polarización por concentración favorece la formación de una capa gel que ayuda que no pase mucha lactosa a la corriente de permeado.

Tabla 6.26. Densidad de flujo de soluto. $T=16 \pm 1^{\circ} \mathrm{C}, Q_{R}=400 \mathrm{~L} / \mathrm{h}$.

\begin{tabular}{lcccccccc}
\hline$\Delta \mathrm{P}$ & \multicolumn{7}{c}{$\mathrm{Js}\left(\mathrm{g} / \mathrm{m}^{2} \mathrm{~h}\right)$} \\
\cline { 2 - 9 } $\mathrm{MPa}$ & lactosa & $\mathrm{Cl}^{-}$ & $\mathrm{SO}_{4}{ }^{-2}$ & $\mathrm{PO}_{4}^{-3}$ & $\mathrm{Na}^{+}$ & $\mathrm{K}^{+}$ & $\mathrm{Ca}^{+2}$ & $\mathrm{Mg}^{+2}$ \\
\hline 0,7 & 26,42 & 7,93 & 0,05 & 0,76 & 2,15 & 6,13 & 0,30 & 0,07 \\
0,8 & 28,39 & 11,30 & 0,06 & 0,94 & 2,60 & 8,11 & 0,40 & 0,13 \\
1,0 & 41,19 & 17,43 & 0,07 & 1,29 & 3,39 & 12,81 & 0,58 & 0,11 \\
1,2 & 24,29 & 21,62 & 0,10 & 1,22 & 4,12 & 16,08 & 0,61 & 0,12 \\
1,5 & 29,02 & 27,41 & 0,11 & 1,35 & 5,30 & 20,39 & 0,63 & 0,11 \\
\hline
\end{tabular}

Tabla 6.27. Densidad de flujo de soluto. $T=16 \pm 1^{\circ} \mathrm{C}, Q_{R}=500 \mathrm{~L} / \mathrm{h}$.

\begin{tabular}{lcccccccc}
\hline$\Delta P$ & \multicolumn{7}{c}{$\mathrm{Js}\left(\mathrm{g} / \mathrm{m}^{2} \mathrm{~h}\right)$} \\
\cline { 2 - 9 } $\mathrm{MPa}$ & lactosa & $\mathrm{Cl}^{-}$ & $\mathrm{SO}_{4}^{-2}$ & $\mathrm{PO}_{4}^{-3}$ & $\mathrm{Na}^{+}$ & $\mathrm{K}^{+}$ & $\mathrm{Ca}^{+2}$ & $\mathrm{Mg}^{+2}$ \\
\hline 0,8 & 19,16 & 11,18 & 0,07 & 0,82 & 2,30 & 8,41 & 0,50 & 0,13 \\
1,0 & 27,22 & 16,90 & 0,09 & 1,08 & 3,47 & 12,77 & 0,89 & 0,32 \\
1,2 & 32,48 & 22,87 & 0,11 & 1,35 & 4,70 & 18,16 & 0,82 & 0,21 \\
1,5 & 64,14 & 31,52 & 0,17 & 2,09 & 6,49 & 24,01 & 1,60 & 0,40 \\
\hline
\end{tabular}

Para ambos caudales de rechazo, el orden de densidad de flujo de soluto obtenido, sigue la siguiente secuencia:

$$
\mathrm{J}(\text { lactosa, } \mathrm{Cl})>\mathrm{J}\left(\mathrm{K}^{+}, \mathrm{Na}^{+}\right)>>\mathrm{J}\left(\mathrm{PO}^{-3}, \mathrm{SO}^{-2}, \mathrm{Ca}^{+2}, \mathrm{Mg}^{+2}\right)
$$

Las pérdidas más bajas de lactosa son las que se obtienen con el caudal de $400 \mathrm{~L} / \mathrm{h}$. 
Si se comparan los resultados obtenidos con el suero real y la disolución modelo ( $\mathrm{pH}=6,5$ y $\kappa=6,02 \mathrm{~ms} / \mathrm{cm}$ ), al caudal de $400 \mathrm{~L} / \mathrm{h}$ puede observarse como las diferencias con este parámetro ya empiezan a notarse, pues las pérdidas de lactosa son mucho más altas con la disolución de suero real, debido a que las pérdidas de lactosa aumentan; con respecto a los iones divalentes no se observan diferencias significativas, mientras que con respecto al ión cloruro y al potasio las diferencias son apreciables, pues el paso de soluto con el suero dulce es el doble que con la disolución modelo. Lo que pone de manifiesto que el comportamiento de la membrana ha cambiado, debido seguramente a las interacciones de los iones presentes en el suero dulce entre si y la membrana.

\section{Índice de rechazo}

En la figura 6.45, se observa que para el ión cloruro se obtienen rechazos negativos, pues la concentración de cloruros en el permeado es más alta que en el alimento, favorecido por las densidades de flujo de permeado, pues a valores más bajos de densidad de flujo, se obtienen valores más negativos, debido a la disminución del flujo de disolvente.

Respecto a la lactosa, puede apreciarse como el fenómeno de polarización por concentración incrementa el índice de rechazo. Pues se observa que este el índice de rechazo aumenta desde los valores más bajos de presión de operación hacia los más altos. Este hecho, favorece que la pérdida de lactosa sea menor. Este comportamiento pudo verse influenciado por el caudal de 
recirculación $(400 \mathrm{~L} / \mathrm{h})$ y la presencia de proteínas en el alimento, pues en la tabla 6.25, puede verse que hay una concentración muy baja en proteínas $(0,22 \%)$ que pudo favorecer la formación de capa gel. Sin embargo, este hecho no afectó la permeabilidad de la membrana, ya que al finalizar los ensayos y limpiarla solo con agua, se comprobó que la densidad de flujo al agua apenas había variado.

Por otro lado, si se comparan los resultados obtenidos con el suero real y la disolución modelo $(\mathrm{pH}=6,5$ y $\kappa=6,02 \mathrm{mS} / \mathrm{cm})$, para el caudal de $400 \mathrm{~L} / \mathrm{h}$ puede observarse cómo las diferencias en cuanto al índice de rechazo han cambiado con respecto a todos los iones y a la lactosa. Una forma de explicar estas diferencias es que la disolución real es mucho más compleja que la disolución modelo.

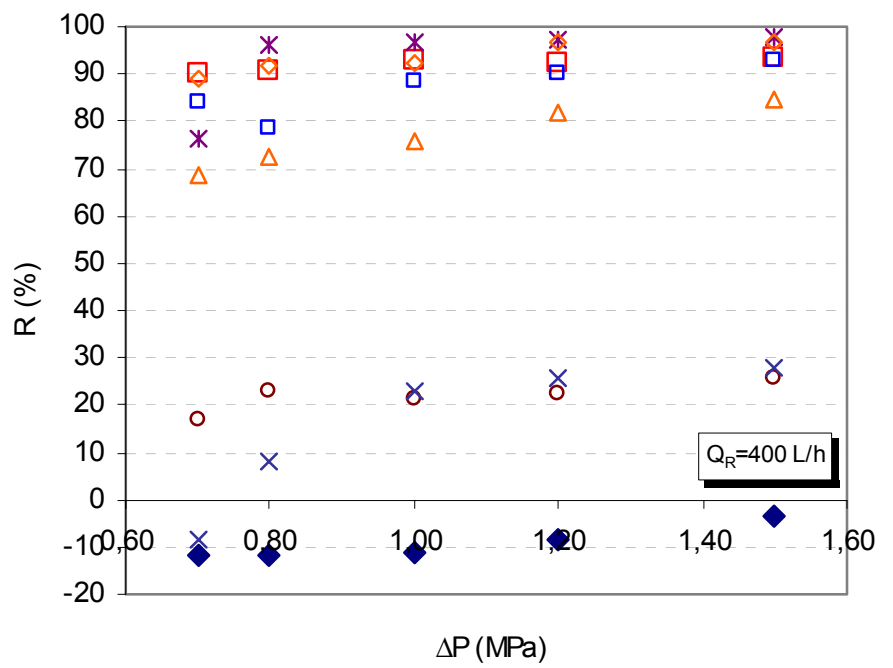

$* \mathrm{Ca}^{+2} ; \square \mathrm{SO}_{4}^{-2} ; \Delta \mathrm{PO}_{4}^{-3} ;+\mathrm{Mg}^{+2} ; \diamond$ lactosa; $\square \mathrm{K}^{+} ; \quad \mathrm{x} \mathrm{Na}^{+} ; \quad \mathrm{Cl}^{-}$ 


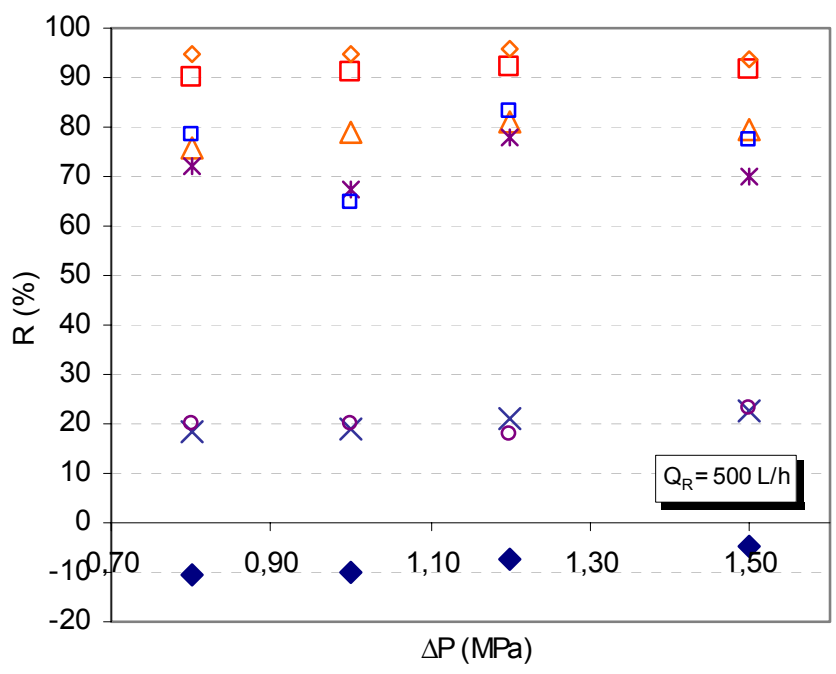

Figura 6.45. Variación de $\mathrm{R}$ con $\triangle \mathrm{P} . \mathrm{T}=16 \pm 1^{\circ} \mathrm{C}$

$* \mathrm{Ca}^{+2} ; \square \mathrm{SO}_{4}{ }^{-2} ; \Delta \mathrm{PO}_{4}^{-3} ;+\mathrm{Mg}^{+2} ; \diamond$ lactosa; $\square \mathrm{K}^{+} ; \mathrm{x} \mathrm{Na}^{+} ; \bullet \mathrm{Cl}^{-}$

A partir de los resultados anteriores y los obtenidos con las disoluciones modelo, puede observarse que la membrana presenta mayores rechazos para los iones sulfato, fosfato, calcio, magnesio y lactosa que para los iones cloruro, potasio y sodio. De todos ellos, es con el ión cloruro con el que se obtienen los valores más bajos para las condiciones estudiadas. Puede decirse que el rechazo no varia casi con la presión, obteniéndose valores más o menos constantes en el rango de presiones estudiadas; excepto para el ión cloruro.

Resumiendo, puede decirse que el orden de selectividad de la membrana es el mismo que el obtenido con las disoluciones modelo. $\mathrm{R}$ (lactosa, $\left.\mathrm{SO}_{4}^{-2}, \mathrm{PO}_{4}^{-3}, \mathrm{Ca}^{+2}, \mathrm{Mg}^{+2},\right)>\mathrm{R}\left(\mathrm{K}^{+}, \mathrm{Na}^{+}, \mathrm{Cl}\right)$ 
Una vez realizada esta parte experimental, lo siguiente es estudiar el efecto de los dos modos de operación: concentración y diafiltración con permeado del suero dulce UF. Este estudio se realiza con la membrana Ds-5 DL a dos presiones de 1 y 2 MPa y a un caudal de $400 \mathrm{~L} / \mathrm{h}$.

6.3.2.3. Desmineralización del permeado del suero UF con la membrana Ds-5 DL

\section{Etapa de concentración}

En la etapa de concentración se opera recirculando el rechazo y extrayendo de manera continúa la corriente de permeado, tal como se esquematizó en la figura 5.5. De esta forma, el alimento se va concentrando en el tanque a medida que disminuye su volumen.

El factor de reducción volumétrico (FRV) que se consigue finalmente es de 2. A continuación se muestran los resultados obtenidos en esta etapa para las dos presiones ensayadas de 1 y 2 MPa. 


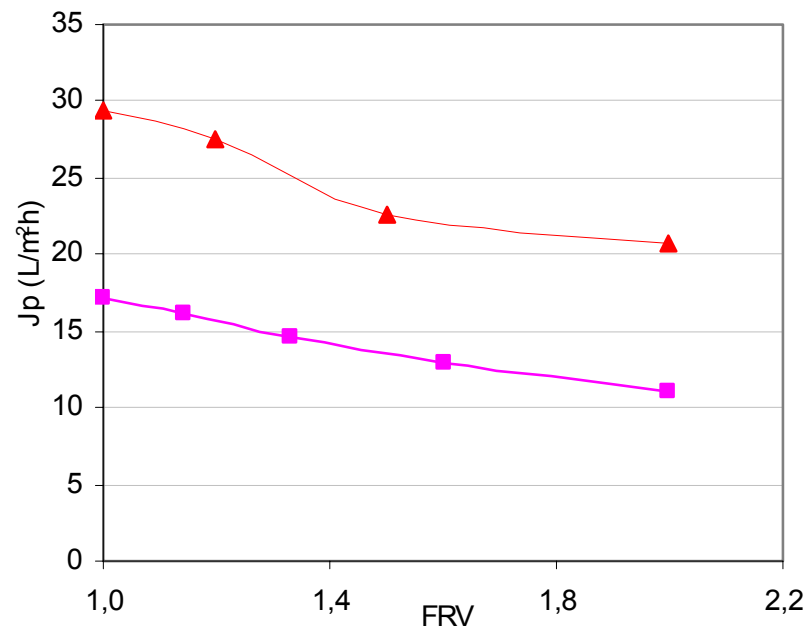

Figura 6.46. Variación de J con el FRV.

$\Delta \Delta \mathrm{P}=2 \mathrm{MPa} ; \kappa=5,0 \mathrm{mS} / \mathrm{cm}$ y $\sim \Delta \mathrm{P}=1 \mathrm{MPa} ; \kappa=4,50 \mathrm{mS} / \mathrm{cm}$

Como puede apreciarse en la figura 6.46, para la presión de 1 MPa, la densidad de flujo de permeado disminuye de forma lineal con una pendiente más acentuados, mientras que a la presión de $2 \mathrm{MPa}$, al principio disminuye mas rápidamente para luego ir estabilizándose y a partir de un FRV de 1,5 es casi asintótica con el eje de las abcisas hasta llegar a 2.

En esta etapa el flujo de permeado fue más alto, la caída de la densidad de flujo disminuye casi de forma lineal con el factor de reducción de volumen hasta llegar a 1,6 y a la presión de 1MPa. Mientras que, a la presión de 2 MPa disminuye en menor proporción. 
Se observa una variación apreciable en la densidad de flujo de permeado al pasar de un factor de reducción volumétrico (FRV) de 1 a 2, para ambos valores de presión.

\section{Índice de rechazo}

Los resultados obtenidos para cada una de las presiones, se muestran a continuación.

El aumento del FRV, produce un incremento de la concentración de todos los solutos en el alimento, excepto el ión cloruro. Al analizar la concentración para cada uno de los solutos presentes en el alimento se puede apreciar que igual que en ocasiones anteriores un aumento en la concentración del alimento provoca una disminución en el índice de rechazo, excepto para el ión cloruro que presenta valores negativos, siendo este hecho coherente con los resultados obtenidos en apartados anteriores.

El rechazo de los iones polivalentes y de la lactosa están alrededor del 90\%, los índices de rechazo más bajos son para los iones monovalentes con valores alrededor del $25 \%$. Otro hecho a constatar es que al modificar la presión no se observan grandes diferencias respecto al rechazo de iones.

Resumiendo, el orden de rechazos obtenidos para todas las especies presentes es el siguiente:

$$
\mathrm{R} \text { (lactosa) }>\mathrm{R}\left(\mathrm{Ca}^{+2}, \mathrm{SO}_{4}^{-2}, \mathrm{PO}_{4}^{-3}, \mathrm{Mg}^{+2}\right)>\mathrm{R}\left(\mathrm{Na}^{+}, \mathrm{K}^{+}\right)>\mathrm{R}(\mathrm{Cl}-)
$$


Tabla 6.28. Índice de rechazo y factor de concentración para un $\mathrm{FRV}=2$ y $\Delta \mathrm{P}=1 \mathrm{MPa}$. $\mathrm{pH}=6,3 ; \kappa=4,50 \mathrm{~ms} / \mathrm{cm}$

\begin{tabular}{lcccc}
\hline Alimento & \multicolumn{2}{c}{$\begin{array}{c}\text { Concentración } \\
\text { (mg/L) }\end{array}$} & $R$ \\
& inicial & final & FC & $(\%)$ \\
\hline lactosa & 36.600 & 57.700 & 1,58 & 84,58 \\
$\mathrm{Ca}^{+2}$ & 223,11 & 334,79 & 1,50 & 72,98 \\
$\mathrm{SO}_{4}^{-3}$ & 99,00 & 144,47 & 1,46 & 77,37 \\
$\mathrm{PO}_{4}^{-3}$ & 350,50 & 538,00 & 1,53 & 77,78 \\
$\mathrm{Mg}^{2+}$ & 66,02 & 95,21 & 1,44 & 73,74 \\
$\mathrm{Cl}^{-1}$ & 1010,00 & 868,20 & 0,86 & $-18,29$ \\
$\mathrm{Na}^{+}$ & 273,87 & 323,24 & 1,18 & 26,56 \\
$\mathrm{~K}^{+}$ & 1126,90 & 1260,54 & 1,12 & 30,08 \\
\hline
\end{tabular}

Tabla 6.29. Índice de rechazo y factor de concentración. FRV $=2$. $\Delta \mathrm{P}=2 \mathrm{MPa} . \mathrm{pH}=6,26 ; \kappa=5,0 \mathrm{mS} / \mathrm{cm}$

\begin{tabular}{lcccc}
\hline \multirow{2}{*}{ Alimento } & \multicolumn{2}{c}{$\begin{array}{c}\text { Concentración } \\
\text { (mg/L) }\end{array}$} & FC & $R$ \\
\cline { 5 - 5 } & inicial & final & $(\%)$ & $(\%)$ \\
\hline Lactosa & 39.100 & 66.700 & 1,71 & 89,06 \\
$\mathrm{Ca}^{+2}$ & 207,55 & 348,05 & 1,68 & 78,44 \\
$\mathrm{SO}_{4}^{-3}$ & 85,76 & 149,45 & 1,74 & 73,24 \\
$\mathrm{PO}_{4}^{-3}$ & 522,57 & 804,30 & 1,54 & 81,60 \\
$\mathrm{Mg}^{2+}$ & 48,39 & 76,89 & 1,59 & 80,46 \\
$\mathrm{Cl}^{-1}$ & 1162,50 & 1087,35 & 0,93 & $-10,36$ \\
$\mathrm{Na}^{+}$ & 292,44 & 351,48 & 1,20 & 29,13 \\
$\mathrm{~K}^{+}$ & 1273,20 & 1504,80 & 1,18 & 33,53 \\
\hline
\end{tabular}


Los valores negativos del índice de rechazo obtenidos para el ión cloruro, se explicó anteriormente por el efecto Donnan, debido al efecto que ejerce la carga negativa de los aniones más rechazados (fosfatos, sulfato) incluso los citratos, los cuales no han sido cuantificados en esta tesis. La membrana al $\mathrm{pH}$ de trabajo posee carga negativa, haciendo que se produzca un paso preferente de los cationes, cargados positivamente. Por lo que al intentar equilibrar las cargas en ambas caras de la membrana para mantener la electroneutralidad, cierta cantidad de aniones tienden a pasar. De todos los aniones, es el ión cloruro el que puede atravesar más fácilmente la membrana, de todos ellos es el que posee menor tamaño y energía de solvatación.

\section{Etapa de diafiltración}

Los resultados obtenidos en la etapa de diafiltración respecto a la densidad de flujo e índice de rechazo para los valores de presión ensayados se muestran a continuación.

\section{Densidad de flujo de permeado}

En los ensayos de diafiltración se utiliza agua desionizada con una conductividad entre $0,83-1,33 \mu \mathrm{S} / \mathrm{cm}$ y $\mathrm{pH}=5,99$. Para incrementar la efectividad del proceso y dado que al tratarse del suero ya ultrafiltrado, se opera a una temperatura de $20^{\circ} \mathrm{C}$.

A medida que el volumen de dilución aumenta, la densidad de flujo también lo hace, mientras que la conductividad disminuye, para ambas presiones el incremento en la densidad de flujo fue 
aproximadamente el mismo siendo del orden del 50\%. A la presión de $1 \mathrm{MPa}$ la densidad de flujo varió de 11 a $17 \mathrm{~L} / \mathrm{h} \cdot \mathrm{m}^{2}$, mientras que a 2 MPa se incrementó de 20 a $30 \mathrm{~L} / \mathrm{h} \cdot \mathrm{m}^{2}$, tal como puede observarse en la figura 6.47.
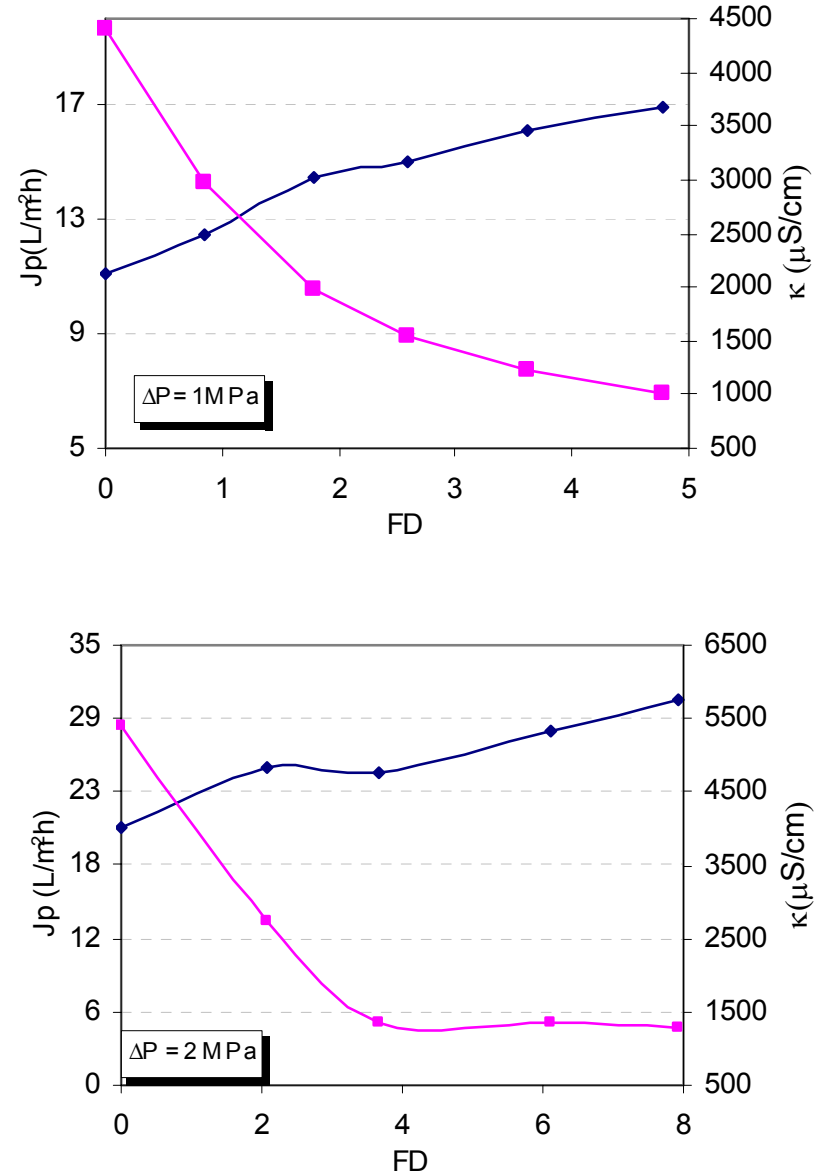

Figura 6.47. Variación de Jp Y к con el FD. - $\kappa$ alimento; $J_{\mathrm{p}}$ 


\section{Índice de rechazo}

Los resultados obtenidos de índices de rechazo para cada uno de los solutos de interés se muestran en la figura 6.48. Para la lactosa a la presión de $1 \mathrm{MPa}$, el índice de rechazo se mantiene alrededor del $90 \%$, mientras que a la presión de 2 MPa esta entorno al $95 \%$.

El índice de rechazo para todos los iones aumenta con el incremento del factor de dilución, debido principalmente a que cada vez la estas especies en el alimento son menores.

Para los dos valores de presión puede observarse cómo el índice de rechazo se mantiene entorno al 85-90\% para los iones sulfato, fosfato, calcio y magnesio. Mientras que para el sodio y el potasio el índice de rechazo aumenta con el factor de dilución llegando a alcanzar valores entorno al $90 \%$.

A continuación en las tablas 6.32 y 6.33 se muestra un resumen de los índices de rechazo obtenidos durante la diafiltración a las dos presiones de operación.

Tabla 6.30. Variación de $\mathrm{R}(\%)$ durante la diafiltración. $\Delta \mathrm{P}=2 \mathrm{MPa}$

\begin{tabular}{lcccccccc}
\hline & \multicolumn{7}{c}{ Concentración alimento(g/L) } \\
\cline { 2 - 9 } FD & Lactosa & $\mathrm{SO}_{4}^{-2}$ & $\mathrm{PO}_{4}^{-3}$ & $\mathrm{Cl}^{-}$ & $\mathrm{K}^{+}$ & $\mathrm{Na}^{+}$ & $\mathrm{Ca}^{+2}$ & $\mathrm{Mg}^{2+}$ \\
\hline 2,06 & 94,53 & 94,76 & 84,30 & $-17,46$ & 42,22 & 58,94 & 94,82 & 94,01 \\
3,68 & 93,88 & 93,82 & 83,26 & $-33,66$ & 86,66 & 85,64 & 95,05 & 93,37 \\
6,11 & 94,04 & 93,63 & 83,41 & $-10,41$ & 87,33 & 85,93 & 94,45 & 93,55 \\
7,92 & 95,11 & 95,46 & 85,30 & 64,10 & 89,73 & 87,67 & 95,78 & 95,35 \\
\hline
\end{tabular}


Tabla 6.31. Variación de R durante la diafiltración. $\Delta P=1 \mathrm{MPa}$

\begin{tabular}{lcccccccc}
\hline & \multicolumn{8}{c}{$\mathrm{R}(\%)$} \\
\cline { 2 - 8 } FD & Lactosa & $\mathrm{SO}_{4}^{-2}$ & $\mathrm{PO}_{4}^{-3}$ & $\mathrm{Cl}^{-}$ & $\mathrm{K}^{+}$ & $\mathrm{Na}^{+}$ & $\mathrm{Ca}^{+2}$ & $\mathrm{Mg}^{2+}$ \\
\hline 0,85 & 83,92 & 80,56 & 79,56 & $-22,37$ & 38,19 & 36,27 & 78,00 & 78,26 \\
1,78 & 85,42 & 85,76 & 74,58 & $-41,88$ & 51,11 & 44,88 & 83,15 & 81,03 \\
2,58 & 86,61 & 84,94 & 81,03 & $-39,91$ & 63,90 & 61,15 & 85,55 & 85,44 \\
3,61 & 87,69 & 87,78 & 77,91 & $-67,13$ & 75,19 & 72,76 & 87,63 & 87,90 \\
4,78 & 88,80 & 86,62 & 80,48 & $-62,16$ & 80,92 & 78,75 & 89,19 & 88,54 \\
\hline
\end{tabular}

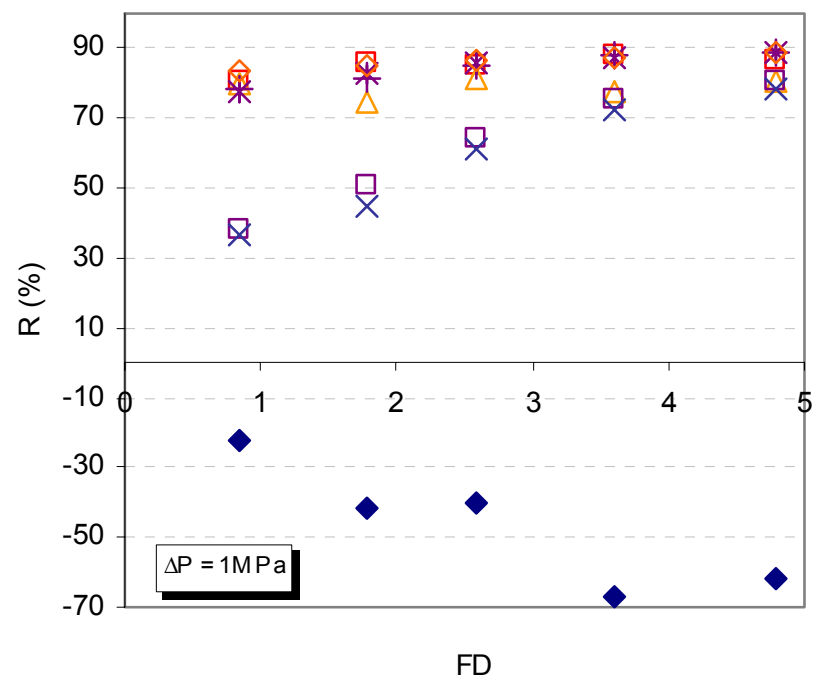

$* \mathrm{Ca}^{+2} ; \square \mathrm{SO}_{4}^{-2} ; \Delta \mathrm{PO}_{4}^{-3} ;+\mathrm{Mg}^{+2} ; \diamond$ lactosa; $\square \mathrm{K}^{+} ; \quad \times \mathrm{Na}^{+} ; \quad \mathrm{Cl}^{-}$ 


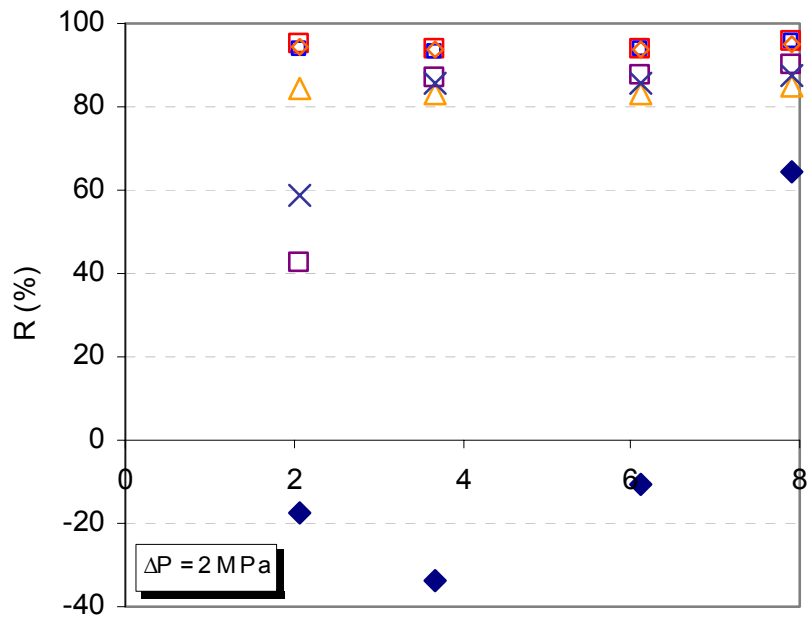

FD

Figura 6.48. Variación de la R con el FD.

$* \mathrm{Ca}^{+2} ; \square \mathrm{SO}_{4}^{-2} ; \Delta \mathrm{PO}_{4}^{-3} ;+\mathrm{Mg}^{+2} ; \diamond$ lactosa; $\square \mathrm{K}^{+} ; \times \mathrm{Na}^{+} ; \bullet \mathrm{Cl}^{-}$

Tabla 6.32. Variación de la concentración durante la diafiltración. $\Delta \mathrm{P}=1 \mathrm{MPa}$

\begin{tabular}{lcccccccc}
\hline & \multicolumn{7}{c}{ Concentración alimento(g/L) } \\
\cline { 2 - 9 } FD & Lactosa & $\mathrm{SO}_{4}^{-2}$ & $\mathrm{PO}_{4}^{-3}$ & $\mathrm{Cl}^{-}$ & $\mathrm{K}^{+}$ & $\mathrm{Na}^{+}$ & $\mathrm{Ca}^{+2}$ & $\mathrm{Mg}^{2+}$ \\
\hline 0 & 57,7 & 0,14 & 0,54 & 0,87 & 1,26 & 0,32 & 0,33 & 0,095 \\
0,85 & 54,1 & 0,13 & 0,54 & 0,44 & 0,84 & 0,20 & 0,29 & 0,083 \\
1,78 & 48,0 & 0,11 & 0,42 & 0,18 & 0,59 & 0,13 & 0,24 & 0,068 \\
2,58 & 44,8 & 0,10 & 0,40 & 0,08 & 0,46 & 0,10 & 0,21 & 0,064 \\
3,61 & 39,8 & 0,094 & 0,30 & 0,02 & 0,36 & 0,077 & 0,18 & 0,056 \\
4,78 & 36,6 & 0,080 & 0,26 & $5 \times 10^{-3}$ & 0,29 & 0,064 & 0,17 & 0,049 \\
\%Elimin 0,85 & 6,24 & 7,14 & 0,00 & 49,43 & 33,33 & 37,50 & 12,12 & 12,63 \\
\%Elimin. 1,78 & 16,81 & 21,43 & 22,22 & 79,31 & 53,17 & 59,38 & 27,27 & 28,42 \\
\%Elimin. 2,58 & 22,36 & 28,57 & 25,93 & 91,03 & 63,49 & 68,75 & 36,36 & 32,63 \\
\%Elimin. 3,61 & 31,02 & 32,86 & 44,44 & 97,70 & 71,43 & 75,94 & 45,45 & 41,05 \\
\%Elimin. 4,78 & 36,57 & 42,86 & 51,85 & 99,43 & 76,98 & 80,00 & 48,48 & 48,42 \\
\hline
\end{tabular}


Como se puede observar en la tabla 6.34 a partir de un factor de dilución de 2,58 la concentración en cloruros se reduce en un 90\% hasta llegar a un 99\%, eliminándose prácticamente la presencia de estos en el alimento.

Al final del proceso de diafiltración se alcanzaron reducciones del $80 \%$ para los iones sodio y potasio. Mientras que para los iones polivalentes solo fue de un $50 \%$ aproximadamente. La pérdida de lactosa aumento con el factor de dilución llegando a valores del $36 \%$.

Analizando los resultados obtenidos, puede considerarse óptimo diafiltrar hasta un factor de dilución de 1,78 a una presión de $1 \mathrm{MPa}$, pues a partir de este la disminución en concentración de los iones que se produce es pequeña y sin embargo, la pérdida de lactosa no es muy alta, por lo que no se justifica continuar con el proceso de diafiltración para esta presión. 
Tabla 6.33. Variación de la concentración durante la diafiltración. $\Delta \mathrm{P}=2 \mathrm{MPa}$

\begin{tabular}{lcccccccc}
\hline & \multicolumn{7}{c}{ Concentración alimento(g/L) } \\
\cline { 2 - 9 } FD & Lactosa & $\mathrm{SO}_{4}{ }^{-2}$ & $\mathrm{PO}_{4}^{-3}$ & $\mathrm{Cl}^{-}$ & $\mathrm{K}^{+}$ & $\mathrm{Na}^{+}$ & $\mathrm{Ca}^{+2}$ & $\mathrm{Mg}^{2+}$ \\
\hline 0 & 66,70 & 0,149 & 0,80 & 1,09 & 1,51 & 0,35 & 0,35 & 0,077 \\
2,06 & 60,30 & 0,143 & 0,63 & 0,24 & 0,75 & 0,17 & 0,31 & 0,068 \\
3,68 & 49,00 & 0,110 & 0,49 & 0,04 & 0,47 & 0,11 & 0,28 & 0,060 \\
6,11 & 47,00 & 0,102 & 0,35 & 0,002 & 0,35 & 0,07 & 0,25 & 0,053 \\
7,92 & 40,90 & 0,090 & 0,25 & $8 \times 10^{-4}$ & 0,27 & 0,05 & 0,22 & 0,046 \\
\%Elimin 2,06 & 9,60 & 4,03 & 21,25 & 77,98 & 50,33 & 51,43 & 11,43 & 11,68 \\
\%Elimin. 3,68 & 26,54 & 26,17 & 38,75 & 96,33 & 70,20 & 68,57 & 20,00 & 22,08 \\
\%Elimin. 6,11 & 29,54 & 31,54 & 56,25 & 99,82 & 76,82 & 80,00 & 28,57 & 31,17 \\
\%Elimin. 7,92 & 38,60 & 39,60 & 68,75 & 99,93 & 82,12 & 85,71 & 37,14 & 40,26 \\
\hline
\end{tabular}

Cuando se opera a una presión de $2 \mathrm{MPa}$, el proceso de diafiltración resulta muy efectivo para reducir la cantidad de sales presentes, obteniéndose altas tasas de desmineralización con un factor de dilución de 2,06 donde las pérdidas de lactosa no son muy altas y el porcentaje de iones monovalentes eliminados es alto y los porcentajes respecto a los polivalentes están entorno al $15 \%$, excepto para el ión sulfato. El continuar con la operación de diafiltración con el objeto de disminuir la concentración de iones sulfato aumentaría las pérdidas de lactosa y la cantidad de agua consumida en la diafiltración. Por otro lado, la pérdida de lactosa también se incrementa con el factor de dilución, estando alrededor del $30 \%$.

Finalmente, puede decirse que lo se concentra de lactosa con la operación de concentración se pierde con la diafiltración. 
Las pérdidas de lactosa fueron menores en la etapa de concentración que en la de DF, incrementándose con el volumen de diafiltración.

En las tablas 6.34 y 6.35 se muestran los resultados obtenidos respecto a la variación de la DQO durante el proceso de concentración y diafiltración. Cabe decir que el valor de la DQO se debe principalmente a la presencia de la lactosa. Puede observarse como a medida que aumenta el factor de dilución la DQO disminuye, logrando valores más bajos a la presión de 1 MPa comparada con la de 2 MPa para el mismo factor de dilución (3,6 aproximadamente).

Tabla 6.34. Comparación de la DQO del alimento y permeado durante la operación de concentración.

\begin{tabular}{|c|c|c|c|c|}
\hline \multirow[b]{3}{*}{ FRV } & \multicolumn{4}{|c|}{$\mathrm{DQO}\left(\mathrm{mg} \mathrm{O}_{2} / \mathrm{L}\right)$} \\
\hline & \multicolumn{2}{|c|}{ Alimento } & \multicolumn{2}{|c|}{ Permeado } \\
\hline & $\Delta \mathrm{P}=1 \mathrm{MPa}$ & $\Delta \mathrm{P}=2 \mathrm{MPa}$ & $\Delta \mathrm{P}=1 \mathrm{MPa}$ & $\Delta \mathrm{P}=2 \mathrm{MPa}$ \\
\hline 1,0 & 47.500 & 53.250 & 2.805 & 1.000 \\
\hline 2,0 & 74.500 & 78.250 & 11.000 & 4.970 \\
\hline
\end{tabular}


Tabla 6.35. Valores de la DQO durante la diafiltración.

\begin{tabular}{|c|c|c|}
\hline \multicolumn{3}{|c|}{$\mathrm{DQO}\left(\mathrm{g} \mathrm{O}_{2} / \mathrm{L}\right), \Delta \mathrm{P}=1 \mathrm{MPa}$} \\
\hline FD & Alimento & Permeado \\
\hline 0,85 & 65,30 & 10,35 \\
\hline 1,78 & 58,25 & 8,10 \\
\hline 2,58 & 55,10 & 7,29 \\
\hline 3,61 & 47,75 & 5,98 \\
\hline 4,78 & 43,73 & 4,89 \\
\hline \multicolumn{3}{|c|}{$\mathrm{DQO}\left(\mathrm{g} \mathrm{O}_{2} / \mathrm{L}\right), \Delta \mathrm{P}=2 \mathrm{MPa}$} \\
\hline FD & Alimento & Permeado \\
\hline 2,06 & 72,50 & 4,19 \\
\hline 3,68 & 62,25 & 3,39 \\
\hline 6,11 & 54,43 & 3,34 \\
\hline 7,92 & 48,98 & 2,35 \\
\hline
\end{tabular}

En la tabla 6.35, se muestra el aporte de DQO de las diferentes corrientes de permeado, debiéndose a las sales minerales y la lactosa, aunque la concentración de esta última sea muy baja, variando entre $0,7 \%$ y llegar a un $0,2 \%$ de lactosa para las dos presiones aplicadas. Es con la mayor presión que se obtienen valores de DQO más bajos para el mismo valor de dilución, siendo entonces a la presión de $2 \mathrm{MPa}$ con la que se desmineraliza más rápido y se pierde menos lactosa. 


\subsection{MODELIZACIÓN DE LAS MEMBRANAS DE NANOFILTRACIÓN}

\subsubsection{Obtención del índice de rechazo real de lactosa}

Para la obtención de cada uno de los números adimensionales necesarios para calcular el coeficiente de transferencia de materia se utilizan las ecuaciones de la 4.7 a la 4.25 descritas en el apartado 4.3 de esta tesis.

Los valores presentados a continuación son tomados de Perry, (1982):

- La viscosidad y densidad de la disolución de lactosa se aproximan a las del agua pura: $\mu=0,9211 \cdot 10^{-3} \mathrm{~kg} / \mathrm{m} \cdot \mathrm{s}$ y $\rho=996,95 \mathrm{~kg} / \mathrm{m}^{3}$

- La constante de Bolztman, $\mathrm{k}=1,23 \times 10^{-23} \mathrm{~kg} \cdot \mathrm{m}^{2} / \mathrm{s}^{2} \cdot \mathrm{K}$

- La difusividad de la lactosa (D_lactosa) es 0,49 $10^{-9} \mathrm{~m}^{2} / \mathrm{s}$

El número de número de Schmidt para la lactosa es: Sc Lactosa $=\frac{\mu}{\rho \cdot D \_ \text {lactosa }}=1886$

El cálculo del diámetro hidráulico para un modulo plano esta dado por: $d_{h}=\frac{4 \cdot A}{\text { perimetro mojado }}=1,967 \times 10^{-3} \mathrm{~m}$ 
El número de Reynolds se determina mediante la ecuación 4.10, $\operatorname{Re}=\frac{\rho d_{h} v_{x}}{\mu}=4344$

El número de Sherwood se determina mediante la ecuación 4.9, $S h \_$lactosa $=0,017 \mathrm{Re}^{0,875} S c_{-}$lactosa $a^{0,296}=245,756$

Conocidos el número de Sherwood, el diámetro hidráulico y la difusividad de la lactosa se halla el coeficiente de transferencia de materia $\left(\mathrm{K}_{\mathrm{TM}}\right)$ con la ecuación 4.8.

$$
K_{T M \_l a c t o s a}=S h \_l a c t o s a \frac{D \_l a c t o s a}{d_{h}}=6,121 \times 10^{-5} \mathrm{~m} / \mathrm{s}
$$

Conocido el coeficiente de transferencia de materia, se calcula el rechazo real de la membrana, a partir de los datos experimentales, mediante la ecuación 4.7. En la tabla 6.38 y 6.39 se muestran los resultados obtenidos con la lactosa.

Tabla 6.36. Valores de los números adimensionales y de $\mathrm{K}_{\mathrm{TM}}$

\begin{tabular}{l|ccccc} 
Soluto & $\mathrm{Sc}$ & $S h$ & $K_{T M}(\mathrm{~m} / \mathrm{s})$ & $r_{i}(\mathrm{~m})$ & $\mathrm{Di}_{\mathrm{i}, \infty}\left(\mathrm{m}^{2} / \mathrm{s}\right)$ \\
\hline Lactosa & 1886 & 245,756 & $6,121 \times 10^{-5}$ & $4,311 \times 10^{-10}$ & $0,49 \times 10^{-9}$ \\
$\operatorname{Re}=4344$ & & & & & \\
$d_{h}=1,967 \times 10^{-3} \mathrm{~m}$ & & & &
\end{tabular}


Tabla 6.37. Rechazos reales de la lactosa $(50 \mathrm{~g} / \mathrm{L})$

\begin{tabular}{cccc}
\hline$\Delta \mathrm{P}(\mathrm{MPa})$ & Membrana & $\mathrm{J}(\mathrm{m} / \mathrm{s})$ & Rreal \\
\hline 0,55 & NF200 & $1,33 \times 10^{-5}$ & 0,997 \\
0,55 & NF270 & $1,04 \times 10^{-5}$ & 0,995 \\
0,55 & Ds-5 DK & $7,19 \times 10^{-6}$ & 0,987 \\
0,55 & Ds-5 DL & $8,32 \times 10^{-6}$ & 0,980 \\
0,93 & NF200 & $2,46 \times 10^{-5}$ & 0,995 \\
0,93 & NF270 & $1,67 \times 10^{-5}$ & 0,990 \\
0,93 & Ds-5 DK & $1,44 \times 10^{-5}$ & 0,989 \\
0,93 & Ds-5 DL & $1,51 \times 10^{-5}$ & 0,985 \\
1,35 & NF200 & $3,07 \times 10^{-5}$ & 0,995 \\
1,35 & NF270 & $2,64 \times 10^{-5}$ & 0,997 \\
1,35 & Ds-5 DK & $2,20 \times 10^{-5}$ & 0,991 \\
1,35 & Ds-5 DL & $2,09 \times 10^{-5}$ & 0,987 \\
\hline
\end{tabular}

\subsubsection{Modelización por DSPM}

Los datos que se van a utilizar para realizar todos los cálculos del modelo DSPM son los obtenidos con las membranas planas (NF200, NF270, Ds-5 DK y Ds-5 DL) y la disolución de lactosa de concentración $50 \mathrm{~g} / \mathrm{L}$.

La ecuación 4.19 predice el índice de rechazo para solutos no cargados en función de la densidad de flujo, para ello es necesario hallar los valores de $\lambda$ y $\phi$ y reemplazarlos en esta ecuación, así como determinar el tamaño del radio de poro $\left(r_{p}\right)$ con la ecuación 4.22 y la relación entre el espesor de la membrana y su porosidad $\left(\Delta \mathrm{x} / \mathrm{A}_{k}\right)$ mediante la ecuación 4.25. 


\subsubsection{Determinación de $r_{p}$ y $\Delta x / A_{k}$}

A partir de la ecuación de Stokes 4.23, se determinó el radio de la lactosa.

$$
r_{- \text {lactosa }}=\frac{k T}{6 \pi \mu D_{-} \text {lactosa }}=4,311 \times 10^{-10} \mathrm{~m}
$$

Si se reemplaza $\phi$ y Ki,c en la ecuación 4.22 , se obtiene el valor de $\lambda=0,929$.

Al reemplazar $\lambda$ en la ecuación 4.22 se obtuvó el valor del radio del poro $\left(r_{p}=4,639 \times 10^{-10} \mathrm{~m}\right)$. Con la ecuación 4.22 de Hagen-Poseville, se calculó la relación entre el espesor y la porosidad de la membrana en metros.

$\Delta x / A_{k}=\frac{r_{p}^{2} \Delta P}{8 \mu \cdot\left(J_{w}\right)}=2,953 \times 10^{-6} \mathrm{~m}$

El mismo procedimiento realizado con la membrana Ds-5 DK, se hace con las demás membranas. En la tabla 6.38, se muestran los valores obtenidos para cada una de las membranas estudiadas. Estos valores se encuentran dentro de los intervalos típicos de membranas de nanofiltración (Mulder, 1991) y además cumple con la suposición hecha inicialmente $\left(\Delta x>>r_{p}\right)$.

Bargeman y otros (2005), obtuvieron con una disolución de glucosa valores de radio de poro de $0,42 \mathrm{~nm}$ y de $0,45 \mathrm{~nm}$ para las membranas Ds-5 DK y Ds-5 DL respectivamente. Adicionalmente reportaron ratios de $2,59 \mu \mathrm{m}$ y de $2,54 \mu \mathrm{m}$ de espesor/porosidad para las membranas Ds-5 DK y Ds-5 DL respectivamente. Los valores 
obtenidos en esta tesis presentan el mismo orden de magnitud y se muestran en la tabla 6.38.

Tabla 6.38. Radios de poro $\left(r_{p}\right)$ y relación entre el espesor/porosidad $\left(\Delta x / A_{k}\right)$.

\begin{tabular}{lcccc}
\hline Parámetros & $\mathrm{NF200}$ & $\mathrm{NF270}$ & Ds-5 DK & Ds-5 DL \\
\hline$r_{p}, \mathrm{~m}$ & $4,128 \times 10^{-10}$ & $4,126 \times 10^{-10}$ & $4,639 \times 10^{-10}$ & $4,735 \times 10^{-10}$ \\
$\Delta \mathrm{x} / \mathrm{A}_{\mathrm{k}}, \mathrm{m}$ & $1,812 \times 10^{-6}$ & $1,874 \times 10^{-6}$ & $2,953 \times 10^{-6}$ & $2,838 \times 10^{-6}$ \\
\hline
\end{tabular}

\subsubsection{Determinación del índice de rechazo propuesto por el modelo}

Finalmente, para calcular el índice de rechazo en función de la densidad de flujo de permeado, se utiliza la ecuación 4.18. Los resultados obtenidos tanto experimentales como los predichos por el modelo se muestran a continuación en las figuras 6.49 y 6.50 para todas las membranas ensayadas. 
Resultados y discusión

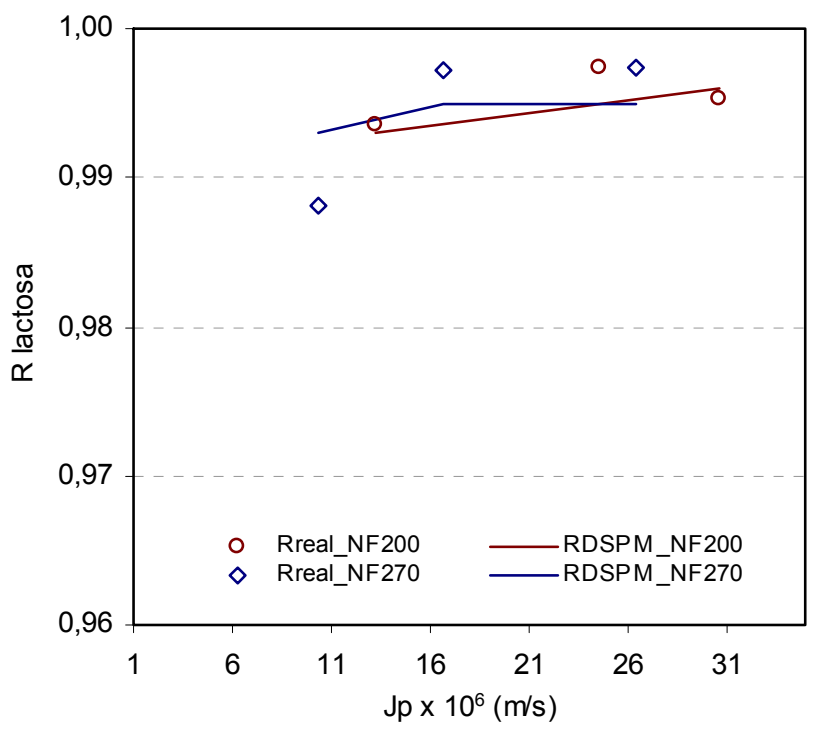

Figura 6.49. Ajuste de los Rreal y RDSPM para las membranas NF200 y 270

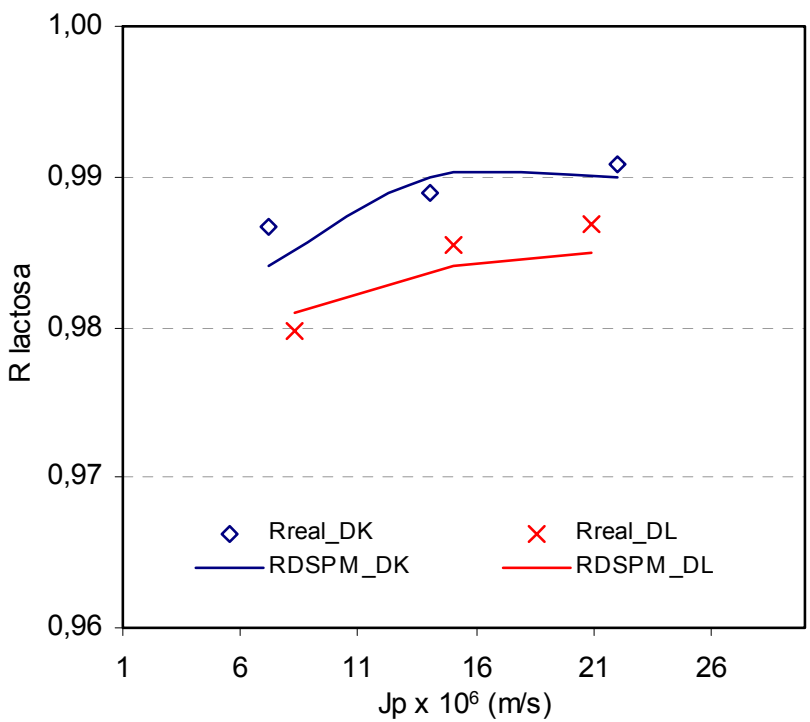

Figura 6.50. Ajuste de los Rreal y RDSPM para las membranas Ds-5 DK y DL 
Como se puede observar de las figuras 6.49 y 6.50 , de todas las membranas ensayadas es con la Ds-5 con la que se obtiene una mayor concordancia entre los datos experimentales y los obtenidos mediante el modelo. Los resultados aportados por el modelo utilizado se ajustan bastante bien a los resultados experimentales, notándose diferencias a partir de la tercera cifra decimal.

\subsection{ANÁLISIS ECONÓMICO DEL PROCESO POR MEMBRANAS}

En este apartado se analiza la viabilidad económica del proceso de separación de lactosa y proteínas aprovechando un vertido de suero lácteo dulce generado en la elaboración del queso, utilizado en ésta tesis mediante técnicas de membrana.

Para la realización de la evaluación económica se tienen en cuenta las características del suero antes de cada una de las etapas de proceso, primero pasa por una centrifuga para eliminar las grasas presentes en el suero dulce, luego se trata mediante un sistema de ultrafiltración con el fin de eliminar principalmente las proteínas presentes en el mismo, el concentrado generado en esta etapa podrá ser devuelto al proceso para su reutilización en la elaboración de productos enriquecidos en proteínas y la corriente de permeado rica en lactosa y sales minerales se lleva a la unidad de nanofiltración para separar las sales minerales de la lactosa, obteniendo una corriente de concentrado rica en lactosa que puede ser utilizada en diferentes procesos como materia prima y otra corriente residual, 
constituida por el permeado con bajo contenido en lactosa. En la figura 6.51 se muestra de forma esquemática el proceso a seguir para la evaluación económica de la obtención de proteínas y lactosa a partir del lactosuero dulce.

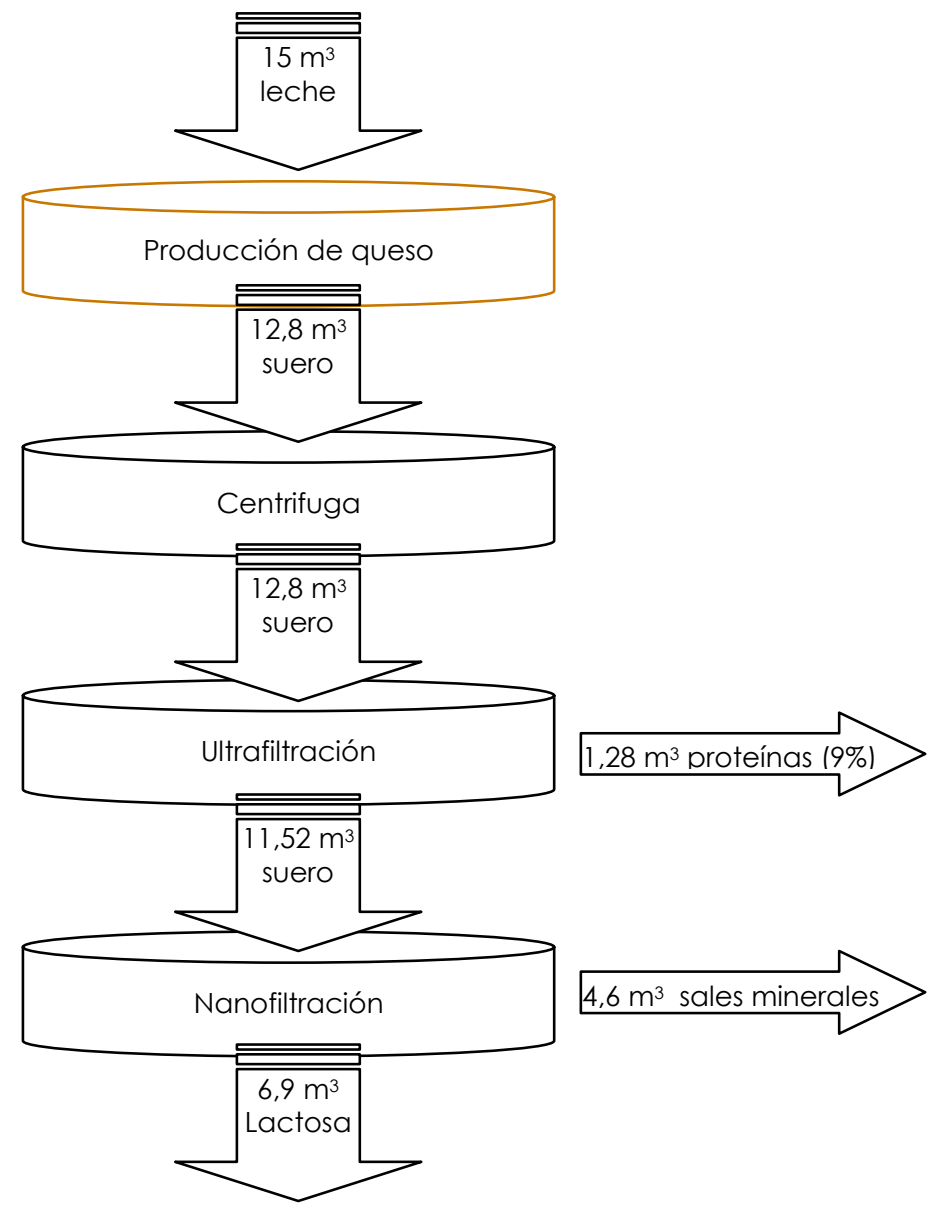

Figura 6.51 Diagrama de flujo del proceso de desmineralización del suero dulce mediante membranas

El suero procedente de la elaboración del queso, debe ser procesado tan pronto como sea posible después de su recogida, 
para evitar su descomposición por crecimiento de bacterias. De no ser así, debe enfriarse hasta $4^{\circ} \mathrm{C}$, en algunos casos si está permitido legalmente, se añaden reactivos para su conservación. Si va a estar refrigerado más de 15 horas, debe pasteurizarse.

Las proteínas, tienen una gran demanda en la industria de alimentos y farmacéutica principalmente, gracias a sus propiedades funcionales y nutritivas. Como en cualquier otro proceso industrial, es vital obtener un producto que sea de calidad y a la vez económico. El éxito de la producción a nivel industrial no solo depende de las condiciones del mercado y del diseño del proceso, sino también de una adecuada información e investigación.

Las proteínas del lactosuero anteriormente se aislaban por precipitación, pero su aplicación era muy limitada (con un $11 \%$ de proteína y alto contenido en lactosa y cenizas). Actualmente se utilizan procesos de membrana para su obtención, consiguiendo así mejores propiedades funcionales, solubilidad, formación de emulsiones y gelificación.

Las proteínas obtenidas por ultrafiltración pueden reincorporarse al proceso de la quesería para la fabricación de productos enriquecidos. La corriente rica en lactosa, todavía de baja calidad por su elevado contenido en sales minerales, se lleva a la unidad de nanofiltración. Sin embargo para obtener una lactosa con una baja cantidad en sales minerales y de acuerdo con lo que se ha comentado en ésta tesis, se diafiltra para mejorar el proceso de desmineralización. La corriente de lactosa finalmente tiene un gran 
valor añadido, ya que puede ser utilizada en la preparación de diferentes productos de interés.

Para hacer el estudio económico, el proceso se diseñó teniendo como dato aportado por la empresa ubicada en la Comunidad Valenciana, que ésta genera $12,8 \mathrm{~m}^{3}$ de suero/día. La planta opera de lunes a viernes durante 9 horas al día. De tal forma que se estima que trabaja 222 días/año.

Los datos necesarios para evaluar el proceso se obtienen a partir de los resultados obtenidos en este trabajo. Los precios de los equipos han sido consultados a diferentes empresas que suministran equipos para la industria láctea (Sociedad Española de Tratamiento de Agua, Westfalia, GE-Osmonics, entre otras).

Como se puede observar en la tabla 6.40, la inversión total de la instalación que comprende costes directos, indirectos y de operación alcanza un valor de $479.000 €$. Esta tabla muestra la inversión total, como una estimación de porcentajes del coste total de los equipos. 
Tabla 6.39. Costes de los equipos necesarios para la desmineralización y concentración del lactosuero.

\begin{tabular}{lr}
\hline Concepto & Coste $(\boldsymbol{\epsilon})$ \\
\hline Filtración de gruesos & 100 \\
Tanque de suero $\left(15 \mathrm{~m}^{3}\right)$ & 10.600 \\
Tanque de permeado $\left(10 \mathrm{~m}^{3}\right)$ & 6.500 \\
Tanque almacenamiento $\left(5 \mathrm{~m}^{3}, 2\right.$ unid.) & 4.500 \\
Centrifuga- Desnatadora & 200.000 \\
Membranas de UF (180 $\mathrm{m}^{2}, 6$ unid.) & 6.000 \\
Membranas de NF $\left(150 \mathrm{~m}^{2}, 4\right.$ unid.) & 4.000 \\
Bombas & 39.000 \\
Generador de frío/calor & 230.000 \\
TOTAL & $\mathbf{4 7 9 . 0 0 0}$
\end{tabular}

En la evaluación de la inversión total del proceso, el procedimiento seguido es el propuesto por Peters y Timmerhaus (1991). 
Tabla 6.40. Inversión total del proceso de desmineralización y concentración del lactosuero.

\begin{tabular}{|c|c|}
\hline Concepto & $(\epsilon)$ \\
\hline \multicolumn{2}{|l|}{ 1. Costes directos } \\
\hline Equipos $€$ & 479.000 \\
\hline Instalación (15\% E) & 71.850 \\
\hline $\begin{array}{l}\text { Elementos auxiliares (válvulas, tuberías, medidores, } \\
\text { etc) }(20 \% \mathrm{E})\end{array}$ & 95.800 \\
\hline Instrumentación y control (10\% E) & 47.900 \\
\hline Instalación eléctrica (10\% E) & 47.900 \\
\hline Servicios Auxiliares (30\% E) & 143.700 \\
\hline Costes directos totales (D) & 886.150 \\
\hline \multicolumn{2}{|l|}{ 2. Costes indirectos } \\
\hline Ingeniería y supervisión (8\% E) & 38.320 \\
\hline Costes indirectos totales (I) & 38.320 \\
\hline Costes directos e indirectos totales $(D+1)$ & 924.470 \\
\hline \multicolumn{2}{|l|}{ 3. Imprevistos } \\
\hline $5 \%$ de los costes (D+I) & 46.223 \\
\hline Inversión total $\Sigma(1+2$ & 970.693 \\
\hline
\end{tabular}

A la hora de calcular los costes de operación, se tienen en cuenta los siguientes criterios:

- Costes por productos de limpieza, se relacionan con la siguiente ecuación (Ali et al, 2005).

$$
C_{q \cos }=Q_{p} \cdot 0,023 € / m^{3} \text { permeado }
$$


donde $Q_{p}$, es el caudal de permeado en $\mathrm{m}^{3} / \mathrm{h}$. dicho caudal de permeado se determina como el sumatorio de los caudals aportados por las membranas de UF y Nanofiltración (4.000 $\left.\mathrm{m}^{3} / a n ̃ o\right)$.

- Costes por consumo eléctrico, se relacionan de manera similar con la siguiente ecuación (Ali et al, 2005).

$$
C_{\text {electrico }}=\left(\frac{Q_{a} \cdot \Delta P}{\eta}+\frac{Q_{R} \cdot \Delta P}{\eta}\right) \cdot 0,06 € / \mathrm{kWh}
$$

Donde: $Q_{R}$ es el caudal de concentrado en $\mathrm{m}^{3} / \mathrm{h} \eta$ es la eficiencia de los equipos de bombeo, que se supone de un $85 \%$. En este cálculo, para la determinación de los caudales se determina como el sumatorio tanto de los caudales de las bombas de UF como los de NF.

Para poder determinar el beneficio del proceso, se ha considerado, de acuerdo con Dairy market report (2004) y Nguyen et al (2003) un precio de venta del suero desmineralizado ( $20 \%$ de sólidos totales) $0,584 € / L$.

El coste de agua para el proceso de desmineralización y limpieza se estima en $0,6 € / \mathrm{m}^{3}$ (García-Lorenzo, 2005)

El resumen de los costes de operación se muestran a continuación en la tabla 6.43. 
Tabla 6.41. Costes de operación del proceso de desmineralización y concentración del lactosuero.

\begin{tabular}{|c|c|c|}
\hline Concepto & consumo & $\epsilon /$ año \\
\hline \multicolumn{3}{|l|}{ Costes de operación variables } \\
\hline Membranas de UF & reemplazar c/2 años & 3.000 \\
\hline Membranas de NF & reemplazar c/2 años & 2.000 \\
\hline Productos de limpieza (UF-NF) & $0,023 € / \mathrm{m}^{3}$ & 120 \\
\hline Agua & $8.000 \mathrm{~m}^{3} / a n ̃ o$ & 4.800 \\
\hline Electricidad y refrigeración & $0,06 € / \mathrm{kWh}$ & 16.236 \\
\hline \multicolumn{2}{|c|}{ Costes de operación variables } & 26.136 \\
\hline \multicolumn{3}{|l|}{ Costes de operación fijos } \\
\hline Mano de obra & $9 € / h$ & 9.000 \\
\hline Supervisión & $15 \%$ mano de obra & 1.350 \\
\hline Mantenimiento & $20 \%$ Inversión fija & 194.139 \\
\hline Gastos de laboratorio & $10 \%$ mano de obra & 900 \\
\hline \multirow[t]{4}{*}{ Gastos generales } & $50 \%$ mano de obra, & 102.244 \\
\hline & isión y mantenimiento & \\
\hline & stes de operación fijos & 307.633 \\
\hline & ste de operación total & 342.993 \\
\hline \multicolumn{3}{|c|}{$\begin{array}{l}\text { Para determinar un valor aproximado del volumen de lactosa } \\
\text { obtenida durante el proceso de } \mathrm{NF} \text { se utiliza un factor de } \\
\text { recuperación del } 40 \% \text { para el módulo total de membranas. ASi, si } \\
\text { entran a proceso } 11,52 \mathrm{~m}^{3} / \text { día (salen como concentrado } 6,9 \mathrm{~m}^{3} / \text { día } \\
\text { rico en lactosa, si además se asume un } 3 \% \text { de pérdidas totales en } \\
\text { toda la instalación, finalmente se obtiene } 1.485 \mathrm{~m}^{3} / \text { año. }\end{array}$} \\
\hline
\end{tabular}


disminución del canon de vertido. La empresa vierte aproximadamente $2841,6 \mathrm{~m}^{3}$ de suero/año, si el coste por depuración es de $3,84 € / \mathrm{m}^{3}$ y suponiendo que a pesar del sistema de membranas tuviera que verter el $40 \%$ de este valor, la empresa ahorraría $4.365 € /$ /año, tal como se aprecia en la tabla 6.42.

A partir de estos resultados se puede analizar no solo desde el punto de vista técnico sino económico la viabilidad de este proceso, tal como se aprecia en la tabla 6.42.

Para el cálculo de la recuperación de la inversión, se utiliza la siguiente ecuación:

Tiempo $_{\text {Recuperación Inversión }}=\frac{\text { Inversión } \text { total }}{\text { Beneficio neto }}$

Teniendo en cuenta el tiempo de recuperación de la inversión el proceso propuesto es rentable y susceptible de ser implementado, tal como puede apreciarse en la tabla 6.42. 
Tabla 6.42. Rentabilidad del proceso de desmineralización y concentración del lactosuero.

\begin{tabular}{lr}
\hline Concepto & ( $€ / \mathbf{a n ̃ o )}$ \\
\hline 1. Producto de la venta de lactosa & 1.004 .328 \\
2. Disminución de vertido (valorización de proteínas) & 4.365 \\
3. Costes de operación anual & 332.993 \\
4. Beneficio bruto (1+2-3) & 675.700 \\
5. Impuestos (33\%) & 222.981 \\
6. Beneficio neto & 452.720 \\
7. Margen bruto [4/(1+2)] & 0,67 \\
Tiempo de recuperación de la inversión & 2,16 años \\
\hline
\end{tabular}


CONCLUSIONES

7. 



\section{CONCLUSIONES}

7.1 Las variables de operación estudiadas (presión aplicada y concentración, caudal), permiten establecer que la presión aplicada y la concentración, son factores determinantes en el comportamiento de las membranas de nanofiltración estudiadas.

7.2 Las membranas NF200 y NF270 no cumplen con las expectativas esperadas; las cuales eran obtener índices de rechazo bajos con respecto a los iones presentes en el alimento.

7.3 Las membranas de la serie Ds-5 separan con mayor efectividad los iones monovalentes de los divalentes en comparación con las membranas de la serie NF, que son menos específicas para estos iones.

7.4 Los resultados obtenidos con las disoluciones modelo y el suero real, para las membranas NF200 y Ds-5 DL, muestran diferencias significativas obteniéndose mayores tasas de desmineralización con la membrana NF200 para las disoluciones modelo y con la membrana Ds-5 para el suero real. Estas diferencias se deben principalmente al tipo de módulo de membranas, así como a las características de las disoluciones empleadas,

7.5 A partir de los resultados experimentales se observa que el efecto Donnan se ve favorecido por la concentración. A mayor 
concentración de iones en el alimento, el rechazo disminuye al producirse una reducción de la carga de la membrana por la mayor presencia de iones de carga opuesta.

7.6 El proceso de ultrafiltración como pretratamiento del suero dulce para la eliminación de las proteínas del mismo es efectivo a la hora de minimizar el ensuciamiento de la membrana de nanofiltración.

7.7 En el proceso de ultrafiltración con la disolución de suero real, se establece que para mejorar el rendimiento de la membrana de UF es necesario eliminar previamente la materia grasa presente.

7.8 La retención de proteínas durante la etapa de ultrafiltración, no se modifica por los cambios de presión, permaneciendo prácticamente constante.

7.9 En el proceso de concentración-diafiltración por nanofiltración a la presión $2 \mathrm{MPa}$ se mejora notablemente la tasa de desmineralización, alcanzando valores entorno al $70 \%$ con pérdidas de lactosa entorno al $9 \%$.

7.10 La membrana Ds-5 DL presenta valores de densidad de flujo para la lactosa y los iones polivalente bajos (sulfatos, fosfatos, magnesio y calcio). De todos ellos el calcio y el magnesio son beneficiosos para la salud humana, por lo que su presencia en la lactosa es positiva, mientras que la densidad de flujo para los iones monovalentes (cloruros, sodio y potasio) es alta. 
7.11En la etapa de concentración-diafiltración de las dos presiones ensayadas y para el mismo factor de dilución, es a la presión de $2 \mathrm{MPa}$ con la que se obtienen las menores pérdidas de lactosa. Sin embargo, es a la presión de 1 MPa con la que se consiguen tasas de desmineralización más altas.

7.12 Incorporar una etapa adicional de concentración por ósmosis inversa posterior al proceso de concentración-diafiltración ayudaría a incrementar la concentración de lactosa como producto final.

7.13 A pesar de que se logran reducir los valores de conductividad hasta $1000 \mu \mathrm{S} / \mathrm{cm}$ en la corriente de permeado de diafiltración, valor que esta dentro de los límites de vertido a una EDAR el valor de la DQO excede el límite de $1000 \mathrm{mg} / \mathrm{L}$, por lo que no se puede efectuar el vertido directo a la EDAR.

7.14 Las corrientes de permeado generadas durante la etapa de concentración-diafiltración podrían reutilizarse en el proceso de salado del queso y de esta forma minimizar el consumo de agua y sales minerales.

7.15El modelo matemático propuesto predice bastante bien el índice de rechazo a la lactosa para las cuatro membranas estudiadas. De todas ellas los mejores ajustes se obtienen con las membranas de la serie Ds-5. 
7.16El proceso de desmineralización de la lactosa presente en el lactosuero dulce es rentable y susceptible de ser implementado tanto técnica como económicamente.

7.17 Desde el punto de vista medioambiental el proceso propuesto es de gran interés, en cuanto a que se valorizan subproductos (lactosa, calcio y magnesio) y se disminuye notablemente el impacto medioambiental del efluente a tratar. 



\section{BIBLIOGRAFIA}

Ali N.; . Mohammad A. W.; Ahmad A.L. (2005). Use of nanofiltration predictive and system cost assesment, Separation and Purification Technology 41, 29-37.

Alkhatim H.S.; . Alcaina M.I.; Soriano E.; Lora J. y Arnal J. (1998). Treatment of whey effluents from dairy industries by nanofiltration membranes, Desalination 119, 177-184.

American Water Works Association Research Foundation. (1998). Tratamiento del agua por procesos de membrana, principios, procesos y aplicaciones. Ed. McGraw-Hill. Madrid.

Argüello M.A.; Álvarez S.; Riera F.A. y Álvarez R. (1995). Enzimatic cleaning of inorganic ultrafiltration membranas used for whey protein fractionation, Journal of Membrane Science 216, 121-134.

American Public Health Association, American Water Works Association, Water Pollution Control Federation. (1992). Métodos Normalizados para el análisis de aguas potables y residuales. Editorial Díaz Santos S.A. Madrid - España.

Bargeman G.; Vollenbroek J.M.; Straatsma J.; Schroën C. G. P. y Boom R.M. Nanofiltration of multi-component feeds. Interactions between neutral and charged components and their effect on retention. Journal of Membrane Science 247, 11-20.

Bartlett M.; Bird M.R.; y Howell J.A. (1995). An experimental study for the development of a qualitative membrane cleaning model, Journal of Membrane Science 105, 147-157. 
Bowen W. et al. (1998) Characterization and prediction of nanofiltration membrane performance-a general assessment, Trans IChemE 76, 885893.

Casado P. (1991). Guía para el análisis químico de la leche y los derivados lácteos. Ediciones Ayala. Madrid.

Causserand et al. (1994). Study of streaming potentials of clean and fouled ultrafiltration membranes. Journal of Membrane Science 88, 211222.

Cheang B., Zydney A.L. (2004). A two-stage ultrafiltration process for fractionation of whey protein isolate. Journal of Membrane Science, 231, 159-167

Cheryan M. (1998). Ultrafiltration and Microfiltration Handbook. Second edition, CRC Press, New York.

Daufin G.; Merin U; Kerhevé F.L.; Labbéz J.P.; Quémeras A. y Bousser C. (1991). Cleaning of inorganic membranes after whey and milk ultrafiltration. Biotechnology and bioengineering 38, 82-89.

De la Fuente, M.A., Hemar, Y., Tamehana, M., Munro, P.A. y Singh, H. (2002). Process-induced changes in whey proteins during the manufacture of whey protein concentrates.

International Dairy Journal 12, 361-369.

Deepak A. et al. (2000). Solvent and pH resistance of surface crosslinked chitosan poly(acrylonitrile) composite nanofiltration membranes, Journal of applied polymer science 77, 1782-1793.

Dickerson R et al. (1992). Principios de química. 3ra Edición. Ed. Reverte S.A. Barcelona.

García Lorenzo A.M. (2005). Tecnología de membranas en medios no acuosos. Aplicación en la industria del aceite de girasol. Tesis Doctoral, Universidad de Oviedo. 
Freger V.; Arnot T.C.; Howell J.A. (2000). Separation of concentrated organic/ionorganic salt mixtures by nanofiltration. Journal of Membrane Science 178 pp185-193.

Gilron J., Gara N., Kedem O. (2001). Experimental analysis of negative salt rejection in nanofiltration membranes. Journal of Membrane Science 185, 223-236.

Gorenflo A. (2003). Rückhalt und fouling von natürlichen organischen substanzen bei der nano- und ultrafiltration. Tesis Doctoral, Universität Karlsruhe $(\mathrm{TH})$.

Gluechauf E. The distribution of electrolytes between cellulose acetate membranes and aqueous solutions, Desalination 18, 155-172. (1976).

Her, N.G.; Amy, G.; Jarusutthirak, C. (2000). Seasonal variations of nanofiltration (NF) foulants: identification and control, Desalination 132, 143-160.

Hagmeyer G. (1998). Modelling the salt rejection of nanofiltration membranes for ternary ion mixtures and for single salts at different $\mathrm{pH}$ values, Desalination 117, 247-256.

James et al. (2003). Membrane fouling during filtration of milk-a microstructural study, Journal of Food Engineering 60, 431-437

Jeantet $R$ et al. (1996). Intérêt de la nanofiltration dans la production de poundres de lactosérum déminéralisées, Lait 76, 283-301.

Jeantet $R$ et al. (2000). Nanofiltration of sweet whey by spiral wound organic membranes: $\quad$ Impact of hydrodynamics, Lait 80, 155-163.

Jegal J et al. (2000). Preparation and characterization of PVA/SA composite nanofiltration membranes, Journal of Applied Polymer Science 77, 347-354. 
Lucas D. et al. (1998). Extraction of $\alpha$ lactalbumin from whey protein concentrate with modified inorganic membranes, Journal of membrane science 148, 1-12.

Madrid V. (1994). Nuevo manual de tecnología quesera. AMV ediciones. Madrid.

Marsilla de Pascual, B. (1994). Efluentes y su tratamiento en industrias lácteas. Curso sobre tratamiento de aguas residuales en la industria agroalimentaria. Ed. Colegio oficial de ingenieros agrónomos de Murcia.

Mohammad A. W., Takriff M.S. (2003). Predicting flux and rejection of multicomponent salts mixture in nanofiltration membranes. Desalination 157, $105-111$.

Morales F.J. et al. (1992). El suero de quesería en la industria alimentaria, Alimentación, equipos y tecnología.

Mucchetti G. et al. (2000). The pre-concentration of milk by nanofiltration in the production of Quarg-type fresh cheeses, Lait 80, 4350 .

Mulder M. (1991). Basic principles of membrane technology, Ed. Kluwer Academic Publishers, The Netherlands.

Nguyen M., Reynolds N. y Vigneswaran S. (2003). By-product recovery from cottage cheese production by nanofiltration. Journal of Cleaner Production 11, 803 - 807.

Norma Española UNE 34-823-83. Determinación del contenido en nitrógeno total por el método Kjedhal.

Norma Española UNE 34826:1983. Determinación del contenido en lactosa. 
Nystöm M., Butylina S. y Platt S. (2004). NF retention and critical flux of small hydrophilic/hydrophobic molecules, Membrane Technology 10, 58.

Paugam L. et al. (2004). Mechanism of nitrate ions transfer in nanofiltration depending on pressure, $\mathrm{pH}$, concentration and medium composition, Journal of Membrane Science 231, 37-46.

Peeters J.M.M., Boom J.P., Mulder M.H.V. y Strathmann. (1998). Retention measurements of nanofiltration membranes with electrolyte solutions, Journal of Membrane Science 145, 199-209.

Peters M.S., Timmerhaus K.D. (1991). Plant design and economics for chemical engineers. Mc Graw Hill, New York.

Perry R. (1982). Manual del ingeniero químico. Quinta edición. McGrawHill. Mexico.

Perry M L, Linder C. (1989). Intermediate reverse osmosis ultrafiltration (RO/UF) membranes for concentration and desalting of low molecular weight organic solutes, Desalination 71, 233-245.

Pontalier P et al. (1999). Specific model for nanofiltration, Journal of Food Engineering 40, 145-151.

Pontalier P.-Y et a I. (1997). Mechanisms for selection rejection of solutes in nanofiltration membranes, Separation Science and Technology 12, 75-181.

Räsänen E.; Nystrom M.; Sahlstein J.; Tossavainen, O. (2002). Comparison of commercial membranes in nanofiltration of sweet whey. Lait 82, pp 343-356.

Rektor A.; y Vatai G. (2004). Membrane filtration of Mozzarella whey. Desalination, 162, 279-286. 
Schaep J. et al. (2001). Modelling the retention of ionic components for different nanofiltration membranes. Separation and Purification Technology 22-23, 169-179.

Schäfer A.I.; Fane A.G.; Waite T.D. (2005). Nanofiltration: Principles and Applications. Elsevier Advanced Technology. UK.

Suárez E.; Lobo A.; Álvarez S.; Riera F.; Álvarez R. (2005). Congreso: Membrane Science and Technology Conference of Visegrad Countries. PERMEA 2005. Proceedings. Polanica Zdrój, Polonia

Suárez E. et al. (1992). Reverse osmosis of whey. Determination of mass transfer coefficients. Journal of membrane science 68, 301-305.

Sydney A.L.; Cheang B. (2004). A two-stage ultrafiltration process for fractionation of whey protein isolate. Journal of membrane Science $231,159-167$.

Szoke Szabolcs, Patzay Gyorgy, Weiser Laszlo. (2002). Characteristics of thin-film nanofiltration membranas at various $\mathrm{pH}$-values. Desalination 151, 123-129.

Tanninen J, Nyström M. (2002). Separation of ions in acidic using NF. Desalination 147, 295-299.

Tetra Pak Processing Systems A.B. (2003). Manual de industrias lácteas.

Timmer, J. (2001). Properties of nanofiltration membranes; model development and industrial application. Tesis doctoral. Technische Universiteit Eindhoven.

Tolkach A., y Kulozik $U$ (2005). Fractionation of whey proteins and caseinomacropeptide by means of enzymatic crosslinking and membrane separation techniques. Journal of Food Engineering, 67, 1320. 
Wang X. et al. (2002). The possibility of separating sccharides from a $\mathrm{NaCl}$ solution by using nanofiltration in diafiltration mode, Journal of Membrane Science 204, 271-281.

Wang X. et al. (1995a). Evaluation of pore structure and electrical properties of nanofiltration membranes, Journal of chemical engineering of Japan 28, 186-192.

Wang X. et al. (1995b). Transport of organic electrolytes with electrostatic and stearic hindrance effects through nanofiltration, Journal of chemical engineering of Japan 28, 372-380.

Wijers M.C. (1998). Use of nanofiltration membranes for the desalting of peptide fractions from whey protein enzymatic hydrolysates, Lait 78, 621-632.

XU X., Spencer H.G. (1997). Transport of electrolytes through a weak acid nanofiltration membrane: effects of flux and crossflow velocity interpreted using a fine-porous membrane model. Desalination 113 pp 85-93

Yaroshchuk A. (1998). Rejection mechanisms of NF membranes, Membrane Technology 100, 9-12.

Yaroshchuk A. et al. (2000). Non steady state membrane potential: theory and measurements by a novel technique to determine the iron transport numbers in active layers of nanofiltration membranes, Journal of membrane science 172, 203-221.

http://www.gewater.com/

http://www.dowchemical.com/

http://www.foodproductiondaily.com 
http://www.fiab.es/

http://www.merck.com/

http://www.doitwithdairy.com

http://www.wheyoflife.org 



\section{NOTACIÓN}

\begin{tabular}{|c|c|}
\hline$A_{m}$ & Área de la membrana $\left(\mathrm{m}^{2}\right)$ \\
\hline$A_{k}$ & Porosidad de la membrana \\
\hline AWWA & American water asociation \\
\hline K & Constante de Boltzman \\
\hline BSA & Seroalbúmina Bobina \\
\hline $\mathrm{Ca}_{\mathrm{a}}$ & Concentración de soluto en el alimento \\
\hline $\mathrm{C}_{\mathrm{m}}$ & Concentración de soluto en la cara de la membrana \\
\hline$C_{p}$ & Concentración de soluto en el permeado \\
\hline $\mathrm{D}$ & Difusidad (m²/s) \\
\hline $\mathrm{Da}$ & Dalton \\
\hline $\mathrm{DBO}_{5}$ & Demanda bioquímica de oxígeno (mg $\mathrm{O}_{2} / \mathrm{L}$ ) \\
\hline$D_{i, \infty}$ & Difusividad del ión i a dilución infinita (m²/s) \\
\hline DIQN & Departamento de Ingeniería Química y Nuclear \\
\hline DQO & Demanda química de oxígeno (mg $\left.\mathrm{O}_{2} / \mathrm{L}\right)$ \\
\hline DF & Diafiltración \\
\hline$d_{h}$ & Diámetro hidráulico (m) \\
\hline DSPM & Donnan steric partioning model \\
\hline $\mathrm{EE}$ & Estado estacionario \\
\hline ENP & Ecuación extendida de Nernst-Planck \\
\hline $\mathrm{F}$ & Constante de Faraday (C/mol) \\
\hline \multirow[t]{2}{*}{$\mathrm{FIAB}$} & Federación Española de Industrias de Alimentación y \\
\hline & Bebidas \\
\hline$F R V$ & Factor de reducción volumétrica \\
\hline FD & Factor de dilución \\
\hline GE & General Electric \\
\hline I.A.A & Industria agroalimentaria \\
\hline
\end{tabular}




\begin{tabular}{|c|c|}
\hline$\|$ & Intercambio iónico \\
\hline I & Fuerza iónica (mol/L) \\
\hline$I_{p}$ & Fuerza iónica del permeado (mol/L) \\
\hline$J_{p}$ & Densidad de flujo de permeado $\left(\mathrm{L} / \mathrm{h} \cdot \mathrm{m}^{2}\right)$ \\
\hline $\mathrm{J}_{\mathrm{s}}$ & Densidad de flujo de soluto $\left(\mathrm{g} / \mathrm{h} \cdot \mathrm{m}^{2}\right)$ \\
\hline$J_{w}$ & Densidad de flujo al agua (L/h $\left.\cdot \mathrm{m}^{2}\right)$ \\
\hline$K_{T M}$ & Coeficiente de transferencia de materia \\
\hline$K_{i, c}$ & Factor de retado convectivo \\
\hline$K_{i, d}$ & Factor de retardo difusivo \\
\hline$L_{p}$ & Coeficiente de permeabilidad de la membrana \\
\hline MF & Microfiltración \\
\hline MWCO & Molecular Weight Cut Off (Umbral de corte) \\
\hline NNP & Nitrógeno no proteico \\
\hline N.D. & No disponible \\
\hline NF & Nanofiltración \\
\hline NNP & Nitrógeno no proteico \\
\hline Ol & Ósmosis Inversa \\
\hline PIE & Punto isoeléctrico \\
\hline PROMETEO & $\begin{array}{l}\text { Proceso de membranas y tratamiento de efluentes } \\
\text { líquidos }\end{array}$ \\
\hline$P$ & Presión (MPa) \\
\hline PA & Poliamida aromática \\
\hline $\mathrm{Pe}$ & Presión del alimento (MPa) \\
\hline$P e$ & Número de Peclet \\
\hline PES & Polietersulfona \\
\hline$P_{s}$ & Presión del concentrado (MPa) \\
\hline$P_{p}$ & Presión de permeado (MPa) \\
\hline PA & Poliamida \\
\hline
\end{tabular}




\begin{tabular}{|c|c|}
\hline Qa & Caudal de alimento (L/h) \\
\hline$Q_{p}$ & Caudal de permeado (L/h) \\
\hline$Q_{R}$ & Caudal de circulación (L/h) \\
\hline$r_{p}$ & Radio del poro de la membrana (m) \\
\hline$r_{i}$ & radio de Stokes (m) \\
\hline $\mathrm{R}$ & Rechazo (\%) \\
\hline $\mathrm{R}$ & Constante de los gases ideales $(\mathrm{J} / \mathrm{mol} \cdot \mathrm{K})$ \\
\hline $\mathrm{Ra}$ & Resistencia al agua después de la limpieza $\left(\mathrm{m}^{-1}\right)$ \\
\hline $\operatorname{Re}$ & Número de Reynolds \\
\hline $\mathrm{Rh}$ & Resistencia hidráulica $\left(\mathrm{m}^{-1}\right)$ \\
\hline$R_{m}$ & Resistencia membrana virgen \\
\hline Rres & Resistencia residual \\
\hline Sc & Número de schmidt \\
\hline Sh & Número de Sherwood \\
\hline ST & Sólidos totales (mg/L) \\
\hline SC & Carga superficial \\
\hline $\mathrm{T}$ & Temperatura $\left({ }^{\circ} \mathrm{C}\right)$ \\
\hline$t$ & Tiempo (min.) \\
\hline TFC & Thin film composite \\
\hline TMS & Theorelll de Meyers y Sievers \\
\hline $\mathrm{TH}$ & Tripticos hidrolizados \\
\hline UF & Ultrafiltración \\
\hline $\mathrm{V}$ & Volumen (L) \\
\hline$v_{x}$ & Velocidad (m/s) \\
\hline $\mathrm{V}_{\mathrm{a}}$ & Volumen de alimento (L) \\
\hline$V_{p}$ & Volumen de permeado (L) \\
\hline$V_{\text {tang }}$ & Velocidad tangencial (m/s) \\
\hline $\mathrm{Zi}$ & carga del ión \\
\hline
\end{tabular}




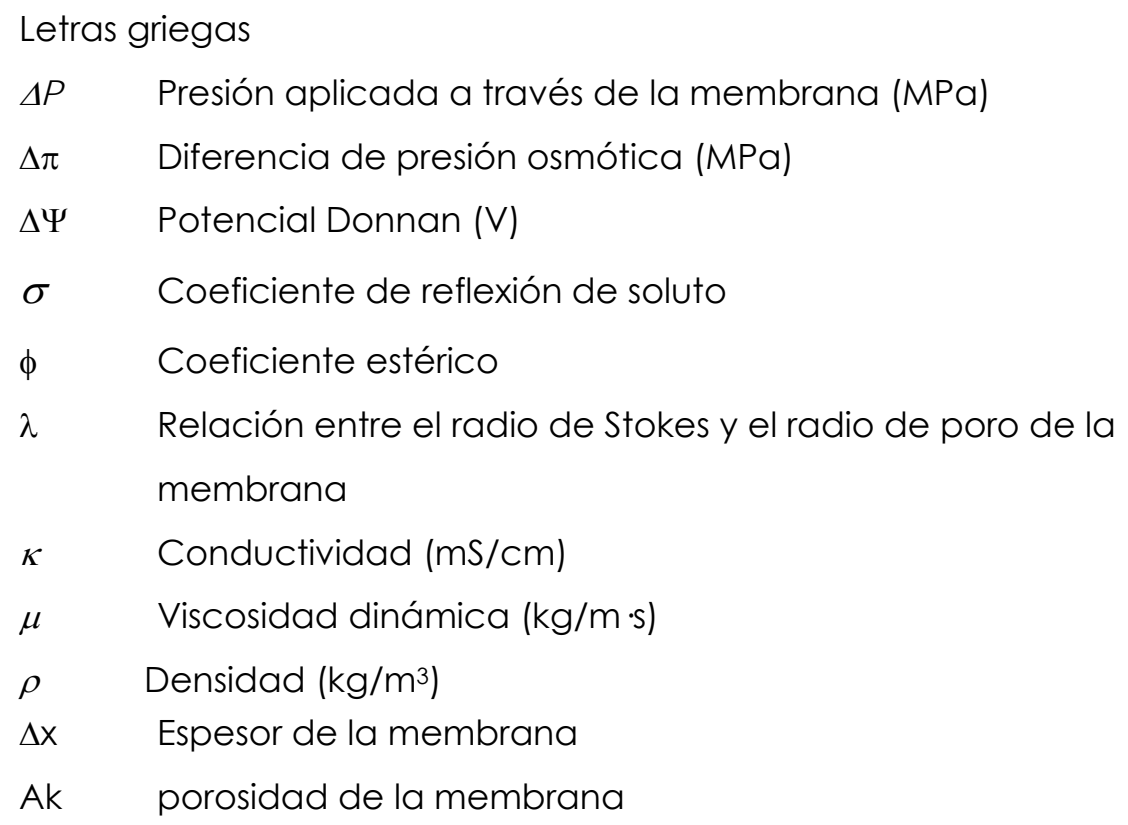





\section{RESÚMENES}

Titulo: Estudio del proceso de nanofiltración para la desmineralización del lactosuero dulce

\section{Resumen}

En la presente tesis se estudia la viabilidad de un tratamiento por tecnologías de membranas para desmineralizar un lactosuero dulce procedente de una industria quesera de la Comunidad Valenciana.

Como técnica de tratamiento se estudia el proceso de nanofiltración para eliminar las sales minerales de la lactosa, si bien previamente se lleva a cabo la eliminación de las proteínas por ultrafiltración. Tanto las proteínas como la lactosa se pueden emplear como ingredientes en una gran variedad de productos.

Los ensayos de membranas han sido realizados tanto en configuración plana como en arrollamiento en espiral en una planta diseñada por el Departamento de Ingeniería Química y Nuclear, que permite operar con ambos tipos de módulos. Para la determinación de todos los componentes implicados en el proceso se emplean diversas técnicas analíticas como absorción atómica, espectrofotometría de UV-Vis, cromatografía iónica, etc.

Los ensayos del proceso de nanofiltración se realizan tanto con disoluciones modelo de suero como con suero dulce real. Los ensayos mediante disoluciones modelo, se llevan a cabo con las 
membranas comerciales NF200, NF270, Ds-5 DK y Ds-5 DL. De todas ellas, la membrana NF200 es la que muestra mayores densidades de flujo e índices de rechazo, mientras que la membrana Ds-5 DL es la que muestran los valores más bajos. Sin embargo, ambas son susceptibles de utilizarse en el proceso de desmineralización, por lo que son seleccionadas para estudiar su comportamiento con el suero real.

Las densidades de flujo obtenidas con las membranas NF200 y Ds-5 $D L$ en los ensayos con el suero real, no muestran diferencias significativas entre si, si bien los índices de rechazo más altos corresponden a la membrana la NF200. Mientras que los valores de densidad de flujo del ión cloruro para las membranas NF200 y Ds-5 DL corresponden a $9,9 \mathrm{~g} / \mathrm{m}^{2} \mathrm{~h}$ y $32,42 \mathrm{~g} / \mathrm{m}^{2} \mathrm{~h}$ respectivamente.

Para mejorar las tasas de desmineralización obtenidas por concentración con la membrana Ds-5 DL, se decide incorporar una etapa adicional de diafiltración. En la etapa de concentración tanto la lactosa como los iones polivalentes se concentraron hasta un $60 \%$ aproximadamente, mientras que los iones monovalentes lo hacen en un $20 \%$ para un factor de reducción de volumen de 2 . En la etapa de diafiltración se alcanzan porcentajes de desmineralización entorno al $20 \%$ para los iones polivalentes y entre el $70-95 \%$ para los iones monovalentes, con pérdidas de lactosa entorno al 10\% para un factor de dilución de 2,06.

Las características finales del suero dulce tratado por concentracióndiafiltración presentan una composición entorno al 65\% para la lactosa con una conductividad de $2500 \mu \mathrm{S} / \mathrm{cm}$, lo que permite 
obtener un suero revalorizado (concentrado en lactosa) a la vez que se minimiza el impacto medioambiental de este tipo de vertidos con un tiempo de retorno de la inversión estimado entorno a los 2 años.

Los resultados obtenidos mediante el modelo matemático (DSPM) respecto al índice de rechazo correspondiente a la lactosa están en concordancia con los resultados obtenidos experimentalmente. 
Titol: Estudi del procés de nanofiltració per a la desmineralització del lactòserum dolç

\section{Resum}

En la present tesi s'estudia la viabilitat d'un tractament per tecnologies de membranes per a desmineralitzar un lactòserum dolç procedent d'una indústria formatgera de la Comunitat Valenciana.

Com a tècnica de tractament s'estudia el procés de nanofiltració per a eliminar les sals minerals de la lactosa, si bé prèviament es porta a terme l'eliminació de les proteïnes per ultrafiltració. Tant les proteïnes com la lactosa es poden emprar com a ingredients en una gran varietat de productes.

Els assajos de membranes realitzats, tant en configuració plana com en enrollament, en espiral es porten a terme en una planta dissenyada pel Departament d'Enginyeria Química i Nuclear, que permet operar amb estos dos tipus de mòduls. Per a la determinació de tots els components implicats en el procés s'empren diverses tècniques analítiques com l'absorció atòmica, espectrofotometria d'UV-Vis, cromatografia iónica, etc.

Els assajos del procés de nanofiltració es realitzen tant amb dissolucions model de sèrum i amb sèrum dolç real. Els assajos per mitjà de dissolucions model, es porten a terme amb les membranes comercials NF200, NF270, Ds-5 DK i Ds-5 DL. De totes elles, la membrana NF200 és la que mostra majors densitats de flux i índexs de retenció, mentres que la membrana Ds-5 DL és la que mostra els 
valors més baixos. No obstant, ambdós són susceptibles d'utilitzar-se en el procés de desmineralització, per la qual cosa s'utilitzen seleccionades per a estudiar el seu comportament amb el sèrum real.

Les densitats de flux obtingudes amb les membranes NF200 i Ds-5 DL en els assajos amb el sèrum real, no mostren diferències significatives entre si, si bé els índexs de retenció més alts corresponen a la membrana la NF200. Mentres que els valors de densitat de flux de l'ió clorur per a les membranes NF200 i Ds-5 DL corresponen a $9,9 \mathrm{~g} / \mathrm{m}^{2} \mathrm{~h}$ i $32,42 \mathrm{~g} / \mathrm{m}^{2} \mathrm{~h}$ respectivament.

Per a millorar les taxes de desmineralització obtingudes per concentració amb la membrana Ds-5 DL, s'incorpora una etapa addicional de diafiltración. En l'etapa de concentració tant la lactosa com els ions polivalents es van concentrar fins a un $60 \%$ aproximadament, mentres que els ions monovalents ho fan en un $20 \%$ per a un factor de reducció de volum de 2. En l'etapa de diafiltración s'aconseguixen percentatges de desmineralització entorn al $20 \%$ per als ions polivalents i entre el $70-95 \%$ per als ions monovalents, amb pèrdues de lactosa entorn al 10\% per a un factor de dilució de 2,06.

Les característiques finals del sèrum dolç tractat per concentraciódiafiltració presenten una composició entorn al $65 \%$ per a la lactosa amb una conductivitat de $2500 \mathrm{mS} / \mathrm{cm}$, la qual cosa permet obtindre un sèrum revalorat (concentrat en lactosa) al mateix temps que es minimitza l'impacte mediambiental d'este tipus d'abocaments amb un temps de retorn de la inversió estimat entorn als 2 anys. 
Els resultats obtinguts per mitjà del model matemàtic (DSPM) respecte a l'índex de retention corresponent a la lactosa estan en concordança amb els resultats obtinguts experimentalment. 
Title: Study of the process of nanofiltration for the sweet whey demineralization

\begin{abstract}
In this Doctoral Thesis the feasibility of treatment with membrane technologies to demineralize sweet whey from a cheese industry of the Community Valenciana has been studied.
\end{abstract}

Nanofiltration is used to eliminate mineral salts from lactose, having previously eliminated the proteins by ultrafiltration. Both proteins and lactose can then be used as ingredients in a great variety of products.

The experiments on membranes both in flat and spiral wounded configuration have been conducted in a plant designed by the Department of Chemical and Nuclear Engineering that is able to operate with both modules. To determine all of the components in the process, diverse analytical techniques have been used as atomic absorption, UV-VIS spectrophotometer, ion chromatographic, etc.

The nanofiltration experiments have been carried out with model solutions of whey and sweet whey. The first have been carried out with four membranes NF200, NF270, Ds-5 DK and Ds-5 DL. From all of them, the NF200 membrane have shown the biggest permeate flux and solute retention values, and the Ds-5 DL membrane have shown the lowest values. Nevertheless, both are susceptible for use in the process of demineralization, so that they have been selected to study their behaviour with the sweet whey. 
The permeate flux obtained with the NF200 and Ds 5 DL membranes in the experiments with the whey do not evidence significant differences between themselves, but the higher solute retention are for the NF200 membrane. Solute flux values of chloride ion are for the NF200 and Ds 5 DL membranes $9,9 \mathrm{~g} / \mathrm{m}^{2} \mathrm{~h}$ and $32,42 \mathrm{~g} / \mathrm{m}^{2} \mathrm{~h}$ respectively.

To increase the demineralization values obtained in the concentration stage with Ds 5 DL membrane, an additional stage of diafiltration was added. In the concentration stage both lactose and polyvalent ions were concentrated up to $60 \%$ approximately, while the monovalent ions did it in $\mathbf{2 0} \%$ for a factor of reduction of volume of 2 . In the stage of diafiltration, the percentages of demineralization were close to $20 \%$ for polyvalent ions and between 70-95\% for monovalent ones with losses of lactose around $10 \%$ for a factor of dilution of 2.06 .

The final characteristics of the sweet whey treated by concentrationdiafiltration offer concentrations around $65 \%$ in lactose with a value conductivity of 2500, that allow to obtain a revalued whey (concentrate in lactose) reducing to the minimum the environmental impact of wastewater with a pullback time of investment estimated at around 2 years.

The results obtained with mathematic model (DSPM) in relation to the lactose retention are in concordance with the results obtained experimentally. 
ANEXOS

11. 



\section{ANEXOS}

11.1 FICHAS TÉCNICAS DE LAS MEMBRANAS EMPLEADAS 


\section{FILMTEC Membranes}

\section{FILMTEC NF200-400 Nanofiltration Element}

The FILMTEC NF200-400 Nanofiltration element is a high area, high productivity element designed to remove a high percentage of TOC such as pesticides, herbicides, and THM precursors while having a medium salt passage; medium hardness passage.

The FILMTEC NF200-400 element is an ideal element for surface and ground water applications where good organic removal is desired with partial softening in order to maintain a minimum level of hardness for organoleptic properties and preservation of distribution networks.

The high active area membrane combined with low net driving pressure of the membrane allows the removal of these compounds at low operating pressure.

Product Specifications

\begin{tabular}{|c|c|c|c|c|}
\hline Product & GMID & $\begin{array}{c}\text { Nominal Surface Area } \\
\mathrm{ft}^{2}\left(\mathrm{~m}^{2}\right)\end{array}$ & $\begin{array}{l}\text { Product Water Flow Rate } \\
\text { gpd }\left(\mathrm{m}^{3} / \mathrm{d}\right)\end{array}$ & $\begin{array}{l}\text { Stabilized Solute } \\
\text { Passage (\%) }\end{array}$ \\
\hline NF200-400 & 135847 & $400(37)$ & & \\
\hline $\mathrm{CaCl}_{2}$ & & & $8,000(30.3)$ & $50-65$ \\
\hline $\mathrm{MgSO}_{4}$ & & & $6,800(25.7)$ & 3 \\
\hline Atrazine & & & & $5^{3}$ \\
\hline $\begin{array}{l}\text { 1. Permeate flow and } \\
500 \mathrm{mg} / \mathrm{CaCl} 2,70 \\
2000 \mathrm{ppm} \mathrm{MgSO} \text {, } \\
\text { 2. Flow rates for indiv } \\
\text { 3. Minimum rejection } \\
\text { 4. The above specific }\end{array}$ & $\begin{array}{l}\text { e rejection ba } \\
.48 \mathrm{MPa}), 77 \\
\text { i }(0.48 \mathrm{MPa}), \\
\text { elements may } \\
\text { to. }\end{array}$ & $\begin{array}{l}\text { he following test conditions: } \\
5, \text { and } 15 \% \text { recovery. } \\
5 \% \text {, and } 15 \% \text { recovery. }\end{array}$ & & \\
\hline
\end{tabular}

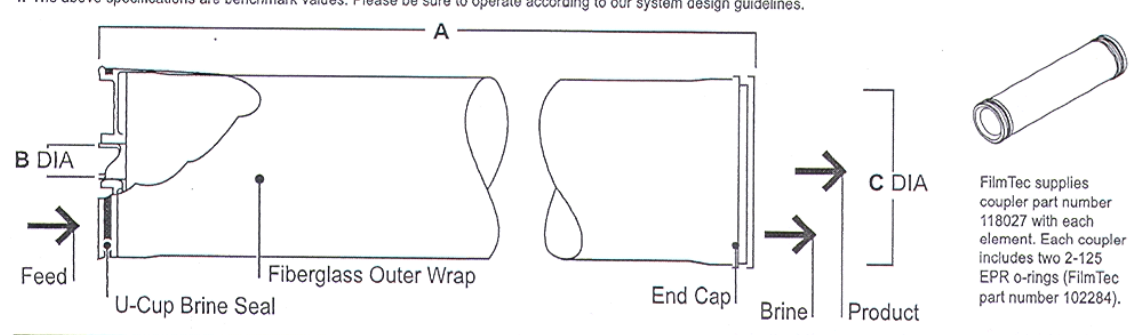

\begin{tabular}{|c|c|c|c|c|}
\hline Product & $\begin{array}{l}\text { Single-Element } \\
\text { Recovery }\end{array}$ & A & $\begin{array}{c}\text { ons - Inc } \\
\text { B }\end{array}$ & C \\
\hline NF200-400 & $15 \%$ & $40(1,016)$ & $1.5(38)$ & $7.9(201)$ \\
\hline
\end{tabular}

1. Consult the most recent DESIGN GUIDELINES for multiple-element applications and recommended element recovery rates for various feed sources. $\quad 1$ inch $=25.4 \mathrm{~mm}$
2. Element to fit nominal 8.00 -inch (203 mm) I.D. pressure vessel.

Operating Limits

Membrane Type....................................................... Polyamide Thin-Film Composite

Maximum Operating Pressure

Maximum Pressure Drop

pH Range, Continuous Operation ${ }^{\mathrm{a}} \ldots$

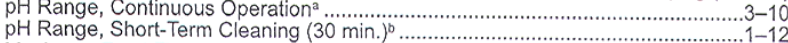

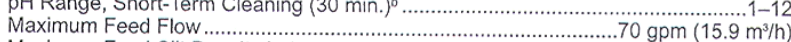

Maximum Feed Silt Density Index .......................................................................

Free Chlorine Tolerance ${ }^{\mathrm{c}}$.........................................................................................

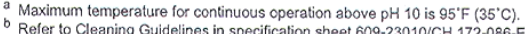

- Under certain conditions, the presence of free chlorine and other oxidizing acents will cause premature membrane failur. Since oxidetion demege is not cover warranty, FilmTec recommends removing residual free chlorine by pretreatment prior to membrane exposure. Please refer to technical bulletin $609-22010 / C H$ 172-144-E
for more information. for more information.

"Trademark of The Dow Chemical Company

FILMTEC Membranes • FilmTec Corporation is a wholly owned subsidiary of The Dow Chemical Company. 
11.1.2 Membrana NF 270

\section{FILMTEC Membranes}

\section{FILMTEC NF270-400 Nanofiltration Element}

The FILMTEC NF270-400 Nanofiltration element is a high area, high productivity element designed to remove a high percentage of TOC and THM precursors while having a medium to high salt passage; medium hardness passage.

The FILMTEC NF270-400 element is an ideal element for surface and ground water applications where good organic removal is desired with partial softening in order to maintain a minimum level of hardness for organoleptic properties and preservation of distribution networks.

The high active area membrane combined with low net driving pressure of the membrane allows the removal of these compounds at low operating pressure.

Product Specifications

\begin{tabular}{|ccccc|}
\hline Product & GMID & $\begin{array}{c}\text { Nominal Active Surface Area } \\
\mathbf{f}^{2}\left(\mathbf{m}^{2}\right)\end{array}$ & $\begin{array}{c}\text { Product Water Flow Rate } \\
\mathbf{g p d}\left(\mathbf{m}^{3} / \mathbf{d}\right)\end{array}$ & $\begin{array}{c}\text { Stabilized Salt } \\
\text { Passage }(\%)\end{array}$ \\
\hline $\mathrm{NF270-400}$ & 148822 & $400(37)$ & & \\
\hline $\mathrm{CaCl}_{2}$ & & $14,700(55.6)$ & $40-60$ \\
\hline $\mathrm{MgSO}_{4}$ & & $12,500(47)$ & $<3$ \\
\hline
\end{tabular}

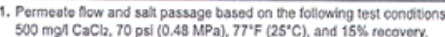

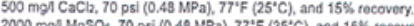

2. Fiow rates for individual elements may vary $115 \%$

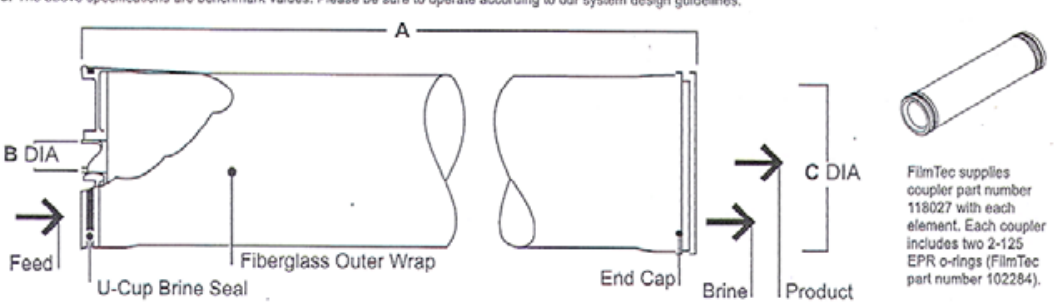

\begin{tabular}{|lcccc|}
\hline Product & $\begin{array}{c}\text { Single-Element } \\
\text { Recovery }\end{array}$ & A & Dimensions - Inches (mm) & C \\
\hline NF270-400 & $15 \%$ & $40(1,016)$ & $1.5(38)$ & $7.9(201)$ \\
\hline 1. Consult the most recent DESIGN GUIDELINES for multiple-element spolications & & & 1 inch $=25.4 \mathrm{~mm}$ \\
\hline
\end{tabular}

1. Consult the most reccent DESIGN GUIDELINES for multople-element opplication 2. Element to fit nominal 8.00 - inchech (203 mm) L.C. pressure vessel.

Operating Limits

Membrane Type .................................................. Polyamide Thin-Film Composite

Maximum Operating Pressure ………......................................

Maximum Pressure Drop.

pH Range, Continuous Operation …………......................................................3-10

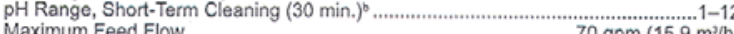

Maximum Feed Flow................................................... gpm (15.9 m//h

Maximum Feed Silt Density Index ............................................................

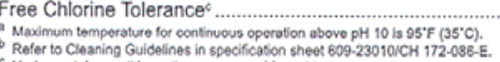

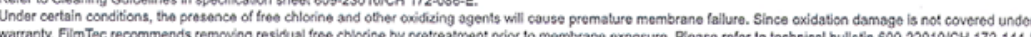
for more information.

Trademark of The Dow Chemical Company

FILMTEC Membranes - FilmTec Corporation is a wholly owned subsidiary of The Dow Chemical Company. 


\title{
11.1.3 Membrana Ds-5 DK
}

\author{
Nanofiltration Membrane Elements-DS-5 Standard Flux \\ Product Information
}

These elements are used for dye removal/concentration, and sodium chloride diafiltration. They feature a fiberglass outerwrap and standard feed spacers. Other materials of construction and special feed spacers are available.

The proprietary DS-5 thin-film nanofiltration membrane is characterized by an approximate molecular weight cut-off of 150-300 daltons for uncharged organic molecules. Divalent and multivalent anions are preferentially rejected by the membrane while monovalent ion rejection is dependent upon feed concentration and composition. Since monovalent ions pass through the membrane, they do not contribute to the osmotic pressure thus enabling DS-5 nanofiltration systems to operate at feed pressures below those of RO systems.

\section{Membrane Specification - DS-5}

Membrane; Proprietary nanofiltration thin-film membrane (TFM).

Applications: Dye removal/concentration, heavy metals removal, acid purification, and sodium chloride diafiltration.

Rejection characteristics: Divalent and multivalent anions are preferentially rejected by the membrane while monovalent ion rejection is dependent upon feed concentration and composition. The membrane is characterized by a
molecular weight cutoff of 150-300 daltons for uncharged organic molecules.

Recommended pH: 2.0-11.0 operating range and 1.0-11.5 cleaning range for standard construction elements.

Chlorine tolerance: 1,000 ppm-hours, dechlorination recommended.

Maximum temperature: $122 \mathrm{~F}(50 \mathrm{C})$ with standard element construction and up to $158 \mathrm{~F}(70 \mathrm{C})$ with special element construction.

Element Series Designation: DK, DL

Element Specifications

\begin{tabular}{|c|c|c|c|}
\hline Model & GPD $(\mathrm{m} / \mathrm{d})$ & MgSO4 Rejection & ActiveArea $\mathrm{ft}(\mathrm{m})$ \\
\hline DK4040F & $2,000(7.56)$ & $98 \%$ & $90(8.36)$ \\
\hline DK8040F & $8,000(30.24)$ & $98 \%$ & $350(32.52)$ \\
\hline
\end{tabular}

Specifications are based on a 2,000 mg/L MgSO4 solution at $100 \mathrm{psig}(690 \mathrm{kPa})$ net pressure, $77 \mathrm{~F}(25 \mathrm{C}), 10 \%$ recovery after 24 hours. Individual element flux may vary $15 \%$.

\section{Operating and Design Parameters}

Membrane: Thin film membrane (TFM)

Typical operating pressure: $70-400 \mathrm{psig}(483-2,758 \mathrm{kPa})$.

Maximum pressure: $500 \mathrm{psig}(3,448 \mathrm{kPa})$.

Maximum temperature: $122 \mathrm{~F}(50 \mathrm{C})$.

Recommended $\mathrm{pH}$ : Operating range $2-11$ ( $\mathrm{pH}<1$ with special element construction), cleanling range 1-11.5.

Chlorine tolerance: 1,000 ppm-hours, dechlorination recommended. 
Recommended per vessel in a system

$$
\begin{array}{ccccccc}
\text { delta P - psig (kPa) } & 10(69) & 20(138) & 30(207) & 38(262) & 45(310) & 50(345) \\
\% \text { Recovery } & 15^{\prime} & 25 & 35 & 45 & 53 & 53
\end{array}
$$

Element Dimensions and Weight

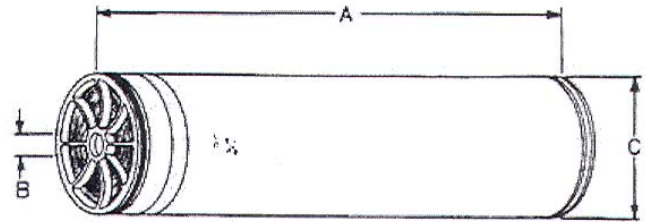

\begin{tabular}{|c|c|c|c|c|}
\hline \multirow{2}{*}{ Model } & \multicolumn{3}{|c|}{ Dimensions, inches (cm) } & $\begin{array}{c}\text { Dry boxed } \\
\text { weight Ibs. (kg) }\end{array}$ \\
\hline & A & B & C & \\
\hline DK4040F & $40.00(101.6)$ & $0.625(1.59)$ & $3.88(9.86)$ & $12(5.45)$ \\
\hline DK8040F & $40.00(101.6)$ & $1.187(3.01)$ & $7.88(20.02)$ & $32(14.53)$ \\
\hline
\end{tabular}

Length includes ATD's. All elements are shipped dry.

\section{Downloads}

\section{Get Acrobat.}

Arobe Reader

Downiload Plant Start-up and Shutdown Instructions for Membranes (23 KB)

Download Membrane Element Loading Instructions (42 KB)

Download Membrane Chemical Compatibility Information (33 KB)

Download Membrane Element Storage Recommendation (73 KB)

Water \& Process Technologies | Products \& Services | Industries | Library \& Downloads | About Us

GE Corporate Home | Investor Information | Privacy Policy | Terms and Conditions

Copyright General Electric Company 1997-2005 


\title{
11.1.4 Membrana Ds-5 DL
}

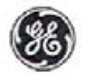

\author{
Nanofiltration Membrane Elements-DS-5 High Flux \\ Product Information
}

These elements are used for dye removal/concentration, and sodium chloride diafiltration. They feature a fiberglass outerwrap and standard feed spacers. Other materials of construction and special feed spacers are available.

The proprietary DS- 5 thin-film nanofiltration membrane is characterized by an approximate molecular weight cut-off of 150-300 daltons for uncharged organic molecules. Divalent and multivalent anions are preferentially rejected by the membrane while monovalent ion rejection is dependent upon feed concentration and composition. Since monovalent ions pass through the membrane, they do not contribute to the osmotic pressure thus enabling DS- 5 nanofiltration systems to operate at feed pressures below those of RO systems.

\section{Membrane Specification - DS-5}

Membrane: Proprietary nanofiltration thin-film membrane (TFM).

Applications: Dye removal/concentration, heavy metals removal, acid purification, and sodium chloride diafiltration.

Rejection characteristics: Divalent and multivalent anions are preferentially rejected by the membrane while monovalent ion rejection is dependent upon feed concentration and composition. The membrane is characterized by a molecular weight cutoff of 150-300 daltons for uncharged organic molecules.

Recommended pH: 2.0-11.0 operating range and 1.0-11.5 cleaning range for standard construction elements.

Chlorine tolerance: 1,000 ppm-hours, dechlorination recommended. Maximum temperature: $122 \mathrm{~F}(50 \mathrm{C})$ with standard element construction and up to $158 \mathrm{~F}(70 \mathrm{C})$ with special element
construction.

Element Series Designation: DK, DL

Element Specifications

\begin{tabular}{|l|c|c|c|}
\hline Model & GPD (m/d) & MgSO4 Rejection & ActiveArea ft $(\mathrm{m})$ \\
\hline DL4040F & $2,800(10.58)$ & $96 \%$ & $90(8.36)$ \\
\hline DL8040F & $10,200(38.56)$ & $96 \%$ & $350(32.52)$ \\
\hline
\end{tabular}
Specifications are based on a $2,000 \mathrm{mg} / \mathrm{L}$ MgSO 4 solution at $100 \mathrm{psig}(690 \mathrm{kPa})$ net pressure, $77 \mathrm{~F}(25 \mathrm{C}), 10 \%$ recovery,
after 24 hours. Individual element flux may vary $15 \%$.

\section{Operating and Design Parameters}

Membrane: Thin film membrane (TFM).

Typical operating pressure: $70-400 \mathrm{psig}(483-2,758 \mathrm{kPa})$.

Maximum pressure: $500 \mathrm{psig}(3,448 \mathrm{kPa})$.

Maximum temperature: $122 \mathrm{~F}(50 \mathrm{C})$.

Recommended $\mathrm{pH}$ : Operating range $2-11(\mathrm{pH}<1$ with special element construction), cleaning range $1-11.5$.

Chlorine tolerance: 1,000 ppm-hours, dechlorination recommended. 


\begin{tabular}{|c|c|c|c|c|c|c|}
\hline \multirow{2}{*}{$\begin{array}{l}\text { Recommended per } \\
\text { vessel in a system }\end{array}$} & \multicolumn{6}{|c|}{ Elements per pressure vessel } \\
\hline & 1 & 2 & 3 & 4 & 5 & 6 \\
\hline delta $\mathrm{P}$ - psig ( $\mathrm{kPa})$ & $10(69)$ & $20(138)$ & $30(207)$ & $38(262)$ & $45(310)$ & $50(345)$ \\
\hline$\%$ Recovery & 15 & 25 & 35 & 45 & 53 & 53 \\
\hline
\end{tabular}

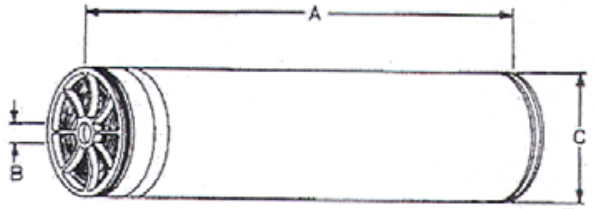

\begin{tabular}{|l|c|c|c|c|}
\hline \multirow{2}{*}{ Model } & \multicolumn{3}{|c|}{ Dimensions, inches (cm) } & \multirow{2}{*}{ Dry Boxed Weight Ibs. (kg) } \\
\cline { 2 - 4 } & A & B & C & \\
\hline DL4040F & $40.00(101.6)$ & $0.625(1.59)$ & $3.88(9.86)$ & $12(5.45)$ \\
\hline DL8040F & $40.00(101.6)$ & $1.125(3.01)$ & $7.88(20.02)$ & $32(14.53)$ \\
\hline
\end{tabular}

Length includes ATD's. All elements are shipped dry.

Downloads

$$
\begin{aligned}
& \text { ThGel Acrobal } \\
& \text { Asoocer Reader }
\end{aligned}
$$

Download Plant Start-up and Shutdown Instructions for Membranes (23 KB)

Download Membrane Element Loading Instructions (42 KB)

Download Membrane Chemical Compatibility Information (33 KB)

Download Membrane Element Storage Recommendation ( $73 \mathrm{~KB}$ )

Water \& Process Technologies | Products \& Services | Industries | Library \& Downloads | About Us

GE Corporate Home | Investor Information | Privacy Policy | Terms and Conditions

Copyright General Electric Company 1997-2005 


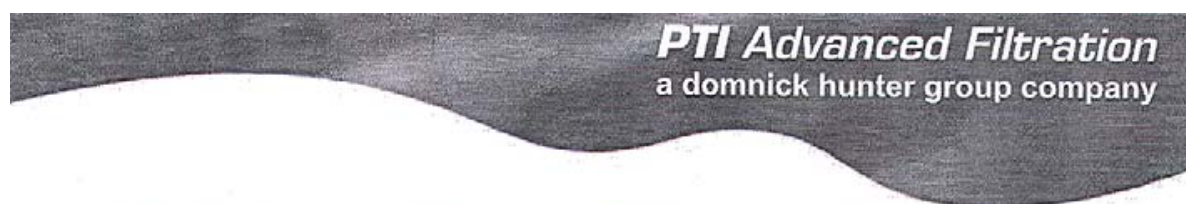

\section{S-SERIES ULTRAFILTRATION (UF) SANITARY SPIRAL ELEMENTS}

Proprietary Polyethersulfone (PES) Membrane with Polyester Support Developed for High Rejection of Proteins

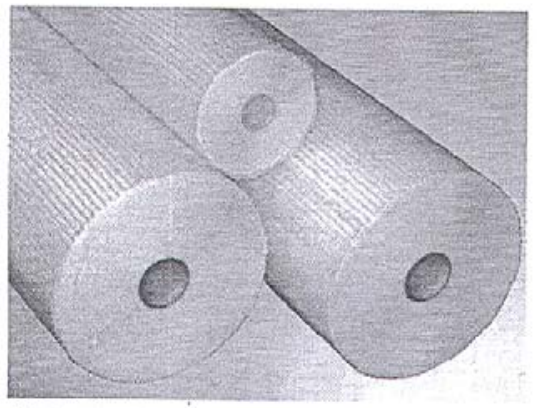

S-Series Ultrafiltration Sanitary Spiral Elements are designed for high protein rejection and extended life in a wide range of food processing and dairy applications. The

Polyethersulfone (PES) membrane provides excellent

chemical and temperature resistance under a variety of

process conditions.

\section{BENEFITS}

- Initial $99.9 \%$ protein rejection

- Designed to withstand daily cleaning cycles

- Element construction (designed to conform to 3-A. FDA. and USDA standards) developed for enhanced durability and extended life

- Available in standard diameter or custom sized

configurations for maximum performance and optimal

cleaning

\section{APPLICATIONS}

- Sweet/Acid Whey Concentration from 35-90\%

- Whole Milk Concentration

- Skim Milk Concentration

- Production of Fresh Cheese

- Gelatin Concentration

- Plasma Fractionation

- Microorganism Removal from Surface Water

\begin{tabular}{|c|c|c|c|}
\hline \multicolumn{4}{|c|}{ SPECIFICATIONS } \\
\hline \multicolumn{4}{|c|}{ MATERIALS OF CONSTRUCTION } \\
\hline \multicolumn{2}{|c|}{ Membrane } & \multicolumn{2}{|c|}{ Proprietary Polyethersulfone } \\
\hline \multicolumn{2}{|c|}{ Backing Material } & \multicolumn{2}{|c|}{ Polyester } \\
\hline \multicolumn{2}{|c|}{ Permeate Tube } & \multicolumn{2}{|c|}{ Polysulfone } \\
\hline \multicolumn{4}{|c|}{$\begin{array}{l}\text { - Special element construction available for high } \\
\text { temperature/high pressure conditions } \\
\text { - Stainless steel permeate tube configurations available }\end{array}$} \\
\hline TYPE & MATERIAL & BACKING MATERIAL & NMWCO- \\
\hline SD & Polyethersulfone (PE. & Polyester & 10,000 \\
\hline SE & Polyethersulfone (PE. & Polvester & 25,000 \\
\hline SF & Polyethersulfone (PE & Polyester & 50,000 \\
\hline
\end{tabular}

-Nominal Molecular Weight Cutoff (NMWCO) is provided as a relative guide to the membrane pore size. For a particular applicotion, pleuse consult with your PTI Technical Representstive

OPERATING CONDITIONS/LIMITS Maximum Inlet Pressure* 150 psi (10.3 bar)

Typical Inlet Pressure* 100-140 psi (7-10 bar)

Maximum Operating Temperature $\quad 122^{\circ} \mathrm{F}\left(50^{\circ} \mathrm{C}\right)$

pH Range, continuous $\quad 3-10$

pH Range, short-term cleaning ${ }^{* *} \quad 2-11.5$

$2-11.5$
(a) $122^{\circ} \mathrm{F}\left(50^{\circ} \mathrm{C}\right)$

Maximum chlorine concentration $\quad 180 \mathrm{ppm} @ 9-11 \mathrm{pH}$

Other oxidizing agents limitations Consult Factory

*Recommended cross flow rates and $\triangle P$ are dependent on various
process parameters. For a specific application please consult with a

"Consult factory for cleaning guidelines 


\section{S-SERIES ULTRAFILTRATION (UF) \\ SANITARY SPIRAL ELEMENTS}

Proprietary Polyethersulfone (PES) Membrane with Polyester Support Developed for High Rejection of Proteins
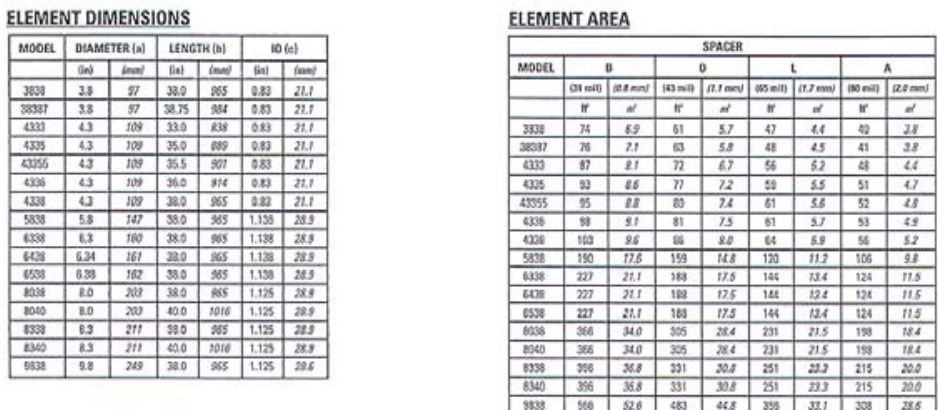

ORDERING INFORMATION

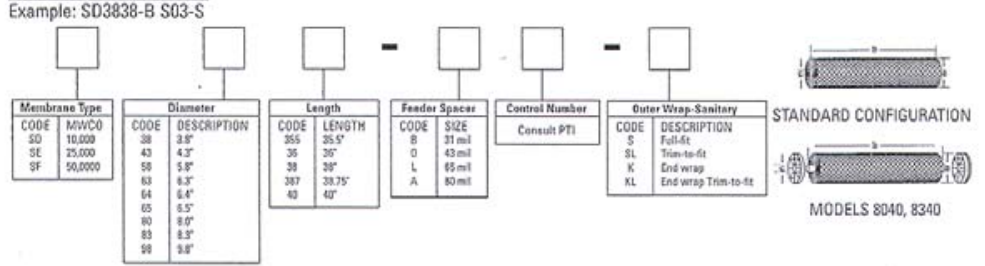

TECHNICAL SUPPORT and PRODUCT ORDERING

PTI Advanced Filtration provides unsurpassed product consistency and cost-efficiency for our customers. Our experienced

professionals can help you select the right solution for your application. for more information or to place an order, contact your local distributor. Information on product specifications, applications and chemical compatibility can be found on our web site at unw.pti-afi.com or through your nearest PTI Advanced Filtration office.

PTI Advanced Filtration designs and manufactures an extensive line of innovative solutions for specific applications in Biopharmaceutical, Microelectronics, Food \& Beverage, Industrial and Chemical industries.

DISTRIBUTED BY:

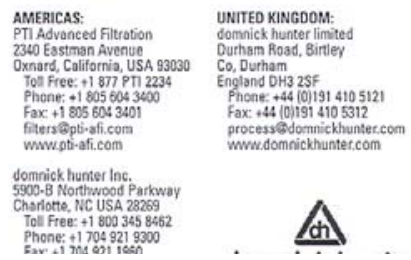




\subsection{MÉTODOS ANALÍTICOS}

Los métodos que se describen a continuación, se utilizaron en las fases inicial e intermedia

\subsubsection{Procedimientos para la toma y conservación de muestras de leche y productos lácteos}

Al realizar un análisis de laboratorio a una muestra, esta debe ser representativa para que los resultados sean válidos. Los materiales de trabajo para muestras lácteas pueden ser: vidrio, ciertos metales y algunos tipos de materiales plásticos y preferiblemente opacos, en caso contrario su contenido debe protegerse de la luz. Si se utilizan reactivos para la preservación de muestras de leche y productos lácteos esterilizados y no esterilizados se debe indicar en la etiqueta así como la cantidad adicionada.

Las muestras de leche y productos lácteos líquidos no esterilizados deberán conservarse a una temperatura entre 0 a $4^{\circ} \mathrm{C}$ después de su recogida en el sitio de muestreo. Si el producto lácteo se encuentra esterilizado este puede almacenarse a temperatura ambiente (máximo $25^{\circ} \mathrm{C}$ ). Una vez las muestras hayan sido tomadas deben llevarse al laboratorio lo más pronto posible (antes de 24 horas). Durante el transporte no deben estar expuestas a olores contaminantes, luz solar directa o a temperaturas entre $0-4^{\circ} \mathrm{C}$.

Se deben llenar prácticamente los recipientes con la muestra de tal forma que se puedan mezclar bien para su análisis y se evite el 
batido durante su transporte. Antes de realizar el análisis es necesario homogeneizar la muestra, esto se puede hacer vertiendo la muestra de un recipiente a otro o utilizando aire comprimido hasta lograr una disolución homogénea. Si no es posible obtenerla, se tomarán alícuotas representativas de $20 \mathrm{~mL}$ como mínimo en diferentes puntos del lugar de muestro y el volumen total a analizar no debe ser inferior a $200 \mathrm{~mL}$. Todos los reactivos utilizados para los análisis deben ser de calidad analítica.

\subsubsection{Técnicas analíticas empleadas}

\subsubsection{Cloruros}

En una disolución neutra o ligeramente alcalina, el cromato potásico puede indicar el punto final de la titulación de cloruros con nitrato de plata. El cloruro precipita cuantitativamente en forma de cloruro de plata antes de formarse el cromato de plata rojo.

Las posibles interferencias presentes en la muestra se darán por la presencia de ortofosfatos si están en concentraciones superiores a 25 $\mathrm{mg} / \mathrm{L}$, ya que estos precipitan con el nitrato de plata en forma de fosfato de plata.

\section{Equipo}

Erlenmeyer, $250 \mathrm{~mL}$

Bureta, $50 \mathrm{~mL}$.

\section{Reactivos}


a) Disolución indicadora de cromato potásico: Se disuelven $50 \mathrm{~g}$ de $\mathrm{K}_{2} \mathrm{CrO}_{4}$ en un poco de agua destilada. Se añade $\mathrm{AgNO}_{3}$ hasta formar un precipitado rojo claro. Se Deja reposar durante 12 horas, se filtra y diluye a $1 \mathrm{~L}$ con agua estilada.

b) Titulante de nitrato de plata 0,0141 N: Se disuelven 2,395 $\mathrm{g}$ de $\mathrm{AgNO}_{3}$ en agua destilada y se lléva a $1 \mathrm{~L}$. Seguidamente se valora con una disolución de $\mathrm{NaCl}$.

c) Cloruro de sodio $0,0141 \mathrm{~N}$ : Se disuelven $824 \mathrm{mg}$ de $\mathrm{NaCl}$ (secado a $140^{\circ} \mathrm{C}$ ) en agua destilada y se lleva a $1 \mathrm{~L}$.

d) Reactivos para eliminación de interferencias

- Hidróxido de sodio 1N. ( para llevar a pH entre 6-10, cuando sea necesario)

- Ácido sulfúrico, 1N. I para llevar a pH entre 6-10, cuando sea necesario)

\section{Procedimiento}

Se utiliza un volumen de muestra conocido. La muestra estaba transparente, así que no hubo necesidad de utilizar la suspensión de hidróxido de aluminio y el pH se encontraba en el rango de 6 a 10.

A dicha muestra se le añade 1,0 mL de disolución de cromato de potasio, para luego titularla con nitrato de plata de concentración conocida hasta llegar al punto final de la titulación amarillo-rosa.

Se procede a determinar la concentración exacta de la disolución de nitrato de plata, para lo cual se toma $5 \mathrm{~mL}$ de la disolución de cloruro de sodio $0,0141 \mathrm{~N}$ y se sigue el mismo procedimiento que para la 
muestra problema. (Para conocer la concentración exacta de la disolución de nitrato de plata se realiza el siguiente cálculo:

$\frac{0,0141 N \times V_{1}}{V_{2}}$

$V_{1}:$ volumen de muestra de $\mathrm{NaCl}$

$V_{2}:$ Volumen de $\mathrm{AgNO}_{3}$ gastado

\section{Cálculo}

$\frac{m g C l^{-}}{L}=\frac{(A-B) \times N \times 35450}{V_{m}}$

$\frac{m g N a C l}{L}=\left(\frac{m g C l^{-}}{L}\right) \times 1,65$

Donde:

$A$ : Volumen gastado de nitrato de plata en muestra problema

$B$ : Volumen gastado de nitrato de plata en blanco

$N$ : Normalidad del nitrato de plata

$V_{m}:$ Volumen de muestra valorada

\subsubsection{Sulfatos}

El ión sulfato precipita en un medio con ácido acético y cloruro de bario para formar cristales de sulfato de bario. La absorbancia de la luz de la suspensión de sulfato de bario se mide con un espectrofotómetro y la concentración de sulfatos se obtiene a partir de la curva de calibración. 
Las posibles interferencias presentes en la muestra se darán por la presencia de color o de sólidos suspendidos en grandes cantidades. Los sólidos suspendidos pueden ser eliminados mediante filtración.

\section{Equipo}

Agitador magnético

Espectrofotómetro

Bureta, $50 \mathrm{~mL}$.

\section{Reactivos}

a) Disolución buffer A: Se disuelven $30 \mathrm{~g}$ de cloruro de magnesio, $\mathrm{MgCl}_{2} \cdot 6 \mathrm{H}_{2} \mathrm{O}, 5 \mathrm{~g}$ de acetato de sodio, $\mathrm{CH}_{3} \mathrm{COONa} \cdot 3 \mathrm{H}_{2} \mathrm{O}, 1 \mathrm{~g}$ de nitrato de potasio, $\mathrm{KNO}_{3}$ y $20 \mathrm{~mL}$ de ácido acético, $\mathrm{CH}_{3} \mathrm{COOH}(99 \%)$ en $500 \mathrm{~mL}$ de agua destilada y se diluye a $1 \mathrm{~L}$. (para muestras que tengan la concentración de sulfatos entre 0 - 40 mg/L)

b) Cristales de cloruro de bario, $\mathrm{BaCl}_{2}$,

C) Disolución estándar de sulfatos: Se prepara una disolución estándar a partir de 10,4 mL de ácido sulfúrico 0,02 N ó se disuelven 0,1479 g de sulfato de sodio anhidro en agua destilada y se afora a $1 \mathrm{~L}$.

\section{Procedimiento}

Se toman $20 \mathrm{~mL}$ de muestra y se agrega $4 \mathrm{~mL}$ de la disolución buffer A y se mezcla utilizando un agitador magnético, mientras se agrega una cucharadita de cristales de cloruro de bario y a partir de aquí se agita a velocidad constante durante sesenta segundos. Después de esto se 
espera cinco minutos y se lee la absorbancia de la muestra a una longitud de onda de $420 \mathrm{~nm}$.

Para preparar la curva de calibración se preparan disoluciones de 0 , $10,20,30$ y $40 \mathrm{mg} \mathrm{SO} 4^{-2} / \mathrm{L}$ y se sigue el procedimiento descrito anteriormente tanto para la curva de calibración como para las muestras problema.

Debido a que las muestras se encontraban fuera del rango de la curva de calibración es necesario realizar diluciones de estas para su cuantificación.

\section{Cálculo}

La concentración de las muestras se lee directamente a partir de la curva de calibración, teniendo en cuenta el factor de dilución empleado.

\subsubsection{Sodio}

Se determinan cantidades de sodio por fotometría de emisión de llama a una longitud de onda de $589 \mathrm{~nm}$. Se pulveriza la muestra en una llama de gas y la excitación se realiza en condiciones controladas y reproducibles. La línea espectral buscada se aísla utilizando filtros de interferencia o por medio de una disposición adecuada de la ranura de los dispositivos de dispersión de luz. La intensidad de la luz se mide con un potenciómetro. Con lo cual la concentración del sodio es 
aproximadamente proporcional a la intensidad de la luz a $589 \mathrm{~nm}$. La curva de calibración puede ser lineal, pero muestra una tendencia a la horizontalidad a altas concentraciones.

En la cuantificación del sodio se pueden presentar interferencias si se trabaja con el método de patrón interno, en tal caso se utiliza una disolución de cloruro de litio.

\section{Equipo}

Espectrofotómetro de llama

Material de vidrio: se enjuaga todo el material de vidrio con $\mathrm{HNO}_{3}$ 1:15 y a continuación con varias porciones de agua destilada desionizada.

\section{Reactivos}

a) Aire: la fuente de suministro de aire normalmente es un compresor con la línea de aire que va a los conductos del equipo o aire embotellado.

b) Acetileno: de calidad comercial estándar.

c) Disolución madre de sodio: Se trabaja con una disolución patrón de sodio de $1000 \mathrm{mg} / \mathrm{L}$. Esta se prepara disolviendo 2,542 $\mathrm{g}$ de $\mathrm{NaCl}$ (secado a $140^{\circ} \mathrm{C}$ ) y se diluye a $1 \mathrm{~L}$ con agua estilada.

d) Preparación de la curva de calibración de sodio: Se preparan concentraciones de sodio entre 0 y $100 \mathrm{mg} / \mathrm{L}$ a partir de disolución madre de sodio.

e) Agua de dilución: para preparar todos los estándares así como las muestras se utiliza agua con ácido nítrico $11 \mathrm{~mL}$ de $\mathrm{HNO}_{3}$ conc./500 $\mathrm{mL}$ de agua desionizada).

f) Disolución de litio: $1,00 \mathrm{mg} \mathrm{Li} / 1,00 \mathrm{~mL}$ 


\section{Procedimiento}

a) Tratamiento de la muestra que contiene sodio:

Si no se van a analizar las muestras inmediatamente, se preservan con $\mathrm{HNO}_{3}$ hasta $\mathrm{pH}<2$ y se guardan en un recipiente de plástico. Todos los reactivos también se deben almacenar en recipientes de plástico.

b) Medida de la intensidad directa:

Se prepara un blanco y los patrones de calibración de sodio con cantidades graduadas en un rango de concentración conocida de 0 a $100 \mathrm{mg} / \mathrm{L}$, se toman alícuotas de $5 \mathrm{~mL}$ y a cada una de ellas se le adicionan $2 \mathrm{~mL}$ de la disolución de litio y se agitan. Se hace la lectura de emisión a 589 nm, de las disoluciones de la curva de calibración de la más alta a la más baja. Se determina la concentración de sodio de la muestra problema a partir de la curva de calibración. Como la concentración de sodio en las muestras está por fuera del rango de concentración se hacen diluciones.

\section{Cálculo}

$$
\begin{aligned}
& \frac{m g N a}{L}=\left(\frac{m g N a e n m u e s t r a}{L}\right) \times F D \\
& F D=\frac{V_{\text {frnal }}}{V_{\text {inicial }}}
\end{aligned}
$$




\subsubsection{Potasio}

La concentración de potasio se determina también por fotometría de emisión de llama a una longitud de onda de 766,5 nm. Mucha de la información suministrada para la cuantificación de sodio se aplica al potasio.

Para la determinación de la concentración de potasio se pueden tener interferencias si:

La relación sodio - potasio es de 5:1 o mayor.

La relación calcio - potasio es de 10:1 o mayor.

La relación magnesio - potasio es de 100:1 o mayor.

El límite de detección del método para el potasio es de aproximadamente $0,1 \mathrm{mg} / \mathrm{l}$.

\section{Equipo}

Espectrofotómetro de llama

Material de vidrio: se enjuaga todo el material de vidrio con $\mathrm{HNO}_{3}$ 1:15 y a continuación con varias porciones de agua destilada desionizada.

\section{Reactivos}

a) Disolución madre de potasio: se trabaja con un patrón de potasio de $1000 \mathrm{mg} / \mathrm{L}$, pero si no también se puede preparar disolviendo $1,9707 \mathrm{~g}$ de $\mathrm{KCl}$ (secado a $110^{\circ} \mathrm{C}$ ) y dilúyase a 1 I con agua estilada. 
b) Preparación de la curva de calibración de potasio: Se preparan concentraciones de potasio entre 0 y $200 \mathrm{mg} / \mathrm{L}$ a partir de la disolución madre de potasio y se afora con el agua de dilución.

c) Agua de dilución: para preparar todos los estándares así como las muestras se utiliza agua con ácido nítrico $(1 \mathrm{~mL}$ de $\mathrm{HNO} 3$ conc./500 mL de agua desionizada).

d) Disolución de litio: $1,00 \mathrm{mg} \mathrm{Li} / 1,00 \mathrm{~mL}$

\section{Procedimiento}

Se realiza el mismo procedimiento que para el sodio.

\section{Cálculo}

$$
\begin{aligned}
& \frac{m g K}{L}=\left(\frac{m g \text { Kmuestra }}{L}\right) \times F D \\
& F D=\frac{V_{\text {final }}}{V_{\text {inicial }}}
\end{aligned}
$$

\subsubsection{Magnesio}

Se determinan cantidades de magnesio por el método directo de aire acetileno. Mucha de la información suministrada para la cuantificación de calcio también se aplica a metales como el sodio, el potasio, el magnesio, entre otros. 
El proceso a seguir es el mismo que para el calcio, solo cambia la preparación de la disolución patrón de magnesio y que se utiliza lantano en vez de litio.

\section{Equipo}

Igual que para el sodio.

\section{Reactivos}

a) Agua de dilución: para preparar todos los estándares así como las muestras se utiliza agua con ácido nítrico $\left(1 \mathrm{~mL}\right.$ de $\mathrm{HNO}_{3}$ conc./500 $\mathrm{mL}$ de agua desionizada).

b) Disolución de lantano: Se disuelven $58,65 \mathrm{~g}$ de óxido de lantano en $250 \mathrm{~mL}$ de ácido clorhídrico concentrado. El ácido se añade lentamente hasta que el material se ha disuelto, para luego aforar a $1 \mathrm{~L}$.

g) Disolución patrón de magnesio: Se Utiliza un patrón de magnesio de $1000 \mathrm{mg} / \mathrm{L}$, en caso de que no se tenga se disuelven 0,1658 $\mathrm{g}$ de óxido de magnesio utilizando una cantidad mínima de ácido nítrico 1:1. Se añaden 10,0 $\mathrm{mL}$ de ácido nítrico concentrado y se diluyen a $1 \mathrm{~L}$ con el agua de dilución.

h) Preparación de la curva de calibración de magnesio: Se preparan concentraciones de magnesio entre 0 y $0,5 \mathrm{mg} / \mathrm{L}$ a partir de disolución madre de magnesio y se afora con el agua de dilución.

\section{Procedimiento}

Se prepara un blanco y patrones de calibración de magnesio con cantidades graduadas en un rango de concentración conocida de 0 a $0,5 \mathrm{mg} / \mathrm{L}$, luego se toman alícuotas de $5 \mathrm{~mL}$ de cada una y se le 
adicionan $1 \mathrm{~mL}$ de la disolución de lantano y se agitan. Se hace la lectura de emisión a 285,2 nm, de las disoluciones de la curva de calibración de la más alta a la más baja. Se determina la concentración de magnesio en las muestra problema a partir de la curva de calibración, como la concentración de magnesio en las muestras estaba por fuera del rango de concentración se tuvieron que hacer las diluciones respectivas.

\section{Cálculo}

$$
\begin{aligned}
& \frac{m g M g}{L}=\left(\frac{m g M g \text { enmuestra }}{L}\right) \times F D \\
& F D=\frac{V_{\text {final }}}{V_{\text {inicial }}}
\end{aligned}
$$

\subsubsection{Conductividad}

Este método se basa en la medición de todos los iones de las sales que se encuentran disueltas en el medio acuoso. La determinación de la conductividad se lleva a cabo con un conductimetro digital a la temperatura de referencia seleccionada.

\subsubsection{Proteínas}

El método Kjeldahl está basado en un proceso de digestión, mediante

el cual se destruyen los compuestos orgánicos con ácido sulfúrico 
concentrado y sulfato de cobre como catalizador. La adición de sulfato potásico eleva el punto de ebullición y acelera el proceso de digestión.

Durante la digestión, el nitrógeno de la materia orgánica se convierte en sulfato amónico.

$$
\text { Suero }+\mathrm{H}_{2} \mathrm{SO}_{4}+\mathrm{CuSO}+\mathrm{K}_{2} \mathrm{SO}_{4} \rightarrow \mathrm{NH}_{4}^{+}+\mathrm{SO}_{2}+\mathrm{CO}_{2}+\mathrm{H}_{2} \mathrm{O}
$$

La muestra digerida se destila en presencia de hidróxido sódico en exceso. Por acción del hidróxido sódico el $\mathrm{NH}_{4}{ }^{+}$se transforma en $\mathrm{NH}_{3}$.

$$
\mathrm{NH}_{4}^{+}+\mathrm{OH}^{-} \rightarrow \mathrm{NH}_{3}+\mathrm{H}_{2} \mathrm{O}
$$

El amoniaco destilado se recoge en una disolución de ácido bórico y se valora con ácido clorhídrico en presencia del indicador mixto hasta que vire de color verde a violeta.

$$
\begin{gathered}
\mathrm{NH}_{4} \mathrm{OH}+\mathrm{HBO}_{2} \rightarrow \mathrm{NH}_{4} \mathrm{BO}_{2}+\mathrm{H}_{2} \mathrm{O} \\
\left(\mathrm{H}_{3} \mathrm{BO}_{3} \leftrightarrow \mathrm{HBO}_{2} \cdot \mathrm{H}_{2} \mathrm{O}\right) \\
\mathrm{NH}_{4} \mathrm{BO}_{2}+\mathrm{HCl} \rightarrow \mathrm{NH}_{4} \mathrm{Cl}+\mathrm{HBO}_{2}
\end{gathered}
$$

\section{Equipo}

Aparato de mineralización

Aparato de destilación

Material de vidrio: matraces aforados, pipetas

Balanza

Bureta 


\section{Reactivos}

a) Sulfato potásico

b) Sulfato de cobre: Se disuelven $5 \mathrm{~g}$ de sulfato de cobre (II) pentahidratado en agua y se completa a $100 \mathrm{~mL}$ en un matraz aforado.

c) Ácido sulfúrico concentrado $(\rho=1,84 \mathrm{~g} / \mathrm{mL})$

d) Sosa cáustica: Se toman $500 \mathrm{~g}$ de $\mathrm{NaOH}$ y $25 \mathrm{~g}$ de tiosulfato sódico $\left(\mathrm{Na}_{2} \mathrm{~S}_{2} \mathrm{O}_{3} \cdot 5 \mathrm{H}_{2} \mathrm{O}\right)$ en $1 \mathrm{~L}$.

e) Ácido bórico: Se toman $40 \mathrm{~g}$ de ácido bórico en 1 I de agua destilada.

f) Ácido clorhídrico $0,1 \mathrm{~N}$.

g) Indicador: disolución de $2 \mathrm{~g}$ de rojo de metilo y $1 \mathrm{~g}$ de azul de metileno en $1 \mathrm{~L}$ de alcohol etílico del $96 \%$.

h) Disolución de carbonato sódico para valorar el ácido clorhídrico.

\section{Procedimiento}

a) Preparación de la muestra: Se Lleva la muestra a una temperatura de $20^{\circ} \mathrm{C}$. Se Mezcla cuidadosamente, si no se obtiene una dispersión homogénea de la grasa, se calienta lentamente al baño María hasta $40^{\circ} \mathrm{C}$ y se mezcla suavemente. Si es necesario se utiliza un homogeneizador apropiado para dispersar mejor la grasa. Una vez obtenida una dispersión uniforme de la grasa se lleva rápidamente a $20^{\circ} \mathrm{C}$. 
b) Se introduce en el matraz Kjedahl algunas perlas de vidrio o trozos de porcelana, aproximadamente $15 \mathrm{~g}$ de sulfato potásico, $1 \mathrm{~mL}$ de la disolución de sulfato de cobre y $5 \mathrm{~g}$ de muestra.

c) Se añaden $25 \mathrm{~mL}$ de ácido sulfúrico y se mezclan.

d) Se calienta cuidadosamente el matraz Kjeldahl en el aparato de mineralización hasta que desaparezca la formación de espuma y el contenido se vuelva líquido.

e) Se prosigue la mineralización calentando más intensamente hasta que el contenido del matraz esté perfectamente límpido e incoloro. Se agita el matraz de vez en cuando durante el calentamiento.

f) Una vez el líquido se haya vuelto límpido, se prosigue la ebullición durante una hora y media evitando cualquier sobrecalentamiento local.

g) Se enfría el contenido del matraz a temperatura ambiente; se añaden $300 \mathrm{~mL}$ de agua destilada y algunos trozos de piedra pómez; mezclado cuidadosamente y se deja enfriar.

h) Se añade al contenido del matraz $70 \mathrm{~mL}$ de sosa caústica. Durante esta operación se mantiene el matraz inclinado para que la disolución de sosa fluya a lo largo de la pared del recipiente y los líquidos no se mezclen.

i) Con una probeta graduada se vierten en un erlenmeyer $50 \mathrm{~mL}$ de la disolución de ácido bórico y se agregan 4 gotas de indicador y se mezcla.

j) Se monta el refrigerante en el erlenmeyer de manera que el extremo del tubo de salida esté sumergido en la disolución de ácido bórico.

k) Se conectan inmediatamente el matraz y el refrigerante por el deflegmador. 
I) Se prosigue la destilación hasta que el contenido del matraz comience a borboteos. Se regula la calefacción de manera que la destilación dure al menos 20 min. Enfriar el destilado para evitar el sobrecalentamiento de la disolución de ácido bórico.

m) Poco antes del final de la destilación se baja el erlenmeyer para que el tubo de salida emerja de la disolución de ácido bórico.

n) Se detiene la calefacción; se limpia el tubo de salida y se lavan las paredes exteriores e interiores con un poco de agua destilada.

o) Se valorar el destilado con ácido clorhídrico 0,1N.

Preparación del blanco: Se sigue el mismo procedimiento descrito anteriormente, utilizando $5 \mathrm{~mL}$ de agua destilada con $0,1 \mathrm{~g}$ de sacarosa en lugar de leche.

\section{Cálculo}

Nitrogeno $(\%)=\frac{1,4 \times N \times\left(V_{1}-V_{0}\right)}{P}$

Proteinas $(\%)=6,38 \times$ Nitrógeno $(\%)$

Donde:

$N$ : Normalidad de ácido clorhídrico

$V_{1}$ : Volumen en $\mathrm{mL}$ de ácido clorhídrico utilizado en la muestra

$V_{0}:$ Volumen en $\mathrm{mL}$ de ácido clorhídrico utilizada en el blanco.

$P: g$ de muestra láctea.

La diferencia entre dos resultados no debe sobrepasar el 0,005\% de nitrógeno. La presente norma se corresponde con la Norma Internacional ISO 8968-2: 2001 


\subsubsection{Lactosa}

Este es el método oficial en España y se corresponde con la Norma UNE 34826/1983, la lactosa monohidratada se cuantifica mediante un método indirecto después de la desproteinización de la leche, por valoración de la cantidad de halógeno reducido al final de la reacción entre la lactosa y el yoduro potásico-cloramina T.

\section{Fundamento}

Después de la desproteinización de la muestra (con la disolución de ácido túngstico), se agrega a una cierta cantidad de filtrado una disolución de cloramina T y una disolución de de yoduro potásico. La cantidad de cloramina T que no ha reaccionado se valora a través de una titulación del yodo liberado, con tiosulfato de sodio. La diferencia entre la cantidad de cloramina $\mathrm{T}$ en el blanco y la gastada en la muestra es equivalente a la cantidad de lactosa en la muestra.

a) Reacción entre la lactosa y la cloramina T. 
b) Reacción entre el exceso de cloramina T y el yoduro potásico:

$$
\mathrm{KI}+\text { cloramina } \mathrm{T} \rightarrow \mathrm{I}_{2}+\text { compuesto reducido }
$$

c) Reacción entre la lactosa y la cloramina T.

$$
\mathrm{KI}+\text { cloramina } \mathrm{T} \rightarrow \mathrm{I}_{2}+\text { compuesto reducido }
$$

c) Valoración de $I_{2}$ liberado:

$$
\mathrm{I}_{2}+\mathrm{S}_{2} \mathrm{O}_{3}{ }^{2-} \rightarrow 2 \mathrm{I}^{-}+\mathrm{S}_{4} \mathrm{O}_{6}{ }^{2-}
$$

\section{Equipo}

Papel de filtro (lavado al ácido, velocidad media, diámetro = 12,5cm) Material de vidrio

Balanza

Bureta semi-micro.

\section{Reactivos}

a) Ácido túngstico: $\mathrm{Se}$ disuelven $7 \mathrm{~g}$ de tungstato sódico ( $N a 2 \mathrm{WO} 4 \cdot 2 \mathrm{H} 2 \mathrm{O}$ ) en $870 \mathrm{~mL}$ de agua, se añaden $0,1 \mathrm{~mL}$ de una disolución de ácido ortofosfórico ( $88 \%$ en masa) y $70 \mathrm{~mL}$ de una disolución de ácido sulfúrico $1 \mathrm{~N}$.

b) Cloramina T, disolución de 0,04N (5,7 g/l) 
c) Tiosulfato sódico, 0,04 N (disolución estandarizada): Se disuelve 10,3 gramos de tiosulfato sódico y se lleva a 1 litro con agua destilada. Para conservar la disolución de tiosulfato sódico se agregan a la misma 0,8 gr de hidróxido sódico.

d) Yoduro potásico, disolución al 10\% recién preparada e incolora.

e) Ácido clorhídrico 2N: Se diluyen 165 millitros de ácido clorhídrico concentrado $(37 \% \mathrm{p} / \mathrm{p})$ en un matraz aforado de $1 \mathrm{~L}$.

f) Almidón soluble al 1\%: El almidón se debe preparar con agua hervida.

\section{Procedimiento}

\section{a) Preparación de la muestra:}

Se Lleva la muestra a $20^{\circ} \mathrm{C}$ y se mezcla cuidadosamente. Si no se obtiene una dispersión homogénea de la grasa, se calienta lentamente en el baño María hasta $40^{\circ} \mathrm{C}$ y se agita suavemente, si es necesario utilizar un homogeneizador para dispersar. Una vez obtenida una dispersión uniforme de la grasa se lleva rápidamente a $20^{\circ} \mathrm{C}$.

\section{b) Determinación:}

Se toman $10 \mathrm{~mL}$ de muestra con una pipeta y se llevan a un matraz aforado de $100 \mathrm{~mL}$. Se añaden $25 \mathrm{~mL}$ de agua, $40 \mathrm{~mL}$ de reactivo de ácido tungstico y se agita suavemente y se afora a $100 \mathrm{~mL}$, se mezcla y se deja precipitar. El filtrado se recoge en un frasco seco.

Se toman $10 \mathrm{~mL}$ del filtrado y se llevan a un erlenmeyer de $150 \mathrm{~mL}$ de tapa esmerilada. Se añaden $5 \mathrm{~mL}$ de la disolución de yoduro potásico y con mucha exactitud $20 \mathrm{~mL}$ de la disolución de cloramina T y se mezcla. Se tapa el erlenmeyer con su tapón previamente humedecido 
con un poco de la disolución de yoduro potásico y se conserva en la oscuridad durante hora y media a $18-20^{\circ} \mathrm{C}$.

Después de transcurrido este tiempo se quita el tapón, se lava sobre el matraz con un poco de agua y se añaden $5 \mathrm{~mL}$ de la disolución de ácido clorhídrico. Se añaden a la microbureta la disolución de tiosulfato de sodio. Se valora con esta disolución de tiosulfato y hacia el final de la valoración se añaden 2 o 3 gotas de almidón y se sigue valorando hasta observar el cambio final de color.

b) Preparación del blanco: Se sigue el mismo procedimiento descrito anteriormente, utilizando $10 \mathrm{~mL}$ de agua destilada en vez del filtrado del suero lácteo.

\section{Cálculo}

$\operatorname{Lactosa}(\%)=\left(V_{0}-V_{1}\right) \times 0,996 \times 0,0072 \times 100=\left(V_{0}-V_{1}\right) \times 0,717$

Donde:

Factor de corrección volumétrico para leche desnatada $=0,996$

0,0072: Factor para convertir a g de lactosa.

$V_{1}$ : Volumen en $\mathrm{mL}$ de tiosulfato utilizado en la muestra

$V_{0}:$ Volumen en $\mathrm{mL}$ de tiosulfato utilizada en el blanco.

La diferencia entre dos resultados no debe sobrepasar el 0,05\% de lactosa. 


\subsubsection{Materia grasa}

Se establece un método habitual (método Gerber) para la determinación en materia grasa de la leche de rutina realizando las correcciones necesarias en los cálculos dependiendo del tipo de leche.

\section{Fundamento}

La separación de la materia grasa se realiza por centrifugación en un butirómetro y posteriormente se diluyen proteínas mediante ácido sulfúrico. La separación de la materia grasa se favorece con la adición de una pequeña cantidad de alcohol amílico. El butirómetro se gradúa de manera que permita realizar una lectura directa del contenido de materia grasa.

\section{Equipo}

Butirómetro Gerber

Pipeta Gerber

Dosificador automático

Baño María

Centrifuga

Material de vidrio

\section{Reactivos}

a) Ácido sulfúrico de densidad $1,816 \mathrm{~g} / \mathrm{mL}$. El ácido debe ser incoloro o de una tonalidad ámbar. 
b) Alcohol amílico, con un contenido mínimo de $98 \%(v / v)$ de alcoholes primarios. Debe estar exento de pentanoles secundarios y derivados del benceno.

\section{Procedimiento}

\section{a) Preparación de la muestra:}

Se determina por duplicado, mediante el método Gerber descrito, el contenido en materia grasa, se utilizan butirométros cuyos errores de escala sean inferiores al $0,01 \%$ y ácido sulfúrico. Después de la centrifugación, colocar los butirómetros al azar y se mantienen así durante todo el proceso

\section{b) Determinación:}

Se agita la muestra suavemente invirtiendo varias veces el recipiente que contiene la muestra para no formar una cantidad excesiva de espuma o batido de la materia grasa.

Se agrega mediante el dosificador automático $10 \mathrm{~mL}$ de ácido sulfúrico y se introducen en el butirómetro, de manera que el ácido no moje el cuello del butirómetro y no arrastre aire. A continuación se adiciona mediante el dosificador automático $1 \mathrm{~mL}$ de alcohol amílico, sin mojar el cuello y evitando la mezcla de los líquidos.

Se tapa y se agita invirtiendo el butirómetro hasta que su contenido esté bien mezclado. Se coloca inmediatamente el butirómetro en la centrifuga durante 4 minutos. Se retira el butirómetro y se coloca hacia 
abajo en el baño de agua durante 5 minutos y seguidamente se efectúa la lectura.

\section{Cálculo}

$\operatorname{Grasa}(\%)=\left(V_{0}-V_{1}\right)$

Donde:

$V_{1}$ : Valor leído en el extremo superior de la columna grasa

$V_{0}:$ Valor leído en el extremo inferior de la columna grasa.

La cantidad de materia grasa se expresa en gramos de materia grasa por $100 \mathrm{~g}$ o por $100 \mathrm{~mL}$ de muestra, según la pipeta elegida.

\subsubsection{Extracto seco}

Método para determinar el contenido en extracto seco total de la leche.

\section{Fundamento}

Por extracto seco se entiende la masa expresada en porcentaje del residuo obtenido después de la desecación siguiendo el método descrito a continuación.

\section{Equipo}

Balanza analítica

Desecador 
Estufa

Cápsulas

Baño María

\section{Procedimiento}

Previamente se secan las cápsulas a $102^{\circ} \mathrm{C}$ por 30 minutos, se dejan enfriar y se pesan, luego se colocan alrededor de $3 \mathrm{~mL}$ de muestra en la cápsula y se pesa.

La cápsula se pone en el baño Maria hirviendo durante 30 minutos. Después se lleva a la estufa a $102^{\circ} \mathrm{C}$ durante 2 horas, se deja enfriar y se pesa como antes hasta que la diferencia entre las dos últimas pesadas no exceda de $0,5 \mathrm{mg}$.

\section{Cálculo}

Extracto $\operatorname{Seco}(\%)=\frac{V_{0}}{V_{1}} \times 100$

Donde:

$V_{1}$ : masa antes de la desecación

$V_{0}:$ masa después de la desecación.

La cantidad de materia grasa se expresa en gramos de materia grasa por $100 \mathrm{~g}$ o por $100 \mathrm{~mL}$ de muestra, según la pipeta elegida. 


\subsubsection{Cromatografía iónica}

La cromatografía de iones es una técnica para la determinación escalonada de aniones o cationes utilizando columnas intercambiadoras de iones.

\subsubsection{Determinación de aniones}

Se utilizó la cromatografía iónica para determinar de aniones como cloruro, fosfato y sulfato presentes en el suero lácteo real. Esta técnica al contrario de otras proporciona una medida secuencial y simultanea de todos los aniones presentes en la disolución.

\section{Fundamento}

La columna aniónica utiliza tres disoluciones:

Eluyente: Disolución de bicarbonato sódico de concentración 1mM y bicarbonato sódico de concentración 3,2 mM

Enjuague: agua bidestilada

Supresor: es una disolución de ácido sulfúrico de concentración 50 mM. Se inyecta una muestra en una corriente de disolvente carbonatobicarbonato, que pasa a través de la columna aniónica, los aniones separados pasan por un supresor. En el supresor mediante el ácido sulfúrico, los aniones ya separados se transforman a su forma ácida de alta conductividad y el elvente carbonato-bicarbonato se convierte en ácido carbónico. Los aniones separados en sus formas ácidas se miden por conductimetria. La identificación se realiza teniendo en cuenta el 
tiempo de retención de los diferentes iones, de acuerdo con los patrones. La determinación cuantitativa se realiza midiendo la altura de cada.

Interferencias: Las interferencias se deben principalmente a iones que tengan el mismo tiempo de retención del ión que se quiere determinar. En este trabajo, los iones que constituyen las muestras a analizar no producen éste tipo de interferencias.

\section{Equipo}

\section{Cromatógrafo de iones}

El cromatógrafo utilizado es de marca Metrohm 790 personal IC que consta de una válvula de inyección, un dosificador, una columna supresora, una célula de conductividad con compensación de temperatura. Ésta constituido por varios elementos:

Columnas iónicas, las columnas catiónica y aniónica utilizadas son la metrosep C2 y metrosep A supp5 respectivamente.

Guarda columna: esta ubicada antes de cada columna (aniónica/catiónica) para protegerla de obstrucciones por partículas o materia orgánica.

Columna de supresión: transforma el diluyente y los aniones separados en su forma ácida.

\section{Reactivos}

a) Agua bidestilada, libre de interferencias al límite mínimo de detección y filtrada con un filtro de membrana de 0,45 $\mu \mathrm{m}$ para evitar que se obturen las columnas. 
b) Disolución diluyente, bicarbonato-carbonato de sodio, $\mathrm{NaHCO}_{3}$ : $1 \mathrm{mmol} / \mathrm{L}$ y $\mathrm{Na}_{2} \mathrm{CO}_{3} 3,2 \mathrm{mmol} / \mathrm{L}$ : Se pesan 0,0843 $\mathrm{g}$ de $\mathrm{NaHCO}_{3}$ y 0,3399 g de $\mathrm{Na}_{2} \mathrm{CO}_{3}$ y se lleva a un litro con agua bidestilada, luego se filtra a través del filtro de membrana de 0,45 $\mu \mathrm{m}$.

c) Disolución supresora, ácido súlfurico $50 \mathrm{mmol} / \mathrm{L}$ : se mide 2,776 mL de $\mathrm{H}_{2} \mathrm{SO}_{4}$ y se lleva a un litro con agua bidestilada.

d) Disoluciones patrón, 1,000 mg/L: Se preparan una serie de disoluciones aniónicas patrón pesando la cantidad indicada de sal, secada a $105^{\circ} \mathrm{C}$ hasta peso constante y hasta $1 \mathrm{~L}$. Estas disoluciones se conservan en botellas de plástico en frigorífico.

A continuación, se muestran las diferentes concentraciones utilizadas para cada nivel de calibración para aniones.

\begin{tabular}{lrrr}
\hline Anión & Nivel 1 & Nivel 2 & Nivel 3 \\
\hline $\mathrm{Cl}^{-}$ & 10,0 & 50,0 & 100 \\
$\mathrm{PO}_{4}{ }^{3-}$ & 1,0 & 10,0 & 50,0 \\
$\mathrm{SO}_{4}{ }^{2-}$ & 1,0 & 10,0 & 50,0 \\
\hline
\end{tabular}

\section{Procedimiento}

a) Puesta a punto del sistema: Se enciende el cromatógrafo de iones, se purga el sistema para eliminar el aire que pueda estar tanto en las conducciones como en la columna, se enciende la bomba del elvente y la del supresor hasta que se estabilice el sistema, las condiciones de operación, se muestran a continuación. 


\begin{tabular}{lr}
\hline Parámetro & Valor \\
\hline Caudal de elvente $(\mathrm{mL} / \mathrm{min})$ & 0,70 \\
$P_{\max }(\mathrm{MPa})$ & 15,00 \\
$P_{\min }$ (MPa) & 0,50 \\
\hline
\end{tabular}

La línea base estable indica que se han alcanzado las condiciones de equilibrio y se puede hacer la calibración del equipo.

Calibración:

Se inyectan cada uno de los niveles de calibración, el software del equipo genera los cromatogramas de cada nivel con su correspondiente concentración. Los tiempos de retención observados para cada uno de los aniones corresponden al siguiente orden: Cloruros, fosfatos y sulfatos. Después de generada la curva de calibración se inyectan las muestras de concentración desconocida.

\section{Cálculos}

El software calcula automáticamente para cada cromatograma la concentración de la muestra problema en $\mathrm{mg} / \mathrm{L}$. Si se ha realizado dilución de la muestra problema, se utiliza la siguiente ecuación:

$C_{\text {muestra }} \frac{m g \text { Anion }}{L}=C_{\text {leida }} \times F D$

$C_{\text {leida }}$ : Concentración leída en el cromatógrafo

$F D$ : Factor de dilución de las muestras analizadas

\subsubsection{Determinación de cationes}


También se utiliza la cromatografía iónica para la determinación de cationes como el sodio, el potasio y el magnesio presentes en el suero real. Esta técnica al contrario de otras proporciona una medida secuencial y simultanea de todos los cationes presentes en la disolución.

\section{Fundamento}

La columna catiónica trabaja con las siguientes disoluciones:

Eluyente: formado por una disolución de ácido tartárico de concentración 4 mM y ácido dipicolínico de concentración 0,75 mM. Supresor: no se utiliza supresor químico

\section{Procedimiento}

El procedimiento es similar al que se explico para los aniones, la diferencia radica en las disoluciones de eluyente y que no trabaja con supresor químico. Se inyecta una muestra de agua en una corriente de eluyente tartarico-dipicolínico, que pasa a través de la columna catiónica, los cationes se separan y se determina por conductivimetria.

Interferencias: de igual manera que para los aniones, lo dicho se aplica para los cationes.

\section{Reactivos}

a) Agua bidestilada, libre de interferencias al límite mínimo de detección y filtrada con un filtro de membrana de 0,45 $\mu \mathrm{m}$ para evitar que se obturen las columnas. 
b) Disolución diluyente, tartarico-dipicolinico, ácido tartárico: $4 \mathrm{mmol} / \mathrm{L}$ y ácido dipicolinico $0,75 \mathrm{mmol} / \mathrm{L}$ : Se pesan $0,1279 \mathrm{~g}$ de dipicolinico y $0,6034 \mathrm{~g}$ de tartarico y se llevan a un litro con agua bidestilada, luego se filtran a través del filtro de membrana de 0,45 $\mu \mathrm{m}$.

d) Disoluciones patrón, 1,000 mg/L: Se preparan una serie de disoluciones catiónicas patrón pesando la cantidad indicada de sal, secada a $105^{\circ} \mathrm{C}$ hasta peso constante y hasta 1L. Estas disoluciones se conservan en botellas de plástico en frigoríico.

A continuación, se muestran las diferentes concentraciones utilizadas para cada nivel de calibración para cationes.

\begin{tabular}{lrrr}
\hline Catión & Nivel 1 & Nivel 2 & Nivel 3 \\
\hline $\mathrm{Na}^{+}$ & 1,0 & 50,0 & 150,0 \\
$\mathrm{~K}^{+}$ & 1,0 & 50,0 & 150,0 \\
$\mathrm{Mg}^{2+}$ & 1,0 & 50,0 & 150,0 \\
$\mathrm{Ca}^{2+}$ & 1,0 & 50,0 & 150,0 \\
\hline
\end{tabular}

\section{Procedimiento}

El procedimiento es similar al de los aniones, se enciende el cromatógrafo de iones, se purga el sistema para eliminar el aire que pueda estar tanto en las conducciones como en la columna, se enciende la bomba de paso del elvente hasta que se estabilice el sistema, las condiciones de operación, se muestran a continuación.

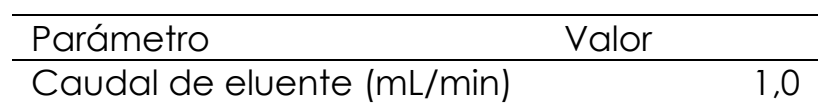


Una línea base estable indica que se han alcanzado las condiciones de equilibrio y se puede hacer la calibración del equipo.

Calibración:

Se realiza el mismo procedimiento que para los aniones.

\section{Cálculos}

El software calcula automáticamente para cada cromatograma la concentración de la muestra problema en mg/L. Si se ha realizado dilución de la muestra problema, se utiliza la siguiente ecuación:

$C_{\text {muestra }} \frac{\text { mgCation }}{L}=C_{\text {leida }} \times F D$

$C_{\text {leida }}$ : Concentración leída en el cromatógrafo

$F D$ : Factor de dilución de las muestras analizadas 